Universidade de São Paulo

Instituto de Física

\title{
ESTUDOS TEÓRICOS DO ESTADO \\ EXCITADO DE MOLÉCULAS \\ ORGÂNICAS EM SOLVENTE
}

\section{CARLOS EDUARDO BISTAFA DA SILVA}

Tese apresentada ao Instituto

de Física da USP para obtenção

do título de Doutor em Ciências

Orientador: Prof. Dr. Sylvio Canuto

Banca Examinadora:

Prof. Dr. Sylvio Roberto Accioly Canuto (IFUSP)

Prof. Dr. Márcio Teixeira do Nascimento Varella (IFUSP)

Prof. Dr. Antônio Carlos Borin (IQUSP)

Prof. Dr. André Luiz Barboza Formiga (UNICAMP)

Prof. Dr. Tertius Lima da Fonseca (UFG) 
AUTORIZO A REPRODUÇÃO E DIVULGAÇÃO TOTAL OU PARCIAL DESTE TRABALHO, POR QUALQUER MEIO CONVENCIONAL OU ELETRÔNICO, PARA FINS DE ESTUDO E PESQUISA, DESDE QUE CITADA A FONTE.

FICHA CATALOGRÁFICA

Preparada pelo Serviço de Biblioteca e Informação do Instituto de Física da Universidade de São Paulo

Silva, Carlos Eduardo Bistafa da

Estudos Teóricos do Estado Excitado de Moléculas Orgânicas em Solvente. São Paulo, 2015.

Tese (Doutorado) - Universidade de São Paulo.

Instituto de Física - Departamento de Física Geral

Orientador: Prof. Dr. Sylvio Roberto Accioly Canuto

Área de Concentração: Física

Unitermos: 1. CASSCF/CASPT2; 2. Estados Excitados; 3. Solvatação;

4. S-QM/MM; 5. Gradiente de Energia Livre; 6. Química Quântica 
Aos meus pais, Sueli e Jair pelo esforço e sacrifícios que permitiram que eu chegasse aonde cheguei

E em memória de meu avô Avelino, que teria orgulho em dizer: "tenho um neto 'Doutor da USP'" 



\section{Agradecimentos}

> Primeiramente a Deus, pelo dom da vida e da saúde em mais uma encarnação bendita, onde tenho a oportunidade de me aprimorar e evoluir mais na direção de seus caminhos;

Aos meus familiares e amigos, pelo apoio e incentivo; em especial minha mãe, que tanto se preocupa e zela por mim e por meu pai, que permitiu que eu me dedicasse apenas aos estudos;

À USP, ao IF, ao DFGE e todos os seus funcionários e colegas pelo agradável ambiente de trabalho propiciado e pelo suporte concedido; em particular aos companheiros do Grupo de Física Molecular e Modelagem pelas discussões enriquecedoras, ajudas, dicas e colaborações estabelecidas;

$>$ À FAPESP, pelo apoio financeiro em minha IC, Mestrado, Doutorado e no meu Estágio no Exterior;

Ao Prof. Dr. Herbert de Castro Georg, da UFG, pela disponibilidade em adaptar o seu programa Diceplayer para os problemas nos quais eu estava interessado e que se tornou um dos pontos chaves deste trabalho, e ao Dr. Yoelvis Orozco Gonzalez, pela ajuda com o programa Molcas, que foi utilizado em todos os cálculos multiconfiguracionais deste trabalho;

> A todos que eu conheci durante meu estágio no Japão: a equipe da Universidade de Nagoya e do dormitório Yamate, os estudantes e professores do curso básico de Japonês para estrangeiros, os estudantes internacionais com quem eu dividi o 
apartamento, e finalmente, mas mais especialmente, a todo o pessoal do NCUBE pela ajuda, pelo companheirismo na longa jornada de trabalho, pelas discussões enriquecedoras (fosse sobre ciência ou fosse sobre história, política, línguas, cultura, ou fosse ainda sobre mangá, anime e vídeo-game!) e pelos momentos felizes; em particular agradeço ao meu supervisor, Nagaoka-Sensei, por ter me aceitado e me acolhido em seu Laboratório. Graças a todos eles, tive uma estada maravilhosa durante esses curtos 6 meses que passei na Terra do Sol Nascente. 皆、どうもありが とうございました！；

E finalmente, mas mais especialmente, ao Prof. Dr. Sylvio Canuto que, em mais essa etapa da minha carreira acadêmica, desempenhou papel importantíssimo, não apenas me orientando no projeto de pesquisa, mas me mostrando a visão que um verdadeiro cientista deve ter. Muito obrigado por todos os seus ensinamentos e conselhos, e pela confiança e responsabilidades que sempre depositou em mim, e sobre as quais espero nunca tê-lo decepcionado.

A todos o meu muitíssimo e sincero obrigado. 
"Dê-me uma equação e eu te explico o universo; dê-me o universo e não vai sair equação."

- De um físico teórico (eu) pensando sobre suas dificuldades em entender um experimento -

"Que Red Bull que nada, a FAPESP te dá asas!"

- Karina Fasson, comentando as minhas inúmeras viagens para congressos. Nenhuma frase expressa melhor minha gratidão à Fapesp pelas 4 bolsas que me concedeu -

"A máquina sempre rouba!"

- Meu irmão, André, expressando sua revolta depois de falhar inúmeras vezes em alguma fase difícil no video-game. A frase pode ser estendida para situações em que seu cálculo caiu/deu errado/não fez o que você queria -

"To understand something is interesting, but what's already understood is boring."

- Zidane Tribal, no jogo Final Fantasy IX (Squaresoft, 2000), CD3. Buscar o novo e explicar o que ainda não compreendemos deveriam ser as exclusivas motivações de um cientista - 



\section{Resumo}

Absorção e Emissão de radiação eletromagnética por moléculas na região do UV-Vis fornece informações sobre os estados eletrônicos excitados, sendo propriedades de grande interesse devido a sua relação com processos biológicos, bem como suas possíveis aplicações em diagnósticos e tecnologia. Essas propriedades são sensíveis ao meio em que as moléculas se encontram, tornando-se assim natural a busca por métodos teóricos que possibilitam descrever essas interações.

Neste trabalho, nós usamos a metodologia Sequential-Quantum Mechanics/Molecular Mechanics para estudar o espectro de absorção e de emissão de moléculas de relevância biológica, quando em solução. Simulações clássicas Monte Carlo foram usadas pra construir uma configuração eletrostática média do líquido para posterior cálculo das propriedades, feito através dos métodos multiconfiguracionais CASSCF e CASPT2. Cuidados especiais foram tomados para incluir a polarização eletrônica que o soluto sofre devido à presença do solvente.

Nossa contribuição é a adaptação do método do Gradiente de Energia Livre para permitir a obtenção de geometrias de estados excitados do soluto em solução. A técnica foi implementada em um programa e aplicada com sucesso nos sistemas estudados.

As perspectivas agora se abrem para a obtenção de intersecções cônicas em meio solvente, permitindo assim o estudo de decaimentos não-radiativos em sistemas solvatados.

Palavras-chaves: S-QM/MM, solvatação, polarização, estados excitados, Gradiente de Energia Livre, CASSCF, CASPT2. 



\section{Abstract}

Absorption and emission of electromagnetic radiation by molecules in the UV-Vis region yields information about the electronic excited states, being properties of great interest due its relation with biological process, as well as its possible applications in diagnostics and technology. These properties are sensible to the environment in which the molecules are, making natural the search for theoretical methods that describe these interactions.

In this work, we have used the Sequential-Quantum Mechanics/Molecular Mechanics methodology to study the spectrum of absorption and emission of molecules of biological relevance, when in solution. Classical Monte Carlo simulations were carried out to construct an average solvent electrostatic configuration and used to represent the liquid in posterior quantum mechanics calculation of the properties, performed by using the multiconfigurational methods CASSCF and CASPT2. Special cares were taken to include the electronic polarization of the solute due the solvent.

Our contribution is the adaptation of the Free Energy Gradient method to allow the determination of the solute excited states geometries in solution. The method was implemented in a computer program and successfully applied in the systems studied.

The perspectives are now open to the calculation of conical intersection in solvent environment, enabling the study of nonradioactive decays in solvated systems.

Keywords: S-QM/MM, solvation, polarization, excited states, Free Energy Gradient, CASSCF, CASPT2. 



\section{Lista de Figuras}

Figura 1.1: Nos modelos contínuos, uma molécula é posta dentro de uma cavidade e o solvente é representado por um contínuo descrito por sua constante dielétrica........................................6

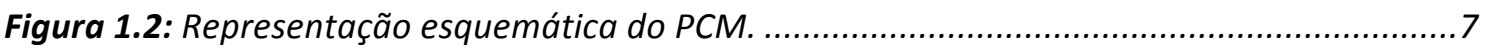

Figura 1.3: Representação esquemática do método $Q M / M M$. A molécula central (grossa) é tratada com Mecânica Quântica enquanto as demais (finas) são tratadas classicamente..........9

Figura 1.4: Representação esquemática do método $S-Q M / M M$. Após uma simulação clássica, algumas configurações estatisticamente descorrelacionadas são separadas e analisadas (esquerda) permitindo assim a escolha a posteriori do que será tratado quanticamente (círculo). A propriedade de interesse é obtida como uma média simples (direita).

Figura 1.5: Caixa de simulação replicada em todas as direções e com condições periódicas de contorno (retirada da ref. ${ }^{42}$ ). É mostrada replicação no plano xy apenas para melhor visualização, mas ela também é feita no eixo $z$.

Figura 1.6: O potencial de Lennard-Jones (adaptado da Ref. ${ }^{51}$ ).

Figura 1.7: Organograma do procedimento iterativo usado para polarizar o soluto.

Figura 1.8: ASEC. Note como a configuração média herda a estrutura do líquido, evidenciando claramente regiões onde ligações de hidrogênio são formadas: adensamento de pontos vermelhos representando $O_{\text {wat }}$ próximos aos $H N$, e o adensamento de pontos brancos representando $H_{\text {wat }}$ próximos ao $O_{\text {soluto. }}$

Figura 2.1: Valores de IP-EA para os átomos. Note que a maioria dos valores está numa faixa entre 0.2 e 0.3 u.a. A linha horizontal representa o valor de 0.25 u.a. (figura adaptada da ref..$^{65}$ ).

Figura 3.1: A família dos isoflavonoides. Para daidzeína, $R=R^{\prime}=O H$.

Figura 3.2: Estruturas otimizadas de diferentes estados eletrônicos da daidzeína.

Figura 3.3: Alteração do valor do momento de dipolo do estado fundamental e excitado da daidzeína em água e em acetonotrila $(A C N)$ durante o procedimento iterativo de polarização. 
Figura 3.4: Orbitais moleculares envolvidos nas transições eletrônicas estudadas. A nomenclatura é baseada no ordenamento obtido no cálculo SCF. .

Figura 3.5: Representação esquemática do mecanismo de desativação da daidzeína em a) água e b) acetonitrila.

Figura 3.6: Alteração nos orbitais moleculares da daidzeína no estado excitado ${ }^{1}\left(\pi \pi^{*} L_{b}\right)$ devida a polarização eletrônica causada pela água.

Figura 4.1: A molécula uracil. O rótulo dos átomos é usado no texto e tabelas.

Figura 4.2: Estruturas não-planares obtidas por Yamazaki e Taketsugu ${ }^{126}$, usando CASPT2(10/8) (esquerda) e por Barone e colaboradores, ${ }^{5}$ usando TD-PBEO/6-31G(d) (direita). Apesar de ambas apresentarem uma forma de "barco", a distorção do anel ocorre para o lado oposto.

Figura 4.3: Espaço ativo utilizado para determinar a estrutura do estado excitado $\pi-\pi^{*}$. Todos os orbitais do tipo $\pi$ foram incluídos (Full- $\pi$ space). Acima, orbitais originalmente duplamente ocupados e abaixo, orbitais virtuais. Os orbitais foram obtidos utilizando HF/ANO-S-MB e então expandidos para a base ANO-L-VDZP. Para calcular as transições eletrônicas, o lone-pair do átomo 02 também foi incluído. 56

Figura 4.4: Superposição das geometrias de equilíbrio do estado fundamental (MP2/aug-ccpVDZ, amarelo) e do estado excitado $\pi-\pi^{*}(\operatorname{CASSCF}(10,8) / A N O-L-V D Z P$, Cores: $O, C, N, H) d a$ molécula uracil em fase gasosa.

Figura 4.5: Alteração no momento de dipolo da uracil no processo de polarização iterativo para (a) o estado fundamental e (b) estado excitado $\pi-\pi^{*}$. Processo iterativo de polarização combinado com o método Free Energy Gradient para encontrar a estrutura de mínimo do estado excitado $\pi-\pi^{*}$ da uracil em água, com a geometria inicial da: (c) Região de FranckCondon e (d) Ref. ${ }^{5}$. O valor obtido com PCM $(\otimes)$ é mostrado para comparação. $O$ valor do momento de dipolo convergido $\left(\mu_{\text {conv }}\right)$ é o valor do último ponto.

Figura 4.6: Variação da distância e ângulos de ligação, força atômica máxima (MAX) e desvio quadrático médio (RMS) da força atômica durante o processo iterativo de polarização combinado com o método FEG, usando a geometria da Região de Franck-Condon como ponto de partida. A magnitude da força atômica em cada átomo, no último passo, também é mostrada. Para ângulos e distâncias de ligação, os resultados estão convergidos após 10 passos. Os rótulos dos átomos referem-se a Figura 4.1. Distâncias de ligação envolvendo os átomos de hidrogênio não são mostradas porque a mudança é muito pequena. Uma ilustração da geometria convergida também é apresentada. .65

Figura 4.7: Variação da distância e ângulos de ligação, força atômica máxima (MAX) e desvio quadrático médio (RMS) da força atômica durante o processo iterativo de polarização combinado com o método Free Energy Gradient, usando a geometria obtida na Ref. ${ }^{5}$ como ponto de partida. A magnitude da força atômica em cada átomo, no último passo, também é mostrada. Os rótulos dos átomos referem-se a Figura 4.1. Distâncias de ligação envolvendo os átomos de hidrogênio não são mostradas porque a mudança é muito pequena. Uma ilustração da geometria convergida também é apresentada. 
Figura 5.1: Estrutura da molécula a) $p N P$ e b) $p N P^{-}$. O rótulo dos átomos é usado no texto $e$ tabelas.....

Figura 5.2: $O$ espaço ativo usado nos cálculos CASPT2 do pNP (metade superior) e pNP ${ }^{-}$ (metade inferior). A nomenclatura dos orbitais é advinda do ordenamento obtido no SCF.......73

Figura 5.3: Esquerda) O modelo ASEC. A molécula de soluto é tratada por um método QM, mas as moléculas de solvente são tratadas como cargas pontuais localizadas na posição dos sítios atômicos. Várias configurações são sobrepostas, e o valor das cargas é normalizado pelo número de configurações. O ASEC foi usado em cálculos CASPT2 para obter as transições eletrônicas; Direita) uma ampliação na região do soluto mostra a cavidade formada devido a interação soluto-solvente, e também a formação das ligações de hidrogênio. Figura construída no software $V M D^{146}$.

Figura 5.4: Configuração usada no cálculo CASPT2 incluindo solvente explícito. As demais moléculas de água da caixa de simulação foram incluídas como cargas pontuais (omitidas na figura para facilitar a visualização). 


\section{Lista de Tabelas}

Tabela 3.1: Energias de absorção para os quatro estados excitados de menor energia da daidzeína em água e em acetonitrila, e energia de emissão em água. Valores energéticos em eV. fé a força de oscilador (adimensional).

46

Tabela 3.2: Valores calculados para acoplamento spin-órbita e diferenças energéticas entre os estados eletrônicos considerados para a daidzeína isolada.

Tabela 4.1: Distâncias (Å) e ângulos $\left({ }^{\circ}\right)$ de ligação das geometrias obtidas para uracil em fase gasosa: estado fundamental (MP2/aug-cc-pVDZ) e estado excitado $\pi-\pi^{*}$ (CASSCF(10,8)/ANO-LVDZP). Também é mostrada a estrutura de mínimo do estado excitado $\pi-\pi^{*}$ da uracil em água $\left(\pi-\pi{ }^{*}\right.$ solv $)$, obtida com a combinação dos métodos CASSCF e FEG, com a geometria inicial na região de Frack-Condon. Os índices dos átomos referem-se à figura 1. Valores experimentais para o estado fundamental são mostrados para comparação ${ }^{a}$.

Tabela 4.2: Absorção e emissão da uracil em fase gasosa (parte superior) e em água (inferior), obtidas com CASPT2(12,9)/ANO-L-C,O,N\{4s3p1d\}/H\{2s1p\}. Valores em eV. .60

Tabela 4.3: Energia total (hartree) do estado excitado $\pi-\pi^{*}$ da uracil em ASEC, após otimização realizada com o método $F E G$, partindo de diferentes geometrias iniciais. A energia total foi obtida usando métodos multiconfiguracionais, com o espaço Full- $\pi$ e conjunto base ANO-LVDZP. Parte inferior: a diferença de energia entre as duas estruturas, em hartree e $\mathrm{kcal} / \mathrm{mol}$. A acurácia estimada do método CASPT2 é 0.1-0.2 eV (0.00367-0.00735 hartree ou 2.3-4.6 $\mathrm{kcal} / \mathrm{mol}$, veja discussão na ref. $\left.{ }^{64}\right)$.

Tabela 5.1: Transições eletrônicas $\pi-\pi^{*}$ de menor energia das moléculas $p N P$ e $p N P^{-}$em gás, calculadas com CASPT2(12,10)/ANO-L. Valores em eV.

Tabela 5.2: Transições eletrônicas $\pi-\pi^{*}$ de menor energia das moléculas $p N P$ e $p N P^{-}$, em solução aquosa, calculada com CASPT2(12,10), usando geometrias obtidas com diferentes métodos. Para incluir o efeito de solvente, utilizamos o modelo ASEC. Valores em eV. .76

Tabela 5.3: Distâncias e ângulos de ligação dos átomos do grupo nitro para as geometrias da molécula pNP obtidas em GAS, PCM e com o método FEG. Para os rótulos atômicos, consulte a Figura 5.1. 


\title{
Lista de Siglas, Abreviaturas e Acrônimos
}

\author{
ACN Acetonitrila \\ ANO Atomic Natural Orbital \\ ANO-L Large ANO Basis Set \\ ANO-L-VDZP Base ANO com largo conjunto de primitivas, com a valência descrita com \\ qualidade Double Zeta e com funções de polarização \\ ANO-RCC Relativistic ANO Basis Set \\ ANO-S Small ANO Basis Set \\ ANO-S-MB Base mínima do tipo ANO-S \\ ASEC Average Solvent Electrostatic Configuration \\ aug-cc-pVDZ Conjunto de bases do tipo correlation consistente, com a valência descrita com \\ qualidade Double Zeta e com funções difusas e de polarização \\ B3LYP Funcional da densidade híbrido, com termo de troca de Becke e termo de \\ correlação de Lee-Yang-Parr \\ CASSCF Complete Active Space Self-Consistent Field \\ CASPT2 Second-Order Perturbation Theory with a CASSCF Reference Function \\ CC Coupled Cluster \\ CCD CC considerando apenas excitações Duplas \\ CCSD $\quad$ CC considerando excitações Simples e Duplas \\ CCSDT $\quad$ CC considerando excitações Simples, Duplas e Triplas \\ $\operatorname{CCSD}(\mathrm{T}) \quad$ CC considerando excitações Simples e Duplas, e incluindo as Triplas de maneira \\ não-iterativa \\ CC2 Modelo aproximado de 2a ordem para CCSD \\ CC3 Modelo aproximado de CC incluindo excitações triplas conexas \\ CHELP Charges derived from electrostatic potential \\ CHELPG Charges from electrostatic potentials using a grid based method \\ $\mathrm{Cl} \quad$ Configuration Interaction \\ CIS $\quad \mathrm{Cl}$ considerando apenas excitações simples \\ CISD $\quad \mathrm{Cl}$ considerando excitações simples e duplas
}




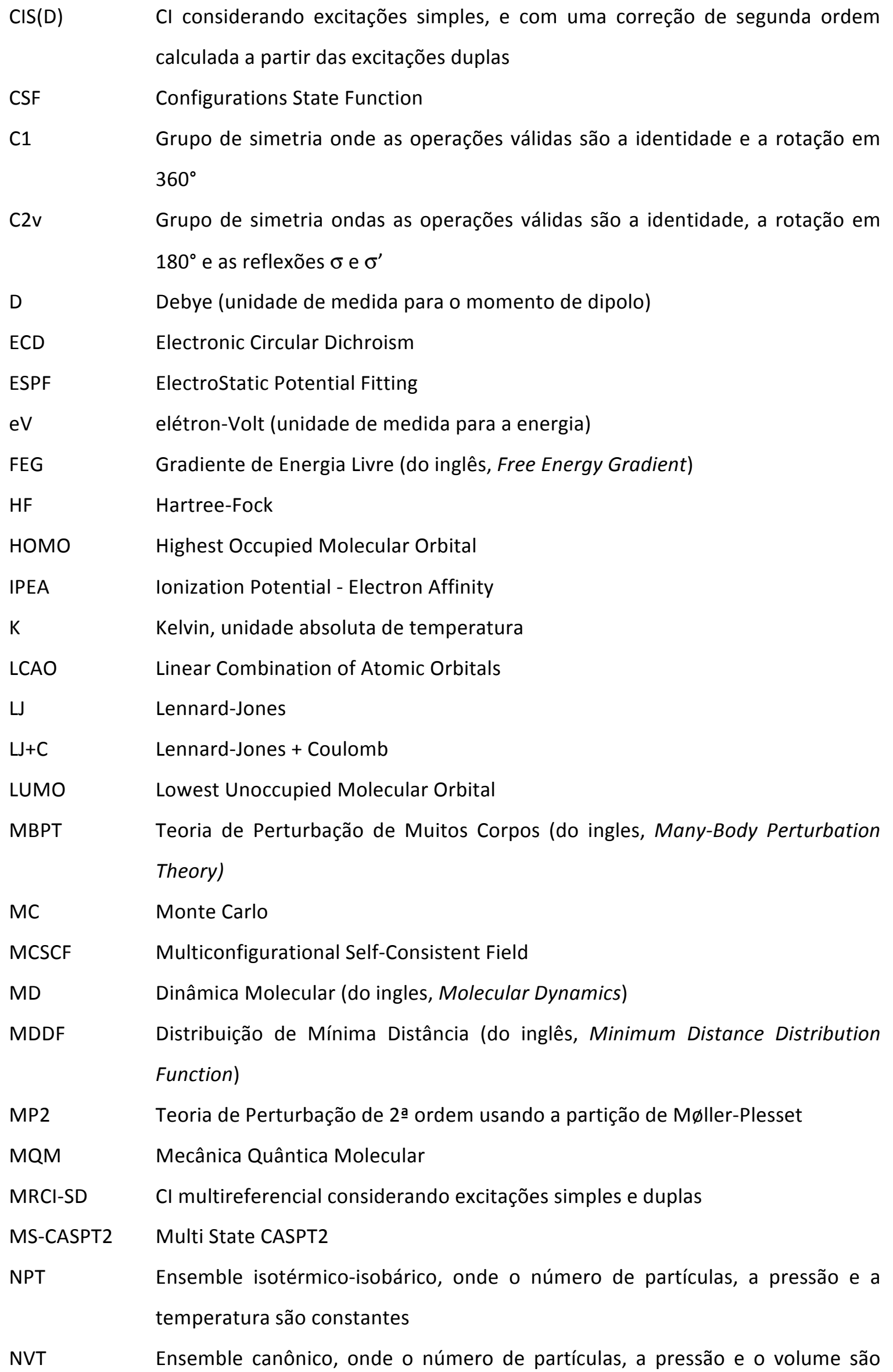


constantes

NR Newton-Rhapson

OPLS-aa Optimized Potentials for Liquid Simulations - all atom

OPLS-ua Optimized Potentials for Liquid Simulations - united atom

PCM Polarizable Continum Model

pNP Paranitrofenol (da grafia em Inglês, paranitrophenol)

$\mathrm{pNP}^{-} \quad$ 4-Paranitrofenolato (ânion do paranitrofenol)

QM Quantum Mechanics

QM/MM Quantum Mechanics/Molecular Mechanics

RASSCF Restricted Active Space Self-Consistent Field

RNA Ribonucleic Acid

SA-CASSCF State-Average CASSCF

SCF Self-Consistent Field

SCRF Campo de reação autoconsistente (do inglês, Self-Consistent Reaction Field)

SOC Spin-Orbit Coupling

SPC Simple Point Charge

S-QM/MM Sequential Quantum Mechanics/ Molecular Mechanics

TIP3P Campo de força para água com 3 sítios

TIP4P Campo de força para água com 4 sítios

TIP5P Campo de força para água com 5 sítios

TD-DFT Time Dependent Density Functional Theory

TD-PBEO Funcional da densidade híbrido que possui energia de troca proveniente de PBE e HF e correlação de PBE. Também chamado PBE1PBE

u.a. Unidades Atômicas

UV-Vis Região do Espectro Eletromagnético cujo comprimento de onda está na faixa do Ultravioleta e Visível (200-780 nm).

VMD Visual Molecular Dynamics, software para visualização de moléculas e de trajetórias obtidas com simulações clássicas 


\section{Lista de Publicações}

Este texto é parcialmente baseado nas seguintes publicações

$>$ Solvent effects on the two lowest-lying singlet excited states of 5-fluorouracil Carlos Bistafa \& Sylvio Canuto, Theoretical Chemistry Accounts 132, 1299 (2013)

$>$ Solvent Effect on the Stokes Shift and on the Nonfluorescent Decay of the Daidzein Molecular System

Yoelvis Orozco-Gonzalez, Carlos Bistafa \& Sylvio Canuto, The Journal of Physical Chemistry A 117, 4404 (2013)

$>$ Combining $a b$ initio multiconfigurational and Free Energy Gradient methods to study the $\pi-\pi^{*}$ excited state structure and properties of uracil in water

Carlos Bistafa, Herbert C. Georg \& Sylvio Canuto, Computational and Theoretical Chemistry 1040-1041, 312 (2014)

$>$ Paranitrophenol and paranitrophenalate solvatochromic shift. A study combining $a b$ initio multiconfigurational calculations and the Free Energy Gradient method Carlos Bistafa, Yukichi Kitamura, Masataka Nagaoka \& Sylvio Canuto (em preparação).

Outras publicações do autor durante o Doutorado

$>$ Theoretically describing the ${ }^{17} \mathrm{O}$ magnetic shielding constant of biomolecular systems: uracil and 5-fluorouracil in water environment

Rodrigo M. Gester, Carlos Bistafa, Herbert C. Georg, Kaline Coutinho \& Sylvio Canuto

Theoretical Chemistry Accounts 133, 1424 (2014)

$>$ Including Thermal Disorder of Hydrogen Bonding to Describe the Vibrational Circular Dichroism Spectrum of Zwitterionic L-Alanine in Water

Ednilsom Orestes, Carlos Bistafa, Roberto Rivelino \& Sylvio Canuto, The Journal of Physical Chemistry A 119, 5099 (2015)

$>$ A systematic study of the lowest $n-\pi^{*}$ and $\pi-\pi^{*}$ electronic transitions of acrolein in solvent

Carlos Bistafa, Lucas Modesto-Costa \& Sylvio Canuto (em preparação) 


\section{Sumário}

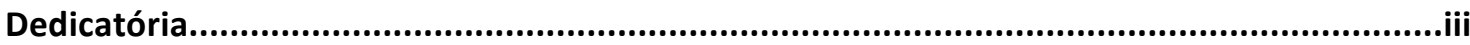

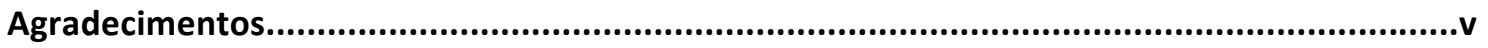

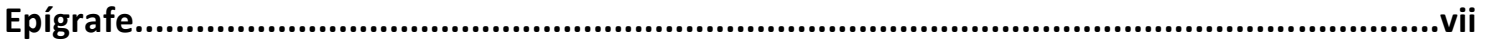

Resumo

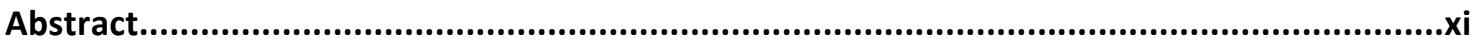

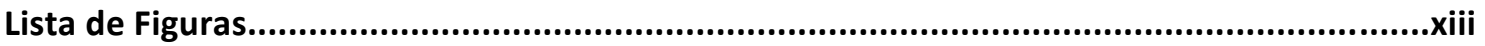

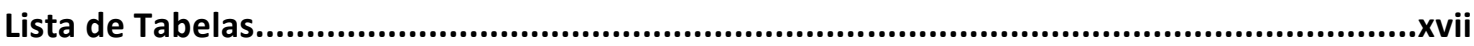

Lista de Siglas, Abreviações e Acrônimos................................................................................xix

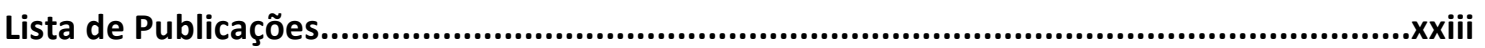

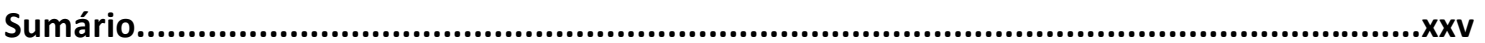

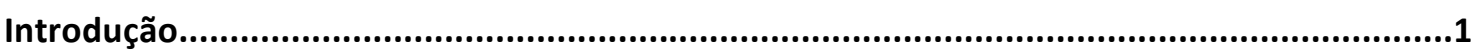

Capítulo 1 : Sequential-QM/MM e o método do Gradiente de Energia Livre combinados para encontrar a geometria do estado excitado em meio solvente ................................................5

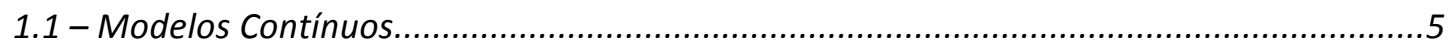

1.2 - Métodos Quantum Mechanics / Molecular Mechanics ................................................

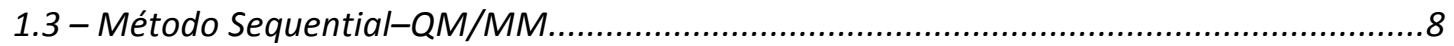

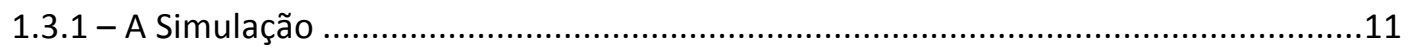

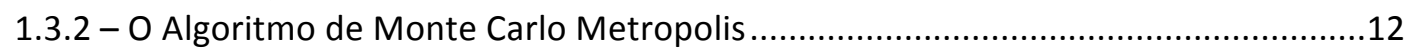

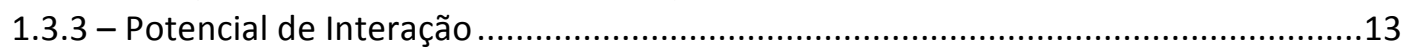

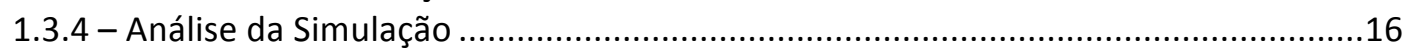

1.3.5 - Melhorando a descrição: Introduzindo a polarização do soluto ............................18

1.3.6 - O Solvente como configuração média: ASEC ........................................................19

1.3.7 - O Gradiente de Energia Livre e a relaxação de geometria em meio solvente.........21

Capítulo 2 : Os métodos multiconfiguracionais CASSCF e CASPT2 ….....................................23

2.1 - Os métodos Pós Hartree-Fock. Por que utilizar métodos multiconfiguracionais?...........24

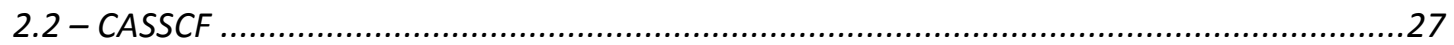

$2.3-$ CASPT2 … 


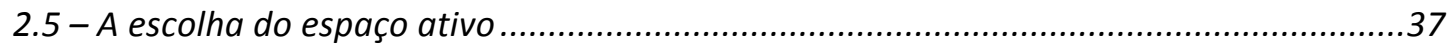

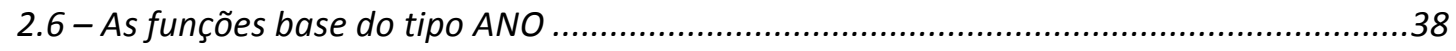

2.7 - Adendo: Ajustando cargas atômicas parciais através do método ElectroStatic Potential

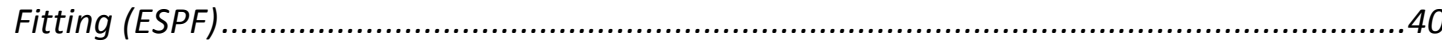

Capítulo 3 : Resultados - Stokes Shift de um isoflavonoide em água e sua não-fluorescência em acetonitrila

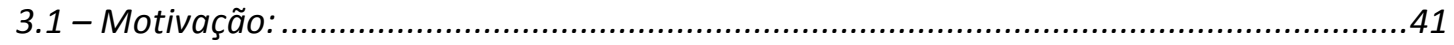

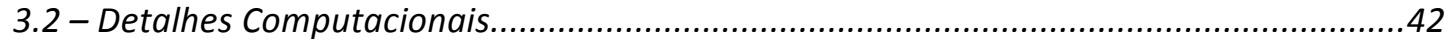

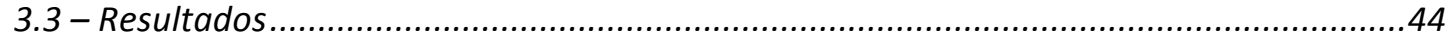

3.3.1 - Espectro de Absorção .............................................................................44

3.3.2 - Espectro de Fluorescência ..............................................................................46

3.3.3 - Supressão da Fluorescência em Acetonitrila ...........................................48

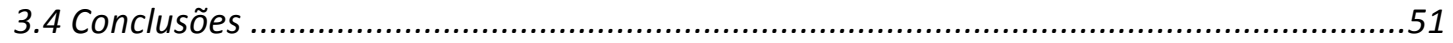

Capítulo 4 : Resultados - Absorção e emissão da Uracil em água ...................................... 53

4.1 - Introdução e Motivação ..................................................................................53

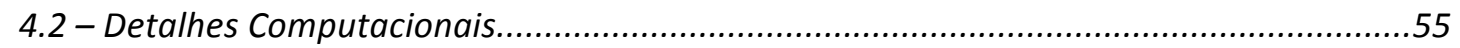

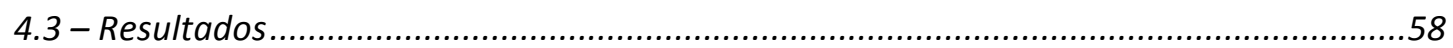

4.3.1 - Geometria e transições eletrônicas em fase gasosa............................................58

4.3.2 - Geometrias e transições eletrônicas em solução ..............................................62

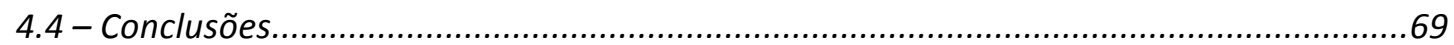

Capítulo 5 : Resultados - Transições eletrônicas do Paranitrofenol e seu ânion em solução

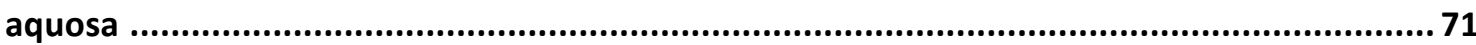

5.1 - Introdução e Motivação ............................................................................. 71

5.2 - Detalhes Computacionais............................................................................ 72

$5.3-$ Resultados............................................................................................ 74

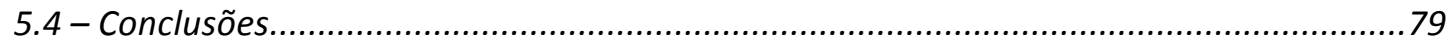

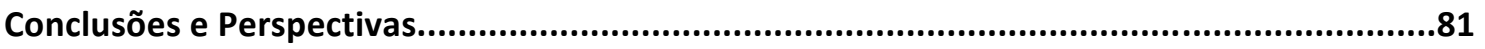

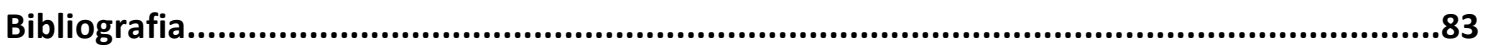

Anexo A: Publicações nas quais este texto foi baseado ..................................................A1

Anexo B: Outras publicações do autor durante o Doutorado..........................................A2 


\section{Introdução}

Emissão de radiação e dinâmica do estado excitado eletrônico de moléculas são temas de enorme interesse atual. A grande motivação é biológica e vai desde a elaboração de sondas (como Prodan e Laurdan ${ }^{1}$ ) até a compreensão dos mecanismos fundamentais das bases nitrogenadas que compõem o DNA. Esta última, aliás, tem levado a um grande número de estudos, culminando inclusive com volumes de revistas internacionais dedicados inteiramente ao assunto ${ }^{2}$. Essa mobilização toda vem do curioso fato de que as bases nitrogenadas, apesar da grande capacidade de absorção de radiação, apresentam um baixo rendimento quântico. Os estudos atuais apontam que isso ocorre principalmente devido ao acoplamento de estados excitados próximos através de efeito pseudo-Jahn-Teller ${ }^{3}$ e a existência de intersecções cônicas ${ }^{4}$, que permitem decaimentos não-radiativos. Biologicamente isso é muito desejável, pois o tempo de vida do estado excitado diminui, passando a ser da ordem de poucas dezenas ou centenas de femtosegundos ${ }^{5,6}$, reduzindo drasticamente a possibilidade de que reações fotoquímicas potencialmente perigosas ocorram².

Apesar de essas moléculas apresentarem sua plena fenomenologia em meio, grande parte dos estudos teóricos é feita com moléculas isoladas ${ }^{7-9}$. Isso advém do fato que um enorme esforço computacional é necessário para obtenção da geometria de uma molécula no estado excitado, pois geralmente são utilizados métodos multiconfiguracionais $\left(\mathrm{CASSCF}^{10}\right)$. A justificativa para tal aproximação é justamente o curto tempo de vida do estado excitado apresentado por essas moléculas que, em tese, seria escasso demais para que interações com o meio sejam significativas.

Os resultados advindos deste tratamento muitas vezes apresentam boa concordância com valores experimentais. Observe, porém, que essa aproximação é limitante: quanto maior o tempo de vida do estado excitado, piores tendem a ser os resultados. Além disso, o caminho de reação pode ser alterado na presença de solvente.

A tentativa inicial de resolver esses problemas pode ser feita com a utilização de modelos contínuos, como PCM, devido a sua simplicidade e baixa exigência computacional ${ }^{4,5}$. 
Entretanto, esses modelos vêm se mostrando insuficientes para a descrição mais precisa de sistemas moleculares onde a interação dominante não é eletrostática.

Para uma melhor descrição, a microsolvatação dos resultados obtidos em fase gasosa tem se tornado uma opção crescente ${ }^{11,12}$. Contudo, novamente surgem dificuldades: como devem ser distribuídas essas poucas moléculas de solvente em torno do soluto? O caminho de reação calculado desta maneira é o mesmo que seria obtido caso o solvente fosse incluído desde o início? A discrepância e/ou inconclusibilidade de alguns resultados mostra que essa aproximação ainda não é o suficiente ${ }^{12,13}$.

É dentro desse questionamento que, baseados nas ideias de Aguilar e colaboradores $^{14,15}$, realizamos o presente trabalho, onde propomos uma maneira de se obter a estrutura e as energias de transição de moléculas em meio solvente, combinando o método Free Energy Gradient ${ }^{16-19}$ e os métodos multiconfiguracionais CASSCF $^{10}$ e CASPT2 ${ }^{20}$, através da metodologia híbrida Sequential - Quantum Mechanics/ Molecular Mechanics (S-QM/MM), desenvolvida em nosso grupo ${ }^{21}$.

Um dos grandes impedimentos para a realização de cálculos incluindo solvente é a elevada demanda computacional envolvida. Isso porque, além dos dispendiosos cálculos para determinação da geometria do estado excitado, tradicionalmente os métodos híbridos (ditos QM/MM) fazem a cada passo de simulação clássica um cálculo quântico. Entretanto, muitos passos são necessários para que mudanças significativas ocorram. No S-QM/MM, simulações clássicas usando método de Monte Carlo Metropolis são feitas primeiramente e configurações descorrelacionadas estatisticamente são separadas para os posteriores cálculos quânticos. Desse modo, o número de cálculos necessários é reduzido drasticamente se comparado ao QM/MM convencional: de centenas de milhares de cálculos, para apenas algumas dezenas (geralmente, algo em torno de 60-150), com a limitação que apenas valores médios podem ser obtidos. Poderia se objetar que desse modo não há polarização do soluto pelo solvente e viceversa. Pensando nisso, em nosso grupo foi desenvolvido um método iterativo para introduzir a polarização do soluto pelo solvente ${ }^{22}$, que tem apresentado excelentes resultados ${ }^{23,24}$, inclusive para o estado excitado ${ }^{25,26}$. Recentemente, esse procedimento foi aprimorado ao ser combinado com o método Free Energy Gradient ${ }^{16-19}$, permitindo a relaxação da geometria do soluto em meio solvente $\mathrm{e}^{27}$. No presente trabalho, nós estendemos este procedimento para o estado excitado, permitindo assim a determinação de sua geometria de equilíbrio em meio. 
O procedimento proposto foi aplicado com sucesso em uma das supramencionadas bases nitrogenadas (uracil). Mesmo para a uracil, cujo tempo de vida do estado excitado é curto, é possível apreciar o efeito de solvente (capítulo 4).

Outras duas aplicações também foram feitas: um estudo preliminar usando uma molécula da família dos flavonoides, onde aplicamos as técnicas estabelecidas anteriormente ao desenvolvimento desta tese (capítulo 3) e um estudo extra, onde em colaboração com o grupo japonês que desenvolveu o Gradiente de Energia Livre, estudamos as transições eletrônicas do paranitrofenol e seu ânion em solução (capítulo 5).

Os resultados obtidos até o momento sugerem que esse método é uma maneira sistemática e factível para se incluir o efeito de solvente no estudo de moléculas em seu estado excitado, sendo um primeiro passo para o estudo de sua dinâmica em meio.

Para a futuro, os resultados atuais nos dão perspectivas para explorar um problema ainda mais complexo: o mecanismo de decaimento não-radiativo de moléculas solvatadas. 
4 Introdução

Carlos Bistafa - IFUSP 2015 


\section{Capítulo 1 :}

\section{Sequential-QM/MM e o método do Gradiente de Energia Livre combinados para encontrar a geometria do estado excitado em meio solvente}

Muitos métodos foram criados e têm sido aprimorados para se estudar teoricamente as alterações em propriedades de moléculas devido aos efeitos causados pela presença de solvente. Neste capítulo ${ }^{*}$, nós resumiremos algumas das principais abordagens e depois detalharemos o método Sequential - Quantum Mechanics / Molecular Mechanics (S-QM/MM), que utilizamos para incluir efeito de solvente em nossos cálculos. No final, descrevemos como combinar S-QM/MM e o método do Gradiente de Energia Livre (FEG) para obter a geometria de moléculas em solução.

\section{1 - Modelos Contínuos}

Com o desenvolvimento da Mecânica Quântica e o surgimento de métodos para tratar a repulsão eletrônica, o interesse e o número de estudos teóricos sobre moléculas cresceram, impulsionados também pelo advento dos computadores. Os estudos visavam o entendimento de propriedades estruturais, eletrônicas e espectroscópicas de moléculas isoladas. Entretanto, a quase totalidade das reações químicas de interesse acontece em solução. Para representar significativamente um sistema líquido, um grande número de moléculas é necessário e as limitações computacionais impediam (e impedem até hoje) o total tratamento quântico de um sistema com um grande número de moléculas. Tornou-se necessário então o desenvolvimento de métodos, técnicas e aproximações para reduzir o número de cálculos de modo a tornar esses estudos factíveis.

É difícil conceber uma teoria microscópica sobre a fase líquida da matéria pois, diferentemente do gás, em um líquido as moléculas não estão afastadas o suficiente para que seja possível desprezar suas interações, ao mesmo tempo que não estão próximas o suficiente

\footnotetext{
" Este capítulo é uma versão modificada, revista, atualizada e expandida do capítulo 1 da ref. ${ }^{28}$.
} 
para dar origem a ordenamentos e simetrias como na fase sólida. Resumindo, um líquido é um sistema denso e desordenado e é a combinação dessas características que torna seu tratamento teórico mais complexo.

O primeiro tratamento de interações de moléculas com solvente surgiu com os trabalhos de Tapia e Goscinski ${ }^{29}$ e Rivail e Rinaldi ${ }^{30}$ na década de 1970 que, baseados nas idéias clássicas e semiclássicas de Onsager $^{31}$ e Kirkwood $^{32}$, desenvolveram o método campo de reação autoconsistente (SCRF). Nessa abordagem, a molécula é posta em uma cavidade cercada por um meio contínuo representado pela constante dielétrica (Figura 1.1). O dipolo da molécula induz um dipolo nesse contínuo que por sua vez altera o dipolo da molécula, de forma autoconsistente, o que justifica o nome do método. A cavidade em geral é esférica ou elipsoidal, para facilitar a resolução matemática do modelo.

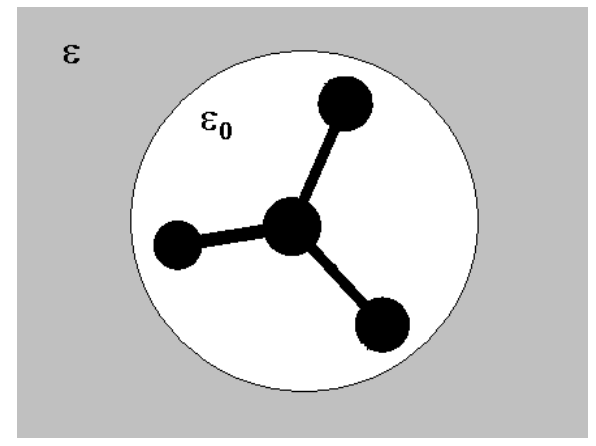

Figura 1.1: Nos modelos contínuos, uma molécula é posta dentro de uma cavidade e o solvente é representado por um contínuo descrito por sua constante dielétrica.

Esse modelo deu origem a muitos outros que apresentam melhores aproximações a fim de representar o solvente mais realisticamente (para uma excelente revisão de modelos contínuos vide a ref. $\left.{ }^{33}\right)$. Entre todos eles, o que mais se destaca é o Modelo Contínuo Polarizável (PCM). O PCM apresenta algumas melhorias em relação ao modelo original: a cavidade não é esférica, sendo formada pela união de esferas centradas nos átomos da molécula, cujo raio é tipicamente $20 \%$ maior que o raio de van der Waals do respectivo átomo, gerando assim uma superfície que possui a mesma forma da molécula. O PCM também tem um tratamento melhor para a interação eletrostática com o meio, considerando, por exemplo, como o soluto gera uma densidade superficial de cargas aparente na superfície da cavidade (Figura 1.2). Uma defasagem em parte das cargas, permite cálculos de não-equilíbrio. A atual 
implementação utiliza um formalismo de equações integrais, que torna o método muito eficiente computacionalmente ${ }^{34}$.

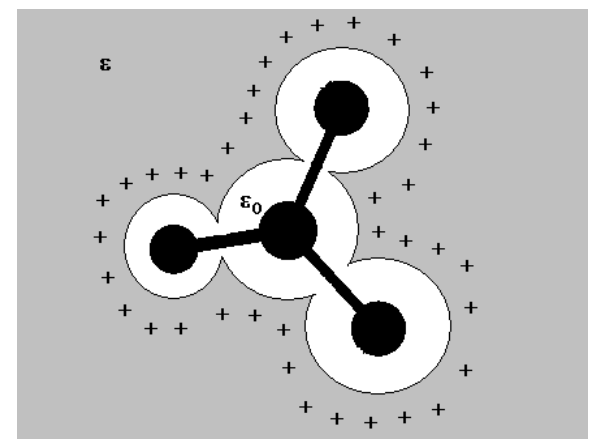

Figura 1.2: Representação esquemática do PCM.

Com a introdução dessas melhorias, o PCM se tornou um método bem aceito, permitindo o estudo de muitas propriedades de moléculas em meio solvente. Porém o método possui suas limitações. Já em seu artigo, Tapia e Goscinski ressaltavam que o método SCRF é uma boa aproximação para moléculas com grande momento de dipolo e cuja interação com o meio seja predominantemente eletrostática. Sistemas onde interações específicas, como ligações de hidrogênio, desempenhem papel importante tendem a ser mal descritos. Transferência de carga do soluto para o solvente, e vice-versa, também não é considerada, uma vez que não há elétrons no solvente.

\section{2 - Métodos Quantum Mechanics / Molecular Mechanics}

Diante das limitações apresentadas pelo modelo contínuo, um tratamento que utilize moléculas explícitas de solvente por vezes se faz necessário. Devido ao alto custo computacional exigido para tratar grandes quantidades de moléculas, vários métodos e aproximações surgiram como alternativa para reduzir o número de moléculas explícitas, sem prejudicar significativamente os resultados.

Uma abordagem que tem se tornado cada vez mais frequente é a combinação de cálculos quânticos e simulações clássicas. Por combinarem mecânica clássica e quântica esses métodos são ditos híbridos e são conhecidos pela sigla QM/MM: Quantum Mechanics / Molecular Mechanics ${ }^{35}$, e tem possibilitado uma série de aplicações e estudos importantes, e 
que levou a Academia de Ciências Sueca a dar o Prêmio Nobel de Química de 2013 aos pioneiros da área: Martin Karplus, Michael Levitt e Arieh Warshel ${ }^{36,37}$.

De um modo geral, em um procedimento QM/MM inicialmente escolhe-se uma parte pequena para ser descrita quanticamente, deixando o restante para ser tratado através da Mecânica Clássica (Figura 1.3). Essa é a primeira dificuldade do método: como escolher a parte crucial que deve ser tratada com os métodos de Mecânica Quântica. O que é suficiente (ou estritamente necessário) para calcular certa propriedade de uma molécula em solução: as moléculas de solvente que fazem ligações de hidrogênio com o soluto? A primeira camada de solvatação? E se a escolha não envolver o número de moléculas, mas sim a parte de uma delas, por exemplo, se o soluto for grande, uma enzima talvez: tratar seu sítio ativo é o suficiente? E que ligações químicas cortar? Isso é realista?

Depois de definido o subsistema que será tratado quanticamente, o segundo passo, tão importante quanto e intimamente relacionado com o primeiro, diz respeito à maneira como acoplar as interações das partes clássica e quântica. É essa parte do tratamento que difere os vários métodos QM/MM.

Uma vez definidos esses passos básicos, alguns problemas persistem: os cálculos ainda podem ser computacionalmente dispendiosos, pois a parte clássica é tratada através de simulações usando o método de Monte Carlo ou Dinâmica Molecular, e essas simulações exigem um grande número de passos para serem representativas. Como um cálculo quântico é feito a cada passo clássico, a exigência computacional total pode ser equiparada a de um cálculo puramente quântico de um sistema de médio porte. Mais que isso, os cálculos são feitos durante a simulação (on-the-fly), mas não há garantias da convergência, o que representa um risco (um voo cego), como pode ser visto na ref. ${ }^{38}$.

\section{3 - Método Sequential-QM/MM}

Para evitar estes problemas e tornar os cálculos mais eficientes, Canuto e Coutinho desenvolveram o Sequential - Quantum Mechanics / Molecular Mechanics (S-QM/MM) ${ }^{21,39,40}$, como uma alternativa ao QM/MM convencional.

Como o nome sugere, no S-QM/MM as partes clássica e quântica são calculadas de modo desacoplado e em sequência: somente após a conclusão das simulações clássicas é que os cálculos quânticos são realizados. Isto traz várias vantagens: 


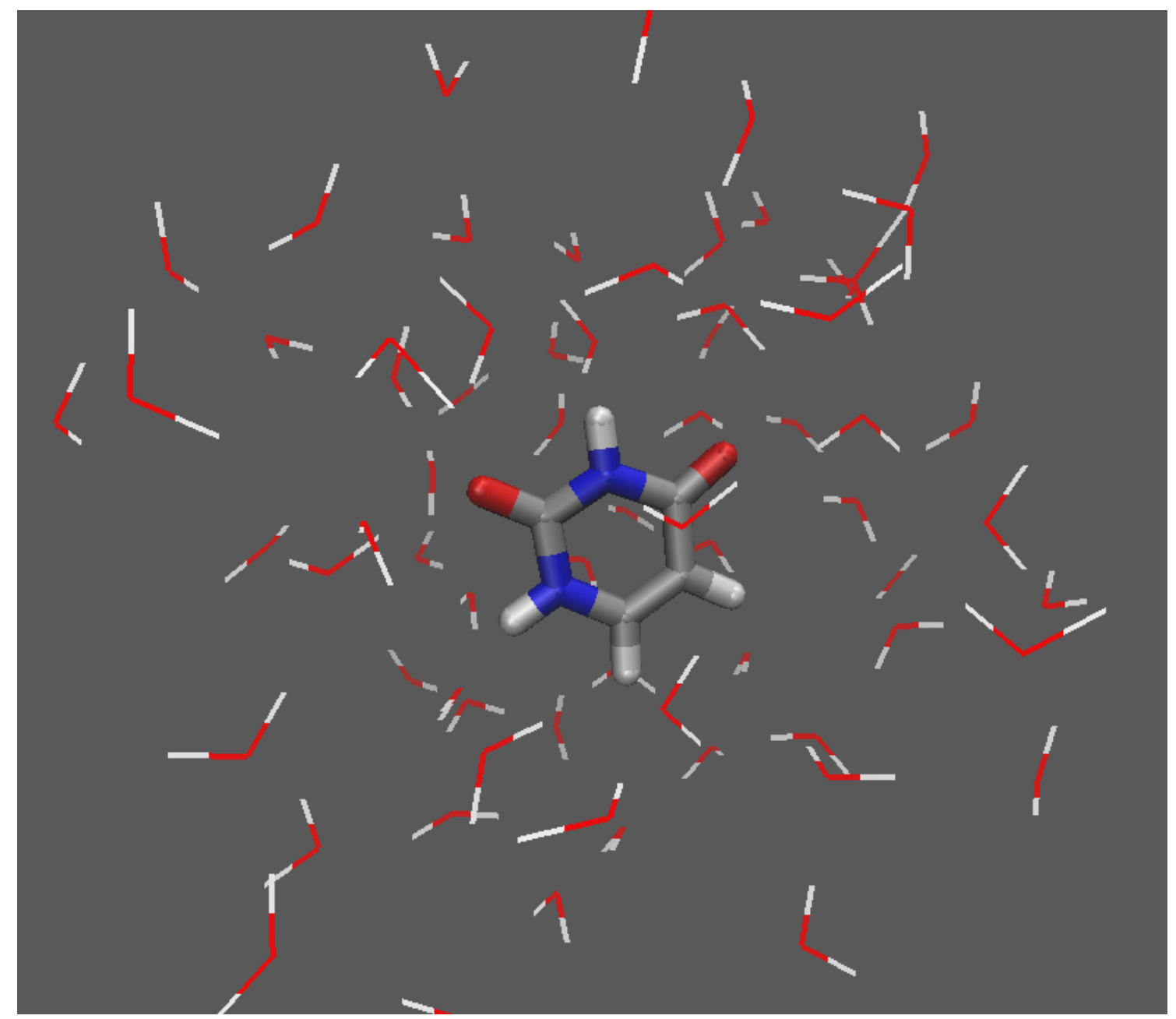

Figura 1.3: Representação esquemática do método $Q M / M M$. A molécula central (grossa) é tratada com Mecânica Quântica enquanto as demais (finas) são tratadas classicamente.

i) Garante que os cálculos quânticos serão feitos a partir de uma simulação clássica convergida;

ii) Permite a escolha de apenas uma pequena amostra das configurações geradas pela simulação clássica, baseando-se no fato que de um passo para outro, as configurações mudam muito pouco e, portanto, incluir todas as configurações teria efeito pouco significativo no valor da média. Isso reduz os cálculos quânticos de centenas de milhares para algumas poucas dezenas (geralmente algo entre 60 e 150 cálculos), ou até para apenas 1, se for possível usar uma aproximação eletrostática para o solvente (detalhes na seção 1.3.6);

iii) Uma mesma simulação pode ser usada para a determinação de mais de uma propriedade quântica; 
iv) O recorte da parte quântica é feito a posteriori, permitindo uma maior liberdade de escolha; além disso, não há mais dificuldades em tratar a fronteira entre as partes clássica e quântica.

Na Figura 1.4 temos uma representação esquemática do método S-QM/MM.
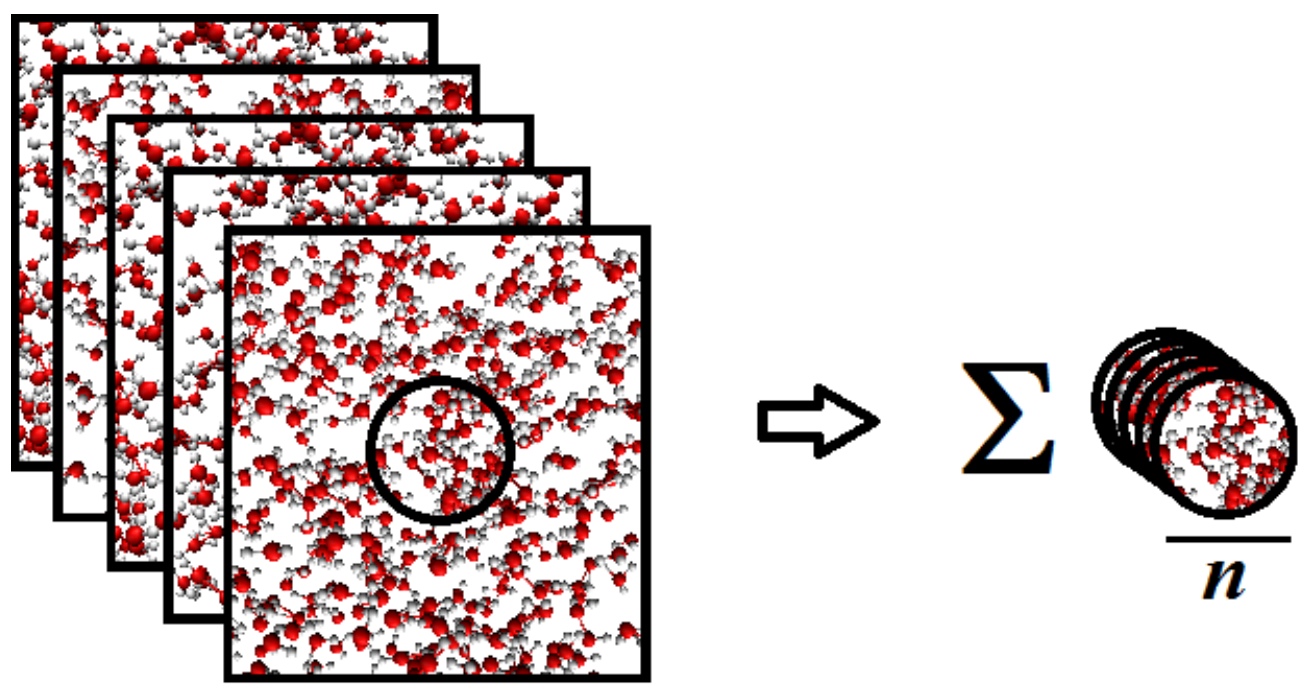

Figura 1.4: Representação esquemática do método S-QM/MM. Após uma simulação clássica, algumas configurações estatisticamente descorrelacionadas são separadas e analisadas (esquerda) permitindo assim a escolha a posteriori do que será tratado quanticamente (círculo). A propriedade de interesse é obtida como uma média simples (direita).

Obviamente o método não goza apenas de vantagens. A principal desvantagem é que fazendo os cálculos de maneira sequencial, não há polarização do soluto pelo solvente. Uma proposta (que discutiremos a seguir) visa corrigir isso. A princípio, a parte clássica poderia ser feita com Dinâmica Molecular ou Monte Carlo; porém originalmente, tradicionalmente e para reduzir ainda mais o esforço computacional nós usamos o método de Monte Carlo com algoritmo de Metropolis, então o S-QM/MM herda as restrições desse método também: por ser um método estocástico, não é possível obter a evolução temporal das configurações; para não reduzir a eficiência do algoritmo de Metropolis, (veja a seguir) as moléculas são tratadas como rígidas durante toda simulação.

Uma vez que esse foi o método que mais utilizamos, vamos detalhá-lo melhor. 


\subsection{1 - A Simulação}

Para as simulações nós utilizamos o programa DICE $^{41}$, desenvolvido em nosso grupo. Inicialmente, na fase de termalização (detalhes a seguir) o programa gera uma configuração de maneira aleatória ou ordenada (o que for mais conveniente para o estudo que se irá realizar) com a quantidade de moléculas desejada distribuídas em uma caixa cúbica, gerada de acordo com a pressão ou densidade fornecida.

Para evitar efeitos de borda, a caixa é replicada em todas as direções, procedimento conhecido como Método das Imagens, garantindo que cada molécula esteja inserida no mesmo ambiente que as demais e levando a condições periódicas de contorno: se uma molécula sair por um lado da caixa, sua réplica será imediatamente reintroduzida no lado oposto (Figura 1.5). Essa periodicidade porém permite que uma molécula interaja ao mesmo tempo com uma réplica e a própria molécula que a originou. Para evitar isso, define-se um raio de corte $r_{c}$ (que no máximo possui a metade do valor do lado da caixa), distância além da qual não se computa mais nenhuma interação, e introduz-se então uma correção para a interação de longas distâncias (vide seção 1.3.3). Analogamente, há um raio de sobreposição ( $r_{\text {overlap }}=0.8$ Å): se a distância entre dois átomos de moléculas distintas em dada configuração é menor que o raio de sobreposição, a configuração já é rejeitada, pois para uma distância tão pequena a repulsão será muito forte, aumentando a energia da configuração e, consequentemente, sua probabilidade de não ser aceita. Frisamos aqui que apesar da utilização das imagens nos cálculos, apenas as moléculas na caixa original compõem a configuração salva.

Para realizar a simulação, também deve se optar entre um dos seguintes ensembles: isotérmico-isobárico (número de partículas, pressão e temperatura fixos - NPT) ou canônico (número de partículas, volume e temperatura fixos - NVT). Se fosse possível uma amostragem infinita, todos os ensembles seriam equivalentes, mas a simulação é finita, o que pode implicar que para certas propriedades um ensemble seja mais vantajoso que outro. Em particular, temos preferido o NPT, onde calculamos a densidade a cada passo, e se ela é compatível com a densidade experimental para o líquido puro (dentro de um erro menor que $4 \%$ ), assumimos que as configurações representam de fato a estrutura do solvente. No NVT, a pressão é calculada e, por depender de uma derivada segunda, observam-se grandes flutuações numéricas, fazendo com que os valores obtidos sejam menos confiáveis para comparação. 


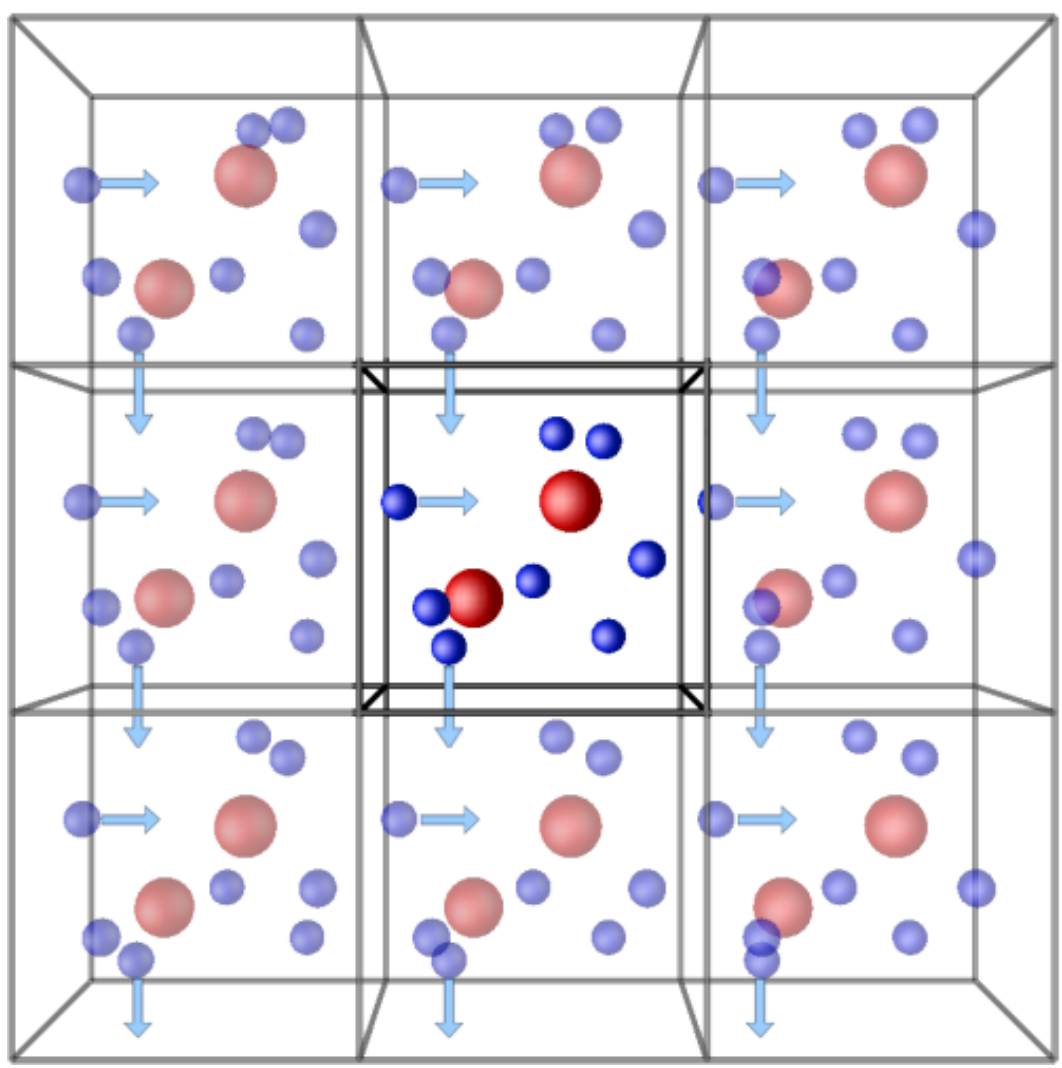

Figura 1.5: Caixa de simulação replicada em todas as direções e com condições periódicas de contorno (retirada da ref. ${ }^{42}$ ). É mostrada replicação no plano $x y$ apenas para melhor visualização, mas ela também é feita no eixo $z$.

Antes da simulação propriamente dita, uma etapa de termalização é realizada para que o sistema atinja o equilíbrio e cujas configurações não entram na composição da média. Como a configuração inicial tem em geral uma energia muito alta (devido à proximidade irreal de algumas moléculas), nos primeiros passos da termalização um resfriamento (coolstep) é realizado, onde a próxima configuração gerada só é aceita se diminuir a energia. Após esse procedimento, a geração de uma nova configuração passa a ser através de um processo Markoviano, seguindo o algoritmo de Metropolis.

\subsection{2 - O Algoritmo de Monte Carlo Metropolis}

Para gerar as configurações, o programa utiliza o algoritmo de Monte Carlo Metropolis ${ }^{43}$, já consagrado em muitos métodos estocásticos. A ideia é a seguinte: 
1) Partindo-se da configuração inicial, seleciona-se uma molécula. Diferentemente da proposta original de Metropolis, onde essa seleção é aleatória, nós selecionamos de forma sequencial, que é equivalente, mas com a vantagem de se gerar menos números aleatórios. Sorteia-se então uma distância para transladar o centro de massa dessa molécula e em seguida um eixo e um ângulo entre -15ㅇ e 15 para realizar-se uma rotação. No ensemble NPT o volume também é variado, sorteando-se um incremento para os lados da caixa;

2) Calcula-se a energia dessa nova configuração: se ela for menor que a energia da configuração anterior, a configuração é aceita de imediato e retorna-se ao primeiro passo;

3) Se a energia é maior, calcula-se a probabilidade de transição de uma configuração para a outra e sorteia-se um número aleatório entre 0 e 1: se a probabilidade é maior que esse número, aceita-se a configuração; caso contrário, mantém-se a configuração anterior. Retorna-se então ao primeiro passo.

Uma vez que todas as moléculas passem por esse ciclo, temos um passo de Monte Carlo. O processo é dito Markoviano, pois cada configuração assim gerada só depende dela mesma e da anterior ${ }^{43}$.

Para que ao sistema seja permitido acessar várias configurações, de modo a melhorar a amostragem do espaço de configurações, as simulações são tipicamente longas, da ordem de $10^{5}$ passos/molécula.

Permitir a flexibilidade das moléculas tende a tornar as simulações $M C$ muito longas, então geralmente, adota-se a aproximação de moléculas rígidas: a geometria das moléculas (distâncias de ligações e ângulos entre átomos) é mantida fixa durante a simulação. Simulações de Dinâmica Molecular são mais eficientes para incluir a flexibilidade das moléculas.

\subsection{3 - Potencial de Interação}

Falamos em energia, mas ainda não dissemos como ela é calculada. Em sua forma mais geral, a energia de interação pode ser escrita como 


$$
U=U_{\text {intra }}+U_{\text {inter }}
$$

onde o primeiro termo se refere às interações intramoleculares e o segundo às intermoleculares. Como estamos dentro da aproximação de moléculas rígidas, a energia intramolecular de cada molécula é a mesma em todos os passos.

O termo restante, referente às interações intermoleculares, pode ser decomposto em várias contribuições: interação de dois corpos, de três corpos etc. Entretanto, para sistemas sem orientação preferencial, como ocorre em líquidos, a contribuição para a energia devida à interação de três corpos ou mais é muito pequena ${ }^{43}$. Dessa forma, o cálculo da energia é feito considerando apenas dois corpos, o que nos leva a

$$
U=\sum_{i=1}^{N_{a}} \sum_{j=1}^{N_{b}} U_{i j}
$$

sendo $N_{a}$ e $N_{b}$ o número de sítios ativos das moléculas $a$ e $b$, respectivamente. Note que esse número não necessariamente é igual ao número de átomos em cada molécula: ele pode ser inferior, quando aproximamos um grupo de átomos ou a molécula inteira por um único sítio, em geral para aumentar a eficiência computacional (como no campo de força OPLS-ua ${ }^{44}$, onde por exemplo, os átomos de hidrogênio ligados aos átomos de carbono estão incluídos implicitamente nos parâmetros do carbono) ou maior (átomos dummy), um artifício geralmente usado para melhor representar a distribuição de cargas ou outra propriedade (é o que ocorre com os modelos TIP4P $\mathrm{P}^{45}$ e TIP5 $\mathrm{P}^{46}$ para água, que contém 4 e 5 sítios ativos respectivamente).

Para representar o potencial $U_{i j}$, nós usamos a soma do potencial de Lennard-Jones e e de Coulomb (LJ+C):

$$
U_{i j}=4 \varepsilon_{i j}\left[\left(\frac{\sigma_{i j}}{r_{i j}}\right)^{12}-\left(\frac{\sigma_{i j}}{r_{i j}}\right)^{6}\right]+\frac{q_{i} q_{j}}{r_{i j}}
$$

com $\sigma_{i j}=\sqrt{\sigma_{i} \sigma_{j}}, \varepsilon_{i j}=\sqrt{\varepsilon_{i} \varepsilon_{j}}$, onde $\sigma_{i}$ e $\varepsilon_{i}$ são os parâmetros Lennard-Jones (LJ) do sítio $i$ e $q_{i}$ é a carga deste mesmo sítio (análogo para $j$ ); $r_{i j}$ é a distância entre os dois sítios.

O potencial de Coulomb representa as interações eletrostáticas enquanto as demais são representadas por LJ. O potencial LJ possui dois termos: o termo atrativo possui uma dependência com o inverso de $r^{6}$ e corresponde aos termos de van der Waals, que descrevem 
a atração a longas distâncias. O termo positivo está associado à repulsão a curtas distâncias, devida tanto a repulsão coulombiana quanto ao princípio de exclusão de Pauli, porém sua dependência com o inverso de $r^{12}$ não têm demonstração e vêm de ajustes de dados experimentais. Aparentemente, usar 10 ou 11 ao invés de 12 fornece um ajuste tão bom quanto: o único comportamento necessário parece ser um rápido crescimento do potencial a curtas distâncias. Lennard-Jones testou valores entre 5 e 25 e concluiu que usando 12 obtinha as melhores aproximações para diversas grandezas ${ }^{47}$. A preferência por esse expoente se mantém hoje também por outro motivo: eficiência computacional. Adotando a dependência com o inverso de $r^{12}$, o termo repulsivo se torna o quadrado do termo atrativo, facilitando os cálculos para interações não-eletrostáticas.

Os parâmetros $\varepsilon$ e $\sigma$ estão relacionados, respectivamente, à profundidade do poço de potencial (ou seja, a intensidade da interação) e a distância (finita) para a qual o potencial de interação se torna nulo (Figura 1.6). Em geral, esses parâmetros são ajustados para reproduzir valores experimentais ou dados de cálculos quânticos.

Assim, para realizar as simulações, o programa DICE precisa, além da geometria da molécula, dos parâmetros $\mathrm{L}$ e das cargas de cada sítio. De um modo geral, para o soluto, a geometria é obtida por cálculos quânticos; para os parâmetros LJ nós utilizamos o campo de força OPLS-aa ${ }^{48,49}$; as cargas são obtidas através de ajustes vindos de cálculos quânticos (mais detalhes nas seções 1.3 .5 e 2.7). Para o solvente nós utilizamos modelos consagrados na literatura (como SPC ${ }^{50}, \mathrm{TIP}^{4} \mathrm{P}^{45}$, etc), que já apresentam geometria, parâmetros LJ e cargas otimizados de forma conjunta para reproduzir determinadas propriedades termodinâmicas em certos intervalos de temperatura e pressão.

A última consideração a ser feita é que para compensar o raio de corte, é necessária uma correção de longo alcance para a energia $\left(U_{C L A}\right)$. O programa DICE corrige apenas as interações correspondentes ao potencial LJ, através da expressão:

$$
U_{C L A}=\sum_{a} \sum_{b>a} \sum_{i}^{\text {sobrea sobreb }} \sum_{j}^{8} \frac{8}{9} \pi N \rho \varepsilon_{i j} \sigma_{i j}^{3}\left[\left(\frac{\sigma_{i j}}{r_{c}}\right)^{9}-3\left(\frac{\sigma_{i j}}{r_{c}}\right)^{3}\right],
$$

já que correções de longo alcance para o potencial de Coulomb são computacionalmente dispendiosas e por isso não são calculadas, uma boa aproximação para sistemas moleculares não carregados (para uma discussão mais ampla, bem como a demonstração da expressão (1.4), veja o capítulo 3 da ref. ${ }^{47}$ ). 


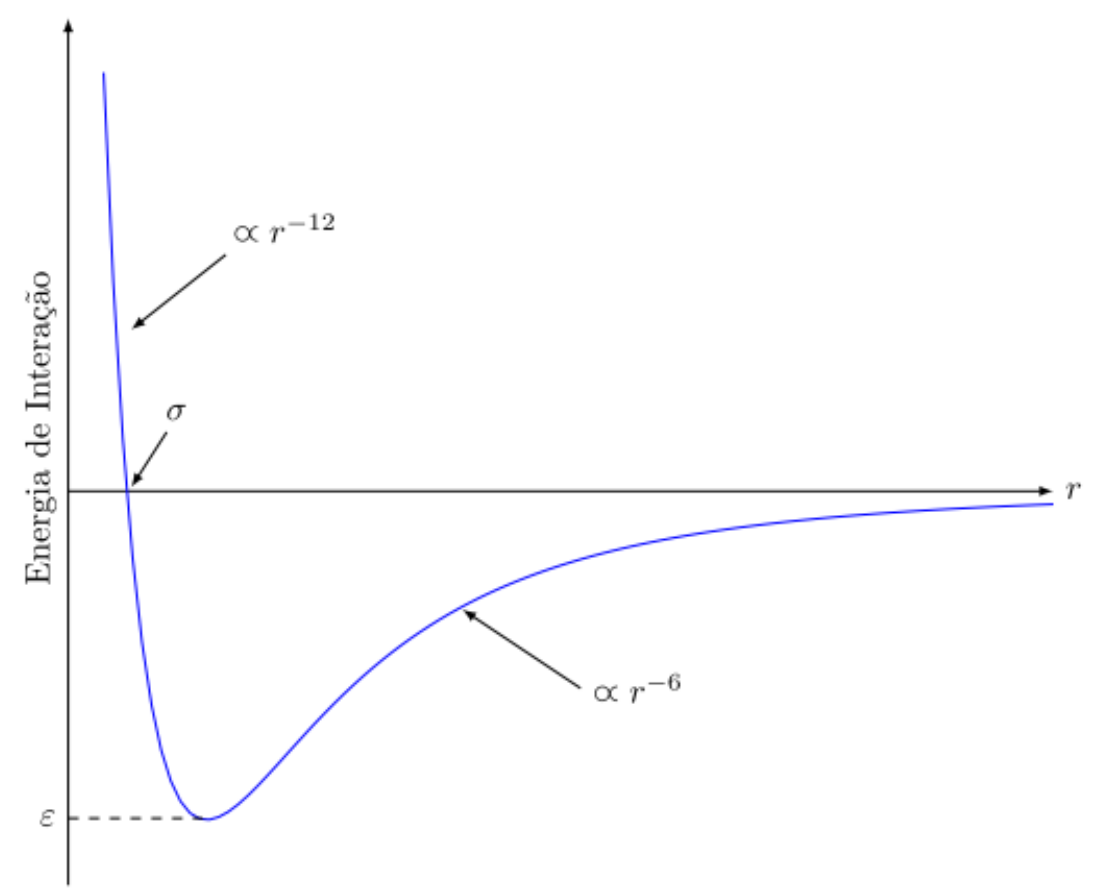

Figura 1.6: O potencial de Lennard-Jones (adaptado da Ref. ${ }^{51}$ ).

\subsection{4 - Análise da Simulação}

Uma vez concluída a simulação, dispomos de um número imenso de configurações. Obviamente é impraticável e indesejável analisá-las separadamente. Nós nos atemos a algumas propriedades para extrair informações da simulação. As duas principais são:

- Função de Distribuição Radial de Pares $G(r)$ :

Essa função nos dá informação sobre a distribuição de moléculas de solvente em torno do soluto e pode ser obtida experimentalmente por difração de raios-X e nêutrons ${ }^{47,52}$. A $G(r)$ fornece a probabilidade de se encontrar um par de átomos a uma dada distância $r$ relativa à probabilidade de se encontrar o mesmo par em uma distribuição aleatória de mesma densidade (conhecida como distribuição de gás ideal). Ela pode ser calculada através da expressão:

$$
G(r)=\frac{N(N-1)}{\rho^{2} Z} \int \wp d \vec{r}_{n-2},
$$


onde $N$ é o número de moléculas, $\rho$ é a densidade, $Z$ é um fator de normalização e $̧$ é a distribuição de probabilidades do ensemble no qual a simulação foi realizada: $\wp_{N V T}=e^{-U / k T}$ e $\wp_{N P T}=e^{-(U+P V) / k T}$. A notação para o elemento diferencial indica que a integração é feita sobre todos os átomos, exceto os dois que definem o par que está sendo analisado.

O número de moléculas até uma dada distância é obtido integrando-se $G(r)$ sobre o volume esférico até essa distância

$$
N=\frac{1}{V} \int_{V} G(r) r^{2} d V
$$

Na simulação, essas grandezas são determinadas na ordem inversa: a $G(r)$ é calculada usando o histograma de distância dos pares $i$ e $j$,

$$
G(r)=\frac{n_{i j}(r, r+d r)}{n_{\text {ideal }}(r, r+d r)},
$$

onde $n_{i j}$ é o número de pares $i j$ separados por uma distância entre $r$ e $r+d r$, enquanto $n_{\text {ideal }}$ é o número de pares equivalentes no gás ideal.

Assim, há mais de uma maneira de se obter a $G(r)$, posto que há mais de uma maneira de se contar as moléculas ao redor do soluto. A mais comum é considerar a distribuição não propriamente das moléculas, mas dos centros de massa delas. Observe, entretanto, que isso pode ser um problema se a molécula de interesse tiver uma das dimensões muito maior do que as outras. Uma aproximação mais realista é utilizar a distribuição de mínima distância (MDDF), onde a distância de uma molécula a outra é considerada como a menor distância entre qualquer par de átomos dessas moléculas ${ }^{23,53}$. Assim é possível obter uma distribuição do solvente em torno do soluto mais igualitária em todas as direções.

\section{- Autocorrelação da Energia:}

No começo da seção 1.3, apontamos como uma das vantagens do S-QM/MM o baixo número de cálculos quânticos necessários para se obter a propriedade de interesse, que advém do fato de apenas configurações relevantes para a média serem usadas. Para determinar estas configurações nós utilizamos a função de autocorrelação da energia: 


$$
C(t)=\frac{\left\langle\delta E_{n} \delta E_{n+t}\right\rangle}{\left\langle\delta E^{2}\right\rangle}=\frac{\sum_{n}\left(E_{n}-\langle E\rangle\right)\left(E_{n+t}-\langle E\rangle\right)}{\sum_{n}\left(E_{n}-\langle E\rangle\right)^{2}}
$$

sendo $E_{n}$ a energia da configuração $n$ e $E_{n+t}$ a energia da configuração gerada $t$ passos de $M C$ depois. Note então que configurações separadas por um número pequeno de passos de $M C$ possuem uma correlação próxima a unidade o que significa que a inclusão de ambas simultaneamente no cálculo da média não fornece informação estatística nova. De modo análogo, só teríamos configurações completamente descorrelacionadas em $t=\infty$. O que fazemos então é ajustar uma função aos valores calculados da autocorrelação da energia, permitindo assim ter uma estimativa de quão correlacionadas estão as configurações após um intervalo de passos de MC. Para processos Markovianos, a autocorrelação pode ser aproximada por uma soma de decaimentos exponenciais ${ }^{54}$ :

$$
C(t)=\sum_{k} c_{k} e^{-t / \tau_{k}}
$$

Temos observado, porém, que dois termos são suficientes para obter um ajuste muito bom ${ }^{40,47,52}$.

Nós consideramos estatisticamente descorrelacionadas configurações separadas por um intervalo tal que a correlação seja menor que $13 \%$. Apenas essas configurações são submetidas aos cálculos quânticos.

\subsection{5 - Melhorando a descrição: Introduzindo a polarização do soluto}

Uma das desvantagens da abordagem sequencial que apontamos é que não há polarização mútua entre o soluto e o solvente e nem relaxação de geometria, uma vez que os parâmetros que definem cada molécula (parâmetros $L J$, cargas e geometria) permanecem fixos durante toda a simulação. Isso muitas vezes não é uma boa aproximação.

Para a polarização do soluto há duas soluções possíveis: a mais simples é colocá-la $a$ priori, obtendo a geometria e as cargas do soluto em meio contínuo (usando o modelo PCM) ao invés de considerá-lo isolado. Em geral, isso aumenta o momento de dipolo da molécula em cerca de $60 \%$, se comparado ao valor obtido quando ela está isolada. Os valores obtidos são usados na simulação, novamente de maneira fixa. Nós chamamos este procedimento de polarização PCM ou polarização implícita. Esse procedimento tem se mostrado bastante 
razoável quando o solvente em questão á a água, mas não parece ser muito eficiente para solvente menos polares ${ }^{55}$.

A outra solução é um procedimento iterativo desenvolvido em nosso grupo para atualizar as cargas da simulação ${ }^{22}$. Nesse procedimento faz-se um cálculo quântico em fase gasosa para determinar as cargas iniciais da simulação. Após a simulação, novas cargas são calculadas em configurações onde o solvente é representado por cargas pontuais ou, mais comumente, pelo ASEC (que será definido na próxima seção). Faz-se nova simulação usando essas cargas, geram-se novas configurações, calculam-se novas cargas e assim por diante até que o valor do momento de dipolo calculado convirja; se o soluto for uma molécula apolar pode-se acompanhar a convergência pelas cargas dos átomos. O procedimento é esquematizado na Figura 1.7.

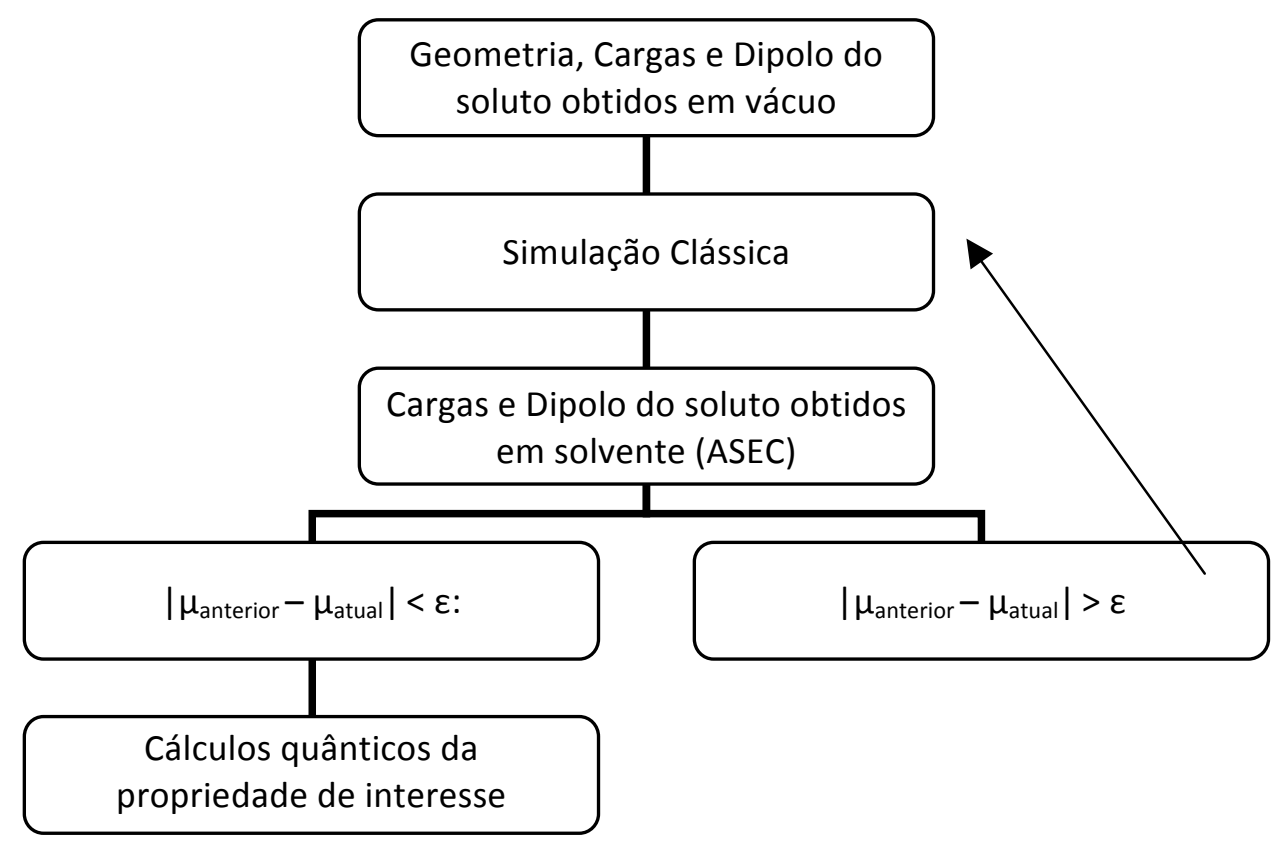

Figura 1.7: Organograma do procedimento iterativo usado para polarizar o soluto.

\subsection{6 - O Solvente como configuração média: ASEC}

Detalharemos agora o que é ASEC. ASEC é o acrônimo para Average Solvent Electrostatic Configuration. Ele foi proposto em nosso grupo ${ }^{56}$ baseado nas ideias de Aguilar $^{57}$, e surgiu como uma alternativa para reduzir o custo computacional para o procedimento iterativo de polarização visto na seção anterior. Como o nome sugere, o ASEC é uma configuração média que representa o solvente. Para gerá-lo, nós sobrepomos as configurações estatisticamente descorrelacionadas que foram selecionadas, representando as moléculas de 
solvente por cargas pontuais normalizadas, isto é, divididas pelo número de configurações. Assim o ASEC contém todas as interações eletrostáticas, e herda toda a informação estrutural do solvente (Figura 1.8). O resultado ${ }^{56}$ é o mesmo que seria obtido se usássemos várias configurações onde o solvente é representado como cargas pontuais para calcular determinada propriedade e tomássemos a média. Para demonstrar isso, considere uma configuração $j$ de um sistema molecular qualquer embebido em um campo eletrostático composto por um número finito de cargas pontuais. O hamiltoniano dessa configuração pode ser escrito como:

$$
H_{m o l}^{(j)}+\sum_{i=1}^{m} \frac{q_{i}^{(j)}}{\left|r_{i}^{(j)}-r^{\left.\right|^{2}}\right|^{2}} \vec{e}
$$

onde $H_{m o l}^{(j)}$ é o Hamiltoniano molecular e $\vec{e}$ é a direção resultante do campo composto pelas $m$ cargas $q_{i}^{(j)}$, cada carga em sua posição $r_{i}^{(j)}$ em relação ao referencial definido por $r^{\prime}$. Se tomarmos a média sobre $N$ configurações, temos:

$$
\frac{1}{N}\left(\sum_{j=1}^{N} H_{m o l}^{(j)}+\sum_{j=1}^{N} \sum_{i=1}^{m} \frac{q_{i}^{(j)}}{\left|r_{i}^{(j)}-r^{\prime}\right|^{2}} \vec{e}_{R}\right)
$$

com $\vec{e}_{R}$ a direção resultante da sobreposição dos campos das $N$ configurações, e que, pelo princípio da linearidade ${ }^{58}$, é a mesma que a direção resultante do campo gerado pelas $m \times N$ cargas. Na equação (1.11) estamos assumindo que todas as configurações possuem o mesmo referencial. Se a geometria do soluto é a mesma em todas as configurações, ou seja, se ela é rígida (e como vimos, em $\mathrm{MC}$, não só o soluto, mas todas as moléculas são tratadas como rígidas) então $H_{m o l}^{(j)}=H_{m o l} \forall j$. Deste modo, a equação (1.11) reduz-se a

$$
\frac{1}{N} \underbrace{\sum_{j=1}^{N} H_{m o l}^{(j)}}_{\text {NH }}+\underbrace{\left(\frac{1}{N} \sum_{j=1}^{N} \sum_{i}^{m} \frac{q_{i}^{(j)}}{\left|r_{i}^{(j)}-r^{\prime}\right|^{2}} \vec{e}_{R}\right)}_{\text {ASEC }}=H_{m o l}+\text { ASEC. }
$$

Dessa forma, se em um dado problema, a contribuição eletrostática for dominante, ao invés de fazermos vários cálculos com o solvente sendo representado por cargas pontuais e tirarmos a média, podemos fazer um único cálculo da propriedade em uma configuração média, o que 
leva ao mesmo resultado, mas com uma enorme economia computacional. O ASEC foi o modelo de solvente utilizado nesse trabalho.

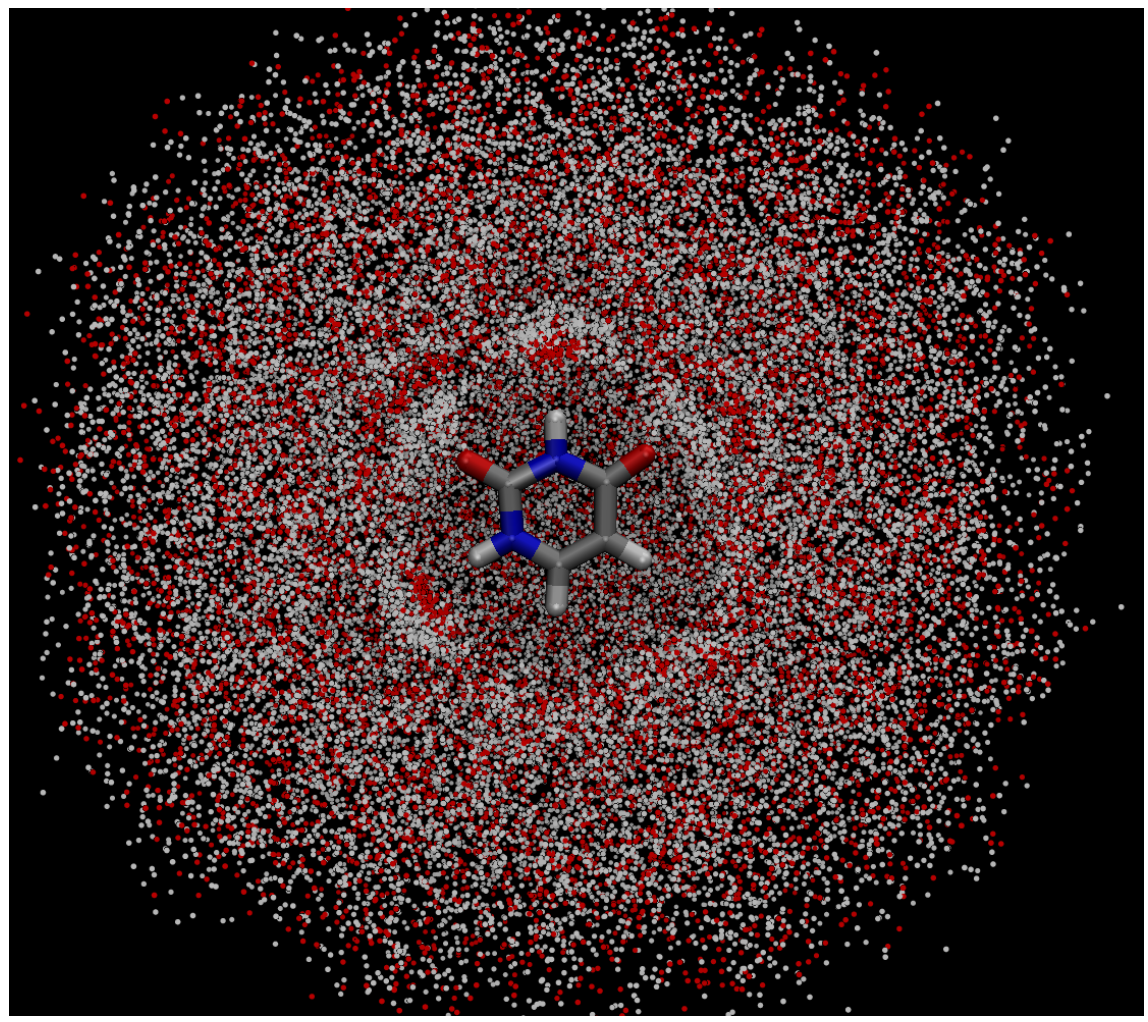

Figura 1.8: ASEC. Note como a configuração média herda a estrutura do líquido, evidenciando claramente regiões onde ligações de hidrogênio são formadas: adensamento de pontos vermelhos representando $O_{\text {wat }}$ próximos aos $\mathrm{HN}$, e o adensamento de pontos brancos representando $\mathrm{H}_{\text {wat }}$ próximos ao $\mathrm{O}_{\text {soluto. }}$.

\subsection{7 - O Gradiente de Energia Livre e a relaxação de geometria em meio solvente}

Para concluir este capítulo, discutiremos como é possível obter as mudanças na estrutura do soluto devido a interação com o solvente através do método do Gradiente de Energia Livre (FEG).

O FEG foi proposto por Nagaoka e colaboradores ${ }^{16-19}$ e objetiva obter estruturas estáveis de moléculas em solução. A ideia é que a partir de uma simulação clássica, é possível obter as forças na superfície de energia livre através da expressão:

$$
F(q)=-\frac{\partial G(q)}{\partial q}=-\left\langle\frac{\partial V(q)}{\partial q}\right\rangle
$$


onde $G(q)$ é a energia livre e $V$ a soma do potencial de interação intramolecular (no caso de MC, constante) e da interação soluto-solvente, ambas funções das coordenadas $q$ do soluto.

Como sugerido por Aguilar e colaboradores ${ }^{14,15}$, é possível aproximar o valor médio da força, expresso pelo lado direito da equação (1.13), pela força da configuração média:

$$
F(q) \cong-\frac{\partial\langle V(q)\rangle}{\partial q}
$$

sendo o erro introduzido por essa aproximação menor que os erros advindos de efeitos térmicos, como discutido e analisado na ref. ${ }^{14}$.

Essas aproximações são na prática incorporadas no S-QM/MM ao se calcular as forças em cada átomo do soluto na presença do ASEC que foi gerado pela simulação clássica.

Seguindo essas ideias, é possível adaptar o procedimento iterativo proposto na seção 1.3.5 para incluir a otimização de geometria do soluto. Assim, fazemos uma simulação clássica para gerar o ASEC. O soluto embebido nesse ASEC é submetido ao cálculo quântico de determinação de forças (apenas um passo de otimização dos algoritmos convencionais) e os átomos são então deslocados no sentido dessas forças. Essa nova geometria dentro do mesmo ASEC é usada em um cálculo de ajuste de cargas atômicas parciais. Faz-se então uma nova simulação clássica, onde a geometria e as cargas originais são substituídas pelas novas obtidas. $O$ procedimento é repetido até que momento de dipolo e as mudanças na geometria atinjam critérios de convergência, critérios esses que devem ser mais flexíveis do que aqueles usados em moléculas isoladas, devido às flutuações termodinâmicas ${ }^{17}$. Estes cálculos foram realizados no programa Diceplayer ${ }^{59}$, que funciona como uma interface entre o programa Dice $^{41}$ e programas de Química Quântica (atualmente Gaussian ${ }^{60,61}$ e Molcas ${ }^{62}$ ), originalmente desenvolvido para relaxar a geometria de moléculas solvatadas em seu estado fundamental e que foi adaptado especialmente para os propósitos deste trabalho, permitindo assim a otimização do estado excitado de moléculas em solução. 


\section{Capítulo 2 : \\ Os métodos multiconfiguracionais CASSCF e CASPT2}

Neste capítulo, vamos discorrer sobre os dois métodos de Mecânica Quântica Molecular (MQM) mais utilizados em nosso estudo: o Complete Active Space Self-Consistent Field (CASSCF) e o Second-Order Perturbation Theory with a CASSCF Reference Function (CASPT2), desenvolvidas pelo Prof. Björn Roos e seus colaboradores. De forma alguma pretendemos substituir os bons textos existentes na literatura (que são bem menos comuns do que aqueles que tratam sobre Hartree-Fock ou Møller-Plesset). Nos atemos a apresentar um texto que discuta de forma breve, porém completa, as principais ideias e dificuldades relacionadas aos métodos CASSCF e CASPT2.

Para aqueles que desejam um estudo mais profundo, destacamos 4 textos: a ref. ${ }^{63}$, uma excelente introdução a ambos os métodos (e escrita em língua portuguesa), a ref. ${ }^{64}$, escrita por dois colaboradores de Roos, bem como a ref. ${ }^{65}$, escrita pelo próprio Roos, excelentes textos sobre os métodos CASSCF e CASPT2, e finalmente os capítulos 5.5 e 12 da ref. ${ }^{66}$, que é um texto mais avançado e que discute métodos multiconfiguracionais de um modo geral. Após essas leituras, pode-se aprofundar ainda mais no assunto, através dos artigos originais que estão referenciados em nosso texto, onde detalhes mais técnicos, como a elaboração de algoritmos eficientes, são discutidos.

Outros poucos métodos de MQM que foram utilizados, como a teoria de perturbação de muitos corpos em segunda ordem com partição de Møller-Plesset (MP2), não serão discutidos aqui (eles são comentados apenas breve e qualitativamente na próxima seção), uma vez que já foram exaustivamente discutidos em livros textos (dentro os quais destacamos a ref. ${ }^{67}$ ) e em teses anteriores, de forma que vemos como dispensável discorrer longamente sobre eles.

Como o programa Molcas ${ }^{62}$ foi utilizado para fazer os cálculos multiconfiguracionais desse trabalho, comentários sobre as opções padrões e implementações também são feitos. 


\section{1 - Os métodos Pós Hartree-Fock. Por que utilizar métodos multiconfiguracionais?}

O método de Hartree-Fock (HF) se destaca como primeiro método a fornecer de forma simples, sistemática e robusta, resultados para a energia de sistemas multieletrônicos. HF se resume a um procedimento variacional, que leva a equações de autovalores e que devem ser resolvidas de maneira autoconsistente (SCF: Self-Consistent Field), e que são advindas de uma aproximação de campo médio, onde cada elétron se move na presença de um campo gerado pelos demais.

Usando essa aproximação de campo médio, obtem-se cerca de $90-95 \%$ do valor da energia total exata não-relativística. Isso, aliado ao fato de que as equações podem ser escritas em forma matricial (formalismo de Hartree-Fock-Roothaan ${ }^{67-69}$ ), possibilitando a implementação em códigos de computador, contribuiu para o sucesso do método.

Apesar de fornecer excelentes valores para a energia total, não se pode dizer o mesmo para outras propriedades físico-químicas calculadas com HF. Surgiu então uma busca por maneiras de recuperar a energia ausente em HF (o que, consequentemente, pode melhorar as descrições de outras propriedades). Como esta energia está relacionada ao fato de que cada elétron deve perceber a presença dos demais como entidades e não como um campo médio, Löwdin a definiu como energia de correlação, sendo ${ }^{70}$ :

$$
E_{\text {corr }}=E_{\text {exata }}-E_{H F} \text {. }
$$

Várias maneiras de se buscar a energia de correlação foram propostas, formando o que chamamos hoje de métodos Pós Hartree-Fock. Dentre eles, se destacam a Teoria de Perturbação de Muitos Corpos (MBPT, do inglês Many-Body Perturbation Theory), Coupled Cluster (CC) e Configuration Interaction (Cl).

No primeiro, usa-se a teoria de perturbação de Rayleigh-Schrödinger, particionando o Hamiltoniano segundo as ideias de Møller e Plesset e usando diagramas para determinar e calcular apenas os termos extensivos ${ }^{67}$. Pode-se mostrar que a correção em primeira ordem para a energia é nula, de modo que a correção de mais baixa ordem é a segunda ${ }^{67}$. Os programas mais utilizados atualmente como, por exemplo, o Gaussian ${ }^{60,61}$, dispõem de MBPT implementado até a $5 \underline{a}$ ordem, mas o mais comum é se corrigir a energia até $4 \underline{a}$ ordem e as demais propriedades até $2 \underline{a}$ ordem. 
Entretanto, as correções ordem a ordem de MBPT se tornam custosas e impraticáveis (sem mencionar tediosas) rapidamente, devido ao crescimento rápido do número de diagramas (consequentemente, número de termos que precisam ser calculados), que de $1 \mathrm{em}$ 2a ordem, passa pra 3 na 3aㅡ, 39 na 4a e 840 na 5a ordem $!^{71}$. Além disso, não há garantias de que a série convirja, havendo casos conhecidos de divergência ${ }^{72}$. Pra contornar isso, surgiu o método $\mathrm{CC}^{73,74}$, adaptado do contexto da física nuclear ${ }^{75}$, no qual usa-se uma função de referência (em geral HF) e escreve-se a função de onda como

$$
|\Psi\rangle_{c C}=e^{T}|\Psi\rangle_{\text {ref }}
$$

onde T é uma soma de operadores de excitação, que promovem os elétrons da função de referência para orbitais virtuais. Fazendo o desenvolvimento matemático apropriado, obtemos um conjunto de equações de trabalho, sendo uma para a energia e uma para cada tipo de excitação que for incluída em $T$ (simples, duplas, triplas, etc), que devem ser resolvidas iterativamente (e que torna o método computacionalmente custoso). Devido à limitação computacional, geralmente inclui-se apenas alguns poucos tipos de excitações (dando origem a métodos como CCD, CCSD, CCSDT), ou uma parte delas não é iterada $\left(C C S D-T^{76}\right.$ ) ou ainda fazse aproximações na equação para maior ordem incluída $\left(\mathrm{CC}^{77}, \mathrm{CC}^{78}\right)^{\dagger}$.

Finalmente, em $\mathrm{Cl}$, busca-se corrigir outra limitação de HF: a aproximação monodeterminantal. HF assume que o estado multieletrônico pode ser descrito por apenas uma configuração, escrita na forma do determinante de Slater

$$
\Psi=\frac{1}{\sqrt{N !}}\left|\begin{array}{cccc}
\varphi_{1}(1) & \varphi_{1}(2) & \ldots & \varphi_{1}(N) \\
\varphi_{2}(1) & \varphi_{2}(2) & \ldots & \varphi_{2}(N) \\
\vdots & \vdots & \ddots & \vdots \\
\varphi_{N}(1) & \varphi_{N}(2) & \ldots & \varphi_{N}(N)
\end{array}\right|
$$

onde $\varphi_{i}(j)$ é o i-ésimo spin-orbital molecular da partícula $j$. Estes spin-orbitais podem ser separados em parte espacial e de spin e a parte espacial é descrita pela aproximação LCAO ${ }^{67}$.

Desde que essa configuração seja dominante, a aproximação é válida e os resultados obtidos são realistas. Entretanto, essa predominância nem sempre é verdadeira e outras configurações podem ter contribuições relevantes. No método $\mathrm{Cl}$, corrige-se isso ao usar como

\footnotetext{
' Para as definições das siglas, veja a Lista de Siglas, Abreviações e Acrônimos, pág. xix.
} 
função de onda uma série de determinantes de Slater, gerados como excitações do determinante correspondente ao estado fundamental

$$
|\Psi\rangle_{c l}=c_{0}\left|\Psi_{0}\right\rangle+\sum_{a, i} c_{i, a}\left|\Psi_{a}^{i}\right\rangle+\sum_{\substack{a<b \\ i<j}} c_{i j, a b}\left|\Psi_{a b}^{i j}\right\rangle+\sum_{\substack{a<b<c \\ i<j<k}} c_{i j k, a b c}\left|\Psi_{a b c}^{i j k}\right\rangle+\ldots
$$

onde os coeficientes $c$ são determinados de modo a minimizar a energia. Perceba que o número de configurações cresce rapidamente com a quantidade de orbitais virtuais disponíveis para a excitação e com o número de elétrons passíveis de serem excitados (esse número de configurações pode ser determinado pela fórmula de Weyl, veja seção 2.5). Se todas as configurações possíveis forem incluídas na função de onda, temos o que é conhecido como Full-Cl, que é o resultado exato, dentro do espaço gerado pelo conjunto base utilizado. Infelizmente este tipo de cálculo ainda é muito custoso para os recursos computacionais atuais, de modo que ele só é factível para sistemas de tamanho bem limitado. Para sistemas maiores, truncamentos são necessários, o que deu origem aos métodos como CIS e CISD onde, respectivamente, apenas excitações simples e excitações simples e duplas são incluídas.

O problema desse tipo de truncamento é que faz com que o método não escale com o tamanho (size-consistent), ou seja, se subdividirmos o sistema, o cálculo das partes não será igual ao cálculo do todo. Isso é fácil de exemplificar: considere um sistema com 4 elétrons e suponha que apenas excitações duplas sejam permitidas. Se dividimos o sistema em dois subsistemas de 2 elétrons, e continuarmos a permitir excitações duplas, a soma de ambos conterá uma contribuição correspondente a excitações quádruplas. Uma maneira de contornar esse problema é através do método $\mathrm{CIS}(\mathrm{D})$, que introduz ao resultado do cálculo $\mathrm{CIS}$ uma correção de segunda ordem baseada nas excitações duplas, usando uma técnica de fatoração para manter o método size-consistent $t^{79,80}$.

Todos esses métodos têm sido largamente utilizados para a obtenção da energia de correlação e estão discutidos com riqueza de detalhes em vários livros textos na literatura, entre os quais destacamos a ref. ${ }^{67}$.

Voltando ao $\mathrm{Cl}$, chamamos a atenção para duas constatações:

i) A utilização de mais de uma configuração para descrever um sistema multieletrônico evidencia que não necessariamente todo sistema/propriedade pode ser descrito por apenas uma configuração. Um exemplo clássico é a 
dissociação da molécula $\mathrm{H}_{2}$, que só é descrita corretamente se pelo menos duas configurações (ligante e anti-ligante) forem incluídas no cálculo;

ii) A princípio, $\mathrm{Cl}$ pode fornecer a solução exata, o que permite supor que se for possível selecionar de alguma maneira as configurações mais relevantes, pode-se obter a maior parte da energia de correlação e valores realistas para as propriedades, com um custo computacional relativamente baixo.

Essas duas constatações deram origem aos métodos multiconfiguracionais (MCSCF), dentre os quais se destacam os métodos $\operatorname{CASSCF}^{10}$ e CASPT2 ${ }^{20}$.

\section{2 - CASSCF}

Quando os métodos multiconfiguracionais começaram a surgir, uma das principais indagações era: como estabelecer uma maneira sistemática para selecionar as configurações mais importantes que irão compor a função de onda? A princípio, seria através da análise de um cálculo $\mathrm{Full-Cl}$ ou, pelo menos, de um cálculo $\mathrm{Cl}$ com vários tipos de excitações, que se determinaria quais configurações seriam importantes. Mas é justamente fazer estes cálculos dispendiosos que se queria evitar!

Esse é provavelmente o grande trunfo do método Complete Active Space SelfConsistent Field $(\mathrm{CASSCF})^{10}$, proposto por Björn Roos: ao invés de se preocupar com as configurações em si, Roos propôs que se selecionasse os orbitais, ocupados e virtuais, mais relevantes para o problema em questão e, uma vez feito isso, determina-se a função de onda multiconfiguracional através de um Full-Cl nesse espaço seleto, dito espaço ativo. A escolha do espaço ativo está no coração do método; ela pode ser simples ou envolver questões delicadas, a depender do sistema que se quer estudar e os resultados são dependentes dessa escolha. Nós discutiremos a escolha do espaço ativo na seção 2.5 .

Agora, uma vez que tenha se escolhido o espaço ativo, a função de onda multiconfiguracional é determinada como segue:

- Gera-se todas as possíveis configurações que tenham mesma simetria espacial e de spin do estado de referência (Configurations State Function - CSF), distribuindo os elétrons ativos de todas as maneiras possíveis nos orbitais ativos. A função de onda é escrita como uma combinação linear dessas configurações; 
- Otimiza-se os orbitais (ativos e os duplamente ocupados que não forem de caroço) e os coeficientes da combinação.

O hamiltoniano multieletrônico, em $2^{\text {a }}$ quantização, pode ser escrito como ${ }^{67}$ :

$$
H=\sum_{i j}\langle i|h| j\rangle a_{i}^{\dagger} a_{j}+\frac{1}{2} \sum_{i j k l}\langle i j \mid k l\rangle a_{i}^{\dagger} a_{j}^{\dagger} a_{1} a_{k}
$$

com a soma correndo sobre spin-orbitais e sendo $a_{m}^{\dagger}$ e $a_{m}$ os operadores de criação e aniquilação atuando no spin-orbital $m$, respectivamente. Integrando sobre spin, e realizando o desenvolvimento matemático apropriado, é possível mostrar que o valor médio da energia $\mathrm{e}^{10,64}$

$$
E=\sum_{i j} h_{i j} D_{i j}+\sum_{i j k l}(i j \mid k l) P_{i j k l}
$$

onde agora a soma é sobre orbitais moleculares e sendo

$$
D_{i j}=\sum_{m n} c_{m}^{*} D_{i j}^{m n} c_{n}, P_{i j k l}=\sum_{m n} c_{m}^{*} P_{i j k l}^{m n} c_{n}
$$

elemento da matriz densidade reduzida de $1 \underline{a}$ e $2 \underline{a}$ ordem, respectivamente, onde

$$
D_{i j}^{m n}=\left\langle m\left|E_{i j}\right| n\right\rangle, P_{i j k l}^{m n}=\frac{1}{2}\left\langle m\left|E_{i j} E_{k l}-\delta_{j k} E_{i i l}\right| n\right\rangle,
$$

são respectivamente os coeficientes de acoplamento de 1 e 2 elétrons e

$$
E_{p q}=\sum_{\sigma=\alpha, \beta} a_{p \sigma}^{\dagger} a_{q \sigma}=a_{p \alpha}^{\dagger} a_{q \alpha}+a_{p \beta}^{\dagger} a_{q \beta}
$$

é o operador de excitação somado sobre spin.

Assim, a expressão (2.6) contém toda a informação dos orbitais e dos coeficientes $\mathrm{Cl}$ e é o ponto de partida para se otimizar ambos. Vários parâmetros têm que ser obtidos simultaneamente e para Ihe dar com isso, duas são as abordagens mais utilizadas:

○ Newton-Rhapson (NR): Nesse método a energia é expandida em série de Taylor e calcula-se então o gradiente e a hessiana, que são então igualados a zero ${ }^{81}$. Assim, determinamos os parâmetros variacionais que são então usados para escrever a 
função de onda multiconfiguracional, permitindo um novo cálculo para a energia, recomeçando o ciclo, até a convergência.

- Super-Cl: Nesse método, usando os orbitais atuais, otimiza-se os coeficientes $\mathrm{Cl}$, que são então usados pra escrever a função de onda Super- $\mathrm{Cl}^{82}$ :

$$
\Phi=\Psi+\sum_{i a} c_{i}^{a} \Psi_{i}^{a}
$$

com $\Psi_{i}^{a}$ excitações simples da função de onda multiconfiguracional atual, e os orbitais são melhorados usando uma fórmula de contração ${ }^{82,83}$.

No programa Molcas ${ }^{62}$, o algoritmo de otimização dos parâmetros variacionais segue um procedimento que combina ambos e se mostrou eficiente para alcançar a convergência da função de onda multiconfiguracional ${ }^{84}$. A otimização começa usando Super-Cl e após certos critérios de convergência serem atingidos, o algoritmo passa a usar NR, por ser computacionalmente menos dispendioso. Se em um dado ciclo de Super-Cl ou NR, a alteração nos valores de convergência é menor que certo limite, uma busca linear é feita ao longo da direção do último passo.

Uma vez que a função de onda é obtida, as propriedades de interesse podem ser calculadas como valor médio do operador apropriado. Como as funções de onda CASSCF são autofunções do operador de spin total, elas podem ser utilizadas para descrever sistemas com camada fechada ou aberta, bem como estados excitados.

\section{3 - CASPT2}

O método CASSCF se mostrou como alternativa simples e eficiente para se gerar uma função de onda multiconfiguracional. Entretanto, como o método se utiliza de um número finito de diferentes configurações para recuperar a correlação, apenas uma parte dela é obtida. É comum na literatura, essa parte ser chamada de "correlação estática" (pois a princípio, ela não está correlacionando os movimentos dos elétrons), sendo que a correlação que aí não estiver contida recebe a adjetivação de "dinâmica". Apesar de ser largamente utilizada, essa nomenclatura é inconsistente: Full-Cl é uma solução exata do problema multieletrônico, mas segundo essa nomenclatura, ele contém apenas correlação estática. Por esse motivo, não a utilizaremos em nossa discussão. 
Apesar dos vários sucessos do método CASSCF, que gera uma função de onda com as características e com a flexibilidade necessária para se tratar variados problemas, os valores numéricos obtidos para a energia total ou para transições eletrônicas permitiam apenas discussões qualitativas. Para incluir o restante da energia de correlação que não estava em CASSCF, permitindo a obtenção de resultados com acurácia química, Roos e coautores propuseram o método Second-Order Perturbation Theory with a CASSCF Reference Function $\left(\right.$ CASPT2) ${ }^{20}$, onde utiliza-se a função de onda CASSCF como referência e corrige-se a energia até segunda ordem e a função de onda até primeira, através da Teoria de Perturbação. Essa perturbação advém de excitações envolvendo também o espaço inativo e o virtual.

Estende-se a partição de Møller-Plesset para o caso multiconfiguracional, escrevendo:

$$
H_{0}=P_{0} F P_{0}+P_{K} F P_{K}+P_{S D} F P_{S D}+P_{T Q} F P_{T Q}
$$

construído com a finalidade de que a função de onda CASSCF seja sua autofunção. Se usássemos como referência uma função de onda HF, recuperaríamos MBPT em 2aㅡordem.

F é o operador de Fock generalizado, cuja definição não é única ${ }^{85,86}$. A mais usada, e que foi empregada em CASPT2, é defini-lo como o operador de Fock da matriz densidade de 1a ordem da função de referência mediado sobre spin:

$$
F=\sum_{i j} f_{i, j} E_{i j}
$$

com

$$
f_{i, j}=h_{i j}+\sum_{k l} D_{k l}\left[(i j \mid k l)-\frac{1}{2}(i k \mid j l)\right] .
$$

Essa escolha traz as vantagens de ser um operador bem definido e que preserva a simetria de spin. Entretanto, ela introduz erros sistemáticos na energia de ligação e de excitação, que podem ser corrigidas através de certas imposições, como veremos no final dessa seção.

Os operadores $P$ da expressão (2.11) são projetores que levam para o espaço de referência $\left(P_{0}\right)$, para o espaço ortogonal ao espaço de referência $\left(P_{\mathrm{K}}\right)$, para o espaço interagente de primeira ordem $\left(P_{\mathrm{SD}}\right)$ e para o espaço de excitações de ordem superior que não interage com a função de referência $\left(P_{\mathrm{TQ}}\right)$. Como o hamiltoniano multieletrônico é composto por operadores de 1 e 2 corpos, é natural que o espaço interagente de primeira ordem $P_{\mathrm{SD}}$ 
(que será usado para calcular a contribuição da energia de correlação) seja composto por excitações simples e duplas (incluindo excitações para fora do espaço ativo), enquanto o espaço de ordem superior seja composto por excitações triplas, quádruplas, etc. Além disso, como discutido por Andersson \& Roos, as excitações simples não necessariamente precisam ser incluídas explicitamente ${ }^{85}$. Temos então 8 tipos diferentes de excitações duplas, que podem ser agrupadas em 3 categorias. Sejam $i, j$ índices para designar orbitais no espaço inativo, $t, u, v$ para o espaço ativo e $a, b$ para o espaço secundário, então as excitações podem ser

\begin{tabular}{|c|l|l|}
\hline Internas & Semi-internas & Externas \\
\hline$E_{t i} E_{u v}|\Phi\rangle$ & $E_{a t} E_{u v}|\Phi\rangle$ & $E_{a t} E_{b u}|\Phi\rangle$ \\
$E_{t i} E_{u j}|\Phi\rangle$ & $E_{a i} E_{t u}|\Phi\rangle, E_{t i} E_{a u}|\Phi\rangle$ & $E_{a i} E_{b t}|\Phi\rangle$ \\
& $E_{t i} E_{a j}|\Phi\rangle$ & $E_{a i} E_{b j}|\Phi\rangle$ \\
\hline
\end{tabular}

onde $|\Phi\rangle$ é a função de onda CASSCF. Em outras palavras, as excitações são ditas internas se não há elétrons no espaço virtual, semi-internas se há um elétron no espaço virtual e externas se há dois elétrons no espaço virtual.

Expandimos a correção da função de onda em 1aㅡ ordem usando as funções do espaço interagente de primeira ordem:

$$
\left|\Psi^{(1)}\right\rangle=\sum_{j=1}^{M} c_{j}|j\rangle,|j\rangle \in\left\{P_{S D}\right\}
$$

e cujos coeficientes são obtidos resolvendo a equação para a correção da função de onda em 1a ordem:

$$
\sum_{j=1}^{M} c_{j}\left\langle i\left|F-E_{0}\right| j\right\rangle=-\langle i|H| \Phi\rangle, i=1, \ldots, M
$$

e a função de onda é finalmente escrita como

$$
|\Psi\rangle=\sqrt{\omega}|\Phi\rangle+\sqrt{1-\omega}\left|\Psi^{(1)}\right\rangle
$$

O valor de $\omega$ depende do conjunto base utilizado, da quantidade de elétrons correlacionados e sua contribuição para a energia e da qualidade da função CASSCF empregada como referência ${ }^{63,85}$, mas ele é um indicativo da validade do tratamento 
perturbativo: se a perturbação é de fato pequena, como a Teoria de Perturbação supõe, o peso da função de referência deve ser grande na composição da função de onda corrigida. Se o valor de $\omega$ for pequeno, o espaço ativo deve ser aumentado.

A resolução dessas equações fornece a função de onda corrigida até primeira ordem. Entretanto, certos aprimoramentos matemáticos permitem um cálculo computacional mais eficiente, inclusive eliminando o inconveniente de $M$ poder ser maior que a dimensão de $\left\{P_{S D}\right\}$, como discutido por Roos e seus colaboradores no artigo onde o método foi originalmente proposto ${ }^{20}$.

A correção para a energia é obtida através da usual equação para a correção em 2a ordem de $\mathrm{MBPT}^{67}$

$$
E^{(2)}=\sum_{\substack{i<j \\ a<b}} \frac{|\langle a b \| i j\rangle|^{2}}{\varepsilon_{a}+\varepsilon_{b}-\varepsilon_{i}-\varepsilon_{j}},
$$

com os índices $a, b$ correndo sobre orbitais ocupados e $i, j$ sobre os orbitais virtuais.

A expressão (2.17) implica que o tratamento perturbativo funciona corretamente quando a separação entre HOMO e LUMO é apreciável, o que torna o denominador grande e portanto a correção pequena, como é suposto quando se faz a expansão da energia e da função de onda numa séria e que resulta na expressão. Infelizmente, nem sempre isso é verdade quando usamos o método CASPT2, pois a energia dos orbitais ativos é intermediária entre a energia dos orbitais ocupados e dos virtuais. Se um orbital ativo tem número de ocupação muito próximo de 2 , sua energia será próxima da energia dos orbitais ocupados, bem como se tiver número de ocupação próximo de zero, sua energia será próxima a dos orbitais virtuais. Isso dá origem ao que chamamos de estados intrusos, pois como na equação (2.17) temos um denominador que envolve diferenças de energia, podem ocorrer correções altas que na verdade são artificiais (discussões mais detalhadas podem ser encontradas nas refs. $\left.{ }^{63-65}\right)$. Se a interação da função de referência com o estado intruso for muito alta, a única solução é aumentar o espaço ativo, incluindo os orbitais que levam aos valores pequenos do denominador. Se isso não for possível, o método CASPT2 não poderá ser empregado para tratar o problema em questão. Para interações pequenas, desenvolveu-se a técnica de level shift $^{87}$, onde somamos ao hamiltoniano um parâmetro vezes o operador de projeção para o espaço interagente de primeira ordem; assim o estado intruso é removido, mas uma nova correção para a energia deve ser feita, pois agora a expressão para a correção em segunda 
ordem será dependente do parâmetro. Posteriormente, uma variação dessa técnica foi proposta, usando um shift imaginário, que é ainda mais eficiente para a remoção dos estados intrusos fracamente interagentes ${ }^{88}$.

Fechamos essa seção discutindo uma recente modificação feita no Hamiltoniano de ordem zero conhecida como IPEA shift ${ }^{89}$, que foi proposta para corrigir os erros sistemáticos introduzidos pela escolha do operador de Fock generalizado e que induziam a uma descrição não-balanceada da energia de ligação e da energia de excitação eletrônica entre estados de diferentes multiplicidades de spin. Considere os termos diagonais da expressão (2.13). Para o caso de camada fechada, eles estariam relacionados ao potencial de ionização (-IP) para orbitais duplamente ocupados e à Eletroafinidade (-EA) para orbitais virtuais. Para orbitais no espaço ativo, $f_{p, p}$ é uma média ponderada dessas grandezas. Podemos reescrever $f_{p, p}$ como uma interpolação dos casos extremos:

$$
f_{p, p}=-\frac{1}{2}\left(D_{p p}(I P)_{p}+\left(2-D_{p p}\right)(E A)_{p}\right)
$$

que se reduz aos casos limites $D_{p p}=0$ e 2, e que também está correta para camada aberta $\left(D_{p p}=1\right):$

$$
f_{p, p}=-\frac{1}{2}\left((I P)_{p}+(E A)_{p}\right)
$$

Aqui surge o erro sistemático comentado no início dessa seção: excitações a partir de ou para orbitais parcialmente ocupados levam a denominadores muito pequenos na expressão (2.17), superestimando assim a correção perturbativa e consequentemente subestimando valores para energia de excitação e de dissociação. A solução proposta por Roos e colaboradores é impor que, para os orbitais do espaço ativo, a interpretação de -IP e -EA seja recuperada, acrescentando em $f_{p, p}$ a expressão

$$
\sigma_{p}^{(E A)}=\frac{1}{2} D_{p p}\left((I P)_{p}-(E A)_{p}\right)
$$

quando se excita para um orbital ativo e

$$
\sigma_{p}^{(I P)}=-\frac{1}{2}\left(2-D_{p p}\right)\left((I P)_{p}-(E A)_{p}\right)
$$


quando se excita a partir de um orbital ativo. Como não é imediato obter valores para IP e EA, optou-se por substituir a diferença entre essas duas grandezas, presente nas equações (2.20) e (2.21), por um parâmetro $\varepsilon$, ao qual foi atribuído um valor de 0.25 u.a., baseado nos valores para os átomos (Figura 2.1) e em testes em 49 moléculas diatômicas ${ }^{89}$, e que mostrou-se suficiente para eliminar esses erros sistemáticos. O Hamiltoniano de ordem zero com IPEA shift está implementado como padrão no programa Molcas para cálculos CASPT2.

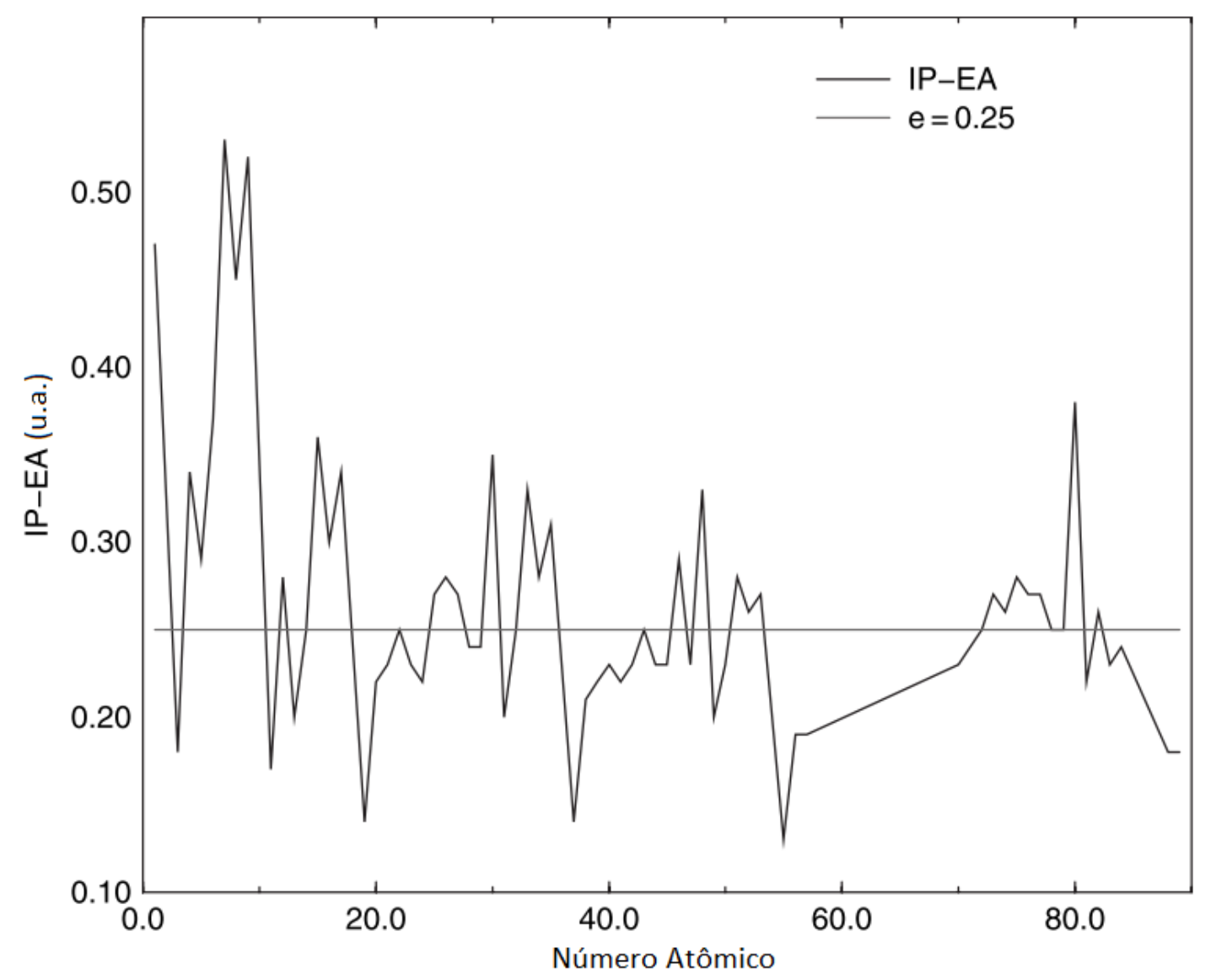

Figura 2.1: Valores de IP-EA para os átomos. Note que a maioria dos valores está numa faixa entre 0.2 e 0.3 u.a. A linha horizontal representa o valor de 0.25 u.a. (figura adaptada da ref. ${ }^{65}$ ).

\section{4 - SA-CASSCF e MS-CASPT2}

Muitas vezes, é preciso determinar muitos estados de uma única vez. Isso é muito comum quando se quer calcular, por exemplo, diferentes transições em um espectro de absorção ou a intersecção cônica entre dois estados. Para isso, foi desenvolvido o StateAverage CASSCF (SA-CASSCF) ${ }^{90}$, onde um mesmo conjunto de orbitais é otimizado simultaneamente para descrever mais de um estado, ao escrevermos a energia como uma média 


$$
E=\sum_{i} \omega_{i} E_{i}
$$

sendo $\omega_{i}$ o peso da energia do i-ésimo estado incluído no cálculo. Esses pesos podem ser escolhidos arbitrariamente, mas recomenda-se defini-los como sendo iguais para todos os estados.

A princípio, a melhor descrição para a função de onda CASSCF seria obtida através de um cálculo onde cada estado é descrito por um conjunto de orbitais otimizados separadamente. Porém isto não garante a ortogonalidade dos estados, além de poder levar a estados altamente contaminados e ao problema de root fliping (quando o ordenamento energético dos estados se altera, por exemplo, um estado excitado com energia menor que o estado fundamental). Ao empregarmos SA-CASSCF, essas dificuldades desaparecem. Para moléculas orgânicas, a perda na qualidade dos resultados SA comparado aos cálculos feitos separadamente para cada estado é, em geral, muito pequena.

As funções de onda obtidas com a aproximação SA-CASSCF podem ser usadas como estado de referência para cálculos CASPT2, dando origem ao Multi State CASPT2 (MSCASPT2 $)^{91}$. Seja $\Phi_{i}$ a função de onda CASSCF do $i$-ésimo estado obtido no procedimento State Average para a qual foi calculada sua correção em 1a ordem $\Psi_{i}^{(1)}$, obtida com CASPT2. Podemos usar as funções assim obtidas como uma base para escrever a forma matricial do Hamiltoniano ${ }^{64,65}$

$$
H_{i j}=\left\langle\Phi_{i}+\Psi_{i}^{(1)}|H| \Phi_{j}+\Psi_{j}^{(1)}\right\rangle=\underbrace{\left\langle\Phi_{i}|H| \Phi_{j}\right\rangle}_{\delta_{i j} E_{i}}+\underbrace{\left\langle\Phi_{i}|H| \Psi_{j}^{(1)}\right\rangle}_{e_{i j}}+\underbrace{\left\langle\Psi_{i}^{(1)}|H| \Phi_{j}\right\rangle}_{e_{j i}}+\left\langle\Psi_{i}^{(1)}|H| \Psi_{j}^{(1)}\right\rangle,
$$

onde $E_{i}$ é a energia CASSCF do $i$-ésimo estado e $e_{i i}$ é a energia de correlação obtida com CASPT2. Assim, os elementos diagonais de $H$ são as energias CASPT2 e os fora da diagonal estão relacionados ao acoplamento da energia de correlação até $2 \underline{a}$ ordem. Note que as funções não são ortonormais, dado que as integrais de recobrimento $S_{i j}$ são

$$
S_{i j}=\left\langle\Phi_{i}+\Psi_{i}^{(1)} \mid \Phi_{j}+\Psi_{j}^{(1)}\right\rangle=\left\langle\Phi_{i} \mid \Phi_{j}\right\rangle+\left\langle\Phi_{i} \mid \Psi_{j}^{(1)}\right\rangle+\left\langle\Psi_{i}^{(1)} \mid \Phi_{j}\right\rangle+\left\langle\Psi_{i}^{(1)} \mid \Psi_{j}^{(1)}\right\rangle=\delta_{i j}+s_{i j},
$$

já que $\left\langle\Phi_{i} \mid \Psi_{j}^{(1)}\right\rangle=\left\langle\Psi_{i}^{(1)} \mid \Phi_{j}\right\rangle=0$. Resta-nos apenas determinar o último termo em (2.23). Para isso, particionamos o Hamiltoniano 


$$
H=H_{i}^{(0)}+H_{i}^{\prime}
$$

o que nos permite reescrever o último termo:

$$
\left\langle\Psi_{i}^{(1)}|H| \Psi_{j}^{(1)}\right\rangle=\left\langle\Psi_{i}^{(1)}\left|H_{i}^{(0)}\right| \Psi_{j}^{(1)}\right\rangle+\underbrace{\left\langle\Psi_{i}^{(1)}\left|H_{i}\right| \Psi_{j}^{(1)}\right\rangle}_{\begin{array}{c}
\text { desprezadopor ser } \\
\text { correçode e3:ordem }
\end{array}} .
$$

Para tornar a matriz simétrica, adotamos

$$
\left\langle\Psi_{i}^{(1)}\left|H_{i}^{(0)}\right| \Psi_{j}^{(1)}\right\rangle \approx \frac{1}{2}\left(\left\langle\Psi_{i}^{(1)}\left|H_{i}^{(0)}\right| \Psi_{j}^{(1)}\right\rangle+\left\langle\Psi_{i}^{(1)}\left|H_{j}^{(0)}\right| \Psi_{j}^{(1)}\right\rangle\right)
$$

onde estamos supondo $H_{i j} \approx H_{j i}$. Se isso não for verdade, deve-se aumentar o espaço ativo para tentar tornar a matriz aproximadamente simétrica. Caso isso não seja possível, o método MS-CASPT2 não pode ser utilizado, restando a opção de se fazer cálculos CASPT2 para os estados individualmente.

Usando a equação (2.15), vem que ${ }^{65}$

$$
\begin{aligned}
& \left\langle\Psi_{i}^{(1)}\left|H_{i}^{(0)}\right| \Psi_{j}^{(1)}\right\rangle=E_{i}^{(0)} s_{i j}-e_{i j} \\
& \left\langle\Psi_{i}^{(1)}\left|H_{j}^{(0)}\right| \Psi_{j}^{(1)}\right\rangle=E_{j}^{(0)} s_{i j}-e_{j i}
\end{aligned}
$$

onde $E_{i}^{(0)}$ é a energia de ordem zero do $i$-ésimo estado: $E_{i}^{(0)}=\left\langle\Phi_{i}\left|H_{i}^{(0)}\right| \Phi_{i}\right\rangle$.

Substituindo (2.28) em (2.23), temos finalmente que

$$
H_{i j}=\delta_{i j} E_{i}+\frac{1}{2}\left(e_{i j}+e_{j i}\right)+\frac{1}{2}\left(E_{i}^{(0)}+E_{j}^{(0)}\right) s_{i j}
$$

Assim, se resolvemos a equação secular

$$
(\boldsymbol{H}-E \boldsymbol{S}) \boldsymbol{C}=\mathbf{0},
$$

obtemos as energias MS-CASPT2, e as funções de onda de cada estado $j$ podem ser escritas como

$$
\Psi_{j}^{\mathrm{MS}-\text { CASPT2 }}=\sum_{i} C_{j i}\left|\Phi_{i}\right\rangle+\Psi_{j}^{(1)}=\left|i_{j}\right\rangle+\Psi_{j}^{(1)}
$$


ou seja, combinações lineares das funções CASSCF ponderadas por pesos determinados pela equação secular mais a correção perturbativa calculada com CASPT2. As funções $\left|i_{j}\right\rangle$ podem ser tomadas como sendo uma nova função de referência para o estado $j$ e são chamadas de perturbation modified CAS. São elas que serão utilizadas para calcular as propriedades no nível MS-CASPT2.

Caso o método MS-CASPT2 seja usado para computar intersecções cônicas, cuidados adicionais devem ser tomados ${ }^{64,92}$, mas como esse não é o foco de nosso estudo, não discutiremos esses detalhes aqui.

\section{5 - A escolha do espaço ativo}

Não há nenhuma maneira fácil e direta para determinar a escolha do espaço ativo, mas conforme o método CASSCF foi sendo empregado, várias estratégias surgiram. Conhecimento sobre a físico-química do sistema de interesse e a definição do que se pretende estudar formam o ponto de partida. Sugestões idealizadas de espaços ativos em certos tipos frequentes de estudos podem ser encontradas no manual do programa Molcas, em uma revisão do método feita pelo próprio Björn Roos que se encontra em um capítulo de livro ${ }^{65} \mathrm{e}$ em um artigo póstumo ${ }^{93}$.

Uma possibilidade para a determinação do espaço ativo é utilizar o método Restricted Active Space Self-Consistent Field (RASSCF) ${ }^{84}$, que divide o espaço ativo em 3 partes e restringe o número de excitações em duas delas, reduzindo o custo computacional, permitindo assim, testar espaços ativos maiores a fim de checar quais são os orbitais mais relevantes. Um problema com esse método é a dificuldade com a convergência dos cálculos. Para estudo de transições eletrônicas, outro modo de se escolher os orbitais seria usar algum método ab initio como $\mathrm{Cl}$ truncado e observar quais orbitais estão envolvidos nas transições que se deseja estudar.

Os recursos computacionais permitem hoje em torno de 12 a 16 orbitais no espaço ativo, pois a quantidade $K$ de CSFs, que pode ser calculada pela fórmula de Weyl, cresce rapidamente:

$$
K(n, N, S)=\frac{2 S+1}{n+1}\left(\begin{array}{c}
n+1 \\
N / 2-S
\end{array}\right)\left(\begin{array}{c}
n+1 \\
N / 2+S+1
\end{array}\right)
$$


onde $n$ é o número de orbitais, $N$ é o número de elétrons e $S$ é o spin total. Apenas para exemplificar a quantidade de CSF com a qual estamos Ihe dando, 16 elétrons em 12 orbitais, em um sistema de spin total zero, geram um total de 70785 CSFs.

Em geral usamos a notação (\# elétrons, \# orbitais) após o nível de cálculo para indicar a quantidade de elétrons e orbitais que compõem o espaço ativo, por exemplo, $\operatorname{CASSCF}(12,9)$ significa que um cálculo CASSCF foi realizado considerando um espaço ativo composto de 12 elétrons em 9 orbitais.

Para cada sistema estudado, nós discutimos e justificamos a escolha do espaço ativo na seção de Detalhes Computacionais do capítulo de Resultados correspondente.

\section{6 - As funções base do tipo ANO}

Conjuntos base tem um importante papel para os cálculos de estrutura eletrônica, pois eles são o ponto de partida inicial para se encontrar os orbitais moleculares através da aproximação LCAO, que serão então utilizados para determinar a função de onda.

É natural usar como inspiração para construir essas bases, as funções de onda do átomo de hidrogênio, posto que para ele, é possível obter solução analítica. Essas funções são classificadas como tipo Slater. Porém, propriedades matemáticas das Gaussianas as tornam mais vantajosas do ponto de vista computacional, de forma que usa-se conjuntos de funções gaussianas para descrever o comportamento de uma função tipo Slater. Alguns desses conjuntos são de larga utilização, devido à sistemática com que foram construídos e pelos bons resultados apresentados a um custo computacional factível. Em particular, dois deles se destacam: os conjuntos base de Pople (i-jkG) e os de Dunning-Huzinaga (cc-pVn孔). Uma excelente discussão sobre esses e outros conjuntos bases, as diferenças entre os tipos existentes, bem como os esquemas de contração, está disponível no capítulo 5 da ref. ${ }^{94}$.

Em nossos cálculos multiconfiguracionais, utilizamos os conjuntos base de funções gaussianas conhecidas como Atomic Natural Orbital (ANO) Basis Set, como construído por Roos e colaboradores ${ }^{95,96}$. O nome advém do fato de que um grande número de funções primitivas foi contraído usando os Orbitais Naturais (que são aqueles que diagonalizam a matriz Densidade), provenientes de funções de onda atômicas, normalmente obtidas no nível CISD. Esses conjuntos foram desenhados para fornecer uma descrição balanceada dos átomos em seus estados fundamental, excitado e iônico. Os coeficientes e expoentes foram obtidos 
como uma média sobre a matriz densidade de cálculos envolvendo átomos neutros, ânions, cátions e submetidos a um campo externo e são os mais recomendados quando se utiliza os métodos CASSCF e CASPT2. Essas bases usam um esquema de contração generalizada, onde todas as funções primitivas são usadas em todos os tipos de funções $(s, p, d, f)$. Funções bases maiores são obtidas ao se diminuir a contração. Isso garante que um conjunto base ANO menor seja verdadeiramente um subconjunto de um maior, uma vez que ambos são construídos a partir do mesmo conjunto de primitivas, facilitando o estudo da dependência dos resultados com o tamanho da base.

No Molcas, 3 tipos de funções ANO foram implementadas: i) Small ANO (ANO-S), que possui um conjunto de primitivas não muito grande; ii) Large ANO (ANO-L), que foi o conjunto construído originalmente e é o utilizado na maior parte das aplicações e iii) Relativistic ANO (ANO-RCC), que foi construído de maneira análoga ao ANO-L, mas a matriz densidade usada foi obtida com CASSCF/CASPT2 ao invés de CISD. Como o nome sugere, este último conjunto foi pensado para ser usado em cálculos onde efeitos relativísticos são importantes, como sistemas que contém metais pesados.

Em nosso estudo, para as otimizações das estruturas dos estados excitados em nível CASSCF, elegemos a base ANO-L-VDZP (valência sendo descrita com qualidade double- $\zeta$ e incluindo funções de polarização), que representa um excelente compromisso entre acurácia e custo. Os orbitais iniciais foram gerados usando HF e a base mínima ANO-S-MB e depois expandidos para a base ANO-L-VDZP. Este é um procedimento recomendado pelos próprios desenvolvedores, pois permite uma identificação mais clara dos orbitais. Para os cálculos da energia de transição em compostos orgânicos, Fülscher e Roos mostraram que funções ANO-L, contraídas segundo o esquema $(14 s 9 p 4 d / 8 s 4 p) \rightarrow[4 s 3 p 1 d / 2 s]$, formam o menor conjunto base que apresenta resultados praticamente convergidos com relação ao tamanho da base para espectros de absorção de moléculas orgânicas, tendo então a melhor relação custo-benefício ${ }^{97}$. Por consistência, nós incluímos funções de polarização também nos átomos de hidrogênio, de forma que o conjunto base que utilizamos pode ser denotado como ANO-L$(14 s 9 p 4 d / 8 s 4 p) \rightarrow[4 s 3 p 1 d / 2 s 1 p]$.

No caso de sistemas onde orbitais de Rydberg desempenhem papel importante, cuidados adicionais para inclusão de funções difusas devem ser tomados ${ }^{98}$. Como nos sistemas estudados isso não ocorreu, não discutiremos este tratamento aqui. 


\section{7 - Adendo: Ajustando cargas atômicas parciais através do método ElectroStatic Potential Fitting (ESPF)}

Como vimos no capítulo 1 , o potencial $L+C$ é usado para descrever as interações intermoleculares. Desse modo, é necessário fazer um ajuste de cargas atômicas parciais, já que as cargas parametrizadas nos campos de força em geral não incluem o efeito de polarização que a presença do solvente causa no soluto.

Como não há um operador para a carga, não é possível determina-la univocamente através da função de onda. Faz-se então necessário o uso de métodos para ajustar valores. De um modo geral, o que se faz é construir um grid de pontos e ajustar as cargas para que elas reproduzam o potencial eletrostático, calculado como ${ }^{94}$

$$
\phi(\vec{r})=\sum_{a}^{\text {Nuc }} \frac{Z_{a}}{\mid \overrightarrow{R_{a}-\vec{r} \mid}}-\int \frac{\Psi^{2}\left(\vec{r}^{\prime}\right)}{\left|\vec{r}^{\prime}-\vec{r}\right|} d \vec{r}^{\prime} .
$$

As cargas são então obtidas ao se minimizar uma função erro:

$$
\operatorname{Err}(Q)=\sum_{r}^{P t s}\left(\phi(\vec{r})-\sum_{a}^{\text {Atoms }} \frac{Q_{a}\left(\vec{R}_{a}\right)}{\left|\vec{R}_{a}-\vec{r}\right|}\right)^{2}
$$

em geral, com a imposição de que a soma das cargas seja igual a carga total do sistema.

Há várias propostas na literatura de como se construir o grid de pontos, como Chelp ${ }^{99}$, ChelpG ${ }^{100}$, Merz-Singh-Kollman ${ }^{101}$, e PNT ${ }^{102}$.

No Molcas, a determinação de cargas atômicas parciais é feita através do método ElectroStatic Potential Fitting (ESPF) ${ }^{103}$. Esse método foi originalmente concebido para cálculos QM/MM convencionais, com o intuito de tornar o operador de interação eletrostática aproximado $Q$ invariante pela trocar da parte $\mathrm{QM}$ com a parte $\mathrm{MM}$. A interação desse operador com o potencial eletrostático sentida em cada sítio a pode ser expressa como

$$
\Delta E=\sum_{a} \sum_{\mu \nu} P_{\mu \nu} Q_{\mu \nu}^{a} \phi^{a}
$$

sendo $P_{\mu \nu}$ a matriz densidade. A princípio, qualquer grid pode ser usado, mas PNT apresenta resultados com menor dependência com o tamanho do grid $^{103}$ e por isso ele é a opção padrão. 


\section{Capítulo 3 : Resultados - Stokes Shift de um isoflavonoide em água e sua não-fluorescência em acetonitrila}

Este estudo foi desenvolvido durante o primeiro ano do projeto de doutorado, e realizado em colaboração com outro estudante do grupo. Aqui, aplicamos os métodos descritos nos capítulos anteriores para descrever o Stokes Shift do menor dos isoflavonoides, a Daidzeína, quando em água e sua não-fluorescência em acetonitrila. Neste capítulo, aplicamos aproximações e métodos que já haviam sido desenvolvidos e/ou utilizados anteriormente em nosso grupo. Em particular, fizemos uso da solvatação de estruturas obtidas em gás, pois a metodologia para a obtenção de estruturas de mínimo do estado excitado em solução foi concluída posteriormente a publicação deste trabalho. Este capítulo serve então como um estudo preliminar pois, apesar de não termos utilizado a metodologia proposta em nosso projeto para obter as estruturas, muitas das nuanças aprendidas aqui foram empregadas nas etapas seguintes do projeto.

\section{1 - Motivação:}

Flavonoides são moléculas que tem despertado grande interesse, devido a estudos recentes que tem comprovado seus benefícios para a saúde, relacionados à sua atividade antioxidante. Destacam-se em particular, os flavonoides presentes na uva ${ }^{104}$ e no cacau ${ }^{105}$, e que sugerem de forma indireta, que o consumo moderado de vinho tinto e chocolate meio amargo pode fazer bem à saúde.

Sob o aspecto das propriedades espectroscópicas, uma classe em particular de flavonoides tem despertado a atenção devido a seu grande Stokes Shift. Trata-se dos isoflavonoides (Figura 3.1). Vários estudos tem tentado explicar teoricamente o valor desse shift pra alguns desses compostos ${ }^{106-108}$. Recentemente, Beyhan et al. ${ }^{109}$ realizaram medidas

\footnotetext{
${ }^{\ddagger}$ Este texto é, em grande parte, a tradução do artigo original (The Journal of Physical Chemistry A vol. 117, 2013, p. 4404-4411) apresentado no Anexo A.
} 
experimentais do Stokes Shift da daidzeína $\left(R=R^{\prime}=O H\right)$ e empregaram o método $C C 2^{77}$ e a microsolvatação para interpretar o que era observado. Eles encontraram um valor teórico de $0.8 \mathrm{eV}$, quando experimentalmente se obtém um Stokes Shift de $1.4 \mathrm{eV}$ em solução aquosa. Eles também propuseram um modelo para explicar o porquê de a daidzeína não fluorescer em acetonitrila.

Motivados pela modesta concordância do resultado teórico acima mencionado, decidimos aplicar a metodologia S-QM/MM para tentar fornecer uma melhor descrição do que é observado experimentalmente.

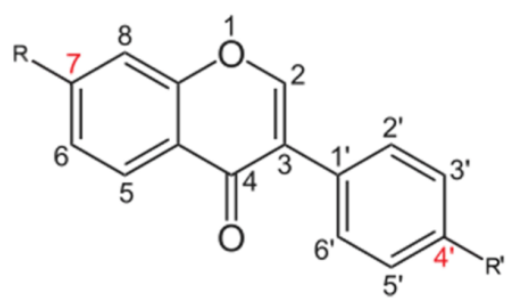

Figura 3.1: A família dos isoflavonoides. Para daidzeína, $R=R^{\prime}=O H$.

\section{2 - Detalhes Computacionais}

As energias de transição foram calculadas usando o método MS-CASPT2 ${ }^{91}$ (seção 2.4). A função de onda CASSCF de referência foi obtida utilizando um espaço ativo de 12 elétrons em 12 orbitais. Os orbitais ativos são os 5 orbitais $\pi$ e os $6 \pi^{*}$ que melhor descrevem os 3 estados $\pi-\pi^{*}$ de menor energia mais o lone-pair do oxigênio, para descrever o estado $n-\pi^{*}$. Esses orbitais foram selecionados analisando a contribuição de cada orbital para os estados excitados em um cálculo multiconfiguracional anterior, onde um espaço ativo maior foi utilizado, mas restringindo as excitações a simples, duplas, triplas e quádruplas. O conjunto de funções base ANO-L ${ }^{95}$ (seção 2.6) com o esquema de contração C,O (14s9p4d)/[4s3p1d] e H $(8 s 4 p) /[2 s 1 p]$ foi utilizado, já que como mostrado por Roos e Fülscher ${ }^{97}$, ele fornece resultados convergidos com o tamanho da base para as energias de transição eletrônicas. Os elétrons de caroço dos átomos de $\mathrm{O}$ e $\mathrm{C}$ foram mantidos congelados durante o procedimento perturbativo. Nos cálculos CASSCF foi empregada a aproximação State Average (seção 2.4), na qual o mesmo conjunto de orbitais moleculares foi utilizado para determinar toda as 5 raízes.

As geometrias do estado fundamental e dos estados excitados foram obtidas em fase gasosa. Para o estado fundamental, o geometria foi otimizada no nível MP2/6-31+G(d), conforme implementado no programa Gaussian $03^{60}$. A influência do solvente na geometria da 
molécula foi testada usando $\mathrm{PCM}^{33}$. Em ambos os solventes considerados, água e acetonitrila, as geometrias são similares e não diferem muito da obtida em fase gasosa. A maior diferença foi a mudança no ângulo diedral 2-3-1'-2' (Figura 3.1), que de $49^{\circ}$ na fase gasosa passou para $57^{\circ}$ e $56^{\circ}$ em acetonitrila e água, respectivamente. É esperado que PCM seja uma aproximação melhor para acetonitrila (solvente aprótico) do que para água (prótico). Considerando isso, nós também otimizamos o complexo daidzeína-água, colocando uma água próxima ao átomo de oxigênio da ligação $C=O$. Como esperado, nesse caso nós encontramos um estiramento do comprimento da ligação de 0.0006 A, e o ângulo diedral 2-3-1'-2' obtido foi de 50, muito próximo do obtido em gás. $\mathrm{O}$ estiramento $\mathrm{C}=\mathrm{O}$ em líquido deve ser ainda menor do que esse obtido em uma estrutura de mínimo. Como este estiramento afeta apenas levemente a energia da transição $n-\pi^{* 110}$, nos ativemos apenas as estruturas obtidas em gás, posto que isso não mudará nossas conclusões.

Para estudar a fluorescência da daidzeína, nós determinamos o estado mais ocupado devido a absorção, e seguimos seu comportamento em solvente. As estruturas dos estados excitados foram obtidas em nível CASSCF, considerando o mesmo espaço ativo e conjunto base supramencionados. Todos os cálculos multiconfiguracionais foram feitos com o programa Molcas $7.4^{62}$, considerando a molécula isolada.

Considerando os resultados experimentais, dois solventes foram considerados em nosso estudo, água e acetonitrila. O efeito de solvente foi incluído através da metodologia S$\mathrm{QM} / \mathrm{MM}^{21}$ (seção 1.3). Simulações MC (conforme detalhadas na seção 1.3) no ensemble NPT foram feitas no programa DICE $^{41}$, para gerar configurações soluto-solvente nas condições termodinâmicas apropriadas $\left(\mathrm{T}=25^{\circ} \mathrm{C}\right.$ e $\mathrm{P}=1 \mathrm{~atm}$, mesmas condições do trabalho experimental). Das $3 \times 10^{5}$ configurações geradas após os $2.1 \times 10^{8}$ passos de $\mathrm{MC}, 100$ com uma correlação menor que $12 \%$ foram selecionadas e usadas para construir o $\operatorname{ASEC}^{56}$ (seção 1.3.6), que foi então empregado nos cálculos multiconfiguracionais para a obtenção das energias de transição. O uso de moléculas de solvente explícitas não foi considerado, devido ao alto custo computacional envolvido. A caixa de simulação continha 1 molécula de daidzeína e 700 de solvente. A interação soluto-solvente foi descrita através do potencial LJ+C (seção 1.3.3). Para a daidzeína, tanto no estado fundamental como no estado excitado, nós adotamos os parâmetros LJ do campo de força OPLS-aa ${ }^{49}$. Para molécula de água, o modelo TIP3P ${ }^{45}$ foi utilizado, enquanto que para a acetonitrila nós adotamos o modelo proposto por Böhm e McDonald ${ }^{111}$. Visando a inclusão do efeito de polarização eletrônica, as cargas atômicas parciais da daidzeína foram obtidas através de um procedimento iterativo ${ }^{22}$ (seção 1.3.5). Para 
ajustar as cargas, foi utilizado o esquema $\operatorname{ESPF}^{103}$ (seção 2.7), como implementado no programa Molcas $7.4^{62}$.

Para explicar a não-fluorescência da daidzeína em acetonitrila, nós realizamos um cálculo do acoplamento spin-órbita (SOC) dos estados singletos e tripletos da daidzeína isolada, através de um Hamiltoniano efetivo aproximado de um elétron ${ }^{112}$, usando o método CASSI ${ }^{113}$, implementado no programa Molcas $7.4^{62}$. A força do acoplamento entre dois estados / e $k$ foi calculada através da expressão ${ }^{114}$ :

$$
\operatorname{SOC}_{l k}=\sqrt{\sum_{u}\left\langle T_{l, u}\left|H_{S O}\right| S_{k}\right\rangle^{2}}
$$

onde $u$ representa cada componente do estado tripleto $(u=x, y, z)$.

\section{3 - Resultados}

\subsection{1 - Espectro de Absorção}

O espectro de absorção em água e em acetonitrila foi obtido utilizando a geometria da daidzeína obtida em fase gasosa (Figura 3.2 a). Essa geometria apresenta o ângulo diedral 2-3$1^{\prime}-2^{\prime}$ de $49^{\circ}$, próximo ao obtido por Beyhan et a $1^{109}$ usando CC2/aug-cc-pVDZ, que foi de $39.9^{\circ}$.

Para incluir o efeito de solvente, um procedimento iterativo ${ }^{22}$ (seção 1.3.5) foi feito, trazendo as cargas atômicas parciais do estado fundamental da daidzeína para o equilíbrio eletrostático com o solvente. Figura $\mathbf{3 . 3}$ a e b mostram a convergência do momento de dipolo da daidzeína em água e em acetonitrila, respectivamente, que aumenta de 2.5D quando isolada, para 10.D em água e para 3.8 D em acetonitrila.

Na Tabela 3.1 temos a energia de transição para os quatro estados excitados de menor energia. Para distinguir os estados $\pi \pi^{*}$, adotamos a nomenclatura de Platt ${ }^{115}$, onde ${ }^{1}\left(\pi \pi^{*} L_{a}\right)$ é dominado pela transição $\mathrm{HOMO} \rightarrow$ LUMO e ${ }^{1}\left(\pi \pi^{*} L_{b}\right)$ é dominado pela transição HOMO$1 \rightarrow$ LUMO. O estado $^{1}\left(\pi \pi^{*}\right)$ é dominado pela transição HOMO-2 $\rightarrow$ LUMO e finalmente o estado ${ }^{1}\left(n \pi^{*}\right)$ é caracterizado pela transição do lone-pair do oxigênio para o LUMO. Esses orbitais são apresentados na Figura 3.4. 
a)

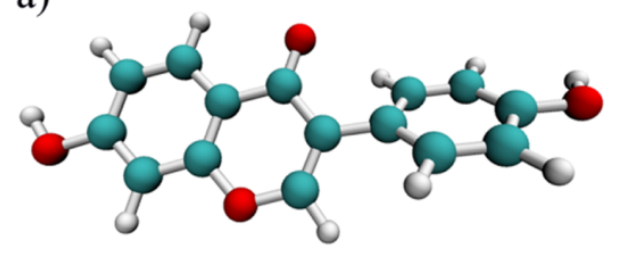

b)

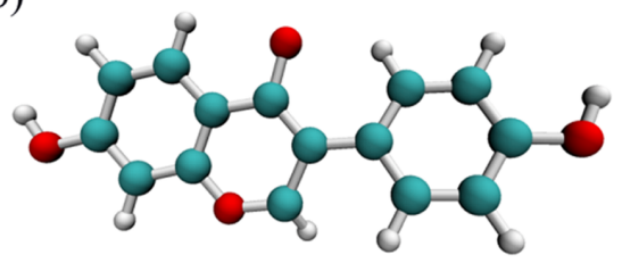

$\mathrm{S}_{0}$

c)

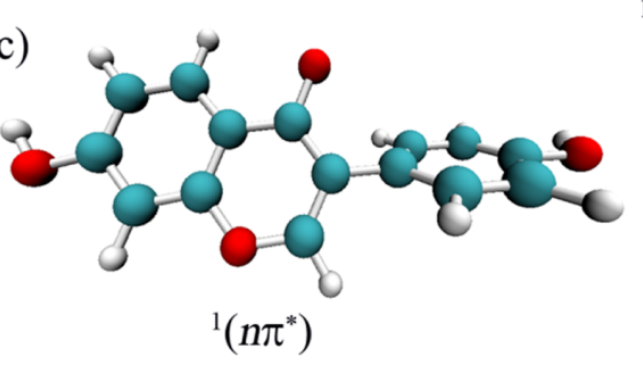

${ }^{1}\left(\pi \pi^{*} \mathrm{~L}_{\mathrm{b}}\right)$

Figura 3.2: Estruturas otimizadas de diferentes estados eletrônicos da daidzeína.

Vamos discutir primeiro os resultados obtidos em água. De acordo com a Tabela 3.1, o espectro de daidzeína em água apresenta duas transições intensas: uma para o estado ${ }^{1}\left(\pi \pi^{*}\right.$ $L_{b}$ ) e outra para o estado ${ }^{1}\left(\pi \pi^{*} L_{a}\right)$, com energias de 4.16 e $4.70 \mathrm{eV}$, respectivamente. $A$ primeira está em excelente concordância com a banda experimental observada com máximo em $4.09 \mathrm{eV}$, e usada como excitação para a fluorescência ${ }^{109}$. A segunda concorda com a banda observada com o máximo em $5.0 \mathrm{eV}$. Por outro lado, a quarta transição, que tem uma energia calculada como $5.44 \mathrm{eV}$, parece estar relacionada a banda que aparece na borda do espectro em $5.85 \mathrm{eV}$, já no limite usual dos espectrômetros. Finalmente, a transição ${ }^{1}\left(n \pi^{*}\right)$ não é observada experimentalmente, devido a sua baixa intensidade e por estar entre duas bandas intensas.

Em acetonitrila, temos apenas uma transição intensa, para o estado ${ }^{1}\left(\pi \pi^{*} L_{b}\right)$, com uma energia de $5.09 \mathrm{eV}$, próxima ao valor experimental de $4.77 \mathrm{eV}^{109}$. Outra transição, para o estado ${ }^{1}\left(\pi \pi^{*} L_{a}\right)$, é obtida com intensidade menor e energia de $4.37 \mathrm{eV}$. Esta transição é próxima a uma transição experimental observada como um ombro no espectro, em torno de $4.09 \mathrm{eV}^{109}$. Pode-se notar que ambos os resultados estão deslocados por cerca de $0.3 \mathrm{eV}$ em relação aos valores experimentais. Este comportamento pode ser devido às limitações do modelo utilizado para representar o solvente nos cálculos quânticos, o ASEC, que descreve apenas interações eletrostáticas, e talvez, para a descrição da iteração com acetonitrila, Exchange e van der Waals possam ter contribuições relevantes. Novamente temos um estado associado à borda do espectro, ${ }^{1}\left(\pi \pi^{*}\right)$, com energia de $5.76 \mathrm{eV}$, e a transição ${ }^{1}\left(n \pi^{*}\right)$, um estado escuro, indicado pela sua força de oscilador nula. 
Tabela 3.1: Energias de absorção para os quatro estados excitados de menor energia da daidzeína em água e em acetonitrila, e energia de emissão em água. Valores energéticos em eV. $f$ é a força de oscilador (adimensional).

\begin{tabular}{|c|c|c|c|c|c|c|c|}
\hline \multicolumn{8}{|c|}{ Absorção } \\
\hline \multicolumn{4}{|c|}{ Água } & \multicolumn{4}{|c|}{ Acetonitrila } \\
\hline Estado & $E_{\mathrm{abs}}$ & $f$ & Exp. $^{109 \text { a) }}$ & Estado & $E_{\mathrm{abs}}$ & $f$ & Exp. ${ }^{109 a)}$ \\
\hline${ }^{1}\left(n \pi^{*}\right)$ & 4.14 & 0.070 & - & ${ }^{1}\left(n \pi^{*}\right)$ & 3.72 & 0.000 & - \\
\hline${ }^{1}\left(\pi \pi^{*} L_{b}\right)$ & 4.16 & 0.196 & 4.09 & ${ }^{1}\left(\pi \pi^{*} L_{a}\right)$ & 4.37 & 0.077 & 4.09 \\
\hline${ }^{1}\left(\pi \pi^{*} L_{a}\right)$ & 4.70 & 0.165 & 5.00 & ${ }^{1}\left(\pi \pi^{*} L_{b}\right)$ & 5.09 & 0.305 & 4.77 \\
\hline${ }^{1}\left(\pi \pi^{*}\right)$ & 5.44 & 0.057 & 5.85 & ${ }^{1}\left(\pi \pi^{*}\right)$ & 5.76 & 0.027 & 5.85 \\
\hline
\end{tabular}

Emissão em Água

\begin{tabular}{ccccc}
\hline Estado Fluorescente & $E_{\mathrm{emi}}{ }^{\mathrm{b})}$ & Stokes shift ${ }^{\mathrm{c})}$ & $E_{\mathrm{emi}}{ }^{\mathrm{a})}$ & $\begin{array}{c}\text { Stokes shift } \\
\text { Exp. }^{109}\end{array}$ \\
\hline${ }^{1}\left(\pi \pi^{*} \mathrm{~L}_{\mathrm{b}}\right)$ & $2.85 / 3.24$ & $1.31 / 0.92$ & 2.70 & 1.40 \\
\hline
\end{tabular}

a) Valores correspondentes ao máximo da banda experimental obtida na ref. ${ }^{109}$;

b) Energia de emissão calculada em equilíbrio/não-equilíbrio eletrostático com o solvente;

c) Stokes shift calculado usando a energia de absorção do estado ${ }^{1}\left(\pi \pi^{*} L_{b}\right)$, que é o usado como excitação para as medidas de fluorescência, e energia de fluorescência obtida em equilíbrio/nãoequilíbrio com o solvente.

\subsection{2 - Espectro de Fluorescência}

Baseado nos resultados acima, o espectro de emissão da daidzeína em água foi obtido a partir de transições da estrutura de mínimo do estado ${ }^{1}\left(\pi \pi^{*} L_{b}\right)$, já que este é o estado mais ocupado devido a absorção e reproduz a energia de excitação da fluorescência. Essa estrutura foi obtida no nível CASSCF/ANO-L, como descrito na seção anterior. Nesta geometria, o chromone e o anel fenil aproximam-se de uma configuração planar ( $\approx 14^{\circ}$, Figura 3.2 b).

A solvatação do estado ${ }^{1}\left(\pi \pi^{*} L_{b}\right)$ foi feita em dois estágios. Primeiro, supomos que o tempo de vida do estado excitado é curto e, consequentemente, o equilíbrio eletrostático entre soluto e solvente não é alcançado. Neste caso, usando a geometria do estado ${ }^{1}\left(\pi \pi^{*} L_{b}\right)$, configurações soluto-solvente foram geradas com o solvente em equilíbrio eletrostático com o estado fundamental (círculos, Figura 3.3 c). Em seguida, consideramos a possibilidade de o estado excitado ter um tempo de vida longo o suficiente para permitir um equilíbrio 
eletrostático entre soluto e solvente antes de a emissão ocorrer (diamantes, Figura 3.3 c). O momento de dipolo convergido do estado excitado é de $19.8 \mathrm{D}$.
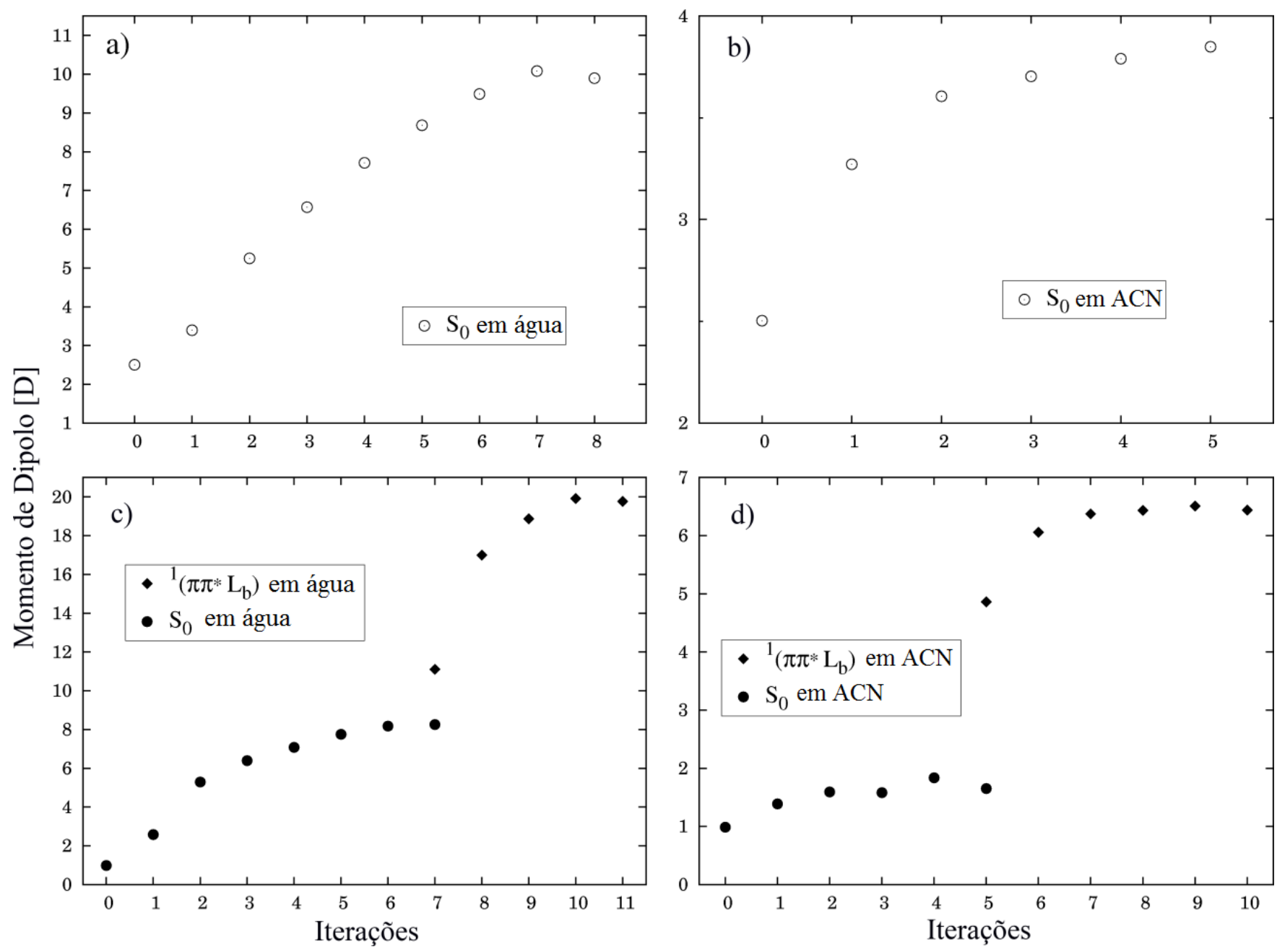

Figura 3.3: Alteração do valor do momento de dipolo do estado fundamental e excitado da daidzeína em água e em acetonotrila (ACN) durante o procedimento iterativo de polarização.

Em ambas as condições, equilíbrio e não-equilíbrio, o estado eletrônico ${ }^{1}\left(\pi \pi^{*} L_{b}\right)$ é o estado excitado de menor energia da daidzeína quando em água, como mostrado esquematicamente na Figura $\mathbf{3 . 5}$ a. Este estado estabiliza consideravelmente devido a sua interação com a água, enquanto o estado ${ }^{1}\left(n \pi^{*}\right)$, que é o de mais baixa energia em gás, é deslocado para o azul.

As energias de emissão em água, calculadas com nível CASPT2/ANO-L são de $3.24 \mathrm{eV}$ para a situação de não-equilíbrio e de $2.85 \mathrm{eV}$ quando o equilíbrio é atingido (Tabela 3.1). Isso leva a Stokes shifts de 0.92 e $1.31 \mathrm{eV}$, respectivamente. Nosso resultado em equilíbrio está em 
excelente concordância com o resultado experimental obtido por Beyhan et al. ${ }^{109}$, que obtiveram um máximo para a banda de emissão de $2.67 \mathrm{eV}$ e um Stokes shift de $1.40 \mathrm{eV}$.

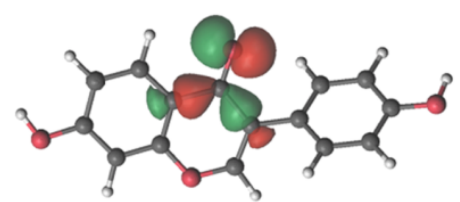

HOMO-5

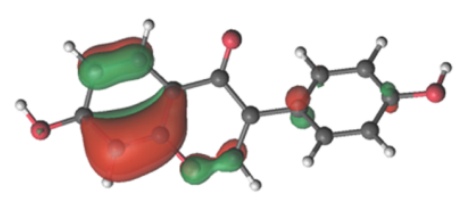

HOMO-2

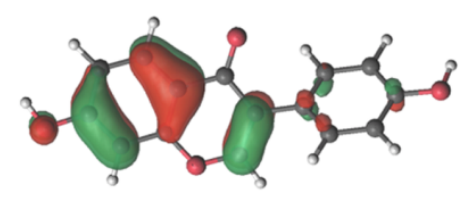

HOMO-1

(Lone-pair)

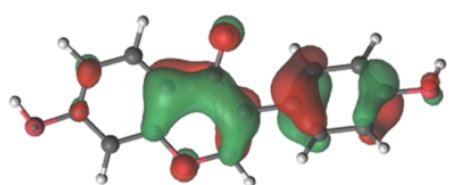

HOMO

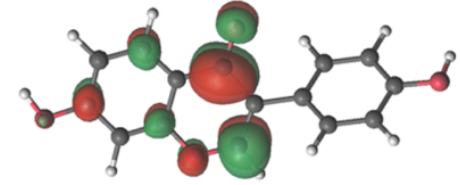

LUMO

Figura 3.4: Orbitais moleculares envolvidos nas transições eletrônicas estudadas. A nomenclatura é baseada no ordenamento obtido no cálculo SCF.

De acordo com esses resultados, a interação com o solvente tem grande influência no Stokes Shift da daidzeína. Nós consideramos que a grande polarização eletrônica do estado ${ }^{1}\left(\pi \pi^{*} L_{b}\right)$, mostrada na Figura 3.3 c, é a principal causa do largo Stokes shift observado experimentalmente. Um possível mecanismo de emissão da daidzeína em água é proposto na Figura 3.5 a. É interessante mencionar o fato de que é possível ver um deslocamento na densidade de cargas devido a interação com o solvente durante o processo de polarização, como fica evidente na Figura 3.6, onde vemos explicitamente que os orbitais moleculares se modificam, com a densidade de cargas do anel fenil tendendo a migrar para o chromone.

\subsection{3 - Supressão da Fluorescência em Acetonitrila}

A fluorescência da daidzeína em solventes polares apróticos, como a acetonitrila, não é observada experimentalmente ${ }^{109}$. Nessa seção nós analisamos este decaimento não-radiativo e uma possível explicação para ele.

Seguindo a argumentação exposta na seção anterior, nós polarizamos o estado ${ }^{1}\left(\pi \pi^{*}\right.$ $L_{b}$ ) em acetonitrila, usando o mesmo procedimento. A interação desse estado com o solvente é 
pequena, como atestado pelo pequeno aumento do momento de dipolo, cujo valor convergido é de 6.4 D (Figura $3.3 \mathrm{~d}$ ). Por causa disso, o estado ${ }^{1}\left(\pi \pi^{*} L_{b}\right)$ não estabiliza o suficiente, sendo menos estável que o estado ${ }^{1}\left(n \pi^{*}\right)$, como mostrado esquematicamente na Figura 3.5 b.

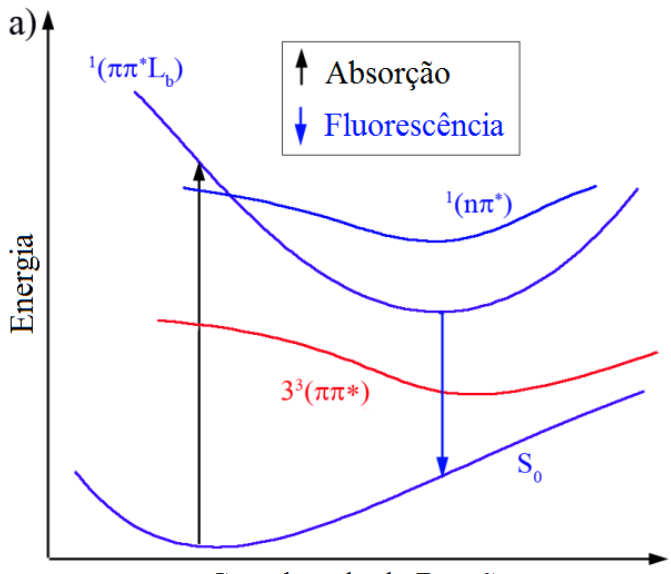

Coordenada de Reação

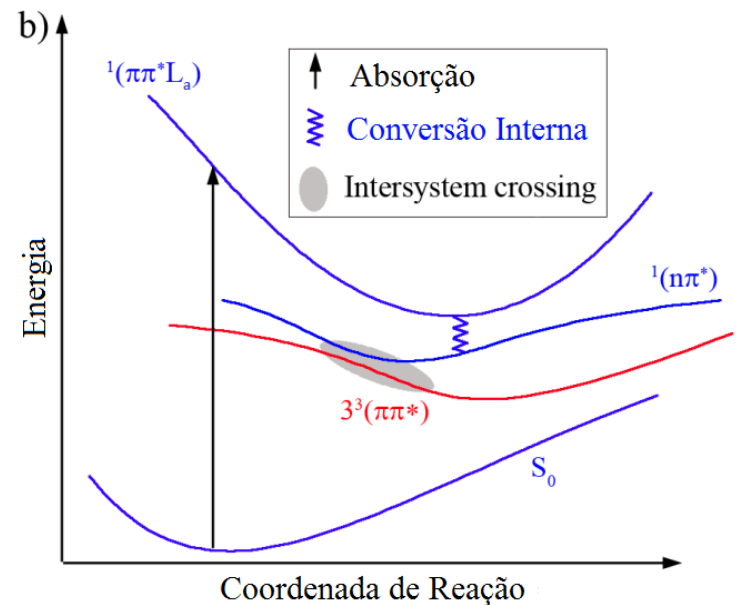

Coordenada de Reação

Figura 3.5: Representação esquemática do mecanismo de desativação da daidzeína em a) água e b) acetonitrila.

Nessas condições, de acordo com a regra de Kasha ${ }^{116}$, o sistema irá decair por conversão interna do estado ${ }^{1}\left(\pi \pi^{*} L_{b}\right)$ para o estado ${ }^{1}\left(n \pi^{*}\right)$. Assim, para melhor compreender esse mecanismo de decaimento não-fluorescente, nós estudamos o intersystem crossing entre o estado eletrônico ${ }^{1}\left(n \pi^{*}\right)$ e os estados tripletos, para a daidzeína isolada, dado o enorme esforço computacional envolvido neste tipo de cálculo. A geometria do estado ${ }^{1}\left(n \pi^{*}\right)$ foi otimizada no nível CASSCF/ANO-L (Figura 3.2 c). Nesse estado, o ângulo entre o chromone e o anel fenil é de $59^{\circ}$. Usando esta geometria, os coeficientes de acoplamento spin-órbita entre este estado eletrônico e os estados tripletos próximos foram calculados (Tabela 3.2). O maior valor, $42.5 \mathrm{~cm}^{-1}$, foi obtido com o terceiro estado tripleto, $3^{3}\left(\pi \pi^{*}\right)$. Apesar de a energia desse estado tripleto estar $0.2 \mathrm{eV}$ acima do estado ${ }^{1}\left(n \pi^{*}\right)$, este perfil pode ser invertido devido a presença da acetonitrila. Nós acreditamos que, apesar de fraca, a interação do sistema com a acetonitrila desloca levemente o estado ${ }^{1}\left(n \pi^{*}\right)$ para o azul, enquanto o estado $3^{3}\left(\pi \pi^{*}\right)$ é deslocado para o vermelho, tornando-o menos energético que o estado singleto. Os resultados apresentados na Tabela 3.2 estão em excelente concordância com a regra de El-Sayed ${ }^{117}$, que indica que o intersystem crossing é permitido quando os estados eletrônicos envolvidos são de simetrias espaciais diferentes, como o estado ${ }^{1}\left(n \pi^{*}\right)$ com os estados tripletos $1^{3}\left(\pi \pi^{*}\right)$ e $3^{3}\left(\pi \pi^{*}\right)$. O acoplamento com o estado tripleto $2^{3}\left(n \pi^{*}\right)$ é desprezível. 
Antes da Polarização

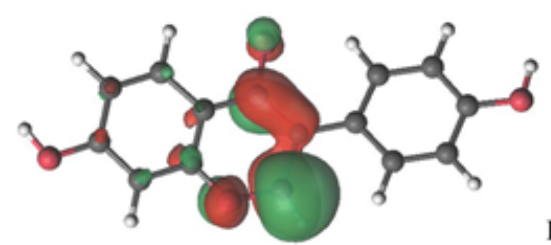

LUMO
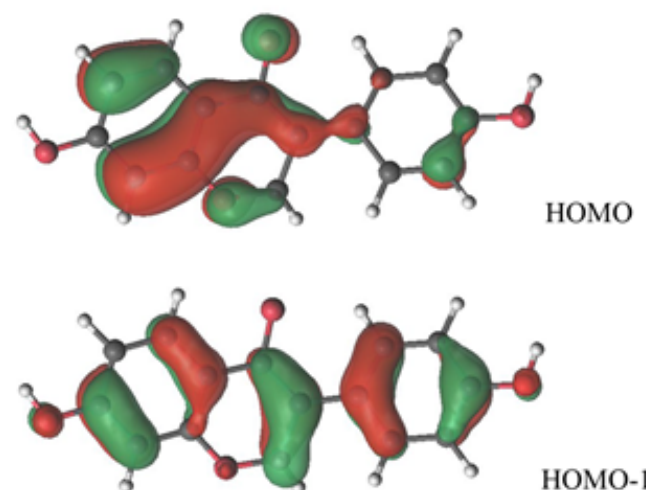

HOMO-1
Após a Polarização
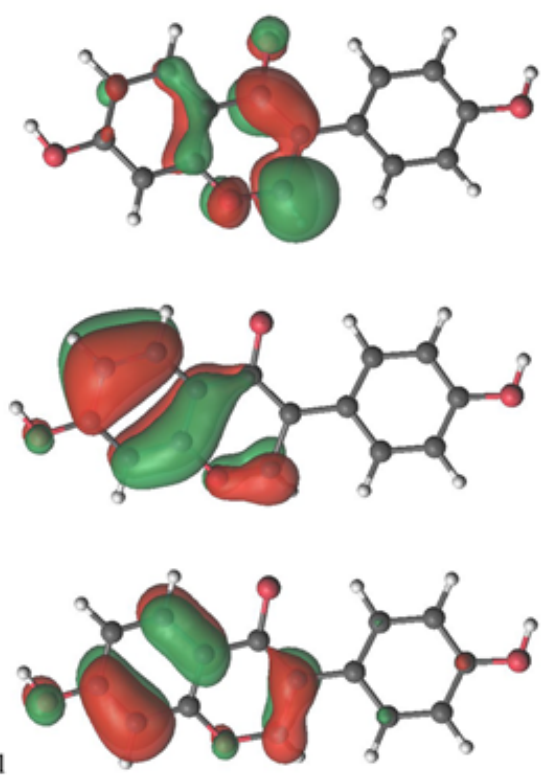

HOMO-2
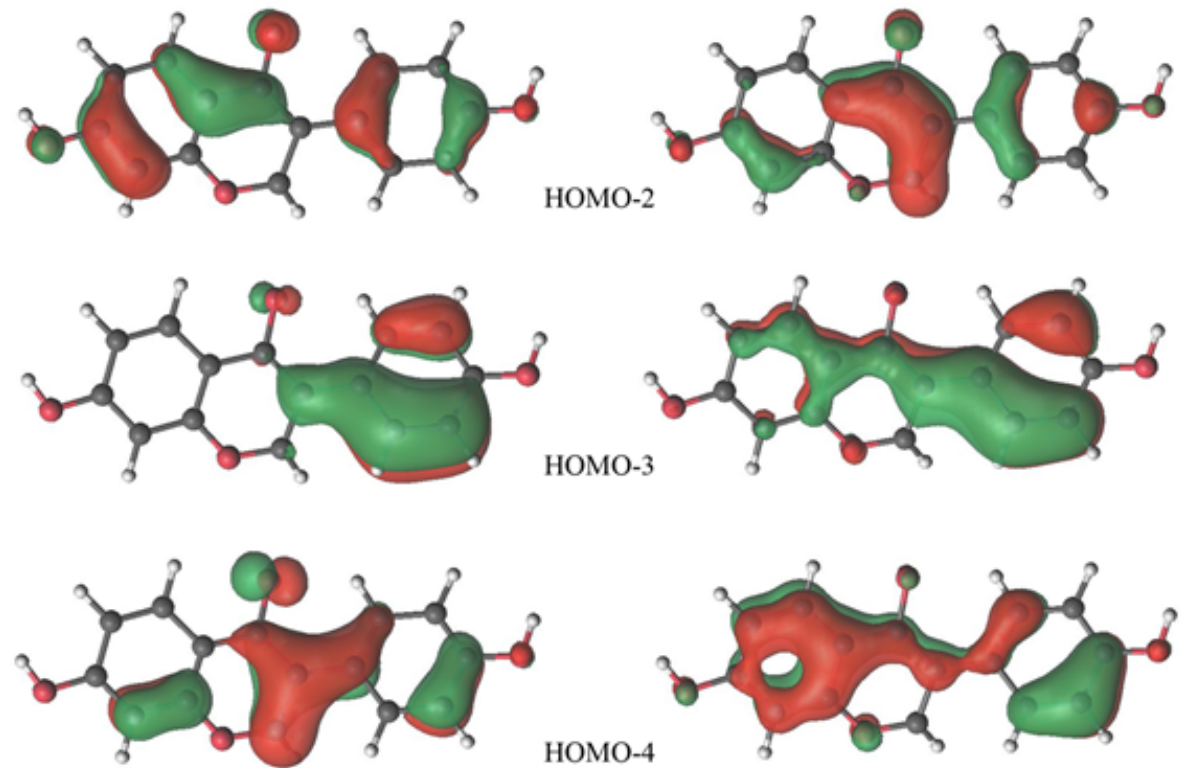

HOMO-4

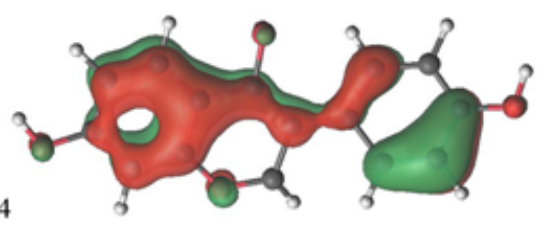

Figura 3.6: Alteração nos orbitais moleculares da daidzeína no estado excitado ${ }^{1}\left(\pi \pi^{*} L_{b}\right)$ devida a polarização eletrônica causada pela água.

Tabela 3.2: Valores calculados para acoplamento spin-órbita e diferenças energéticas entre os estados eletrônicos considerados para a daidzeína isolada.

\begin{tabular}{cccc}
\hline \multicolumn{2}{c}{ Estado } & $\mathrm{SOC}\left(\mathrm{cm}^{-1}\right)$ & $\Delta E^{\mathrm{a})}(\mathrm{eV})$ \\
\hline \multirow{3}{*}{${ }^{1}\left(n \pi^{*}\right)$} & $1^{3}\left(\pi \pi^{*}\right)$ & 31.4 & -3.64 \\
& $2^{3}\left(n \pi^{*}\right)$ & - & -0.29 \\
& $3^{3}\left(\pi \pi^{*}\right)$ & 42.5 & 0.20
\end{tabular}

a) Valor da energia em relação ao estado eletrônico ${ }^{1}\left(n \pi^{*}\right)$. 
A taxa de ocorrência do intersystem crossing $f_{I S C}$ é inversamente proporcional à diferença de energia dos estados $\Delta E$ e proporcional à magnitude do $\mathrm{SOC}^{118}$

$$
f_{I S C}=\frac{S O C^{2}}{\Delta E^{2}}
$$

Assim, o largo acoplamento entre os estados ${ }^{1}\left(n \pi^{*}\right)$ e $3^{3}\left(\pi \pi^{*}\right)$ e a pequena diferença energética entre eles pode levar a um intersystem crossing bastante eficiente, prevenindo o decaimento fluorescente. Este mecanismo de desativação proposto está esquematizado na Figura 3.5 b.

É interessante observar que diferentes mecanismos de decaimento dependendo do tipo de solvente foram também experimentalmente observados na molécula 5-fluorouracil. Neste sistema, foi observado que a taxa de fluorescência é muito menor em acetonitrila do que em água. Os resultados teóricos e experimentais de Improta e colaboradores ${ }^{4,119}$ indicam, em geral, que em acetonitrila o estado eletrônico $n \pi^{*}$ (escuro) e o estado $\pi \pi^{*}$ (intenso) são energeticamente muito próximos. Assim, apesar da fluorescência a partir do estado $\pi \pi *$, outro mecanismo de desativação é possível, através de uma intersecção cônica entre esses estados eletrônicos. Este comportamento não é observado em água, onde o estado $n \pi^{*}$ é mais energético que o estado $\pi \pi^{*}$.

\subsection{Conclusões}

Neste capítulo, estudamos teoricamente a fotofísica do sistema daidzeína em água e em acetonitrila. O espectro de absorção foi apropriadamente descrito em ambos os solventes. Já o mecanismo de desativação eletrônico é diferente, dependendo do tipo de solvente, como indicado pelos trabalhos experimentais. Os resultados obtidos estão resumidos na Figura 3.5. A fluorescência da daidzeína em água, após a absorção, é mostrado na Figura 3.5 a. O estado ${ }^{1}\left(n \pi^{*}\right)$, que em gás e em acetonitrila é o de mais baixa energia, é deslocado para o azul devido a interação da molécula com a água, enquanto o estado ${ }^{1}\left(\pi \pi^{*} L_{b}\right)$ estabiliza e se torna o menos energético. A energia de emissão a partir deste estado eletrônico está em excelente acordo com os resultados experimentais, assim como o valor do Stokes shift.

Em acetonitrila a situação é diferente, como indicado na Figura 3.5 b. O estado ${ }^{1}\left(\pi \pi^{*}\right.$ $L_{b}$ ) é o mais ocupado devido a absorção. Este estado, na geometria de equilíbrio, é fracamente 
52 Capítulo 3: Resultados - Stokes Shift de um isoflavonoide em água e sua...

Carlos Bistafa - IFUSP 2015

solvatado e não estabiliza o suficiente. Do mesmo modo, o estado ${ }^{1}\left(n \pi^{*}\right)$ é levemente deslocado para o azul e permanece como sendo o menos energético. De acordo com a regra de Kasha, o estado ${ }^{1}\left(n \pi^{*}\right)$ deve ser ocupado por conversão interna. Esse estado mostra condições muito favoráveis de um intersystem crossing com o estado $3^{3}\left(\pi \pi^{*}\right)$, o que explicaria o decaimento não-fluorescente da daidzeína em acetonitrila (Figura 3.5 b). O mecanismo de desativação do estado tripleto é uma questão em aberto para futuras investigações. 


\section{Capítulo 4 : \\ Resultados - Absorção e emissão da Uracil em água}

Neste capítulo ${ }^{\S}$ apresentaremos os resultados para o espectro de absorção e emissão da molécula de uracil, isolada e em meio aquoso, obtidos empregando os métodos explicados nos capítulos anteriores. Os resultados estão em boa concordância com os valores medidos experimentalmente e sugerem que a geometria do estado excitado é plana e que seu tempo de vida é grande o suficiente para que o efeito do solvente seja observado na energia de emissão.

\section{1 - Introdução e Motivação}

A molécula uracil (Figura 4.1) tem sido objeto de muitos estudos devido a sua relevância biológica como base nitrogenada do RNA. Seus espectros de absorção e emissão foram observados com acurácia em diferentes solventes ${ }^{6,120,121}$. Do ponto de vista teórico, seu pequeno número de elétrons (58) permite o uso de métodos ab initio sofisticados.

Estudos teóricos anteriores ${ }^{4,122,123}$, focados na descrição do espectro de absorção concordam que a transição dominante tem caráter $\pi-\pi^{*}$ e, próximo a ela, existe uma transição $\mathrm{n}-\pi^{*}$ fraca. A ordem dessas transições depende do meio, sendo bem estabelecido que em fase gasosa $^{* *}$ a transição $n-\pi^{*}$ é a menos energética ${ }^{9,123,124}$, enquanto o oposto é obtido em água ${ }^{5}$.

Apesar de todos os esforços, algumas questões ainda estão em aberto. Uma interessante é "como é a estrutura do estado excitado oriundo da transição $\pi-\pi^{*}$ e que em solvente leva à emissão?". Alguns trabalhos na literatura tentam responder essa questão. Serrano-Andres e coautores ${ }^{125}$ usaram o método $\operatorname{CASSCF}^{10}$ (seção 2.2) com um espaço ativo composto por todos os orbitais $\pi$ (Full- $\pi$ space) e obtiveram uma estrutura plana. Lischka e coautores $^{9}$ usaram o método CASSCF com um espaço ativo similar e obtiveram uma estrutura

\footnotetext{
$\S$ Este texto é, em grande parte, a tradução do artigo original (Computational and Theoretical Chemistry vol. 1040-1041, 2014, p. 312-320) apresentado no Anexo A.

${ }^{* *}$ Do ponto de vista teórico, a molécula em fase gasosa é a molécula isolada (aproximação de gás ideal).
} 
plana, mas com um dos átomos de hidrogênio (H3 na Figura 4.1) fora do plano, e corroboraram o resultado usando o método MR-CISD. Recentemente, Yamazaki e Taketsugu ${ }^{126}$ usaram os métodos CASSCF e CASPT2 ${ }^{20}$ (implementado no programa MolPro, que apresenta diferenças do CASPT2 original implementado no Molcas) com o Full- $\pi$ space. Com CASSCF, eles obtiveram uma estrutura similar à de Lischka e coautores, mas o resultado obtido com CASPT2 apresenta uma geometria não-planar que lembra um barco (Figura 4.2). Barone e coautores usaram TD-DFT combinada com PCM e microsolvatação para estudar o estado excitado da uracil em solvente e obtiveram uma estrutura na forma de barco ${ }^{5}$, enquanto uma estrutura planar foi obtida em fase gasosa ${ }^{123}$. É interessante observar que apesar da similaridade na forma, as geometrias obtidas por Barone e coautores com DFT e por Yamazaki e Taketsugu com CASPT2 não são iguais, uma vez que os átomos são deslocados para lados opostos (Figura 4.2).

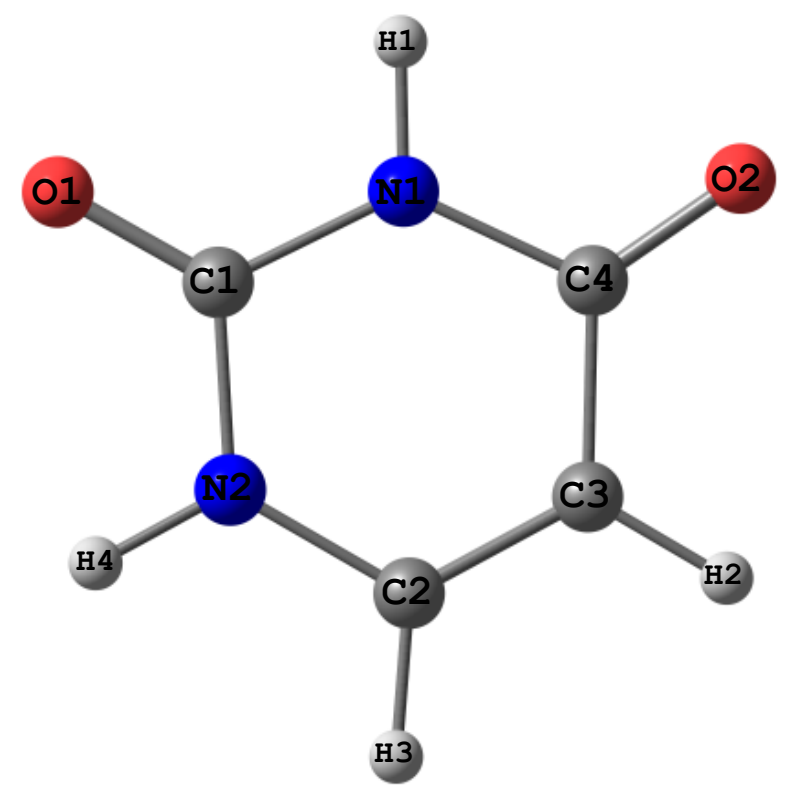

Figura 4.1: A molécula uracil. O rótulo dos átomos é usado no texto e tabelas.

Assim, neste estudo, nós revisitamos esta questão usando o método S-QM/MM ${ }^{21}$ (seção 1.3). Os métodos $\operatorname{CASSCF}^{10}$ (seção 2.2) e CASPT2 $^{20}$ (seção 2.3) foram usados respectivamente para obter a geometria do estado excitado e as energias de transição. 0 efeito de solvente foi incluído usando simulações de Monte Carlo para gerar uma configuração eletrostática média. Um esquema baseado no método do Gradiente de Energia Livre (FEG) ${ }^{16-19}$ (seção 1.3.7) foi empregado para obter a geometria do estado excitado em solvente. 

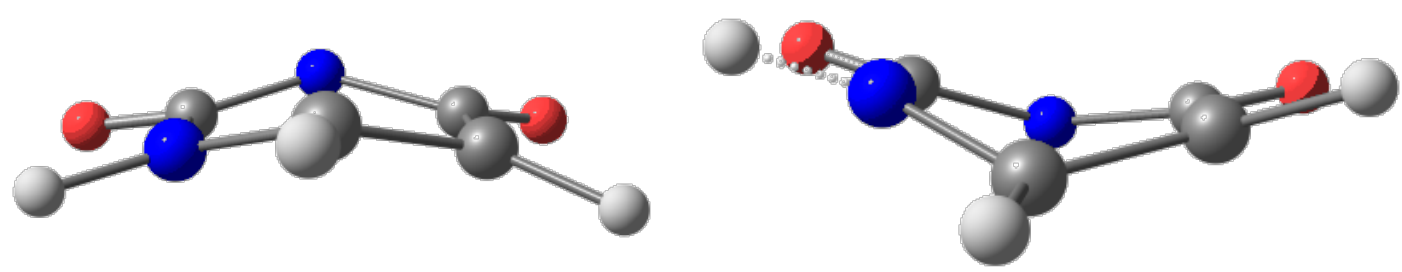

Figura 4.2: Estruturas não-planares obtidas por Yamazaki e Taketsugu ${ }^{126}$, usando CASPT2(10/8) (esquerda) e por Barone e colaboradores, usando TD-PBE0/6-31G(d) (direita). Apesar de ambas apresentarem uma forma de "barco", a distorção do anel ocorre para o lado oposto.

\section{2 - Detalhes Computacionais}

A geometria do estado fundamental da uracil foi obtida no nível MP2/aug-cc-pVDZ, utilizando o programa Gaussian $03^{60}$. A geometria do estado excitado foi obtida no nível SACASSCF/ANO-L-VDZP ${ }^{10,95}$ (seções 2.4 e 2.6), considerando o Full- $\pi$ space como espaço ativo (5 orbitais ocupados e 3 virtuais, Figura 4.3, denotado como $\operatorname{CASSCF}(10,8)$, onde 5 estados foram incluídos (fundamental + 4 estados excitados), sendo o segundo (primeiro estado excitado, dominado pela transição HOMO $\rightarrow$ LUMO) otimizado, uma vez que estudos teóricos e experimentais anteriores apontaram que o estado que passa a ser mais ocupado devido a excitação eletrônica tem caráter $\pi-\pi^{* 4,9,120,125,127}$. Como notado anteriormente ${ }^{9,128}$, alguns trabalhos reportaram que a otimização irrestrita desse estado pode levar diretamente para a intersecção cônica. Nós evitamos isso fazendo uma primeira otimização usando a base mínima ANO (ANO-S-MB) e tomando o resultado convergido como ponto de partida para a otimização definitiva. Apenas a forma diketo da uracil foi considerada, uma vez que é bem estabelecido que ela é a mais estável ${ }^{129}$.

As energias de transição (absorção e emissão) foram calculadas usando o método MSCASPT2 $^{91}$ (seção 2.4), considerando o Full- $\pi$ space mais o lone-pair do átomo 02, para descrever a transição $n-\pi^{*}$. Yamazaki \& Taketsugu ${ }^{126}$ mostraram que o lone-pair relacionado ao átomo 01 dá origem a transições cujas energias estão além do intervalo considerado em nosso estudo, então ele não foi incluído no espaço ativo. Os três estados de mais baixa energia foram incluídos no cálculo: o fundamental, e os estados excitados $n-\pi^{*}$ e $\pi-\pi^{*}$. O conjunto base ANO-L, com esquema de contração $C, O(14 s 9 p 4 d) /[4 s 3 p 1 d], H(8 s 4 p) /[2 s 1 p]$ foi usado. Esse conjunto base fornece resultados convergidos para a energia das transições eletrônicas, como previamente verificado por Roos \& Fülscher ${ }^{97}$. Nós denotamos esses cálculos como 
CASPT2 $(12,9)$. Todos os cálculos para determinação das estruturas do estado excitado e das energias das transições eletrônicas foram feitos no programa Molcas $7.6^{62}$.
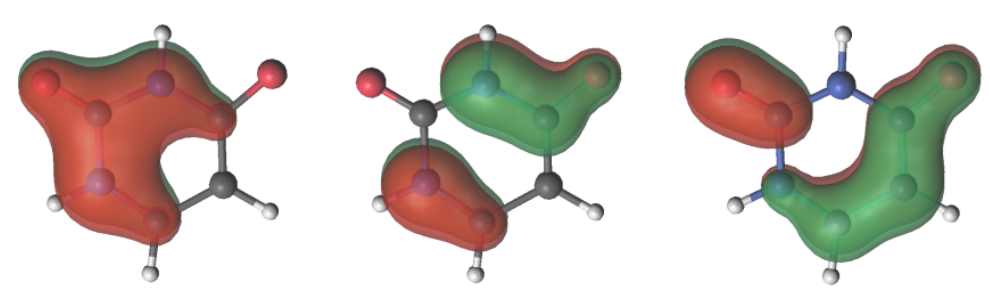

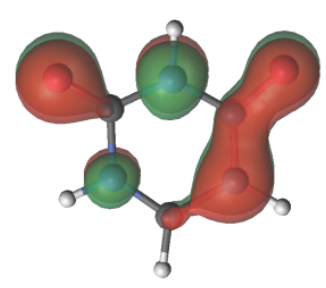

HOMO-1

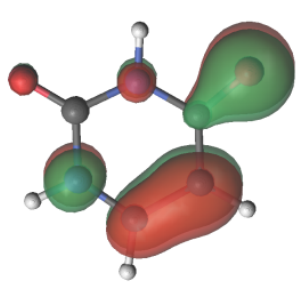

HOMO

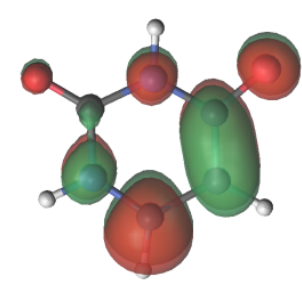

LUMO

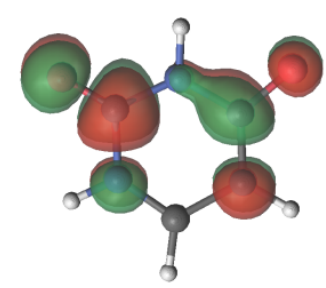

LUMO+1

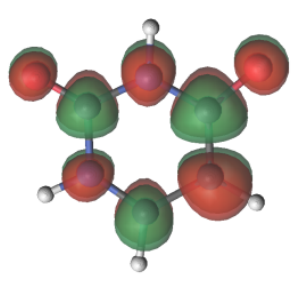

LUMO+2

Figura 4.3: Espaço ativo utilizado para determinar a estrutura do estado excitado $\pi-\pi^{*}$. Todos os orbitais do tipo $\pi$ foram incluídos (Full- $\pi$ space). Acima, orbitais originalmente duplamente ocupados e abaixo, orbitais virtuais. Os orbitais foram obtidos utilizando HF/ANO-S-MB e então expandidos para a base ANO-L-VDZP. Para calcular as transições eletrônicas, o lone-pair do átomo $\mathrm{O} 2$ também foi incluído.

Para descrever o efeito do solvente, a metodologia S-QM/MM²1 (seção 1.3) foi usada. Simulações Clássicas de Monte Carlo com algoritmo de Metropolis (seção 1.3.2) foram executadas primeiramente para gerar configurações estatisticamente descorrelacionadas, que foram então utilizadas para construir o Average Solvent Electrostatic Configuration - ASEC ${ }^{56}$ (seção 1.3.6), uma configuração média, onde as 250 moléculas de água mais próximas foram incluídas e representadas pela carga pontual normalizada de seus átomos em suas respectivas coordenadas cartesianas. O ASEC descreve todas as interações eletrostáticas, e preserva a informação estatística do líquido. A molécula uracil embebida no ASEC foi então usada nos cálculos quânticos.

As simulações foram realizadas no programa Dice ${ }^{41}$. O ensemble escolhido foi o NPT, e as condições termodinâmicas foram as mesmas dos experimentos ${ }^{120}\left(\mathrm{~T}=20^{\circ} \mathrm{C}\right.$ e $\left.\mathrm{P}=1 \mathrm{~atm}\right)$. Após a fase de termalização, foram realizados $3 \times 10^{5}$ passos/molécula. A caixa de simulação foi 
composta por 1 molécula de uracil e 500 moléculas de água. Condições periódicas de contorno e método das imagens foram empregados (seção 1.3.1). As moléculas foram adotadas como sendo rígidas e o potencial de interação foi descrito pela soma dos potencias $L J$ e Coulomb (seção 1.3.3). Para a uracil, os parâmetros LJ do campo de força OPLS-aa ${ }^{48}$ foram usados em ambos os estados, fundamental e excitado, mas para incluir o efeito de polarização eletrônica, as cargas atômicas parciais foram ajustadas através do método ESPF $^{103}$ (seção 2.7), no nível SACASSCF(10,8)/ANO-L-VDZP (veja detalhes abaixo). Para as moléculas de água, o modelo SPC ${ }^{50}$ foi adotado.

Uma vez que os cálculos clássico e quântico são feitos sequencialmente, cuidados apropriados são necessários para incluir a polarização eletrônica do soluto devida à presença do solvente. Aqui, nós usamos um procedimento iterativo ${ }^{22}$ (seção 1.3.5) que tem sido usado com sucesso em várias aplicações ${ }^{55,130,131}$, incluindo estados excitados ${ }^{25,26}$. Neste procedimento, uma simulação inicial é feita usando as cargas ajustadas em fase gasosa. Após a simulação, o ASEC é gerado e usado para ajustar novas cargas que são usadas em uma nova simulação. $O$ ciclo é realizado até a convergência do momento de dipolo $(\Delta \mu \leq 0.1 \mathrm{D})$.

Por fim, nós estendemos para o estado excitado, uma metodologia originalmente desenvolvida para obter a geometria do estado fundamental de moléculas em solução ${ }^{27}$. Essa metodologia (seção 1.3.7) combina o método $\mathrm{FEG}^{16-19}$ e o procedimento iterativo de polarização, e foi usada para obter a geometria do estado excitado da uracil em água. Neste caso, o ASEC é usado para representar o solvente e as forças nos átomos da molécula de soluto são calculadas. Os átomos são então deslocados na direção das forças e novas cargas parciais são ajustadas. Assim, em cada passo do procedimento iterativo, cargas e geometria são atualizadas e o ciclo é feito até que o momento de dipolo calculado e as mudanças na geometria atinjam critérios de convergência pré-estabelecidos, critérios esses que devem ser mais flexíveis dos que os usados em cálculos de moléculas isoladas, devido às flutuações termodinâmicas ${ }^{17}$. Estes cálculos foram feitos nos programa Diceplayer ${ }^{59}$, que funciona como uma interface entre o programa Dice e pacotes de Química Quântica (atualmente Gaussian 03 e 09 e Molcas 7.6) e que foi especialmente modificado para os objetivos deste trabalho. Para otimização em solução, duas geometrias iniciais foram consideradas: a estrutura planar da região de Franck-Condon e a estrutura em forma de barco obtida por Barone e coautores usando TD-DFT e microsolvatação. No último passo do procedimento, um cálculo CASPT2(12,9) foi realizado para determinar o valor da energia de emissão. 


\section{3 - Resultados}

\subsection{1 - Geometria e transições eletrônicas em fase gasosa}

A Tabela 4.1 mostra as distâncias e os ângulos de ligação, para as estruturas que obtivemos para o estado fundamental e para o estado $\pi-\pi^{*}$. Também são mostradas uma média dos valores experimentais, compilada por Kowalski e coautores ${ }^{124}$. Nós obtivemos estruturas planares em ambos os casos. Para facilitar a comparação, nós sobrepusemos as estruturas calculadas (Figura 4.4). As mudanças são pequenas, porém perceptíveis. A estrutura que nós obtivemos para o estado $\pi-\pi^{*}$ está em boa concordância com a obtida por SerranoAndrés e coautores, que usaram CASSCF com espaço ativo similar ao nosso e um conjunto base de Pople (veja detalhes no material suplementar da ref. ${ }^{125}$ ).

Tabela 4.1: Distâncias $(\AA ̊)$ e ângulos $\left({ }^{\circ}\right)$ de ligação das geometrias obtidas para uracil em fase gasosa: estado fundamental (MP2/aug-cc-pVDZ) e estado excitado $\pi-\pi^{*}$ (CASSCF(10,8)/ANO-L-VDZP). Também é mostrada a estrutura de mínimo do estado excitado $\pi-\pi^{*}$ da uracil em água $\left(\pi-\pi_{\text {solv }}^{*}\right)$, obtida com a combinação dos métodos CASSCF e FEG, com a geometria inicial na região de FrackCondon. Os índices dos átomos referem-se à figura 1. Valores experimentais para o estado fundamental são mostrados para comparação ${ }^{a}$.

\begin{tabular}{|c|c|c|c|c|c|c|c|c|c|}
\hline Distância & $\operatorname{Exp}^{a)}$ & Fund. & $\pi-\pi^{*}$ & $\pi-\pi^{*}{ }_{\text {solv }}$ & Ângulo & $\operatorname{Exp}^{\text {a) }}$ & Fund. & $\pi-\pi^{*}$ & $\pi-\pi^{*}{ }_{\text {solv }}$ \\
\hline $\mathrm{N} 2-\mathrm{C} 1$ & 1.379 & 1.394 & 1.373 & 1.340 & $\mathrm{C} 2-\mathrm{N} 2-\mathrm{C} 1$ & 121.3 & 123.7 & 127.3 & 120.0 \\
\hline C1-N1 & 1.373 & 1.389 & 1.377 & 1.342 & N2-C1-N1 & 114.8 & 113.0 & 113.3 & 123.0 \\
\hline N1-C4 & 1.383 & 1.412 & 1.374 & 1.432 & C1-N1-C4 & 127.0 & 128.4 & 124.7 & 122.4 \\
\hline $\mathrm{C} 4-\mathrm{C} 3$ & 1.440 & 1.463 & 1.351 & 1.401 & $\mathrm{~N} 1-\mathrm{C} 4-\mathrm{C} 3$ & 114.7 & 113.6 & 121.6 & 114.3 \\
\hline C3-C2 & 1.338 & 1.364 & 1.494 & 1.431 & $\mathrm{C} 4-\mathrm{C} 3-\mathrm{C} 2$ & 119.2 & 119.6 & 116.8 & 123.0 \\
\hline $\mathrm{C} 2-\mathrm{N} 2$ & 1.380 & 1.381 & 1.360 & 1.401 & $\mathrm{C} 3-\mathrm{C} 2-\mathrm{N} 2$ & 122.8 & 121.8 & 116.3 & 117.4 \\
\hline C1-O1 & 1.218 & 1.228 & 1.203 & 1.267 & O1-C1-N1 & 122.0 & 124.1 & 123.7 & 119.2 \\
\hline $\mathrm{C} 4-\mathrm{O} 2$ & 1.227 & 1.232 & 1.335 & 1.310 & $\mathrm{O} 2-\mathrm{C} 4-\mathrm{C} 3$ & 125.4 & 126.1 & 128.5 & 127.9 \\
\hline $\mathrm{N} 1-\mathrm{H} 1$ & -- & 1.014 & 1.003 & 1.023 & $\mathrm{H} 4-\mathrm{N} 2-\mathrm{C} 1$ & -- & 115.1 & 113.3 & 117.6 \\
\hline $\mathrm{C} 3-\mathrm{H} 2$ & -- & 1.089 & 1.074 & 1.079 & $\mathrm{H} 1-\mathrm{N} 1-\mathrm{C} 4$ & -- & 116.2 & 117.6 & 121.0 \\
\hline $\mathrm{C} 2-\mathrm{H} 3$ & -- & 1.092 & 1.072 & 1.073 & $\mathrm{H} 2-\mathrm{C} 3-\mathrm{C} 2$ & -- & 121.5 & 121.4 & 118.3 \\
\hline $\mathrm{N} 2-\mathrm{H} 4$ & -- & 1.018 & 1.004 & 1.030 & $\mathrm{H} 3-\mathrm{C} 2-\mathrm{N} 2$ & -- & 115.6 & 117.8 & 117.4 \\
\hline
\end{tabular}

a) Valores obtidos como média de medidas de raio-x em estruturas cristalinas (veja ref. ${ }^{124}$ );

Conforme discutimos na introdução, diferentes resultados para a estrutura do estado $\pi-\pi^{*}$ foram obtidas com diferentes métodos. Em fase gasosa, basicamente 3 diferentes situações foram encontradas: 


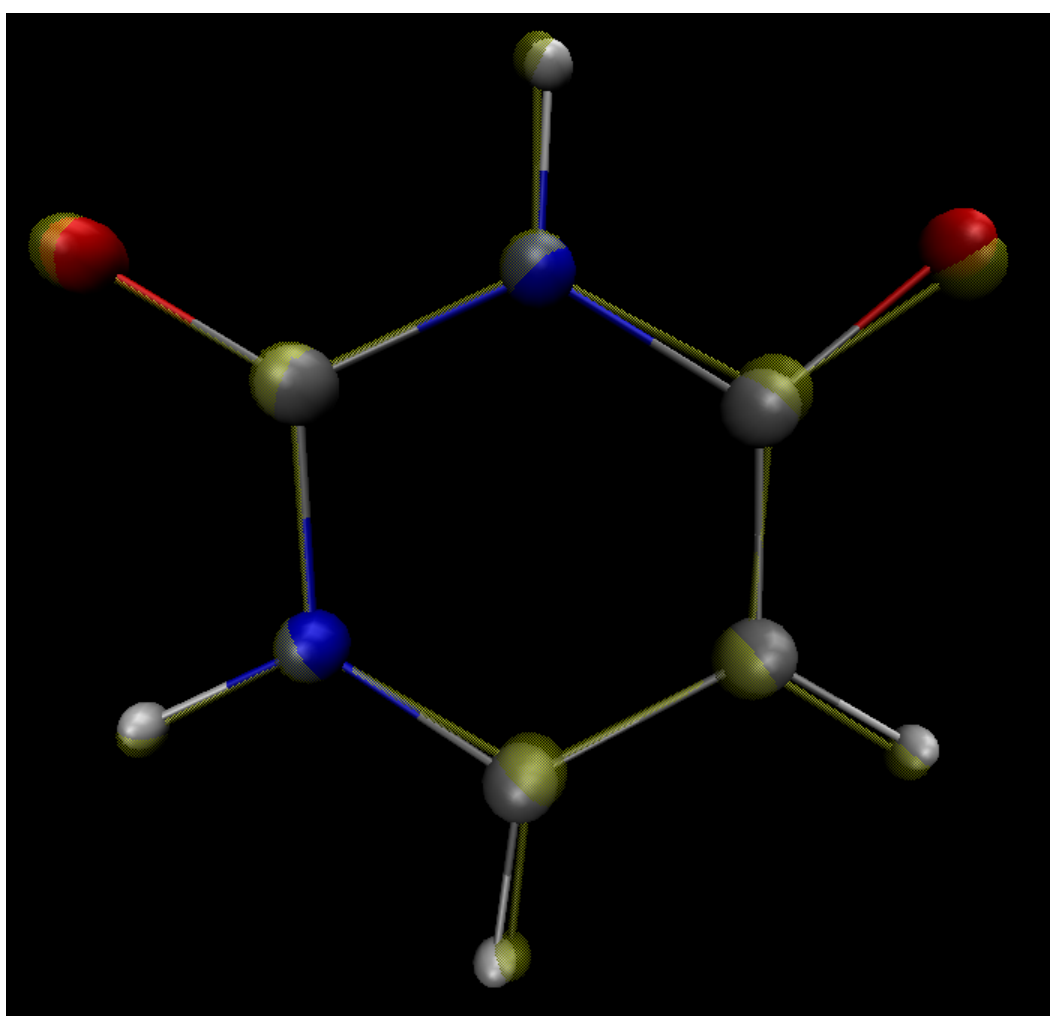

Figura 4.4: Superposição das geometrias de equilíbrio do estado fundamental (MP2/aug-cc-pVDZ, amarelo) e do estado excitado $\pi$ $\pi^{*}$ (CASSCF(10,8)/ANO-L-VDZP, Cores: O, C, N, H) da molécula uracil em fase gasosa.

1) estruturas planares foram obtidas em nosso trabalho e por Serrano-Andrés e coautores ${ }^{125}$, usando o método CASSCF combinado com o Full- $\pi$ space e também por Barone e coautores ${ }^{123}$ usando o funcional TD-PBEO ${ }^{132}$ e um conjunto de bases de Pople;

2) estruturas quase planares, com apenas o H3 fora do plano foram obtidas por Lischka e coautores ${ }^{9}$, usando CASSCF e um espaço ativo composto por 7 (dos 8) orbitais $\pi$ mais o lonepair do $\mathrm{O} 2$ e também usando o método MRCI-SD. Yamazaki e Taketsugu ${ }^{126}$, usando CASSCF com o Full- $\pi$ space e um conjunto base diferente obtiveram o mesmo tipo de estrutura;

3) estruturas em forma de barco foram obtidas por Yamazaki e Taketsugu, usando CASPT2 (como implementado no MolPro) com o Full- $\pi$ space. Um tipo similar de geometria foi obtida por Barone e coautores em solvente, usando TD-PBE0 e microsolvatação ${ }^{5}$ (Figura 4.2).

O uso do método CASPT2 para otimizar estruturas requer um grande esforço computacional, uma vez que em sua formulação original, como a que está implementada no programa Molcas, apenas gradientes numéricos estão disponíveis, então nós não o utilizamos. 
Para clarificar esta questão, nós recorremos ao espectro UV-Vis, que é muito sensível à geometria. A consistência dos resultados para as energias de absorção, emissão e consequentemente para o Stokes Shift darão credibilidade às estruturas obtidas. Como detalhado na seção anterior, nós realizamos um cálculo CASPT2 $(12,9)$ para obter a energia das transições eletrônicas (absorção e emissão). Para a fase gasosa, existe resultado experimental para o espectro de absorção ${ }^{127}$, enquanto para o espectro de emissão, o dado experimental disponível foi obtido usando a técnica de supersonic jet ${ }^{133}$. Esses valores experimentais são apresentados juntos com nossos resultados obtidos com CASPT2(12,9) na Tabela 4.2.

Tabela 4.2: Absorção e emissão da uracil em fase gasosa (parte superior) e em água (inferior), obtidas com CASPT2(12,9)/ANO-L-C,O,N\{4s3p1d $\} / \mathrm{H}\{2 \mathrm{~s} 1 \mathrm{p}\}$. Valores em eV.

\begin{tabular}{cccccc}
\hline & & \multicolumn{2}{c}{ Absorção } & Emissão & Stokes Shift \\
& & $n-\pi^{*}$ & $\pi_{-} \pi^{*}$ & $\pi_{-1 *}$ & \\
\hline GAS & & 4.91 & 5.19 & 4.29 & 0.89 \\
Exp. & -- & $5.08^{\mathrm{a})}$ & $4.37^{\mathrm{b})}$ & 0.71 \\
\hline Polarização & Modelo de & \multicolumn{2}{c}{ Absorção } & Emissão & Stokes Shift \\
& Solvente & $\boldsymbol{n}^{*} \boldsymbol{\pi}^{*}$ & $\boldsymbol{\pi}^{*} \boldsymbol{\pi}^{*}$ & $\boldsymbol{\pi}^{*} \boldsymbol{\pi}^{*}$ & \\
\hline Iterativo & ASEC & 5.70 & 4.99 & $4.28 / 3.95^{\mathrm{c})}$ & 1.04 \\
Iterativo + FEG & ASEC & & & 3.68 & \\
Exp. & & $5.17^{\mathrm{d})}$ & $4.79^{\mathrm{e})}$ & $3.88^{\mathrm{e})}$ & 0.91 \\
\hline
\end{tabular}

Para a absorção, nós obtivemos um valor de $5.19 \mathrm{eV}$, superestimando em apenas 0.11 eV o máximo da banda experimental ${ }^{127}$. Este valor também está em concordância com valores teóricos obtidos anteriormente. Serrano-Andrés e coautores ${ }^{125}$ também obtiveram o valor de $5.18 \mathrm{eV}$. Ludwig et al. ${ }^{135}$ usando TD-B3PW91/6-31G(2d,2p) também obtiveram o valor de 5.18 $\mathrm{eV}$ e o valor um pouco menor de $5.14 \mathrm{eV}$ com TD-B3PW91/6-31+G(d,p). Barone e coautores ${ }^{5}$ reportaram o valor teórico de $\sim 5 \mathrm{eV}$. Mais recentemente, Yamazaki \& Taketsugu ${ }^{126}$ obtiveram o valor de $4.92 \mathrm{eV}$.

Para a energia de emissão, nosso resultado é $4.29 \mathrm{eV}$, em excelente acordo com o valor obtido em um experimento de supersonic jet, que é de $4.37 \mathrm{eV}^{133}$, e que pode ter sido 
erroneamente classificado como uma transição $n-\pi^{*}$. Por esta razão, nós também calculamos a fraca emissão a partir do estado $n-\pi^{*}$ e encontramos o valor de $3.37 \mathrm{eV}$, apenas $0.45 \mathrm{eV}$ distante no mesmo experimento e sugerida como sendo uma (possível) transição $n-\pi^{*}$ do tautômero dienol da uracil. Assim, nós atribuímos a emissão observada em 4.37 eV como sendo devida a transição $\pi-\pi^{*}$ em 4.29 eV que nós calculamos. Como discutido por Merchán \& Serrano-Andrés ${ }^{64}$, o método CASPT2 é capaz de fornecer transições eletrônicas com uma acurácia de 0.1-0.2 eV, desde que todos os orbitais relevantes para o problema em questão estejam no espaço ativo, e então, nossos resultados permitem contestar a interpretação anterior. Nós devemos notar também que o trabalho experimental foi feito antes do trabalho teórico de Roos e coautores ${ }^{122}$ ter clarificado a questão do caráter dos estados excitados de mais baixa energia da uracil. Alguns trabalhos têm mostrado que o estado $n-\pi *$ (que em faze gasosa está abaixo do estado $\pi-\pi^{*}$ ) pode ser ocupado através de intersecções cônicas, mas também, o estado $n-\pi^{*}$ pode acoplar com o estado fundamental através de outra intersecção cônica. Este mecanismo, juntamente com um canal direto acoplando os estados fundamental e $\pi-\pi^{*}$, são os mecanismos padrões para explicar o baixo rendimento quântico da uracil ${ }^{9,126,136}$.

Usando os valores que calculamos para as energias de absorção e emissão, nós obtivemos um Stokes shift de 0.89 eV, em boa concordância com o valor experimental de 0.71 eV, que pode ser derivado dos dois experimentos ${ }^{127,133}$. A concordância é significativamente melhor do que aquela obtida na ref. ${ }^{126}$ por exemplo, na qual a emissão é calculada como 4.53 eV e o Stokes Shift como 0.39 eV.

Alguns estudos anteriores levantam dúvidas acerca da estabilidade do estado excitado $\pi-\pi^{*}$ da uracil em fase gasosa ${ }^{137}$, até mesmo sugerindo que a estrutura planar de mínimo obtida com CASSCF é perdida quando mais correlação é incluída no cálculo ${ }^{128}$. Os resultados obtidos no presente trabalho podem ser tomados como um indicativo de que o mínimo da superfície de energia do estado excitado $\pi-\pi^{*}$ é muito raso, sendo sensível ao efeito da correlação eletrônica. Mais ainda, um mínimo raso, um tempo de vida curto e um caminho quase sem barreira para a intersecção cônica formam um quadro consistente com a falta de resultados experimentais diretos da emissão da uracil em gás, com o experimento de supersonic jet sendo o único resultado disponível. Na próxima seção nós mostraremos que enquanto a estrutura do estado excitado $\pi-\pi^{*}$ da uracil em gás pode ser considerada uma questão aberta, o mesmo não é verdade para o sistema em solução aquosa. 


\subsection{2 - Geometrias e transições eletrônicas em solução}

Agora nós analisaremos as transições eletrônicas e o Stokes Shift em solução aquosa.

Primeiramente, nós descrevemos o efeito de solvente dentro da aproximação usual de solvatar estruturas obtidas em fase gasosa. Como detalhado na seção 4.2 , simulações MC foram usadas para gerar configurações do líquido e construir o ASEC, que por sua vez foi usado para representar o solvente no cálculo do espectro.

Para incluir a polarização eletrônica, o procedimento iterativo descrito na seção 1.3 .5 foi usado. A mudança no momento de dipolo dos estados fundamental e excitado é mostrada na Figura 4.5a e b, respectivamente. Para o estado fundamental, o momento de dipolo aumenta de 4.48 para 7.5 D, em concordância com os resultados anteriores obtidos com MP2/aug-cc-pVDZ ${ }^{135}$.

Para incluir a polarização do soluto no estado excitado, nós temos que considerar o tempo de vida. Experimentalmente, o tempo de vida do estado excitado $\pi-\pi^{*}$ da uracil em água foi medido como sendo de 0.1 ps. ${ }^{5}$ Como pode ser notado na Figura 4.4, as diferenças entre a geometria dos estados fundamental e excitado são pequenas. Assim, o tempo de vida deve ser longo o bastante para permitir mudanças intermoleculares do soluto, mas não é claro se a polarização do solvente acompanha essa mudança ou permanece em equilíbrio eletrostático com o estado fundamental. Deste modo, dividimos o procedimento de polarização em duas partes, com o propósito de estudar a emissão nos regimes de nãoequilíbrio e equilíbrio eletrostático com o solvente ${ }^{26}$ (vide capítulo anterior). No primeiro estágio, nós assumimos que o tempo de vida do estado excitado é curto, de modo que o processo de relaxação é rápido o bastante para que o solvente não acompanhe as mudanças geométricas sofridas pelo soluto. Assim, usando a geometria do estado excitado, as cargas são ajustadas com o solvente em equilíbrio com o estado fundamental do soluto (círculos vazios, Figura 4.5b). No segundo estágio, nós assumimos que o tempo de vida é grande o bastante para permitir que o solvente alcance o equilíbrio eletrostático com a estrutura de mínimo do soluto (diamantes, Figura 4.5b). Neste último caso, o momento de dipolo apresenta um valor convergido de 13.6 D. No fim de cada estágio, um cálculo CASPT2(12,9) é realizado, para obter as energias das transições eletrônicas em não-equilíbrio (último círculo vazio) e em equilíbrio (último diamante) com o solvente. Os resultados são apresentados na parte inferior da Tabela 4.2. 
a)
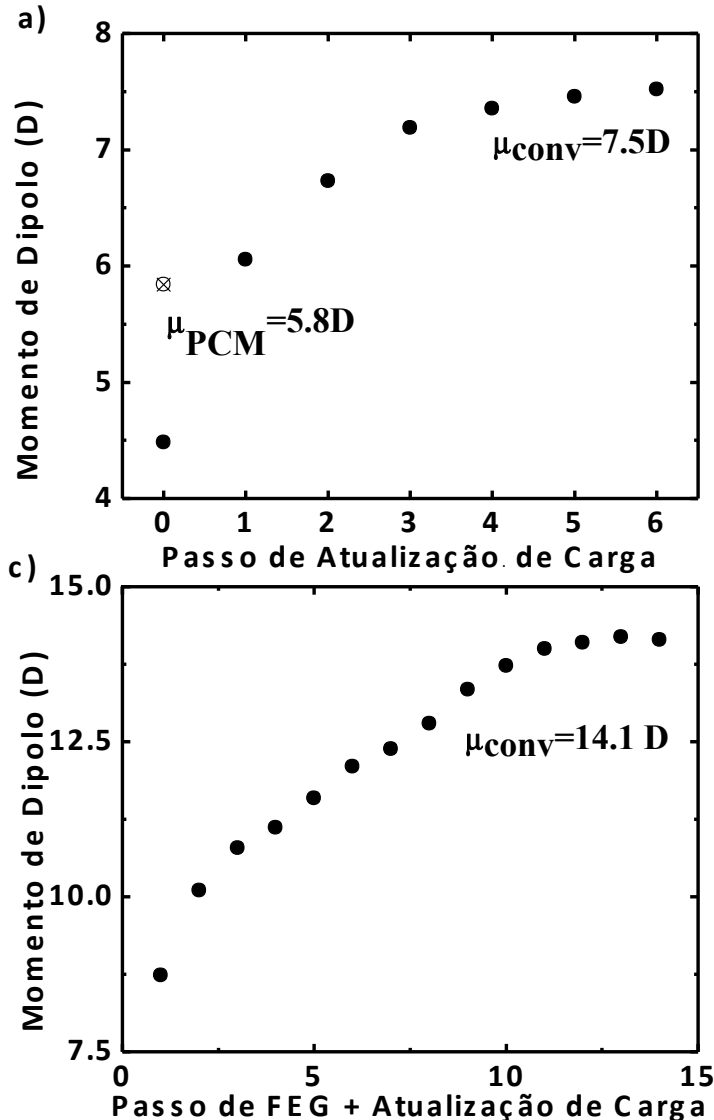

b)
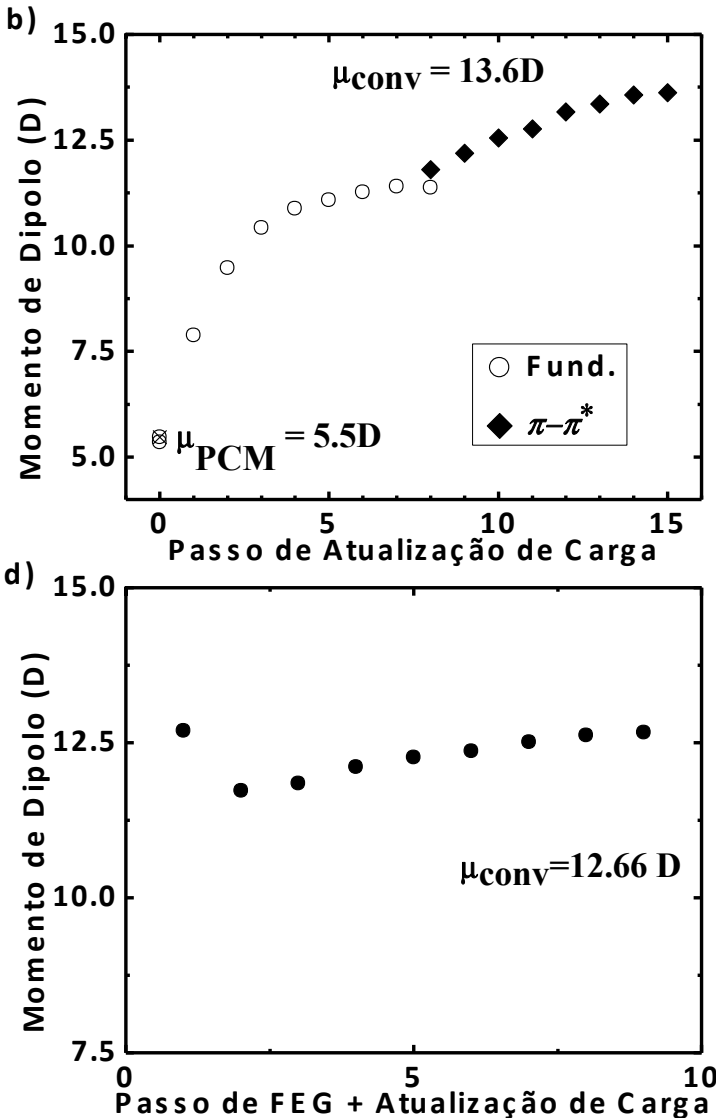

Figura 4.5: Alteração no momento de dipolo da uracil no processo de polarização iterativo para (a) o estado fundamental e (b) estado excitado $\pi-\pi^{*}$. Processo iterativo de polarização combinado com o método Free Energy Gradient para encontrar a estrutura de mínimo do estado excitado $\pi-\pi^{*}$ da uracil em água, com a geometria inicial da: (c) Região de FranckCondon e (d) Ref. ${ }^{5}$. O valor obtido com PCM $(\otimes)$ é mostrado para comparação. O valor do momento de dipolo convergido ( $\mu_{\text {conv }}$ ) é o valor do último ponto.

A transição $\pi-\pi^{*}$ é calculada como $4.99 \mathrm{eV}$, em boa concordância com o valor experimental de $4.79 \mathrm{eV}^{120}$. Para a emissão, nós obtivemos um valor de $4.28 \mathrm{eV}$ quando o solvente está em não-equilíbrio com o solvente, enquanto o valor experimental para emissão é $3.88 \mathrm{eV}^{120}$; na situação de equilíbrio eletrostático, a emissão é calculada como $3.95 \mathrm{eV}$, em muito bom acordo com o experimento. Este resultado mostra que o tempo de vida do estado excitado (medido como $0.1 \mathrm{ps})^{5}$ é o bastante para permitir que soluto e solvente alcancem um equilíbrio eletrostático. Nós enfatizamos que em água, o efeito solvatocrômico reverte a posição das transições $n-\pi^{*}$ e $\pi-\pi^{*}$, como pode ser notado pelos resultados obtidos na Tabela 4.2 e em um trabalhos anteriores ${ }^{5,55}$. Então, somente uma intersecção cônica entre o estado $\pi$ $\pi^{*}$ e o estado fundamental poderia diminuir o rendimento quântico.

Usando os valores calculados para a absorção e emissão, nós obtemos um Stokes Shift de $0.71 \mathrm{eV}$, na situação de não-equilíbrio e $1.04 \mathrm{eV}$ na de equilíbrio, enquanto o valor 
experimental é de $0.91 \mathrm{eV}^{120}$. Apesar de que ambos os valores podem ser considerados como estando em concordância com o valor experimental, o valor em equilíbrio mostra um resultado mais satisfatório, já que a situação em não-equilíbrio apresenta uma tendência incorreta, tendo um Stokes Shift com o valor igual ao que foi obtido em gás.

Por fim nós consideramos o efeito de solvente na geometria do estado excitado. Barone e coautores ${ }^{5}$ estudaram o efeito de solvente na estrutura do estado excitado $\pi-\pi^{*}$, bem como nas energias de transição, combinando TD-DFT e modelos de solvatação contínuo $(P C M)^{33}$ e microsolvatação. No nível TD-PBE0/6-31G(d), uma estrutura na forma de barco foi encontrada considerando a uracil em acetonitrila (descrita pelo PCM) e em água (4 moléculas de água explícitas + PCM), enquanto no mesmo nível de cálculo, a estrutura desse estado em fase gasosa é planar ${ }^{123}$. Isso motivou-nos a usar o S-QM/MM para calcular o efeito de solvente na geometria de mínimo do estado $\pi-\pi^{*}$.

Com esta finalidade, nós usamos uma variação do método de polarização iterativa, combinando-o com o método FEG (seção 1.3.7), que já havia sido utilizado com sucesso para descrever o estado fundamental da água líquida em condições normais ${ }^{27}$, e que aqui foi estendido para o caso de estados excitados. Assim, antes de ajustar as cargas, as forças nos átomos da uracil em presença do ASEC foram determinadas no nível SA-CASSCF(10,8)/ANO-LVDZP e os átomos foram deslocados na direção das forças. Deste modo, geometria e cargas são atualizadas em cada passo. Dos resultados acima, nós assumimos que a emissão ocorre no equilíbrio eletrostático, então nós usamos apenas um procedimento iterativo, aquele que considera o equilíbrio eletrostático (Figura 4.5 c). Neste caso, o momento de dipolo aumenta para 14.1 D, similar ao valor convergido obtido anteriormente, que é de $13.6 \mathrm{D}$, uma vez que as mudanças geométricas induzidas pela presença do solvente são pequenas. Entretanto, o momento de dipolo convergido evidencia apenas a polarização. A Figura 4.6 mostra a variação da distância e dos ângulos de ligação da molécula uracil, em função das iterações. Fica claro que após o 10 ำ passo, não ocorrem variações significativas. No último passo, a variação máxima é de $0.004 \AA ̊$ para as distâncias de ligação e $0.3^{\circ}$ para os ângulos, então nós tomamos a geometria como convergida. As forças atômicas no último passo também são mostradas. Note que elas são maiores que os valores tipicamente adotados como critério de convergência em otimizações em fase gasosa, porém são menores que os efeitos termodinâmicos ${ }^{17}$. Os valores máximo e médio das forças atômicas convergem para uma constante, com o desvio médio sendo próximo de zero. 

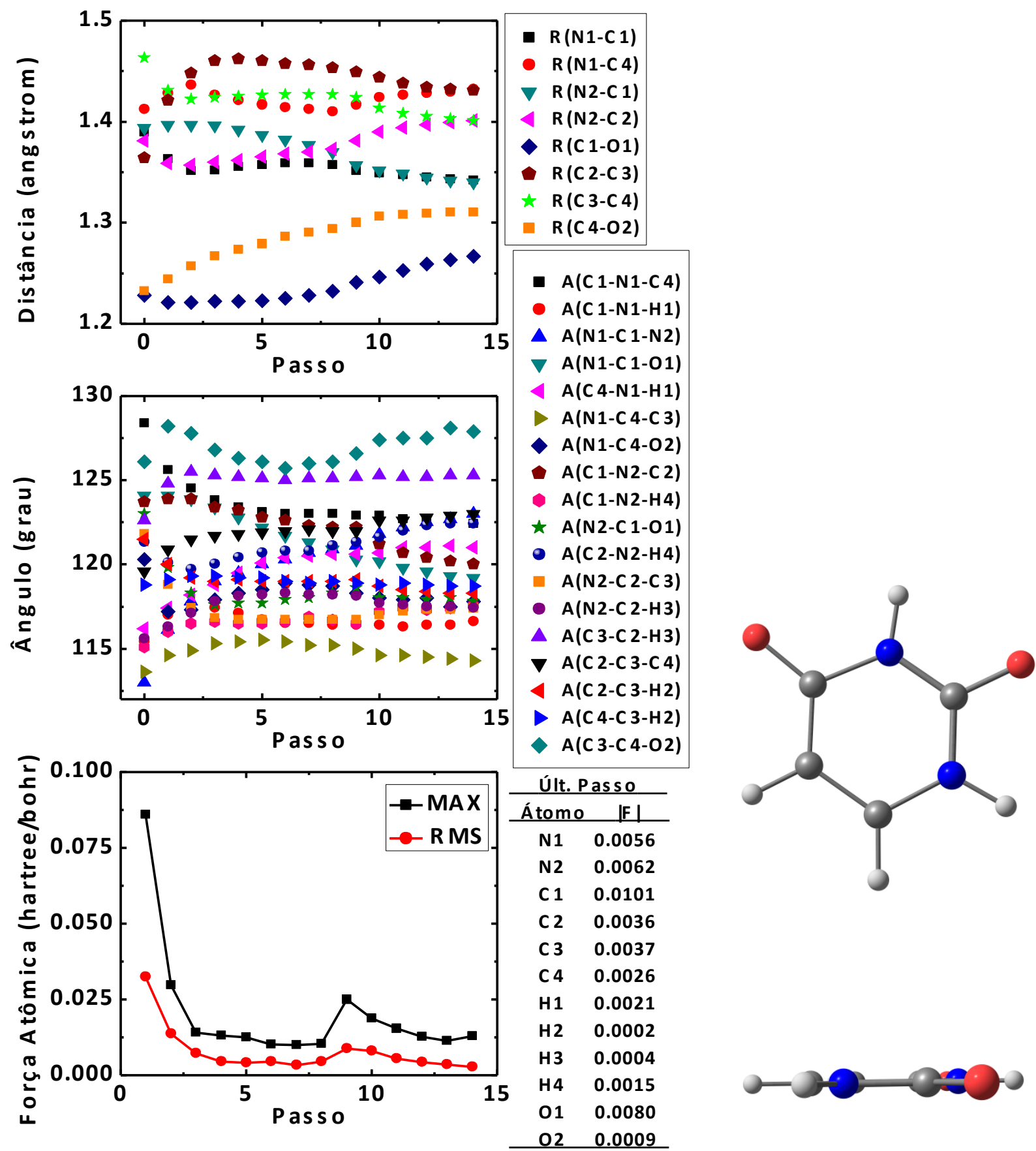

\begin{tabular}{|cc}
\multicolumn{3}{c}{ Últ. Passo } \\
\hline \multicolumn{3}{|c}{ Átomo } & $|F|$ \\
\hline N1 & 0.0056 \\
N2 & 0.0062 \\
C1 1 & 0.0101 \\
C2 & 0.0036 \\
C 3 & 0.0037 \\
C4 & 0.0026 \\
H1 & 0.0021 \\
H2 & 0.0002 \\
H3 & 0.0004 \\
H4 & 0.0015 \\
O1 & 0.0080 \\
02 & 0.0009 \\
\hline
\end{tabular}

Figura 4.6: Variação da distância e ângulos de ligação, força atômica máxima (MAX) e desvio quadrático médio (RMS) da força atômica durante o processo iterativo de polarização combinado com o método FEG, usando a geometria da Região de Franck-Condon como ponto de partida. A magnitude da força atômica em cada átomo, no último passo, também é mostrada. Para ângulos e distâncias de ligação, os resultados estão convergidos após 10 passos. Os rótulos dos átomos referem-se a Figura 4.1. Distâncias de ligação envolvendo os átomos de hidrogênio não são mostradas porque a mudança é muito pequena. Uma ilustração da geometria convergida também é apresentada.

É interessante notar que o comportamento do aumento do momento de dipolo é diferente dos casos anteriores: aqui temos uma parte quase linear, onde as mudanças na geometria 
parecem ser mais pronunciadas que mudanças nas cargas. Uma vez que as mudanças geométricas se tornam pequenas, o aumento do dipolo passa a ser o efeito dominante, e nós recuperamos o mesmo comportamento do procedimento iterativo de polarização feito com geometria fixa (Figura 4.5c).

Após a convergência ter sido alcançada, a estrutura do estado excitado está em equilíbrio eletrostático e geométrico com o solvente. Novamente, nós obtivemos uma estrutura planar. Usando essa estrutura e representado o solvente pelo ASEC, nós realizamos um cálculo CASPT2(12,9) para determinar as energias das transições eletrônicas (Tabela 4.2). O valor obtido para a emissão foi de $3.69 \mathrm{eV}$, subestimando o resultado experimental em 0.2 eV e em contraste com o resultado anterior, que superestimava o valor em $0.1 \mathrm{eV}$, ambos dentro da acurácia esperada para o método CASPT2. Considerando o Stokes Shift e o valor das transições, o resultado parece estar a favor da transição calculada sem o efeito de solvente na geometria. Isto pode ser um indicativo de que o tempo de vida do estado excitado permite um equilíbrio eletrostático entre soluto e solvente, mas a emissão ocorre antes do completo equilíbrio do estado $\pi-\pi^{*}$ em meio aquoso. Note que após o passo 10 (Figura 4.6) as mudanças são muito pequenas, então a geometria do soluto está quase convergida. Entretanto, o momento de dipolo continua a crescer, de $13.7 \mathrm{D}$ no passo 10 (praticamente o valor convergido obtido no cálculo anterior, onde apenas as cargas foram atualizadas) para 14.1 D. Este aumento está possivelmente relacionado a acomodação final do solvente devida as mudanças estruturais no soluto e, para esta parte, parece não haver tempo. De fato, ao fazer um cálculo CASPT2 $(12,9)$ no passo 10 , obtemos um valor para emissão de $3.82 \mathrm{eV}$, em melhor concordância com o resultado experimental do que o valor obtido na convergência.

Quanto ao efeito de solvente no Stokes Shift, o resultado experimental ${ }^{120}$ de $0.91 \mathrm{eV}$ em solução aquosa pode ser comparado ao valor experimental em fase gasosa (derivado de 2 experimentos $^{127,133}$ ) de $0.71 \mathrm{eV}$, resultando em um efeito de $0.20 \mathrm{eV}$. Nossos resultados teóricos apresentam um efeito de solvente no Stokes Shift de $0.15 \mathrm{eV}$, em muita boa concordância com o valor experimental. Este efeito é uma consequência do fato de o desvio solvatocrômico ser mais pronunciado na emissão do que na absorção.

Por fim, nós consideramos uma possível dependência da geometria de estado excitado calculada com a estrutura inicial utilizada ${ }^{16}$. Para isso, nós repetimos o procedimento anterior, mas começando com a geometria otimizada em forma de barco, obtida anteriormente com microsolvatação e TD-PBEO 5 . Neste caso, devido ao ponto inicial ser próximo a um ponto de mínimo, as mudanças são muito pequenas (Figura 4.7). O momento de dipolo decresce, para 
em seguida aumentar, até voltar ao valor inicial (Figura 4.5d). No último ponto, um cálculo CASPT2 $(10,8)$ foi feito, apresentando um valor para a emissão de $3.0 \mathrm{eV}, 0.9 \mathrm{eV}$ abaixo do resultado experimental. Note que, diferentemente dos casos anteriores, nós não fizemos um cálculo CASPT2(12,9), pois neste caso, o sistema apresenta uma rotação de orbital no espaço ativo tal que o lone-pair se torna um orbital inativo.

Nós também comparamos a energia total do sistema, a fim de encontrar qual apresenta a estrutura mais estável. A Tabela 4.3 apresenta os valores da energia total do sistema (soluto + ASEC), obtidos com os métodos SA-CASSCF, SS-CASPT2 e MS-CASPT2, a base ANO-L-VDZP e o espaço Full-r. Em todos os casos, a estrutura planar é a mais estável por pelo menos $14 \mathrm{kcal} / \mathrm{mol}$, indicando que essa é a estrutura do estado excitado $\pi-\pi^{*}$ em solução.

Em suma, nossos resultados mostram que a geometria do estado $\pi-\pi^{*}$ da uracil em água é planar. Usando este resultado em cálculos de emissão, encontramos boa concordância com os experimentos em ambas as fases, gasosa e solução. Os resultados também indicam que o tempo de vida do estado excitado seria longo o suficiente para permitir um equilíbrio eletrostático entre soluto e solvente, mas a emissão possivelmente ocorre antes de um completo equilíbrio estrutural de todo o sistema.

Tabela 4.3: Energia total (hartree) do estado excitado $\pi-\pi^{*}$ da uracil em ASEC, após otimização realizada com o método FEG, partindo de diferentes geometrias iniciais. A energia total foi obtida usando métodos multiconfiguracionais, com o espaço Full- $\pi$ e conjunto base ANO-LVDZP. Parte inferior: a diferença de energia entre as duas estruturas, em hartree e $\mathrm{kcal} / \mathrm{mol}$. A acurácia estimada do método CASPT2 é 0.1-0.2 eV (0.00367-0.00735 hartree ou 2.3-4.6 $\mathrm{kcal} / \mathrm{mol}$, veja discussão na ref. ${ }^{64}$ ).

\begin{tabular}{lccc}
\hline Geometria Inicial & SA-CASSCF & SS-CASPT2 & MS-CASPT2 \\
\hline Ref. $^{5}$ & -412.58560 & -413.74232 & -413.74322 \\
Franck-Condon & -412.61969 & -413.76565 & -413.76733 \\
& & & \\
$\Delta \mathrm{E}($ hartree $)$ & -0.03409 & -0.02333 & -0.024111 \\
$\Delta \mathrm{E}(\mathrm{kcal} / \mathrm{mol})$ & -21.38 & -14.63 & -15.12 \\
\hline
\end{tabular}



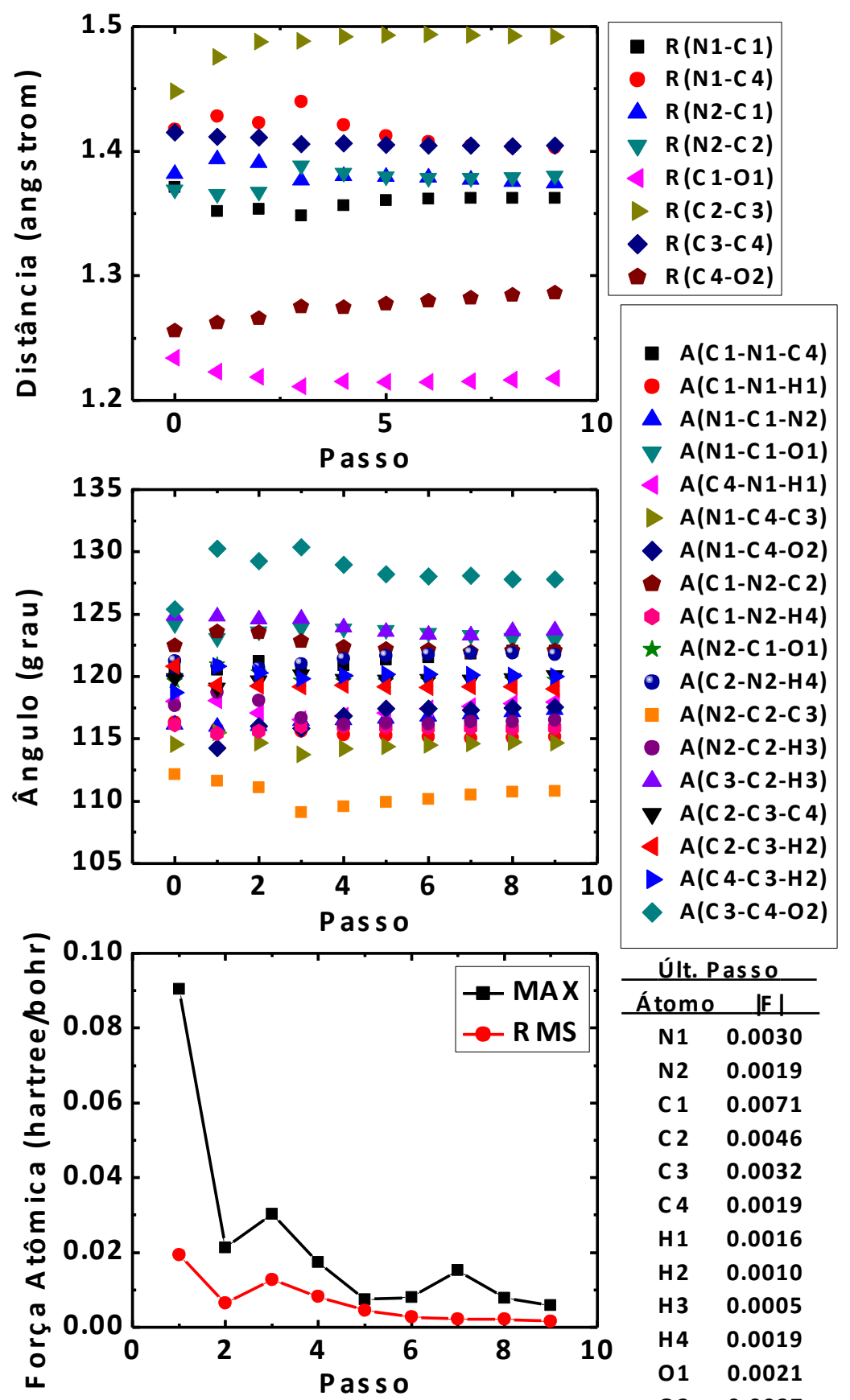

\begin{tabular}{cc}
\multicolumn{3}{c}{ Últ. Passo } \\
\hline Átomo & $|F|$ \\
\hline N1 & 0.0030 \\
N2 & 0.0019 \\
C1 & 0.0071 \\
C2 & 0.0046 \\
C 3 & 0.0032 \\
C4 & 0.0019 \\
H1 & 0.0016 \\
H2 & 0.0010 \\
H3 & 0.0005 \\
H4 & 0.0019 \\
O1 & 0.0021 \\
O2 & 0.0027 \\
\hline
\end{tabular}

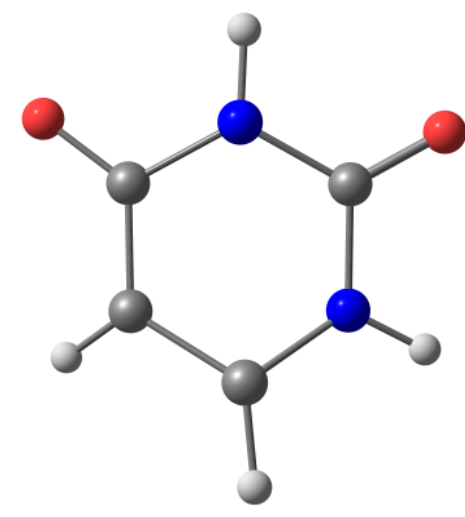

Figura 4.7: Variação da distância e ângulos de ligação, força atômica máxima (MAX) e desvio quadrático médio (RMS) da força atômica durante o processo iterativo de polarização combinado com o método Free Energy Gradient, usando a geometria obtida na Ref. ${ }^{5}$ como ponto de partida. A magnitude da força atômica em cada átomo, no último passo, também é mostrada. Os rótulos dos átomos referem-se a Figura 4.1. Distâncias de ligação envolvendo os átomos de hidrogênio não são mostradas porque a mudança é muito pequena. Uma ilustração da geometria convergida também é apresentada. 


\section{4 - Conclusões}

Neste capítulo, estudamos a influência do solvente na estrutura do estado excitado $\pi$ $\pi^{*}$ da uracil, e suas consequências na absorção e emissão. O efeito de solvente foi incluído através do método S-QM/MM. Simulações clássicas foram usadas para gerar uma configuração eletrostática média para representar o solvente. Cuidados especiais foram tomados com relação ao processo de polarização eletrônica da uracil devida ao meio aquoso.

Usando o método SA-CASSCF para obter a estrutura do estado excitado e o método MS-CASPT2 para a estrutura eletrônica, com conjuntos base ANO-L, nós obtemos a emissão em fase gasosa como sendo $4.29 \mathrm{eV}$, em boa concordância com o valor de 4.37 eV, obtido em experimentos de supersonic jet. Em meio aquoso, a emissão é encontrada em 3.95 eV, também em boa concordância com o valor experimental (3.88 eV). O efeito de solvente no Stokes Shift é calculado como $0.15 \mathrm{eV}$, comparado ao valor experimental de $0.20 \mathrm{eV}$, adicionando credibilidade à estrutura do estado excitado obtida.

Combinando o processo iterativo de polarização com o método do Gradiente de Energia Livre, nós fomos capazes de determinar a estrutura do soluto em solução no nível CASSCF/ANO-L-VDZP, com Full- $\pi$ space. Uma estrutura plana foi obtida, como ocorreu na fase gasosa. Em fase gasosa o mínimo é muito raso para ser observado. Em água, a estrutura plana é mais estável que a em forma de barco obtida anteriormente. 
70 Capítulo 4: Resultados - Absorção e emissão da Uracil em água Carlos Bistafa - IFUSP 2015 


\section{Capítulo 5 : Resultados - Transições eletrônicas do Paranitrofenol e seu ânion em solução aquosa}

Neste capítulo, apresentamos os resultados obtidos durante um estágio de 6 meses na Nagoya University, sob a supervisão do Professor Masataka Nagaoka, que desenvolveu o método do Gradiente de Energia Livre. Aqui, nós empregamos a formulação original do método, como proposto por ele e seus colaboradores. Assim, a metodologia usada neste capítulo é ligeiramente diferente dos demais: para a otimização em solvente nós usamos a equação 1.13 ao invés da equação 1.14, e como o procedimento está implementado em uma interface que acopla os programas Amber e Gaussian, nós realizamos as simulações clássicas com Dinâmica Molecular ao invés de Monte Carlo. ${ }^{+t}$

\section{1 - Introdução e Motivação}

Paranitrofenol (pNP, da grafia em inglês, paranitrophenol) e seu ânion, 4paranitrofenolato $\left(\mathrm{pNP}^{-}\right)$, Figura 5.1, têm sido estudados tanto teórica quanto experimentalmente nos últimos anos. O interesse está relacionado às chamadas moléculas push-pull, moléculas com grupos doadores e aceitadores de ligações de hidrogênio, boas candidatas a molecular switches, ou seja, moléculas que podem mudar reversivelmente entre dois ou mais estados. $O$ espectro de absorção dessas moléculas em gás ${ }^{138,139}$ e em solução ${ }^{138,140}$ foi medido recentemente e cálculos teóricos ${ }^{138,139}$ em fase gasosa foram feitos para fornecer algumas explicações sobre o que é observado experimentalmente. Bons resultados teóricos foram obtidos, mas não há cálculos incluindo o efeito de solvente.

Devido às limitações que o uso de moléculas isoladas traz na compreensão teórica de sistemas solvatados, nós estudamos estas moléculas através do procedimento $Q M / M M$ descrito nos capítulos anteriores, com o intuito de fornecer uma melhor descrição quantitativa

\footnotetext{
${ }^{\dagger+}$ Um manuscrito com os resultados deste capítulo está em fase de elaboração, para ser submetido em revista científica revisada por pares.
} 
das transições eletrônicas destes sistemas em meio. Para esta finalidade, nós combinamos as técnicas desenvolvidas em nosso grupo com as desenvolvidas pelo grupo do Professor Masataka Nagaoka, da Nagoya University, Japão.

a)

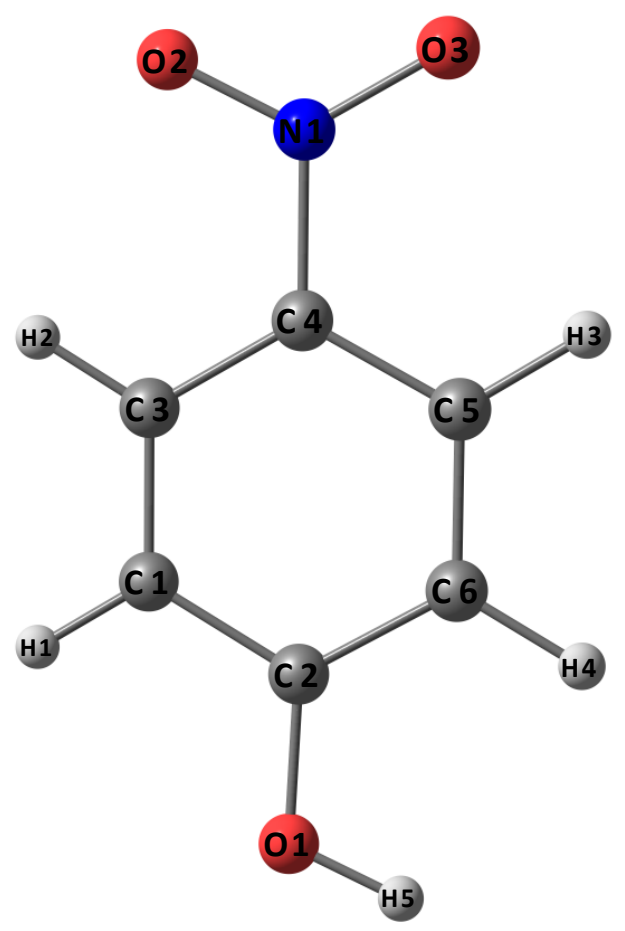

b)

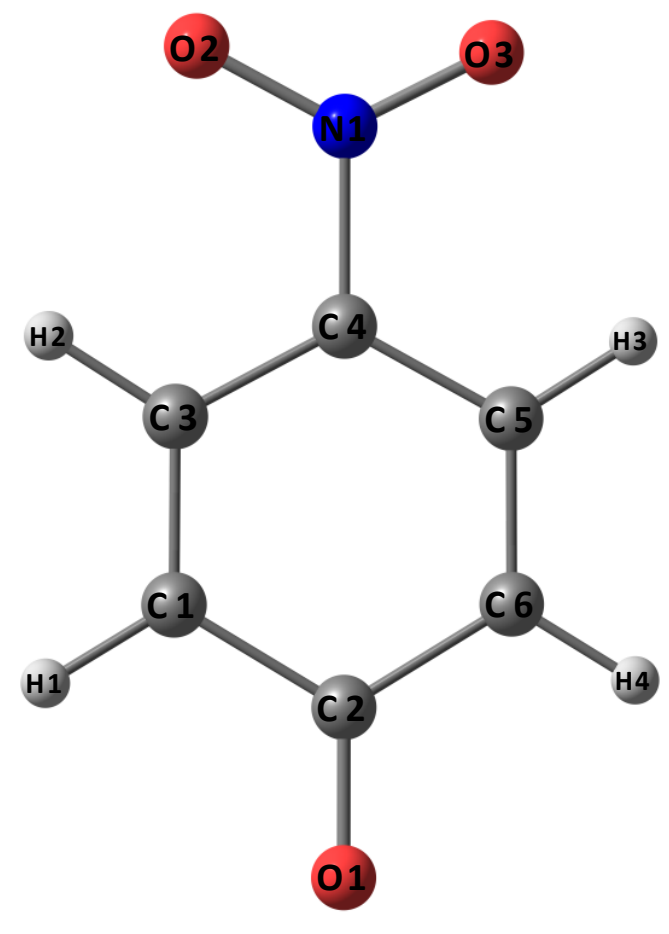

Figura 5.1: Estrutura da molécula a) pNP e b) $\mathrm{pNP}^{-}$. O rótulo dos átomos é usado no texto e tabelas.

\section{2 - Detalhes Computacionais}

Em fase gasosa, a geometria de ambas as moléculas foram otimizadas no nível de cálculo B3LYP/aug-cc-pVDZ ${ }^{141,142}$, usando o programa GAUSSIAN $09^{61}$. Para o pNP, nenhuma imposição foi feita na geometria (simetria $\mathrm{C} 1$ ), mas para o $\mathrm{pNP}^{-}$, nós impusemos simetria $\mathrm{C} 2 \mathrm{v}$.

Os cálculos das transições eletrônicas foram feitos utilizando o programa Molcas $7.6^{62}$. Nós usamos o método Multi-State CASPT $2^{91}$, um método perturbativo baseado na função de onda State Average CASSCF (seção 2.4). Como estudos teóricos e experimentais anteriores apontam que a transição eletrônica de menor energia é uma transição $\pi-\pi^{*}{ }^{138,139}$, nós selecionamos como espaço ativo todos os orbitais $\pi$ (Full- $\pi$ space): 6 orbitais ocupados e 4 virtuais, um total de 12 elétrons em 10 orbitais (Figura 5.2). Nós denotamos este cálculo como CASPT2(12,10). Neste cálculo, 5 raízes foram incluídas (estado fundamental +4 estados 
excitados). Nós adotamos o conjunto base ANO- $\mathrm{L}^{95}$, com o esquema de contração $\mathrm{C}, \mathrm{O}, \mathrm{N}(14 \mathrm{~s} 9 \mathrm{p} 4 \mathrm{~d}) /[4 \mathrm{~s} 3 \mathrm{p} 1 \mathrm{~d}], \mathrm{H}(8 \mathrm{~s} 4 \mathrm{p}) /[2 \mathrm{~s} 1 \mathrm{p}]$, que geralmente apresenta resultados convergidos com relação ao tamanho da base para as transições eletrônicas de mais baixa energia de moléculas orgânicas ${ }^{97}$. Um imaginary shift ${ }^{88}$ de 0.1 foi usado para reduzir a presença de estados intrusos, como sugerido anteriormente ${ }^{138}$.
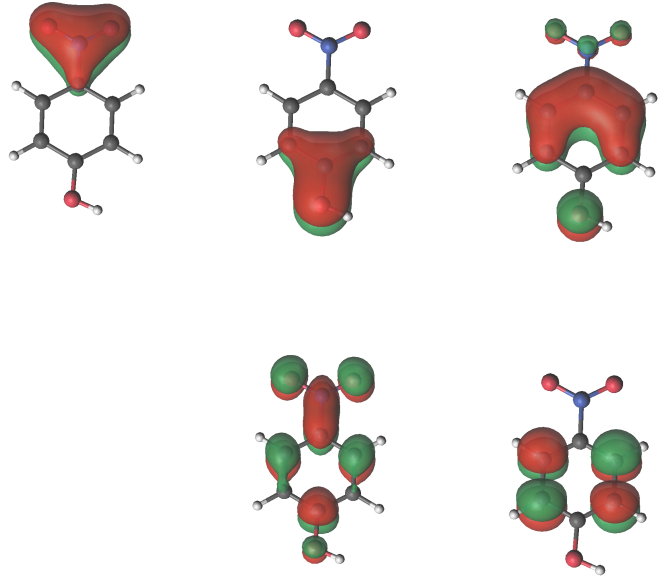

LUMO

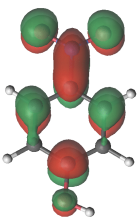

$$
\text { LUMO + } 1
$$
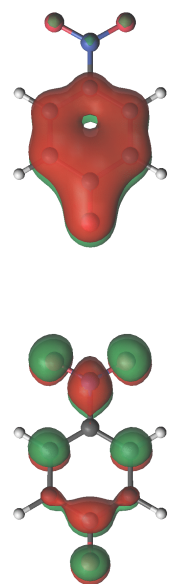

LUMO

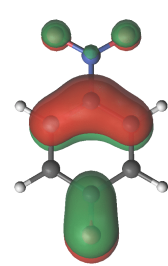

HOMO - 4

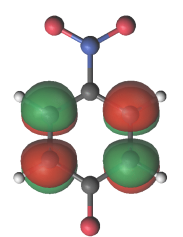

LUMO+1

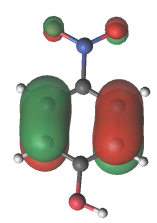

HOMO -2

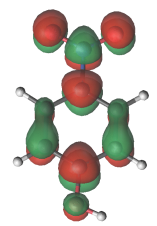

LUMO + 2

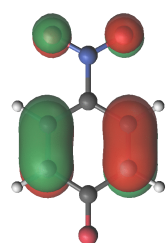

HOMO - 3

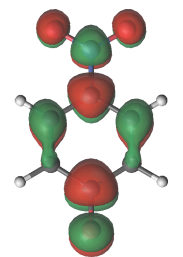

LUMO+2

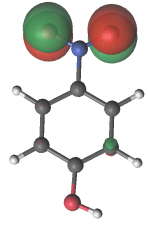

HOMO -1

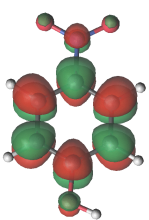

LUMO + 3
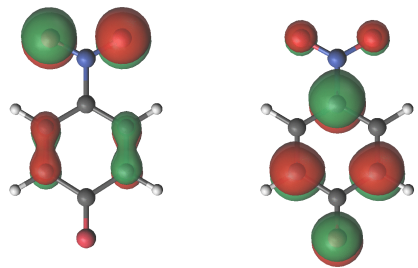

HOMO - 2

HOMO

Figura 5.2: O espaço ativo usado nos cálculos CASPT2 do pNP (metade superior) e pNP ${ }^{-}$ (metade inferior). A nomenclatura dos orbitais é advinda do ordenamento obtido no SCF.

Para incluir o efeito de solvente nas transições eletrônicas, a metodologia Sequential QM/MM foi usada ${ }^{21}$ (seção 1.3). Para incluir o efeito de polarização do soluto devido a interação com o solvente, a geometria e cargas de ambas as moléculas foram obtidas considerando-as em um modelo contínuo (PCM) ${ }^{33}$, usando o nível de cálculo B3LYP/6-31+G(d). 
Neste caso, como é esperado que a presença do solvente quebre a simetria, nenhuma imposição foi feita para a molécula pNP- Nós também utilizamos o método do Gradiente de Energia Livre (FEG) para otimizar as estruturas em solução ${ }^{16-19,143}$ (seção 1.3.7). Neste caso, a otimização é feita através de um procedimento $\mathrm{QM} / \mathrm{MM}$, usando uma interface ${ }^{144}$ que conecta os programas Gaussian $09^{61}$ e Amber $09^{145}$. O custo computacional da otimização usando FEG é muito alto, mas como ficará claro em nossos resultados, ela é necessária para a correta descrição das transições eletrônicas em solução.

A geometria e as cargas obtidas foram então usadas em simulações de Dinâmica Molecular (MD), realizadas no programa Amber $09^{145}$. Para os parâmetros das moléculas pNP e $\mathrm{pNP}^{-}$, nós usamos o campo de força Amber 7, como implementado no programa Amber. A caixa de simulação foi composta por 1 molécula de soluto +854 moléculas de água. Para as moléculas de água, o modelo TIP3P foi usado ${ }^{45}$. As simulações foram feitas a $300 \mathrm{~K}$, com um passo de $1 \mathrm{fs}$ e divididas em 2 estágios: primeiro, um estágio de termalização de $10^{5}$ passos no ensemble NPT; uma vez que a termalização foi atingida, nós passamos para um estágio de produção de $3 \times 10^{5}$ passos no ensemble NVT. Na simulação, todos os graus de liberdade do soluto foram removidos, com o intuito de usar as configurações geradas na simulação para construir o $\mathrm{ASEC}^{56}$, que foi então utilizado em cálculos de transição eletrônica com o método CASPT2.

No modelo ASEC (seção 1.3.6), Figura 5.3, as moléculas de água são representadas por cargas pontuais localizadas nas posições dos sítios atômicos. Várias configurações obtidas da simulação clássica são selecionadas e, desde que os graus de liberdade da molécula de soluto foram removidos, sua geometria está fixa em todas as configurações, sendo possível sobrepor essas configurações para representar o ensemble da distribuição do solvente. $O$ valor das cargas é normalizado pelo número de configurações usadas para construir o modelo. Neste trabalho, nós usamos 100 configurações, uma a cada 3 mil passos da simulação MD. Todas as moléculas de água na caixa foram incluídas, então o ASEC foi composto por 256200 cargas pontuais.

\section{3 - Resultados}

Os resultados para as transições eletrônicas são apresentados na Tabelas 5.1 e 5.2.

Na Tabela 5.1, nós podemos observar a grande acurácia do método CASPT2 na obtenção de transições eletrônicas de moléculas isoladas. Os resultados estão em 
concordância com os valores experimentais dentro de $0.2 \mathrm{eV}$, como esperado ${ }^{64}$, e também concordam com os trabalhos teóricos anteriores. Isto valida nossa escolha do conjunto base e do espaço ativo para estudar essas duas moléculas. A diferença observada em nosso cálculo e o estudo anterior ${ }^{138}$ é devido ao uso de diferentes bases ANO-L.

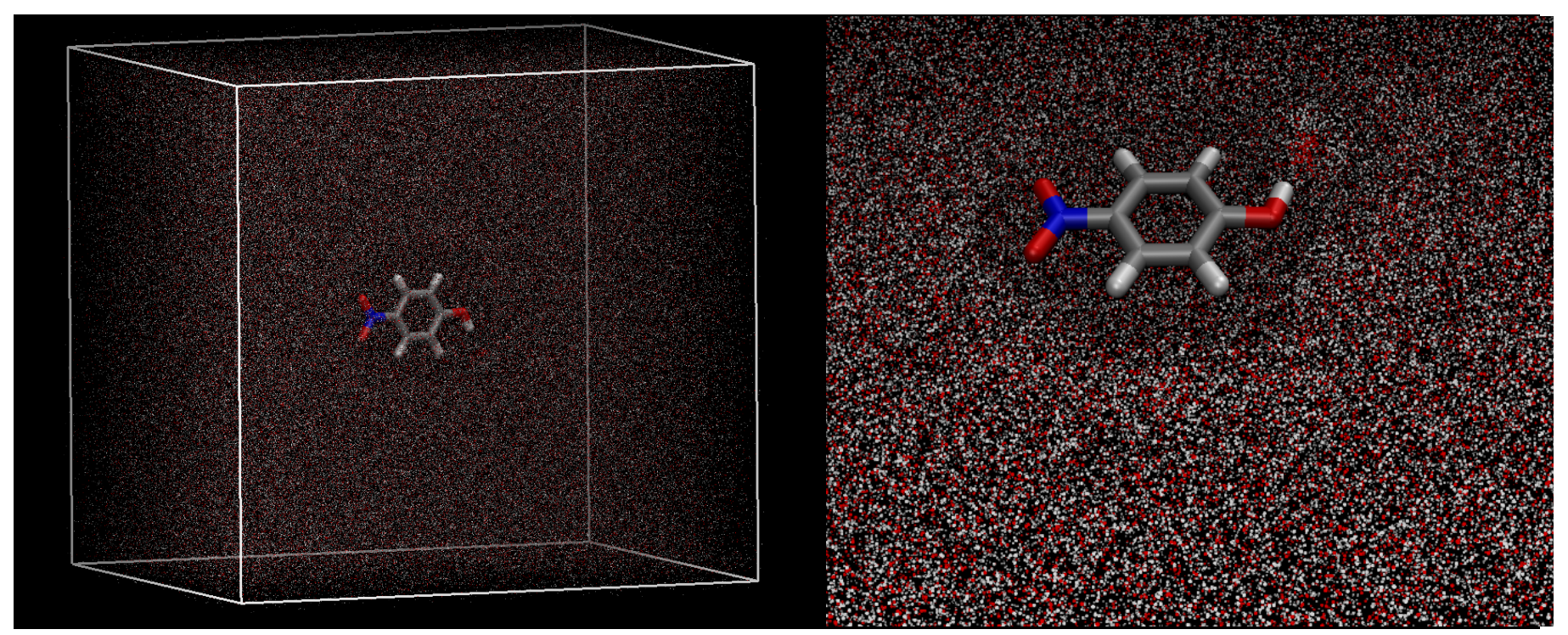

Figura 5.3: Esquerda) O modelo ASEC. A molécula de soluto é tratada por um método QM, mas as moléculas de solvente são tratadas como cargas pontuais localizadas na posição dos sítios atômicos. Várias configurações são sobrepostas, e o valor das cargas é normalizado pelo número de configurações. O ASEC foi usado em cálculos CASPT2 para obter as transições eletrônicas; Direita) uma ampliação na região do soluto mostra a cavidade formada devido a interação soluto-solvente, e também a formação das ligações de hidrogênio. Figura construída no software $\mathrm{VMD}^{146}$.

Tabela 5.1: Transições eletrônicas $\pi-\pi^{*}$ de menor energia das moléculas pNP e pNP $^{-}$em gás, calculadas com CASPT2(12,10)/ANO-L. Valores em eV.

\begin{tabular}{cccc}
\hline Molécula & Este trabalho & Trabs. Anteriores & EXP(GAS) \\
\hline pNP & 4.93 & $4.87^{\mathrm{a}}$ & $4.71^{\mathrm{a}}$ \\
pNP & 3.18 & $3.19^{\mathrm{b}}$ & $3.16^{\mathrm{b}}$ \\
\hline${ }^{\text {a) }}$ Cálculo CASPT2 $(12,10)$, mas usando um conjunto base diferente: ANO-L-VDZP (vide Ref. ${ }^{138}$ ); \\
${ }^{\text {b) }}$ CC2/aug-cc-pVDZ (vide Ref. ${ }^{139}$ ).
\end{tabular}

Na Tabela 5.2, nós apresentamos os valores para as transições em solução aquosa. Para analisar a importância da relaxação da molécula em solução, nós usamos diferentes metodologias no procedimento de otimização. As geometrias obtidas são usadas em simulações MD, onde elas são mantidas fixas. Essa condição é necessária para construção do 
modelo ASEC ${ }^{56}$, que será usado nos cálculos CASPT2 para a obtenção das transições eletrônicas em solução.

Vamos iniciar a discussão com as transições da molécula pNP. Primeiro, usamos na simulação a estrutura obtida em fase gasosa. Fazendo isso, obtivemos um resultado não satisfatório, superestimando a energia da transição em $0.6 \mathrm{eV}$ em relação ao valor experimental ${ }^{138}$. Como esperado, a estrutura obtida em gás não é adequada para descrever a molécula em solução, e a presença do solvente é responsável por menos da metade do shift solvatocrômico. A descrição pode ser melhorada ao se obter a geometria otimizada em um modelo contínuo, como o PCM e usá-la em uma simulação para construir o ASEC. Neste caso, o valor da transição eletrônica diminui em $0.3 \mathrm{eV}$, em relação ao cálculo anterior, comprovando a importância da relaxação da molécula em solução.

Tabela 5.2: Transições eletrônicas $\pi-\pi^{*}$ de menor energia das moléculas pNP e pNP', em solução aquosa, calculada com CASPT2(12,10), usando geometrias obtidas com diferentes métodos. Para incluir o efeito de solvente, utilizamos o modelo ASEC. Valores em eV.

\begin{tabular}{cccc}
\hline Geometria & pNP & pNP $^{-}$ & Shift \\
\hline GAS & 4.51 & $-^{a^{a}}$ & \\
PCM & 4.22 & 3.37 & 0.85 \\
FEG & 3.99 & 3.38 & \\
\hline EXP & $3.90^{b}$ & $3.09^{b, c}$ & 0.81 \\
\hline${ }^{\text {a) }}$ Em fase gasosa, a geometria da molécula pNP & tem simetria C2v, \\
enquanto a interação com o solvente quebra essa simetria (grupo C1); \\
b) Ref. ${ }^{138} ;$ \\
c) Ref. $^{140}$.
\end{tabular}

A partir dos orbitais envolvidos na transição, HOMO e LUMO, podemos compreender a origem da variação da energia de transição obtida. No HOMO, a densidade eletrônica está deslocalizada sobre o anel. Após a excitação, a densidade migra para o grupo nitro, como pode ser visto no LUMO (Figura 5.2). Então, mudanças no grupo nitro afetam a transição eletrônica. Transições eletrônicas são muito sensíveis a pequenas mudanças de geometria. Por exemplo, um discussão sobre como a distância da ligação $C=0$ afeta transições $n-\pi^{*}$ foi feita na Ref. ${ }^{110}$. Por isso, na Tabela 5.3, nós apresentamos os valores para as distâncias e o ângulo de ligação do grupo nitro obtidos com as metodologias usadas para se obter a geometria. Quando comparamos os valores obtidos para a geometria da molécula isolada com os obtidos com ela em PCM, vemos que a distância C4-N1 e o ângulo $\angle \mathrm{O} 2-\mathrm{N} 1-\mathrm{O} 3$ diminuem, enquanto as distâncias N1-O2 e N1-O3 aumentam. Assim, uma descrição mais precisa de como este grupo 
(e/ou a geometria da molécula como um todo) se comporta em solução é desejável, se quisermos uma descrição mais precisa das transições. Deste modo, se faz necessário uma aproximação além do modelo contínuo para o procedimento de otimização. Isto pode ser feito usando o método do Gradiente de Energia Livre (FEG) ${ }^{16-19,143}$ (seção 1.3.7). No FEG, nós usamos um procedimento $\mathrm{QM} / \mathrm{MM}$, obtendo o gradiente da parte clássica do sistema (neste caso, o solvente) atuando na região QM (o soluto). Então, nós estamos otimizando a molécula de soluto na presença de um ensemble de moléculas de solvente.

Usando o FEG, nós obtivemos uma nova estrutura para o pNP. Podemos ver na Tabela 5.3 que essa estrutura apresenta a mesma tendência da otimização em PCM, diminuindo ainda mais o ângulo $\angle 02-N 1-03$ e a distância C4-N1, e aumentando ainda mais as distâncias N1-O2 e N1-03. Nós então repetimos o procedimento anterior, usando essa geometria em uma simulação MD e gerando o ASEC. Fazendo isso, a transição eletrônica obtida no cálculo CASPT2 $(12,10)$ passa a ser $3.99 \mathrm{eV}$, em muito boa concordância com o valor experimental de $3.90 \mathrm{eV}^{138}$. Vemos assim que uma descrição precisa da geometria do pNP é de suma importância para a correta descrição da transição eletrônica, e que para o caso da molécula pNP, tal descrição de geometria só é possível com o FEG, que considera a interação solutosolvente no procedimento de otimização.

Tabela 5.3: Distâncias e ângulos de ligação dos átomos do grupo nitro para as geometrias da molécula pNP obtidas em GAS, PCM e com o método FEG. Para os rótulos atômicos, consulte a Figura 5.1.

\begin{tabular}{cccc}
\hline & GAS & PCM & FEG \\
\hline C4-N1 & 1.46557 & 1.45000 & 1.41231 \\
N1-O2 & 1.23075 & 1.23967 & 1.25721 \\
N1-O3 & 1.23111 & 1.23944 & 1.25442 \\
CO2-N1-O3 & 124.237 & 122.838 & 120.308 \\
\hline
\end{tabular}

Para a forma aniônica, as mudanças no grupo nitro são 10 vezes menores do que as observadas no caso neutro. Assim, não é possível obter melhoras nos resultados empregando métodos sofisticados para a obtenção da geometria. De fato, o valor obtido para a transição eletrônica é praticamente o mesmo em ambas as metodologias, PCM e FEG, considerando a acurácia do CASPT2 (Tabela 5.2). A diferença entre os valores por nós calculados e os valores medidos experimentalmente podem estar relacionados as limitações do ASEC, que não inclui atualização de cargas nas moléculas de solvente próximas, o que poderia ser crucial para a 
descrição de um sistema que não é neutro. Interações não-eletrostáticas também desempenhar um papel importante. Assim, a princípio, cálculos com a inclusão de moléculas de solvente explicitamente, i.e., tratadas usando QM, poderiam sanar essa discordância.

Entretanto, cálculos CASPT2 envolvendo solvente explícito são deveras custosos, ainda mais quando uma série deles usando várias configurações seria necessário para fornecer uma média convergida. Assim, com o intuito de apenas mostrar um indicativo sobre a discussão acima, nós selecionamos uma configuração, a última da simulação, e fizemos um cálculo CASPT2 $(12,10)$ tratando com QM as 5 moléculas de água mais próximas ao grupo $C=0$ e as demais 849 moléculas de água da caixa como cargas pontuais (Figura 5.4). Nós escolhemos essa região para a inclusão das moléculas de água pois é onde a formação de pontes de hidrogênio é mais provável e porque, como vemos da Figura 5.2, a densidade de cargas tem contribuição relevante aqui, em comparação ao caso do pNP. Neste cálculo, obtemos um valor de $3.29 \mathrm{eV}$ para a transição eletrônica $\pi-\pi^{*}$. Nós repetimos o cálculo, mas agora tratando essas 5 moléculas de água como cargas pontuais, assim como as demais da caixa. Isso nos dá um valor de $3.38 \mathrm{eV}$, o que é esperado, já que essa é uma das configurações que compõe o ASEC. Assim, podemos inferir que a inclusão de moléculas de solvente explícita deve contribuir com a redução do valor da transição eletrônica, com pelos menos $0.1 \mathrm{eV}$, aumentando o shift para $0.71 \mathrm{eV}$, em boa concordância com o valor experimental de $0.81 \mathrm{eV}$. Nós já havíamos observado anteriormente este tipo de comportamento para o caso das transições eletrônicas da molécula 5-fluorouracil, porém usando TD-DFT ${ }^{55}$. Assim, para o caso da molécula pNP a estrutura eletrônica do líquido pode ser desprezada, mas isso pode não ser o caso para a molécula $\mathrm{pNP}^{-}$. Outras possíveis fontes de erro seriam ainda: o tamanho limitado da base utilizada na otimização; a falta do lone-pair do oxigênio 01 no espaço ativo pois, apesar de a transição ter caráter $\pi-\pi^{*}$, ele poderia se correlacionar com os orbitais $\pi$; a possível necessidade de incluir uma molécula explícita de água na otimização, para uma correta descrição do grupo $\mathrm{C}=\mathrm{O}$.

Quanto ao shift entre as transições de ambas as moléculas em solução, já usando apenas as geometrias obtidas em PCM, temos uma boa descrição, mostrando que, apesar de superestimar os valores, os resultados assim obtidos podem fornecer insights qualitativos sobre as transições. 


\section{4 - Conclusões}

Neste capítulo, nós combinamos as técnicas desenvolvidas pelo Grupo de Física Molecular e Modelagem (IF-USP) e pelo Nagaoka Laboratory (Nagoya University) para estudar propriedades espectroscópicas de moléculas em solução. Nós aplicamos estas técnicas à molécula pNP e seu ânion. Os resultados precisos permitem-nos discutir o shift solvatocrômico de um ponto de vista atomístico.

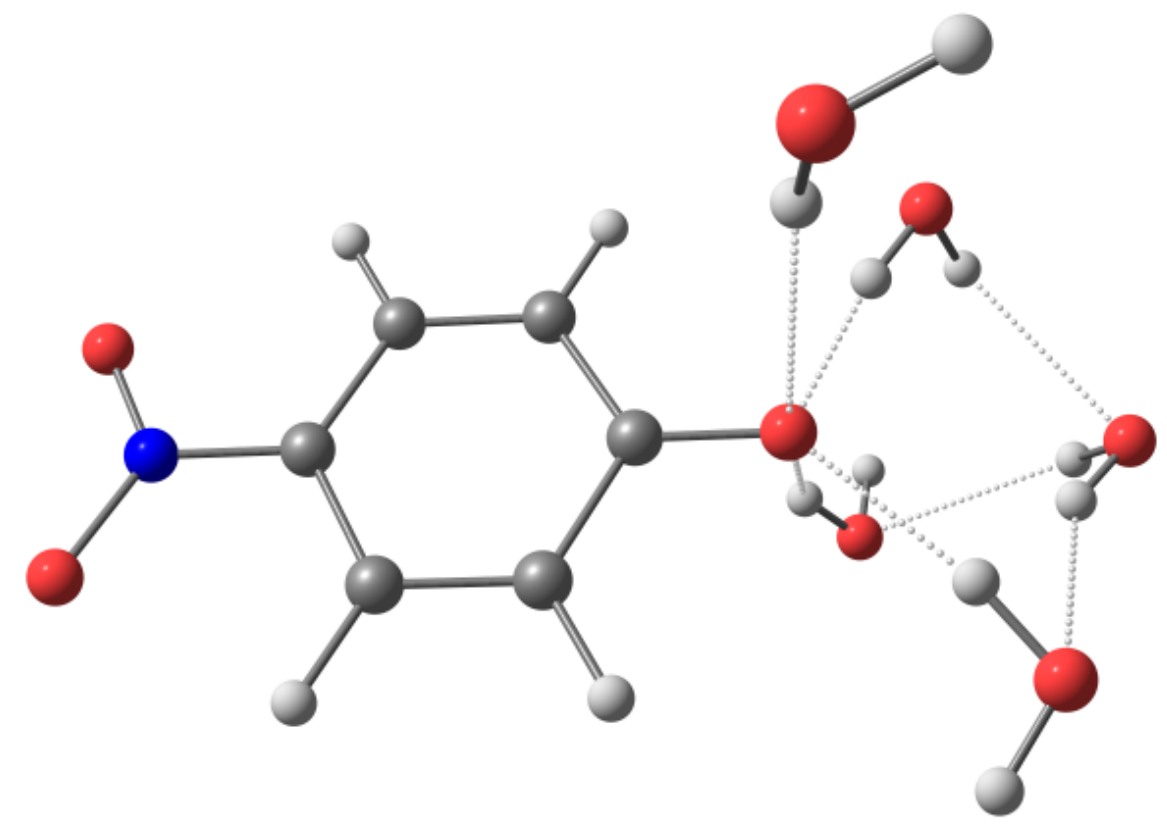

Figura 5.4: Configuração usada no cálculo CASPT2 incluindo solvente explícito. As demais moléculas de água da caixa de simulação foram incluídas como cargas pontuais (omitidas na figura para facilitar a visualização).

Nossos cálculos das transições eletrônicas mostram que para o pNP, a transição de menor energia é dominada pelo orbitais HOMO e LUMO, envolvendo uma migração da densidade de cargas, que passa do anel, no estado fundamental, para o grupo nitro, após a excitação. Assim, uma descrição precisa da geometria desse grupo quando interagindo com o solvente tem papel importante na correta descrição da transição. Tal acurácia na geometria só foi alcançada com o método FEG.

Para a molécula na forma aniônica, a mudança na geometria devido à interação com solvente é dez vezes menor que a observada para a forma neutra. Aqui, interações nãoeletrostáticas entre soluto e solvente no cálculo tanto da transição, como da otimização 
parecem ser mais importantes para a descrição correta do valor energético da transição eletrônica.

Por fim, nós notamos que para o shift entre as transições $\pi-\pi^{*}$ das moléculas pNP e $\mathrm{pNP}^{-}$, a geometria obtida em PCM já fornece um valor adequado, apesar de superestimar as energias de transição. 


\section{Conclusões e Perspectivas}

Neste trabalho nós estudamos efeitos de solvente em espectroscopia eletrônica de absorção e emissão em moléculas orgânicas de interesse. Nosso objetivo era desenvolver um método que permitisse a obtenção da geometria de moléculas do estado excitado em solução através da metodologia S-QM/MM. Esse objetivo foi alcançado ao combinarmos o procedimento de polarização iterativo com o método do Gradiente de Energia Livre, estendendo uma ideia que já havia sido proposta e testada para o estado fundamental. 0 método foi implementado em um programa de computador e aplicado com sucesso para o caso da emissão da molécula uracil em solução aquosa, apresentando resultados coerentes com os observados experimentalmente e fornecendo indicativos de como é a estrutura do estado excitado dessa molécula em meio.

Em colaboração com o grupo que desenvolveu o Gradiente de Energia Livre, nós também aplicamos a metodologia aqui desenvolvida para estudar a absorção da molécula de paranitrofenol e seu ânion, obtendo também bons resultados e permitindo-nos discutir, de um ponto de vista atomístico, a origem do shift solvatocrômico observado experimentalmente.

Assim, temos um caminho aberto para o estudo de processos espectroscópicos onde a influência do meio sobre a estrutura do solvente se faça importante.

Nossa perspectiva a médio prazo é a aplicação da metodologia no estudo de intersecções cônicas. Estados excitados podem ter pontos em comuns em suas superfícies de energia potencial, permitindo decaimentos não-radiativos bastante eficientes, como é conhecido para as bases do DNA ${ }^{9,126,136}$. A obtenção dessas intersecções em solvente é um problema atual do estado da arte. A usual microsolvatação de resultados obtidos em gás aqui não é uma alternativa viável, pois o efeito de solvente é, em geral, diferente em estados de diferente caráter. Muitas vezes isso faz com que a inclusão do solvente faça desaparecer a intersecção cônica obtida em gás. Deste modo, intersecções cônicas em solução só podem ser obtidas se o solvente for incluído durante a busca dessas interseç̧ões. Essa foi a motivação original da criação do Diceplayer e acreditamos que este tipo de estudo seja possível em um futuro breve. 
82 Conclusões e Perspectivas

Carlos Bistafa - IFUSP 2015 


\section{Bibliografia}

1. Lakowicz, J. R. Principles of Fluorescence Spectroscopy. (Springer, 2004).

2. Sobolewski, A. L. \& Domcke, W. Molecular mechanisms of the photostability of life. Phys. Chem. Chem. Phys. 12, 4897-8 (2010).

3. Lim, E. C. Proximity Effect in Molecular Photophysics: Dynamical Consequences of Pseudo-Jahn-Teller Interaction. J. Phys. Chem. 90, 6770-6777 (1986).

4. Santoro, F., Barone, V., Gustavsson, T. \& Improta, R. Solvent effect on the singlet excited-state lifetimes of nucleic acid bases: A computational study of 5-fluorouracil and uracil in acetonitrile and water. J. Am. Chem. Soc. 128, 16312-16322 (2006).

5. Gustavsson, T. et al. Singlet Excited-State Behavior of Uracil and Thymine in Aqueous Solution: A Combined Experimental and Computational Study of 11 Uracil Derivatives. J. Am. Chem. Soc. 128, 607-619 (2006).

6. Gustavsson, T., Sarkar, N., Lazzarotto, E., Markovitsi, D. \& Improta, R. Singlet excited state dynamics of uracil and thymine derivatives: A femtosecond fluorescence upconversion study in acetonitrile. Chem. Phys. Lett. 429, 551-557 (2006).

7. Delchev, V. B., Sobolewski, A. L. \& Domcke, W. Comparison of the non-radiative decay mechanisms of 4-pyrimidinone and uracil: an ab initio study. Phys. Chem. Chem. Phys. 12, 5007-5015 (2010).

8. Nachtigallová, D. et al. The effect of C5 substitution on the photochemistry of uracil. Phys. Chem. Chem. Phys. 12, 4924-4933 (2010).

9. Nachtigallová, D. et al. Nonadiabatic Dynamics of Uracil: Population Split among Different Decay Mechanisms. J. Phys. Chem. A 115, 5247-5255 (2011).

10. Roos, B. O. in Advances in Chemical Physics: Ab Initio Methods in Quantum Chemistry Part 2, Volume 69 (ed. Lawley, K. P.) 399-445 (John Wiley \& Sons, Inc, 1987).

11. Etinski, M. \& Marian, C. M. Ab initio investigation of the methylation and hydration effects on the electronic spectra of uracil and thymine. Phys. Chem. Chem. Phys. 12, 4915-4923 (2010).

12. Szymczak, J. J., Müller, T. \& Lischka, H. The effect of hydration on the photodeactivation pathways of 4-aminopyrimidine. Chem. Phys. 375, 110-117 (2010).

13. Ludwig, V. et al. Photophysics and photostability of adenine in aqueous solution: A theoretical study. Chem. Phys. Lett. 492, 164-169 (2010). 
14. Galván, I. F., Sánchez, M. L., Martín, M. E., Olivares del Valle, F. J. \& Aguilar, M. A. Geometry optimization of molecules in solution: Joint use of the mean field approximation and the free-energy gradient method. J. Chem. Phys. 118, 255 (2003).

15. Galván, I. F., Martín, M. E. \& Aguilar, M. A. A new method to locate saddle points for reactions in solution by using the free-energy gradient method and the mean field approximation. J. Comput. Chem. 25, 1227-1233 (2004).

16. Okuyama-Yoshida, N., Nagaoka, M. \& Yamabe, T. Transition-State Optimization on Free Energy Surface: Toward Solution Chemical Reaction Ergodography. Int. J. Quantum Chem. 70, 95-103 (1998).

17. Okuyama-Yoshida, N., Kataoka, K., Nagaoka, M. \& Yamabe, T. Structure optimization via free energy gradient method: Application to glycine zwitterion in aqueous solution. $J$. Chem. Phys. 113, 3519-3524 (2000).

18. Hirao, H., Nagae, Y. \& Nagaoka, M. Transition-state optimization by the free energy gradient method: Application to aqueous-phase Menshutkin reaction between ammonia and methyl chloride. Chem. Phys. Lett. 348, 350-356 (2001).

19. Nagaoka, M. Structure Optimization of Solute Molecules via Free Energy Gradient Method. Bull. Korean Chem. Soc. 24, 805-808 (2003).

20. Andersson, K., Malmqvist, P.-Å., Roos, B. O., Sadlej, A. J. \& Wolinski, K. Second-Order Perturbation Theory with a CASSCF Reference Function. J. Phys. Chem. 94, 5483-5488 (1990).

21. Coutinho, K., Rivelino, R., Georg, H. C. \& Canuto, S. in Solvation Effects on Molecules and Biomolecules. Computational Methods and Applications (ed. Canuto, S.) 159-189 (Springer, 2008).

22. Georg, H. C., Coutinho, K. \& Canuto, S. Converged electronic polarization of acetone in liquid water and the role in the $n-\pi^{*}$ transition. Chem. Phys. Lett. 429, 119-123 (2006).

23. Georg, H. C., Coutinho, K. \& Canuto, S. Solvent effects on the UV-visible absorption spectrum of benzophenone in water: a combined Monte Carlo quantum mechanics study including solute polarization. J. Chem. Phys. 126, 034507 (2007).

24. Fonseca, T. L., Coutinho, K. \& Canuto, S. Polarization and solvatochromic shift of orthobetaine in water. Chem. Phys. 349, 109-114 (2008).

25. Orozco-González, Y., Coutinho, K. \& Canuto, S. Excited state electronic polarization and reappraisal of the $n \leftarrow \pi *$ emission of acetone in water. Chem. Phys. Lett. 499, 108-112 (2010).

26. Orozco-Gonzalez, Y., Bistafa, C. \& Canuto, S. Solvent Effect on the Stokes Shift and on the Nonfluorescent Decay of the Daidzein Molecular System. J. Phys. Chem. A 117, 4404-4411 (2013). 
27. Georg, H. C. \& Canuto, S. Electronic Properties of Water in Liquid Environment. A Sequential QM/MM Study Using the Free Energy Gradient Method. J. Phys. Chem. B 116, 11247-11254 (2012).

28. Bistafa, C. Efeito de Solvente no Espectro de Absorção da 5-Fluorouracil. Análise de Diferentes Procedimentos Teóricos. (Dissertação de Mestrado - Universidade de São Paulo, 2011).

29. Tapia, O. \& Goscinski, O. Self-Consistent reaction field theory of solvent effects. Mol. Phys. 29, 1653-1661 (1975).

30. Rivail, J.-L. \& Rinaldi, D. A QUANTUM CHEMICAL APPROACH TO DIELECTRIC SOLVENT EFFECTS IN MOLECULAR LIQUIDS. Chem. Phys. 18, 233-242 (1976).

31. Onsager, L. Electric Moments of Molecules in Liquids. J. Am. Chem. Soc. 58, 1486 (1936).

32. Kirkwood, J. G. \& Westheimer, F. H. The Electrostatic Influence of Substituents on the Dissociation Constants of Organic Acids. J. Chem. Phys. 6, 506 (1938).

33. Tomasi, J. Thirty years of continuum solvation chemistry: a review, and prospects for the near future. Theor. Chem. Acc. 112, 184-203 (2004).

34. Cossi, M., Scalmani, G., Rega, N. \& Barone, V. New developments in the polarizable continuum model for quantum mechanical and classical calculations on molecules in solution. J. Chem. Phys. 117, 43 (2002).

35. Senn, H. M. \& Thiel, W. QM/MM Methods for Biomolecular Systems. Angew. Chemie Int. Ed. 48, 1198-1229 (2009).

36. Warshel, A. \& Levitt, M. Theoretical Studies of Enzymic Reactions: Dielectric, Electrostatic and Steric Stabilization of the Carbonium Ion in the Reaction of Lysozyme. J. Mol. Biol. 103, 227-249 (1976).

37. Field, M. J., Bash, P. A. \& Karplus, M. A combined quantum mechanical and molecular mechanical potential for molecular dynamics simulations. J. Comput. Chem. 11, 700733 (1990).

38. Hopmann, K. H. et al. Explicit versus Implicit Solvent Modeling of Raman Optical Activity Spectra. J. Phys. Chem. B 115, 4128-4137 (2011).

39. Canuto, S. \& Coutinho, K. From Hydrogen Bond to Bulk: Solvation Analysis of the $n-\pi^{*}$ Transition of Formaldehyde in Water. Int. J. Quantum Chem. 77, 192-198 (2000).

40. Coutinho, K. \& Canuto, S. Solvent effects in emission spectroscopy: A Monte Carlo quantum mechanics study of the $n-\pi^{*}$ shift of formaldehyde in water. J. Chem. Phys. 113, 9132-9139 (2000).

41. Coutinho, K. \& Canuto, S. DICE, A Monte Carlo program for molecular liquid simulation. Version 2.9 (2010).

42. 
43. Allen, M. P. \& Tildesley, D. J. Computer Simulation of Liquids. (Oxford University Press, 1987).

44. Jorgensen, W. L. \& Tirado-Rives, J. The OPLS Potential Functions for Proteins. Energy Minimizations for Crystals of Cyclic Peptides and Crambin. J. Am. Chem. Soc. 110, 16571666 (1988).

45. Jorgensen, W. L., Chandrasekhar, J., Madura, J. D., Impey, R. W. \& Klein, M. L. Comparison of simple potential functions for simulating liquid water. J. Chem. Phys. 79, 926-935 (1983).

46. Mahoney, M. W. \& Jorgensen, W. L. A five-site model for liquid water and the reproduction of the density anomaly by rigid, nonpolarizable potential functions. J. Chem. Phys. 112, 8910-8922 (2000).

47. Coutinho, K. Modelo Discreto de Solvente. Solvatocromismo no Espectro de Absorção Molecular. (Tese de Doutorado - Universidade de São Paulo, 1997).

48. Pranata, J., Wierschke, S. G. \& Jorgensen, W. L. OPLS Potential Functions for Nucleotide Bases. Relative Association Constants of Hydrogen-Bonded Base Pairs in Chloroform. J. Am. Chem. Soc. 113, 2810-2819 (1991).

49. Jorgensen, W. L., Maxwell, D. S. \& Tirado-Rives, J. Development and Testing of the OPLS All-Atom Force Field on Conformational Energetics and Properties of Organic Liquids. J. Am. Chem. Soc. 118, 11225-11236 (1996).

50. Berendsen, H. J. C., Postma, J. P. M., van Gunsteren, W. F. \& Hermans, J. in Intermolecular Forces (ed. Pullman, B.) 331-338 (D. Reidel Publishing Company, 1981).

51. Manzoni, V. Estudo das Propriedades Espectroscópicas de Moléculas Orgânicas em Solução Utilizando a Combinação do Modelo Contínuo PCM e o Método Sequencial QM/MM. (Tese de Doutorado - Universidade Federal de Alagoas, 2010).

52. Georg, H. C. Efeitos do Meio em Propriedades Conformacionais e Eletrônicas de Moléculas. (Tese de Doutorado - Universidade de São Paulo, 2006).

53. Canuto, S., Coutinho, K. \& Trzesniak, D. New Developments in Monte Carlo/ Quantum Mechanics Methodology . The Solvatochromism of Beta-Carotene in Different Solvents. Adv. Quantum Chem. 41, 161 (2002).

54. Chatfield, C. The Analysis of Time Series. An Introduction. (Chapman \& Hall, 1984).

55. Bistafa, C. \& Canuto, S. Solvent effects on the two lowest-lying singlet excited states of 5-fluorouracil. Theor. Chem. Acc. 132, 1299 (2013).

56. Coutinho, K., Georg, H. C., Fonseca, T. L., Ludwig, V. \& Canuto, S. An efficient statistically converged average configuration for solvent effects. Chem. Phys. Lett. 437, 148-152 (2007).

57. Sanchez, M. L., Aguilar, M. A. \& Del Valle, F. J. O. Study of Solvent Effects by Means of Averaged Solvent Electrostatic Dynamics Data. J. Comput. Chem. 18, 313-322 (1997). 
58. Frenkel, J. Princípios de Eletrodinâmica Clássica. (Edusp, 2005).

59. Georg, H. C. \& Canuto, S. Diceplayer. (2013).

60. Frisch, M. J. et al. Gaussian 03. (2004).

61. Frisch, M. J. et al. Gaussian 09. (2009).

62. Karlström, G. et al. MOLCAS: a program package for computational chemistry. Comput. Mater. Sci. 28, 222-239 (2003).

63. Borin, A. C. in Métodos de Química Teórica e Modelagem Molecular (eds. Morgon, N. H. \& Coutinho, K.) (Livraria da Física Editora, 2007).

64. Merchán, M. \& Serrano-Andrés, L. in Computational Photochemistry (ed. Olivucci, M.) 16, 35-91 (Elsevier B.V., 2005).

65. Roos, B. O. in Radiation Induced Molecular Phenomena in Nucleic Acids (eds. Shukla, M. \& Leszczynski, J.) 125-156 (Springer, 2008).

66. Helgaker, T., Jørgensen, P. \& Olsen, J. Molecular Electronic Structure Theory. (John Wiley \& Sons, 2000).

67. Szabo, A. \& Ostlund, N. S. Modern Quantum Chemistry. (Dover Publications, 1982).

68. Roothaan, C. C. J. New Developments in Molecular Orbital Theory. Rev. Mod. Phys. 23, 69-89 (1951).

69. Roothaan, C. C. J. Self-Consistent Field Theory for Open Shells of Electronic Systems. Rev. Mod. Phys. 32, 179-185 (1960).

70. Löwdin, P.-O. Quantum Theory of Many-Particle Systems. III. Extension of the HartreeFock Scheme to Include Degenerate Systems and Correlation Effects. Phys. Rev. 97, 1509-1520 (1955).

71. Canuto, S. Introdução às Teorias de Muitos Corpos: Correlação Eletrônica em Átomos e Moléculas.

72. Christiansen, O., Olsen, J., Jørgensen, P., Koch, H. \& Malmqvist, P.-Å. On the inherent divergence in the Møller-Plesset series. The neon atom - a test case. Chem. Phys. Lett. 261, 369-378 (1996).

73. Čížek, J. On the Correlation Problem in Atomic and Molecular Systems. Calculation of Wavefunction Components in Ursell-Type Expansion Using Quantum-Field Theoretical Methods. J. Chem. Phys. 45, 4256 (1966).

74. Paldus, J., Čížek, J. \& Shavitt, I. Correlation Problems in Atomic and Molecular Systems. IV. Extended Coupled-Pair Many-Electron Theory and Its Application to the BH3 Molecule. Phys. Rev. A 5, 50-67 (1972).

75. Kümmel, H. Origins of the Coupled Cluster Method. Theor. Chim. Acta 80, 81-89 (1991). 
76. Pople, J. A., Head-Gordon, M. \& Raghavachari, K. Quadratic configuration interaction . A general technique for determining electron correlation energies. J. Chem. Phys. 87, 5968-5975 (1987).

77. Christiansen, O., Koch, H. \& Jørgensen, P. The second-order approximate coupled cluster singles and doubles model CC2. Chem. Phys. Lett. 243, 409-418 (1995).

78. Koch, H., Christiansen, O., Jørgensen, P., Merás, A. M. S. de \& Helgaker, T. The CC3 model: An iterative coupled cluster approach including connected triples. J. Chem. Phys. 106, 1808-1818 (1997).

79. Head-Gordon, M., Rico, R. J., Oumi, M. \& Lee, T. J. A doubles correction to electronic excited states from configuration interaction in the space of single substitutions. Chem. Phys. Lett. 219, 21-29 (1994).

80. Hirata, S., Fan, P.-D., Shiozaki, T. \& Shigeta, Y. in Radiation Induced Molecular Phenomena in Nucleic Acids (eds. Shukla, M. \& Leszczynski, J.) 15-64 (Springer, 2008).

81. Siegbahn, P. E. M., Almlöf, J., Heiberg, A. \& Roos, B. O. The complete active space SCF (CASSCF) method in a Newton-Raphson formulation with application to the HNO molecule. J. Chem. Phys. 74, 2384-2396 (1981).

82. Grein, F. \& Chang, T. C. MULTICONFIGURATION WAVEFUNCTIONS OBTAINED BY APPLICATION OF tHe GeNERALIZED BRILlOUIN THEOREM. Chem. Phys. Lett. 12, 44-48 (1971).

83. Siegbahn, P., Heiberg, A., Roos, B. O. \& Levy, B. A Comparison of the Super-Cl and the Newton-Raphson Scheme in the Complete Active Space SCF Method. Phys. Scr. 21, 323-327 (1980).

84. Malmqvist, P.-Å., Rendell, A. \& Roos, B. O. The Restricted Active Space Self-ConsistentField Method, Implemented with a Split Graph Unitary Group Approach. J. Phys. Chem. 94, 5477-5482 (1990).

85. Andersson, K. \& Roos, B. O. in Modern Eletronic Structure Theory Part I (ed. Yarkony, D. R.) (World Scientific Publishing Co Pte Ltd, 1995).

86. Pulay, P. A Perspective on the CASPT2 Method. Int. J. Quantum Chem. 111, 3273-3279 (2011).

87. Roos, B. O. \& Andersson, K. Multiconfigurational perturbation theory with level shift the Cr 2 potential revisited. Chem. Phys. Lett. 245, 215-223 (1995).

88. Forsberg, N. \& Malmqvist, P.-Å. Multiconfiguration perturbation theory with imaginary level shift. Chem. Phys. Lett. 274, 196-204 (1997).

89. Ghigo, G., Roos, B. O. \& Malmqvist, P.-Å. A modified definition of the zeroth-order Hamiltonian in multiconfigurational perturbation theory (CASPT2). Chem. Phys. Lett. 396, 142-149 (2004). 
90. Werner, H.-J. \& Meyer, W. A quadratically convergent MCSCF method for the simultaneous optimization of several states. J. Chem. Phys. 74, 5794-5801 (1981).

91. Finley, J., Malmqvist, P.-Å., Roos, B. O. \& Serrano-Andrés, L. The multi-state CASPT2 method. Chem. Phys. Lett. 288, 299-306 (1998).

92. Serrano-Andrés, L., Merchán, M. \& Lindh, R. Computation of conical intersections by using perturbation techniques. J. Chem. Phys. 122, 104107 (2005).

93. Veryazov, V., Malmqvist, P.-Å. \& Roos, B. O. How to Select Active Space for Multiconfigurational Quantum Chemistry? Int. J. Quantum Chem. 111, 3329-3338 (2011).

94. Jensen, F. Introduction to Computational Chemistry. (John Wiley \& Sons, 2007).

95. Widmark, P.-O., Malmqvist, P.-Å. \& Roos, B. O. Density matrix averaged atomic natural orbital (ANO) basis sets for correlated molecular wave functions. Theor. Chim. Acta 77, 291-306 (1990).

96. Widmark, P.-O., Persson, B. J. \& Roos, B. O. Density matrix averaged atomic natural orbital (ANO) basis sets for correlated molecular wave functions. Theor. Chim. Acta 79, 419-432 (1991).

97. Fülscher, M. P. \& Roos, B. O. The excited states of pyrazine: A basis set study. Theor. Chim. Acta 87, 403-413 (1994).

98. Merchán, M. \& Roos, B. O. A theoretical determination of the electronic spectrum of formaldehyde. Theor. Chim. Acta 92, 227-239 (1995).

99. Chirlian, L. E. \& Francl, M. M. Atomic charges derived from electrostatic potentials: A detailed study. J. Comput. Chem. 8, 894-905 (1987).

100. Breneman, C. M. \& Wiberg, K. B. Determining Atom-Centered Monopoles from Molecular Electrostatic Potentials. The Need for High Sampling Density in Formamide Conformational Analysis. J. Comput. Chem. 11, 361-373 (1990).

101. Singh, U. C. \& Kollman, P. A. An approach to computing electrostatic charges for molecules. J. Comput. Chem. 5, 129-145 (1984).

102. Chipot, C. \& Ángyán, J. G. GRID Version 3.0: Point Multipoles Derived from electrostatic potentials. Quantum Chem. Progr. Exch. Bull. 14, 4 (1994).

103. Ferré, N. \& Ángyán, J. G. Approximate electrostatic interaction operator for QM / MM calculations. Chem. Phys. Lett. 356, 331-339 (2002).

104. Bagchi, D. et al. Free radicals and grape seed proanthocyanidin extract: importance in human health and disease prevention. Toxicology 148, 187-197 (2000).

105. Serafini, M. et al. Plasma antioxidants from chocolate. Nature 424, 1013 (2003). 
106. Wolfbeis, O. S. \& Schipfer, R. ACIDITY DEPENDENCE OF THE ABSORPTION AND FLUORESCENCE SPECTRA OF ISOFLAVONE AND 7-HYDROXYISOFLAVONE. Photochem. Photobiol. 34, 567-571 (1981).

107. De Rijke, E. et al. Natively fluorescent isoflavones exhibiting anomalous Stokes' shifts. Anal. Chim. Acta 468, 3-11 (2002).

108. Dunford, C. L., Smith, G. J., Swinny, E. E. \& Markham, K. R. The fluorescence and photostabilities of naturally occurring isoflavones. Photochem. Photobiol. Sci. 2, 611 (2003).

109. Beyhan, S. M., Götz, A. W., Ariese, F., Visscher, L. \& Gooijer, C. Computational study on the anomalous fluorescence behavior of isoflavones. J. Phys. Chem. A 115, 1493-1499 (2011).

110. Coutinho, K., Saavedra, N. \& Canuto, S. Theoretical analysis of the hydrogen bond interaction between acetone and water. J. Mol. Struct. 466, 69-75 (1999).

111. Böhm, H. J. \& McDonald, I. R. An effective pair potencial for liquid acetonitrile. Mol. Phys. 49, 347-360 (1983).

112. Heß, B. A., Marian, C. M., Wahlgren, U. \& Gropen, O. A mean-field spin-orbit method applicable to correlated wavefunctions. Chem. Phys. Lett. 251, 365-371 (1996).

113. Malmqvist, P.-Å. \& Roos, B. O. THE CASSCF STATE INTERACTION METHOD. Chem. Phys. Lett. 155, 189-194 (1989).

114. Merchán, M., Serrano-Andrés, L., Robb, M. A. \& Blancafort, L. Triplet-State Formation along the Ultrafast Decay of Excited Singlet Cytosine. J. Am. Chem. Soc. 127, 1820-1825 (2005).

115. Platt, J. R. Classification of Spectra of Cata-Condensed Hydrocarbons. J. Chem. Phys. 17, 484-495 (1949).

116. Kasha, M. CHARACTERIZATION OF ELECTRONIC TRANSITIONS IN COMPLEX MOLECULES. Discuss. Faraday Soc. 9, 14-19 (1950).

117. El-Sayed, M. A. Spin-Orbit Coupling and the Radiationless Processes in Nitrogen Heterocyclics. J. Chem. Phys. 38, 2834-2838 (1963).

118. Turro, N. J. Modern Molecular Photochemistry. (University Science Books, 1991).

119. Gustavsson, T. et al. Solvent Effect on the Singlet Excited-state Dynamics of 5Fluorouracil in Acetonitrile as Compared with Water. J. Phys. Chem. B 110, 1284312847 (2006).

120. Gustavsson, T., Sarkar, N., Bányász, Á., Markovitsi, D. \& Improta, R. Solvent Effects on the Steady-state Absorption and Fluorescence Spectra of Uracil Thymina and 5Fluorouracil. Photochem. Photobiol. 83, 595-599 (2007). 
121. Gustavsson, T., Bányász, Á., Sarkar, N., Markovitsi, D. \& Improta, R. Assessing solvent effects on the singlet excited state lifetime of uracil derivatives: A femtosecond fluorescence upconversion study in alcohols and D2O. Chem. Phys. 350, 186-192 (2008).

122. Lorentzon, J., Fülscher, M. P. \& Roos, B. O. Theoretical Study of the Electronic Spectra of Uracil and Thymine. J. Am. Chem. Soc. 117, 9265-9273 (1995).

123. Improta, R. \& Barone, V. Absorption and fluorescence spectra of uracil in the gas phase and in aqueous solution: a TD-DFT quantum mechanical study. J. Am. Chem. Soc. 126, 14320-14321 (2004).

124. Epifanovsky, E. et al. On the electronically excited states of uracil. J. Phys. Chem. A 112, 9983-9992 (2008).

125. Climent, T., González-Luque, R., Merchán, M. \& Serrano-Andrés, L. On the intrinsic population of the lowest triplet state of uracil. Chem. Phys. Lett. 441, 327-331 (2007).

126. Yamazaki, S. \& Taketsugu, T. Nonradiative Deactivation Mechanisms of Uracil, Thymine, and 5-Fluorouracil: A Comparative ab Initio Study. J. Phys. Chem. A 116, 491-503 (2012).

127. Clark, L. B., Peschel, G. G. \& Tinoco Jr, I. Vapor Spectra and Heats of Vaporization of Some Purine and Pyrimidine Bases. J. Phys. Chem. 69, 3615-3618 (1965).

128. Lan, Z., Fabiano, E. \& Thiel, W. Photoinduced Nonadiabatic Dynamics of Pyrimidine Nucleobases: On-the-Fly Surface-Hopping Study with Semiempirical Methods. J. Phys. Chem. B 113, 3548-3555 (2009).

129. Marian, C. M., Schneider, F., Kleinschmidt, M. \& Tatchen, J. Electronic excitation and singlet-triplet coupling in uracil tautomers and uracil-water complexes. Eur. Phys. J. D 20, 357-367 (2002).

130. Almeida, T. S., Coutinho, K., Cabral, B. J. C. \& Canuto, S. Electronic properties of liquid ammonia: A sequential molecular dynamics/quantum mechanics approach. J. Chem. Phys. 128, 014506 (2008).

131. Gester, R. M., Georg, H. C., Canuto, S., Caputo, M. C. \& Provasi, P. F. NMR Chemical Shielding and Spin-Spin Coupling Constants of Liquid NH3. A Systematic Investigation using the Sequential QM/MM Method. J. Phys. Chem. A 113, 14936-14942 (2009).

132. Adamo, C. \& Barone, V. Toward reliable density functional methods without adjustable parameters: The PBEO model. J. Chem. Phys. 110, 6158-6170 (1999).

133. Fujii, M., Tamura, T., Mikami, N. \& Ito, M. Electronic Spectra of Uracil in a Supersonic Jet. Chem. Phys. Lett. 126, 583-587 (1986).

134. Sprecher, C. A. \& Johnson, W. C. Circular Dichroism of the Nucleic Acid Monomers. Biopolymers 16, 2243-2264 (1977).

135. Ludwig, V., Coutinho, K. \& Canuto, S. A Monte Carlo-quantum mechanics study of the lowest $n-\pi^{*}$ and $\pi-\pi^{*}$ states of uracil in water. Phys. Chem. Chem. Phys. 9, 4907-4912 (2007). 
136. Yoshikawa, A. \& Matsika, S. Excited electronic states and photophysics of uracil-water complexes. Chem. Phys. 347, 393-404 (2008).

137. Matsika, S. Radiationless Decay of Excited States of Uracil through Conical Intersections. J. Phys. Chem. A 108, 7584-7590 (2004).

138. Ando, R. A., Borin, A. C. \& Santos, P. S. Saturation of the Electron-Withdrawing Capability of the NO2 Group in Nitroaromatic Anions: Spectroscopic and QuantumChemical Evidence. J. Phys. Chem. A 111, 7194-7199 (2007).

139. Kirketerp, M.-B. S. et al. Absorption Spectra of 4-Nitrophenolate lons Measured in Vacuo and in Solution. ChemPhysChem 10, 1207-1209 (2009).

140. Abe, T. Electronic Spectra of Polynitrophenols and their Anions. Bull. Chem. Soc. Jpn. 35, 318-322 (1962).

141. Becke, A. D. A new mixing of Hartree-Fock and local density-functional theories. J. Chem. Phys. 98, 1372-1377 (1993).

142. Dunning, T. H. Gaussian basis sets for use in correlated molecular calculations. I. The atoms boron through neon and hydrogen. J. Chem. Phys. 90, 1007 (1989).

143. Nagaoka, M., Nagae, Y., Koyano, Y. \& Oishi, Y. Transition-State Characterization of the Ammonia Ionization Process in Aqueous Solution via the Free-Energy Gradient Method. J. Phys. Chem. A 110, 4555-4563 (2006).

144. Okamoto, T. et al. A Minimal Implementation of the AMBER-GAUSSIAN Interface for Ab Initio QM/MM-MD Simulation. J. Comput. Chem. 32, 932-942 (2011).

145. Case, D. A. et al. AMBER 9. (2006).

146. Humphrey, W., Dalke, A. \& Schulten, K. VMD: Visual Molecular Dynamics. J. Mol. Graph. 14, 33-38 (1996). 


\section{ANEXO A:}

Publicações nas quais este texto foi baseado:

$>$ Solvent effects on the two lowest-lying singlet excited states of 5-fluorouracil Carlos Bistafa \& Sylvio Canuto, Theoretical Chemistry Accounts 132, 1299 (2013)

$>$ Solvent Effect on the Stokes Shift and on the Nonfluorescent Decay of the Daidzein Molecular System

Yoelvis Orozco-Gonzalez, Carlos Bistafa \& Sylvio Canuto, The Journal of Physical Chemistry A 117, 4404 (2013)

$>$ Combining ab initio multiconfigurational and Free Energy Gradient methods to study the $\pi-\pi^{*}$ excited state structure and properties of uracil in water

Carlos Bistafa, Herbert C. Georg \& Sylvio Canuto Computational and Theoretical Chemistry 1040-1041, 312 (2014)

> Paranitrophenol and paranitrophenalate solvatochromic shift. A study combining $a b$ initio multiconfigurational calculations and the Free Energy Gradient method Carlos Bistafa, Yukichi Kitamura, Masataka Nagaoka \& Sylvio Canuto (em preparação) 



\title{
Solvent effects on the two lowest-lying singlet excited states of 5-fluorouracil
}

\author{
Carlos Bistafa $\cdot$ Sylvio Canuto
}

Received: 23 July 2012/ Accepted: 6 November 2012

(C) Springer-Verlag Berlin Heidelberg 2012

\begin{abstract}
Different solvation models based on the sequential-QM/MM methodology are used to investigate the two lowest $n-\pi^{*}$ and $\pi-\pi^{*}$ transitions of 5 -fluorouracil in water and acetonitrile. Electronic polarization of the solute, use of discrete and explicit solvent models and different QM models ranging from semiempirical, timedependent DFT, size-extensive CI and equation of motion are considered. The results show that DFT-based methods provide good results for the energy transitions, but fail to describe the relative energy shifts. Very good and equivalent shifts are obtained using CIS(D) and EOM-CCSD methods combined with the polarizable continuum model solute polarization and discrete solvent description. Our best results give the $\pi-\pi^{*}$ transition lower than the $n-\pi^{*}$ by $0.1 \mathrm{eV}$ in water and, in acetonitrile, place these two states essentially as degenerate in the Franck-Condon region of the ground state. The relative position of these two excited states is of crucial importance for understanding the photophysics of 5-fluorouracil in solvent environment.
\end{abstract}

Keywords Solvent effects - 5-Fluorouracil - Absorption spectrum $\cdot$ Solvatochromic shifts

\section{Introduction}

Recent data of the World Health Organization show that cancer is now among the three main causes of death in the world [1]. One important possible treatment uses 5-fluorouracil (5FU, Fig. 1) because of its great efficiency in two

C. Bistafa $\cdot$ S. Canuto $(\bowtie)$

Instituto de Física, Universidade de São Paulo,

CP 66318, São Paulo, SP 05314-970, Brazil

e-mail: canuto@if.usp.br cytotoxic effects: the RNA falsification and the inhibition of the TYMS enzyme [2]. This has increased the interest for more experimental and theoretical investigations on 5FU. Recent works have experimentally studied the absorption, emission and NMR spectra. Theoretical works have considered the isolated molecule or included the solvent effects using the continuum model [3-6]. In the aftermath of the work of Barone, Improta and coworkers [7], there is considerable interest in the photophysics of 5FU, and one central aspect is the location of the low-lying singlet excited states.

The two lowest-lying singlet excited states of 5FU are of $n-\pi^{*}$ and $\pi-\pi^{*}$ character, respectively. In the gas phase (isolated molecule) the $n-\pi^{*}$ should lie lower than the $\pi-\pi^{*}$ state. As it is normally expected, the solvent effect will blue shift the lowest $n-\pi^{*}$ and red shift the $\pi-\pi^{*}$. Depending on the amount of the shifts, there may be a crossing and thus an inversion of the two states in solvent environment. Indeed, recent theoretical and experimental results suggest that there is such an inversion of the $n-\pi^{*}$ and $\pi-\pi^{*}$ transitions of the $5 \mathrm{FU}$ in solvent environment, compared to the gas phase [7]. Santoro et al. [7] used a cluster model composed of four water molecules within the polarizable continuum model (PCM) [8] to represent the solvent, to investigate $5 \mathrm{FU}$ in water and found evidences for the inversion. In a series of interesting theoretical and experimental studies, Improta and coworkers have analyzed the photophysics of 5FU and also the lifetime of the excited states [9]. The reversal of these two states in water seems clear, but in acetonitrile it is less certain. On the basis of the photochemistry studies, these two states should lie very close in the Franck-Condon region of the ground state, a condition that should be confirmed by high-level calculations.

Inversion of the excited states is known in the DNA bases and was pointed as one of the reasons for the low 


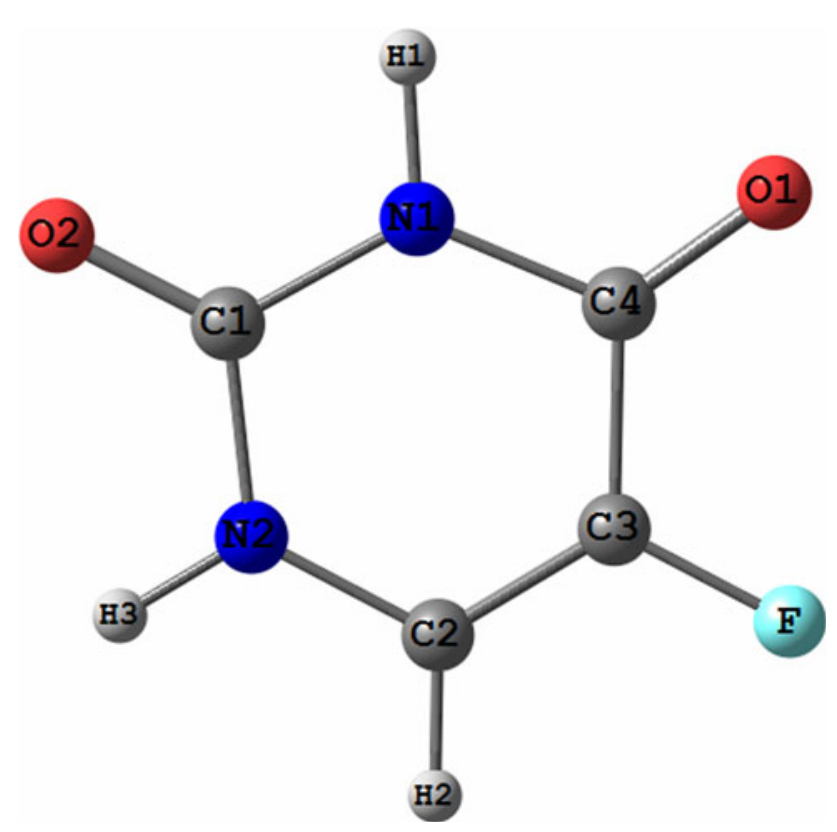

Fig. 1 5-Fluorouracil. Atomic labels are used in Table 1 and along the text

quantum yield presented by these molecules because this inversion would be related to coupling of the near excited states [10] and the existence of conical intersections [7]. Biologically, this is very desirable because the lifetime of the excited states decreases, becoming the order of a few tens or hundreds of femtoseconds [11, 12], drastically reducing the possibility that potentially dangerous photochemical reactions occur [13].

Experimentally, the typical low intensity of $n-\pi^{*}$ transitions makes it difficult to be observed, especially when it is located near or under the intense and broad $\pi-\pi^{*}$ transitions. The observed $\pi-\pi^{*}$ excitation in acetonitrile is located at $4.70 \mathrm{eV}$, whereas this same transition in water lies at $4.66 \mathrm{eV}$ [3]. Thus, the redshift of the $\pi-\pi^{*}$ excitation in water is larger than in acetonitrile by $0.04 \mathrm{eV}$ (i.e., only $300 \mathrm{~cm}^{-1}$ ). The description of this very small shift may be considered a great challenge for the present solvation models. However, this difference is important for understanding the distinct photophysical behavior of $5 \mathrm{FU}$ in acetonitrile and water. Thus, in this work we analyze the performance of different solvation models and the possible inversion of the $n-\pi^{*}$ and $\pi-\pi^{*}$ lowest energy transition of the 5FU in solvent environment. We also consider the relative location of the $\pi-\pi^{*}$ in acetonitrile and water.

Solvent effects are considered using the sequential-QM/ MM methodology [14], where Monte Carlo simulations are made to generate the liquid structure that will be submitted to the quantum mechanical (QM) calculations. Two central aspects are analyzed: (1) the electronic polarization of the solute due to its interaction with the solvent and (2) the corresponding QM model adopted for calculating the excitation energies. We consider two possibilities of including the solute polarization. First, the polarization is obtained using the PCM and, second, the iterative procedure that brings the solute into electrostatic equilibrium with the solvent [15]. Monte Carlo Metropolis simulations were performed to generate statistically uncorrelated configurations to represent the system, on which the QM calculations are performed. For the QM calculations, we select four distinct approaches. First, we consider different DFT models such as B3LYP [16], O3LYP [17], BHandHLYP and PBE0 [18] functionals. The excitation energies are obtained using the time-dependent DFT (TDDFT) approach. Second, we consider size-extensive CIS(D) configuration interaction models [19]. This is a singly excited CI calculation followed by a perturbative doubly excited calculation and has successfully been used in previous studies [20]. Thus, we also report CIS results, although this is normally expected to provide overestimated excitation energies. Third, we consider more sophisticated models such as the equation-of-motion coupled-cluster with single- and double-excitations (EOMCCSD) [21]. Fourth, we also use the semiempirical QM intermediate neglect of differential overlap INDO/CIS model as this allows for consideration of a large number of explicit solvent molecules. The solvent was included using three approaches: (1) continuum model as obtained from PCM, (2) discrete model, where the solvent is treated as simple point charges, and (3) explicit model, where some explicit solvent molecules are used. In this latter case an electrostatic embedding surrounding the explicit solvent molecules is used to account for the long-range bulk effects.

This work thus focuses on the theoretical assessment of the relative location of the two lowest-lying excited states of 5FU in water and acetonitrile and the relative position of the observed $\pi-\pi^{*}$ states in these two solvents.

\section{Computational details}

The 5FU geometry was optimized both isolated and considering the PCM representation of the two solvents, water and acetonitrile. In all cases these optimizations were made using the B3LYP/aug-cc-pVDZ level, using Gaussian 03 [22]. Frequency calculations were performed only to verify that each geometry corresponds to true energy minimum.

The Monte Carlo simulations were made using the Dice Program [23], in the NVT ensemble, at $25{ }^{\circ} \mathrm{C}$ and $1 \mathrm{~atm}$. The system was composed of a solute molecule surrounded by 500 solvent molecules in a cubic box. After a thermalization phase, a total of $10^{8}$ MC steps, or $2 \times 10^{5}$ steps/molecule, were made in the simulation. 
The site-site interaction was treated using Lennard-Jones (LJ) plus Coulomb potential. The 5FU LJ parameters were obtained from the all-atom optimized potentials for liquid simulation (OPLS-AA) force field [24]. The atomic charges were obtained using the CHELPG scheme [25] in the MP2/aug-cc-pVDZ level. The LJ potential for water was the SPC model [26] and, for acetonitrile, the model of Böhm and McDonald [27]. More details on the classical simulations can be found in our previous works [28-31].

To include the solute polarization effect, two methods were used: a computationally non-expensive PCM + MM/ QM approach [15] and a more accurate, but expensive iterative procedure [32]. In the first, we obtain the solute geometry and the charges considering them surrounded by the solvent described by the PCM method, and the resulting atomic charges are directly used in the Coulomb part of the classical potential of the MC simulation. In the second procedure, we first determine the solute geometry and all the atomic charges for the isolate solute molecule and then perform a simulation using these values to generate an average solvent electrostatic configuration (ASEC) [33], which is used to calculate the dipole moment and a new set of charges. This new set is used in a next simulation, repeating the procedure until the convergence of the calculated dipole moment $\mu$, within an accuracy of $\Delta \mu=0.01 \mathrm{D}$.

The absorption electronic transitions were calculated using the time-dependent DFT methods in the exchangecorrelation parameterization adopted by B3LYP, O3LYP, BHandHLYP and PBE0. The reference states for the calculation of the excitation energies are obtained by using the Kohn-Sham approach. In addition, the CIS, CIS(D) and EOM-CCSD are used with Hartree-Fock as the reference state. In all cases we have used the $6-311++\mathrm{G}(\mathrm{d}, \mathrm{p})$ basis set. All these calculations were performed using Gaussian 03 and Gaussian 09 [34]. Because of the large computational demand, only a relatively small number of explicit solvent molecules can be used. For the use of a larger number of solvent molecules, the INDO semiempirical method in the spectroscopic parameterization (INDO/CIS) [35], as implemented in the ZINDO Program [36], was used.

In these calculations, three levels of approach were used to include the solvent: (1) continuum, using the default PCM available in Gaussian 03, which is a computationally inexpensive method, but with difficulties in treating specific interactions. It was noted before that the PCM results on 5FU do not depend on the choice of the cavity radii [7], so we did not consider analysis of the influence of the cavity radius in our study, although it may have some influence in the general case; (2) discrete, where the solvent molecules were represented only by point charges located in their atomic sites. The charges used are the same of the classical simulation. In this case instead of using the ensemble of configurations generated, it is possible to use only one average configuration (ASEC). This has similar computational cost than PCM, but only treats the electrostatic interactions between the solute and the solvent; (3) explicit, where some solvent molecules close to the solute are explicitly included and the remaining solvent molecules are treated as an electrostatic embedding generated by more than 200 molecules. In this third approach, the calculations were carried out over 100 statistically uncorrelated configurations (composed of the reference molecules, the explicit solvent molecules and the electrostatic embedding), and the values of the transition energies and oscillator strength (f) were obtained as an average. The use of a spectral convolution using the calculated transition energies and intensities will also be discussed. In this case the wave function is antisymmetric with respect to the electrons of the solute and the solvent molecules and allows for the exchange and van der Waals interactions.

\section{Results and discussion}

\subsection{Geometry, charges and dipole moment}

We start by discussing the geometry of 5FU. We have considered only the 5FU in the diketo form, which is known to be the most stable form of 5FU, being the only one found in nature [37]. The structures obtained for the isolated gas phase and PCM are very similar, as noted before [38], indicating that the solvent effect in the calculated geometry of 5FU is not very important. Using this structure, we have calculated the atomic charges (using the CHELPG scheme) and the dipole moments (Table 1).

The calculated dipole moment for the isolated molecule, corresponding to the in-vacuum situation, is $3.89 \mathrm{D}$, in reasonable agreement with a previous result of $4.20 \mathrm{D}$ obtained using the same basis set and the B3PW91 functional [38]. Apparently, the experimental gas-phase dipole moment of 5FU has not been reported. These values are, however, not much different from the experimental value of uracil (3.87 D) [39]. This is simply because the charge in fluorine for $5 \mathrm{FU}$ is similar to the value obtained for the corresponding hydrogen atom in the case of uracil [38]. Table 1 summarizes the influence of the solute polarization on the dipole moment. In the case of water as the solvent, we obtain the dipole moments of 5FU as 5.92 D and 6.29 D in the PCM and iterative polarizations, respectively. Using the gas-phase geometry, the dipole moments considering the PCM polarization are calculated as 5.57 D and 5.52 D for $5 \mathrm{FU}$ in water and in acetonitrile, respectively. Relaxing the geometry, these corresponding numbers are 5.92 D and $5.85 \mathrm{D}$, respectively. In the iterative procedure, the calculated dipole moment in water increases to $6.29 \mathrm{D}$, whereas the value in acetonitrile decreases to $5.10 \mathrm{D}$. The dipole 
Table 1 Atomic charges (e) and dipole moments (Debye) of 5-fluorouracil in gas phase, in water and in acetonitrile (parenthesis), calculated in the MP2/aug-cc-pVDZ level

\begin{tabular}{lcccc}
\hline Atom & Gas & PCM & PCM/PCM & Iterative \\
\hline $\mathrm{N} 1$ & -0.6469 & $-0.6911(-0.6910)$ & $-0.7018(-0.7029)$ & $-0.7738(-0.6882)$ \\
$\mathrm{C} 1$ & 0.7933 & $0.8741(0.8726)$ & $0.8886(0.8874)$ & $0.9881(0.8404)$ \\
$\mathrm{N} 2$ & $-0.5603(-0.5596)$ & $-0.5613(-0.5613)$ & $-0.6215(-0.5536)$ \\
$\mathrm{C} 2$ & $0.0488(0.0473)$ & $0.0689(0.0674)$ & $0.1206(0.0611)$ \\
$\mathrm{C} 3$ & -0.5238 & $0.0045(0.0054)$ & $-0.0110(-0.0106)$ & $-0.0404(-0.0006)$ \\
$\mathrm{C} 4$ & 0.0077 & $0.7688(0.7666)$ & $0.7886(0.7871)$ & $0.8722(0.7415)$ \\
$\mathrm{H} 1$ & 0.0349 & $0.4263(0.4247)$ & $0.4357(0.4340)$ & $0.4720(0.4148)$ \\
$\mathrm{O} 1$ & 0.6965 & $-0.6267(-0.6229)$ & $-0.6471(-0.6424)$ & $-0.7233(-0.5848)$ \\
$\mathrm{F}$ & 0.3672 & $-0.2017(-0.2006)$ & $-0.2056(-0.2042)$ & $-0.1797(-0.1949)$ \\
$\mathrm{H} 2$ & -0.5112 & $0.2134(0.2125)$ & $0.2110(0.2100)$ & $0.1964(0.1909)$ \\
$\mathrm{H} 3$ & -0.1746 & $0.4233(0.4218)$ & $0.4292(0.4274)$ & $0.4587(0.4096)$ \\
O2 & 0.1744 & $-0.6796(-0.6768)$ & $-0.6952(-0.6919)$ & $-0.7695(-0.6361)$ \\
$\mu$ & 0.3551 & $5.57(5.52)$ & $5.92(5.85)$ & $6.29 \pm 0.03^{\mathrm{b}}(5.10 \pm 0.02)^{\mathrm{b}, \mathrm{c}}$ \\
\hline
\end{tabular}

a This means the geometry and the charges were obtained considering the solute involved in PCM

b These values were obtained adjusting an exponential plus a constant function to the data (see Fig. 2)

${ }^{c}$ Obtained value starting the iterative process using the gas-phase value. Using PCM as starting point gives the same value

moment of $5 \mathrm{FU}$ is expected to be larger in water than in acetonitrile. This feature is well reproduced by the iterative method that gives the dipole moment in water larger than in acetonitrile by $1.19 \mathrm{D}$. In the case of the PCM polarization, these values are very close, differing only in $0.07 \mathrm{D}$.

Figure 2 shows the calculated results using the iterative procedure. For water, the PCM results for the insolvent dipole moment represent ca. $90 \%$ of the converged iterative value, as we have also seen in previous applications. However, in the case of acetonitrile, the PCM result is larger than the iterative value. As it can be seen, the iterative result is the same whether it starts from the isolated or the PCM results. However, it is unexpected that the PCM dipole moment value is so large for acetonitrile. In the next section we discuss how these different polarizations affect the transition energies.

\subsection{Lowest electronic transitions of 5-fluorouracil} in solvent environment

For reference, Table 2 shows the results obtained using the different theoretical models for the isolated molecule, corresponding to the case of a low-density gas. All theoretical models agree that the $n-\pi^{*}$ transition is lower than the $\pi-\pi^{*}$ transition. Next, Tables 3 and 4 summarize the results for the calculated transition energies in water and acetonitrile, respectively, using different QM methods. Only the two lowest transitions representing the $n-\pi^{*}$ and $\pi-\pi^{*}$ are presented. The $n-\pi^{*}$ transition is dominated by the $\operatorname{HOMO}-1(n) \rightarrow \operatorname{LUMO}(\pi)$ promotion, whereas the $\pi-\pi^{*}$ is dominated by the $\operatorname{HOMO}(\pi) \rightarrow \operatorname{LUMO}(\pi)$. The Kohn-Sham (KS) orbitals obtained in the B3LYP/6$311++G(d, p)$ level are shown in Fig. 3. They are very similar to that obtained with Hartree-Fock (HF). The delocalization of the orbitals when $5 \mathrm{FU}$ is in aqueous solution is seen, but it is less pronounced when the solvent is acetonitrile. This picture is obtained in both methodologies, KS and HF orbitals.

We will focus first on the $\pi-\pi^{*}$ transition of $5 \mathrm{FU}$ in water (Table 3), as it is experimentally observed. We first present the results obtained using the B3LYP functional and different treatments of the solvent, starting with PCM and improving until the explicit use of sixteen water molecules. Using the PCM polarization, the best agreement with experiment for the excitation energy using B3LYP is $4.79 \mathrm{eV}$. This value is an average over 100 configurations, where the solvent is represented by 16 explicit water molecules and an electrostatic embedding composed of the atomic charges of 238 water molecules. The value is equivalent to that of $4.80 \mathrm{eV}$ obtained using the iterative polarization (shown in parenthesis) and slightly larger than the experimental result with a band maximum at $4.66 \mathrm{eV}$ [3]. The PCM overestimates the transition energy, and the results improve by adding explicit water molecules. As noted before [40], the use of the electrostatic embedding is very important in accelerating the convergence with respect to the number of explicit solvent molecules used.

A single vertical excitation may not represent the absorption maximum observed. A more realistic way of obtaining the transition energies when dealing with a 

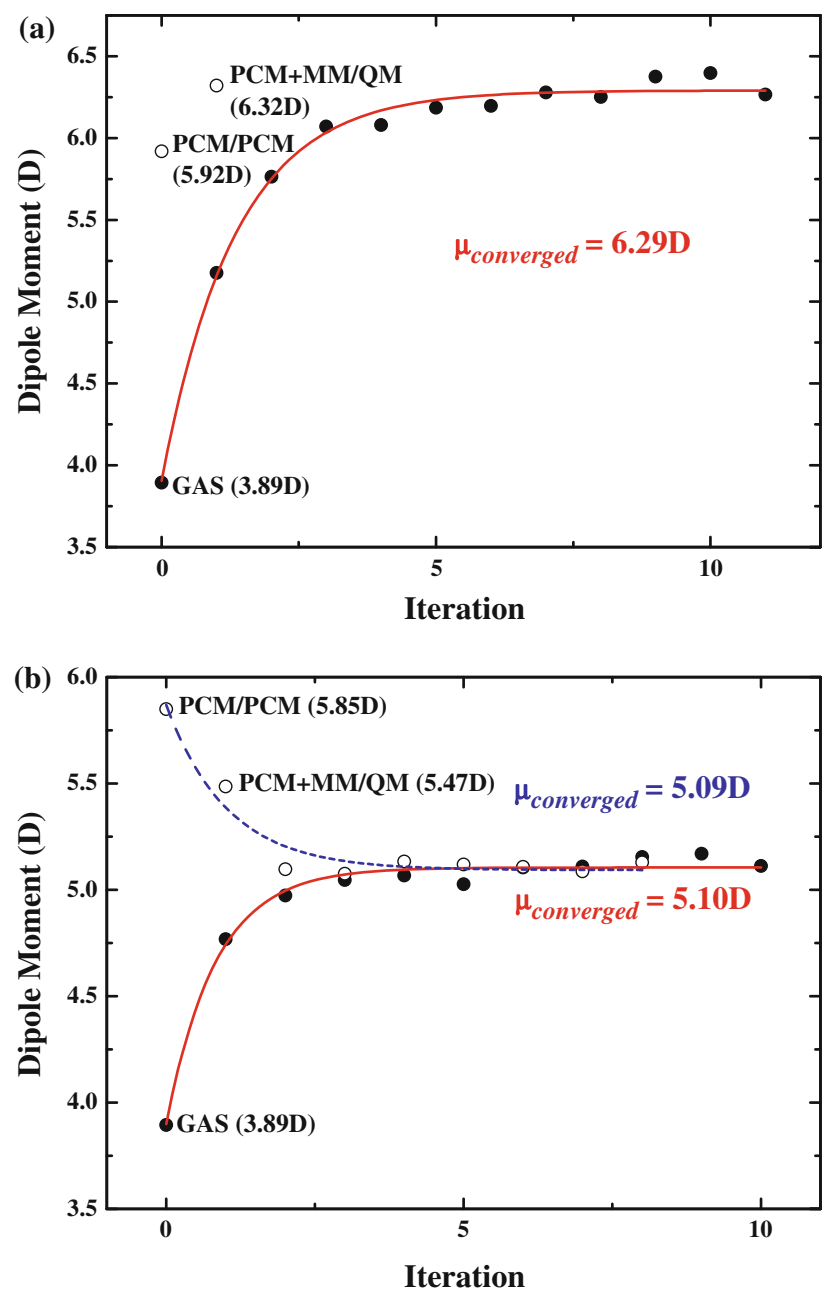

Fig. 2 Converged dipole moment of 5FU in a water and $\mathbf{b}$ acetonitrile, obtained using an iterative procedure. "GAS" indicates that the dipole moment was obtained using the optimized geometry of isolated 5FU; "PCM/PCM" indicates that dipole moment was calculated considering the solvent effect in this approach in a geometry optimized also in this approach; in "PCM + MM/QM," dipole moment is calculated using the ASEC generated after a Monte Carlo simulation which uses the values obtained in "PCM/PCM" as starting point. The converged dipole moment values were obtained by a fitting procedure

sample of configurations is by convoluting the results to obtain the spectral shape and include the inhomogeneous broadening due to the structural fluctuations, as we have done before [41]. However, in the present case, we obtained the same results. As we have an intense $\left(\pi-\pi^{*}\right)$ band near the weak $\left(n-\pi^{*}\right)$ transition, the Lorentzian convolution produced a broad $\pi-\pi^{*}$ and a weak $n-\pi^{*}$ bands, but with the two maxima corresponding to the average values.

The result of $4.42 \mathrm{eV}$, obtained using seven molecules (corresponding to the number of molecules in the microsolvation shell, using a minimum-distance distribution
Table 2 The two lowest electronic transitions of isolated 5-fluorouracil using the geometry optimized with the B3LYP/aug-cc-pVDZ level

\begin{tabular}{llllll}
\hline QM method & \multicolumn{2}{l}{$n-\pi^{*}$} & & \multicolumn{2}{l}{$\pi-\pi^{*}$} \\
\cline { 2 - 3 } & $\mathrm{E}(\mathrm{eV})$ & $f$ & & $\mathrm{E}(\mathrm{eV})$ & $f$ \\
\hline B3LYP & 4.67 & 0.000 & 4.88 & 0.125 \\
O3LYP & 4.33 & 0.000 & 4.69 & 0.096 \\
PBE0 & 4.65 & 0.000 & 4.95 & 0.137 \\
BHandHLYP & 5.16 & 0.000 & 5.36 & 0.219 \\
CIS & 6.12 & 0.000 & 6.26 & 0.448 \\
CIS(D) & 4.82 & 0.000 & 5.36 & 0.448 \\
EOM-CCSD & 5.14 & 0.000 & 5.50 & 0.218 \\
INDO/CIS & 3.99 & 0.001 & 5.20 & 0.438 \\
\hline
\end{tabular}

$f$ is the calculated oscillator strength (dimensionless)

function) [42], underestimates the experimental value. Adding the electrostatic embedding, the result increases to $4.82 \mathrm{eV}$, close to the value that is converged with respect to the number of solvent molecules included. Figure 4 illustrates one of the configurations with 16 explicit water molecules in the electrostatic embedding composed of 238 water molecules. The result obtained with ASEC corresponds to the sole inclusion of the electrostatic interaction between 5FU and the solvent. Comparing this with the converged result obtained with explicit solvent indicates a decrease of $0.1 \mathrm{eV}$ when using explicit solvent molecules. This value is relatively small, and the explicit use of solvent molecule will not be considered in the more expensive ab initio methods. As expected, CIS gives a value for the excitation energy that is too large. Using only the electrostatic interaction, the values obtained with CIS(D) and EOM-CCSD are equivalent and slightly larger than the experimental value. This indicates that the essential contributions of the double excitations are obtained in loworder perturbation theory. Assuming the correction of $\sim 0.1 \mathrm{eV}$ for the contribution of the explicit solvent molecules still indicates that these values are overestimated by ca. $0.5 \mathrm{eV}$. The results for the $n-\pi^{*}$ transition are also shown in Table 3, but the experimental location of this transition is uncertain [3]. It should be noted that except for the $5 \mathrm{FU}+7 \mathrm{H}_{2} \mathrm{O}$ and INDO/CIS results, all theoretical models now agree that the $\pi-\pi^{*}$ transition is lower than the $n-\pi^{*}$ transition. The INDO/CIS calculation includes 150 explicit $\mathrm{H}_{2} \mathrm{O}$ molecules, corresponding to including all solvent molecules within a distance of $8 \AA$ from the center of mass of 5FU. In all cases, as expected, the $n-\pi^{*}$ transition blue shifts compared to the isolated case, whereas the $\pi-\pi^{*}$ transition red shifts. This is also the case in the INDO/CIS, where the two shifts have the correct sign, but quantitatively are not enough to promote the reversal of the two excited states. This failure has also been noted in the 


\section{$5 F U$ in gas phase}

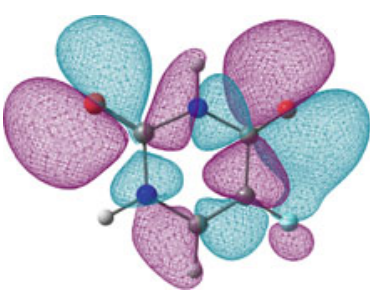

HOMO-1 (n)

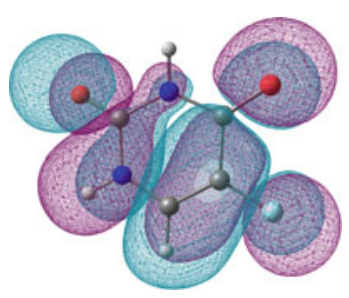

HOMO $(\pi)$

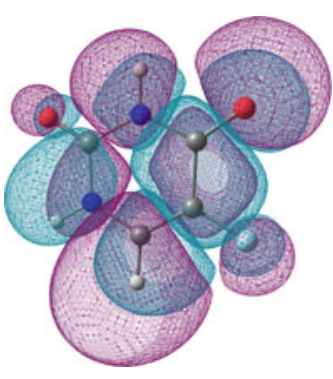

$\operatorname{LUMO}(\pi)$

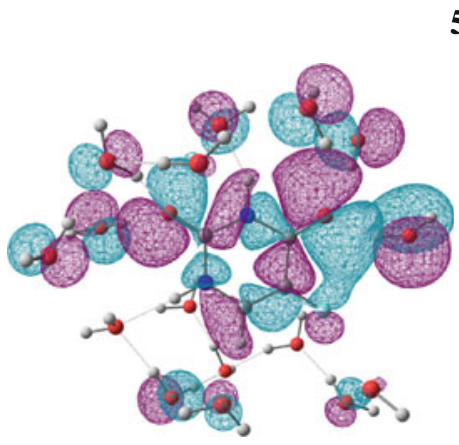

$5 \mathrm{FU}+16 \mathrm{H}_{2} \mathrm{O}+247 \mathrm{H}_{2} \mathrm{O}$ (p.c.)

HOMO-1 (n)
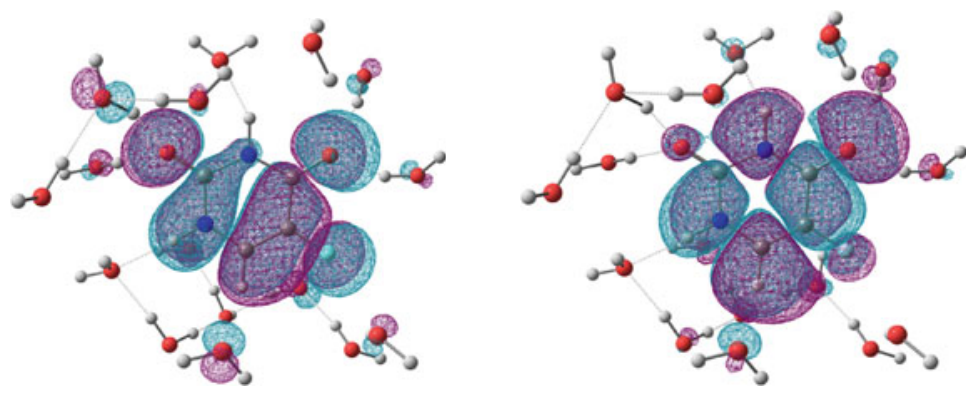

$\operatorname{HOMO}(\pi)$

LUMO ( $\pi)$

\section{$5 \mathrm{FU}+8 \mathrm{CH}_{3} \mathrm{CN}+246 \mathrm{CH}_{3} \mathrm{CN}$ (c.p.)}

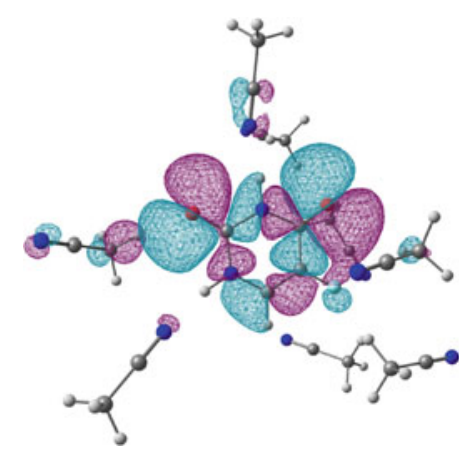

HOMO-1 (n)

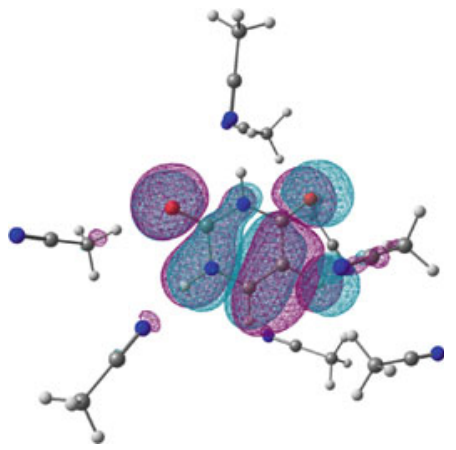

$\operatorname{HOMO}(\pi)$

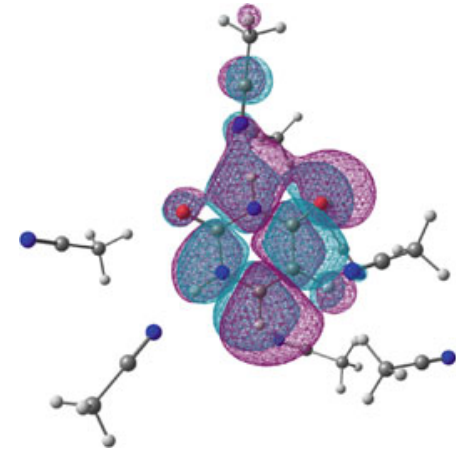

$\operatorname{LUMO}(\pi)$

Fig. 3 The 5FU Kohn-Sham orbitals involved in the lowest transitions in gas phase (top) and a configuration in each solvent: water (medium) and acetonitrile (bottom). The B3LYP/6-311++G(d,p) level of calculation was used

case of uracil [43] and should be traced to the original parameterization.

Now, we analyze the case of acetonitrile as the solvent (Table 4). The theoretical results are obtained in a similar manner as in the case of water. Again, the explicit use of all solvent molecules within a distance of $8 \AA$ is used in the INDO/CIS case. The experimental result locates the $\pi-\pi^{*}$ band maximum at $4.70 \mathrm{eV}$, separated from the same band in water by only $0.04 \mathrm{eV}$ (corresponding to $300 \mathrm{~cm}^{-1}$ or $2 \mathrm{~nm}$ in the band maximum) [3]. As expected, the experimental redshift of the $\pi-\pi^{*}$ transition is larger in water than in acetonitrile, though the difference is very small. Qualitatively, one can note that some theoretical methods fail in this aspect. The PCM method is not able to distinguish the two solvents giving the $\pi-\pi^{*}$ transition of $5 F U$ located at $4.81 \mathrm{eV}$ for the two solvents. This has been noted before [7] and justified the use of some explicit solvent molecules. In general, all DFT-based methods also fail in giving the relative location of the $\pi-\pi^{*}$ transition of $5 \mathrm{FU}$ in water and acetonitrile. Interestingly, this is the case 
Table 3 The two lowest electronic transitions of 5-fluorouracil in water
The results obtained using explicit solvent molecules are converged averages over 100 statistically uncorrelated configurations (the statistical error is less than the decimal presented). ASEC is an average electrostatic configuration. Results in parenthesis correspond to the iterative polarization. Except for the INDO/CIS, all results were obtained using the $6-311++\mathrm{G}(\mathrm{d}, \mathrm{p})$ basis set. $f$ is the calculated oscillator strength (dimensionless)

\begin{tabular}{|c|c|c|c|c|c|}
\hline \multirow[t]{2}{*}{ QM method } & \multirow[t]{2}{*}{ Solvent model } & \multicolumn{2}{|l|}{$\pi-\pi^{*}$} & \multicolumn{2}{|l|}{$n-\pi^{*}$} \\
\hline & & $E(\mathrm{eV})$ & $f$ & $E(\mathrm{eV})$ & $f$ \\
\hline B3LYP & PCM & 4.81 & 0.176 & 4.99 & 0.000 \\
\hline B3LYP & ASEC & $4.88(4.90)$ & $0.139(0.140)$ & $5.10(5.30)$ & $0.000(0.000)$ \\
\hline B3LYP & $5 \mathrm{FU}+07 \mathrm{H}_{2} \mathrm{O}$ & 4.42 & 0.034 & 4.40 & 0.003 \\
\hline B3LYP & $\begin{array}{l}5 \mathrm{FU}+07 \mathrm{H}_{2} \mathrm{O}+247 \mathrm{H}_{2} \mathrm{O} \\
\quad \text { (p.c.) }\end{array}$ & 4.82 & 0.164 & 5.07 & 0.003 \\
\hline B3LYP & $\begin{array}{l}5 \mathrm{FU}+10 \mathrm{H}_{2} \mathrm{O}+244 \mathrm{H}_{2} \mathrm{O} \\
\text { (p.c.) }\end{array}$ & 4.81 & 0.164 & 5.07 & 0.003 \\
\hline B3LYP & $\begin{array}{l}5 \mathrm{FU}+12 \mathrm{H}_{2} \mathrm{O}+242 \mathrm{H}_{2} \mathrm{O} \\
\quad \text { (p.c.) }\end{array}$ & 4.80 & 0.161 & 5.05 & 0.004 \\
\hline B3LYP & $\begin{array}{l}5 \mathrm{FU}+14 \mathrm{H}_{2} \mathrm{O}+240 \mathrm{H}_{2} \mathrm{O} \\
\quad \text { (p.c.) }\end{array}$ & 4.79 & 0.156 & 5.05 & 0.004 \\
\hline B3LYP & $\begin{array}{l}5 \mathrm{FU}+16 \mathrm{H}_{2} \mathrm{O}+238 \mathrm{H}_{2} \mathrm{O} \\
\quad \text { (p.c.) }\end{array}$ & $4.79(4.80)$ & $0.154(0.156)$ & $5.04(5.14)$ & $0.004(0.006)$ \\
\hline PBE0 & ASEC & $4.99(5.00)$ & $0.151(0.152)$ & $5.22(5.43)$ & $0.000(0.000)$ \\
\hline BHandHLYP & ASEC & $5.37(5.38)$ & $0.218(0.215)$ & $5.77(5.96)$ & $0.000(0.000)$ \\
\hline O3LYP & ASEC & $4.76(4.79)$ & $0.117(0.121)$ & $4.90(5.12)$ & $0.000(0.000)$ \\
\hline CIS & ASEC & $6.25(6.28)$ & $0.418(0.409)$ & $6.82(6.96)$ & $0.000(0.000)$ \\
\hline CIS(D) & ASEC & $5.18(5.19)$ & $0.418(0.409)$ & $5.32(5.55)$ & $0.000(0.000)$ \\
\hline EOM-CCSD & ASEC & $5.29(5.30)$ & $0.226(0.220)$ & $5.56(5.76)$ & $0.000(0.000)$ \\
\hline INDO/CIS & $5 \mathrm{FU}+150 \mathrm{H}_{2} \mathrm{O}$ & 5.05 & 0.441 & 4.40 & 0.003 \\
\hline Exp. [3] & & 4.66 & - & - & - \\
\hline
\end{tabular}

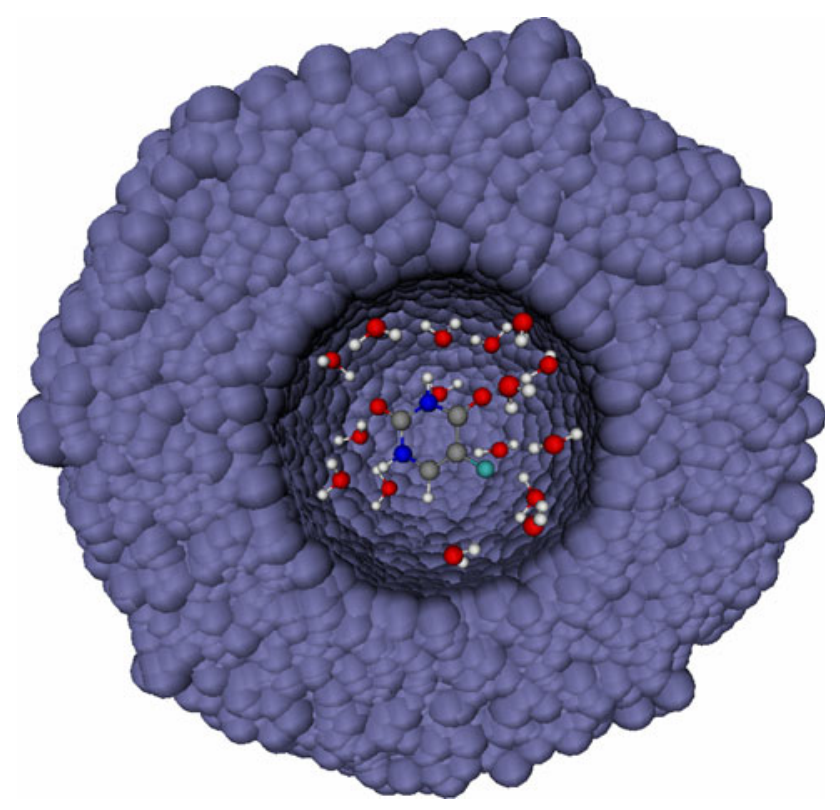

Fig. 4 One of the configurations used in the quantum mechanical calculations. The illustration shows 5FU and 16 explicit water molecules embedded in the electrostatic field of 238 remaining water molecules represented by simple point charges on the atomic positions

even when using the explicit solvent molecules of the first solvation shell in the electrostatic embedding of the remaining solvent molecules. Indeed, the B3LYP result of $4.77 \mathrm{eV}$ for $5 \mathrm{FU}+8 \mathrm{CH}_{3} \mathrm{CN}+246 \mathrm{CH}_{3} \mathrm{CN}(\mathrm{pc})$ is lower in energy than the corresponding result for $5 \mathrm{FU}+7$ $\mathrm{H}_{2} \mathrm{O}+247 \quad \mathrm{H}_{2} \mathrm{O}(\mathrm{pc})$ or even $5 \mathrm{FU}+16 \quad \mathrm{H}_{2} \mathrm{O}+238$ $\mathrm{H}_{2} \mathrm{O}(\mathrm{pc})$. The INDO/CIS method with a large number of explicit solvent molecules correctly describes the qualitative positioning of the $\pi-\pi^{*}$ transition in water and acetonitrile. However, the magnitude of separation of this band in the two solvents is too large. As in the case of water, comparing the result for B3LYP using only the electrostatic solute-solvent interaction with the use of explicit solvent molecules gives an estimate of the contribution of the explicit molecules of $\sim 0.1 \mathrm{eV}$. Using only the electrostatic solute-solvent (ASEC), all CI-based and the EOM-CCSD methods correctly obtain the $\pi-\pi^{*}$ transition of $5 \mathrm{FU}$ in acetonitrile located higher in energy than in water. Table 5 summarizes the situation. The results indicate that within the approximations used here, common to several studies of solvent effects in spectroscopy, the CIS(D) and EOM-CCSD perform very well and give equivalent results. Although the individual transition energies are slightly larger than in experiment, the relative location of the $\pi-\pi^{*}$ transition is well described. Also, it can be noted that the PCM polarization used in the CIS(D) and EOM-CCSD gives the relative location with better precision, whereas the iterative polarization leads to an overestimation. There are different possibilities for this. One is that the iterative procedure may overpolarize the solute $[44,45]$. Indeed, this has been analyzed before and may require the reconsideration of the $\mathrm{LJ}$ parameters for 
Table 4 The two lowest electronic transitions of 5-fluorouracil in acetonitrile

The results obtained using explicit solvent molecules are converged averages over 100 statistically uncorrelated configurations (the statistical error is less than the decimal presented). ASEC is an average configuration. Results in parenthesis correspond to the iterative polarization. Except for INDO/CIS, the results were obtained using the 6-311++G(d,p) basis set. $f$ is the calculated oscillator strength (dimensionless)

\begin{tabular}{|c|c|c|c|c|c|}
\hline \multirow[t]{2}{*}{ QM method } & \multirow[t]{2}{*}{ Solvent model } & \multicolumn{2}{|l|}{$\pi-\pi^{*}$} & \multicolumn{2}{|l|}{$n-\pi^{*}$} \\
\hline & & $E(\mathrm{eV})$ & $f$ & $E(\mathrm{eV})$ & $f$ \\
\hline B3LYP & PCM & 4.81 & 0.177 & 4.98 & 0.000 \\
\hline B3LYP & ASEC & $4.84(4.89)$ & $0.128(0.132)$ & $4.83(4.92)$ & $0.001(0.000)$ \\
\hline B3LYP & $\begin{array}{l}5 \mathrm{FU}+08 \mathrm{CH}_{3} \mathrm{CN} \\
\quad+246 \mathrm{CH}_{3} \mathrm{CN} \text { (p.c.) }\end{array}$ & $4.77(4.79)$ & $0.152(0.148)$ & $4.84(4.92)$ & $0.003(0.010)$ \\
\hline PBE0 & ASEC & $4.95(5.00)$ & $0.139(0.145)$ & $4.95(5.05)$ & $0.002(0.000)$ \\
\hline BHandHLYP & ASEC & $5.36(5.40)$ & $0.217(0.217)$ & $5.48(5.55)$ & $0.000(0.000)$ \\
\hline O3LYP & ASEC & $4.71(4.76)$ & $0.106(0.110)$ & $4.62(4.74)$ & $0.000(0.000)$ \\
\hline CIS & ASEC & $6.26(6.30)$ & $0.431(0.428)$ & $6.49(6.51)$ & $0.000(0.000)$ \\
\hline CIS(D) & ASEC & $5.22(5.29)$ & $0.431(0.428)$ & $5.09(5.21)$ & $0.000(0.000)$ \\
\hline EOM-CCSD & ASEC & $5.33(5.38)$ & $0.223(0.218)$ & $5.29(5.38)$ & $0.000(0.004)$ \\
\hline INDO/CIS & $5 \mathrm{FU}+63 \mathrm{CH}_{3} \mathrm{CN}$ & 5.23 & 0.502 & 4.87 & 0.002 \\
\hline Exp. [3] & & 4.70 & - & - & - \\
\hline
\end{tabular}

Table 5 Difference between the energy of $5 \mathrm{FU} \pi-\pi^{*}$ transition in water and in acetonitrile

\begin{tabular}{lll}
\hline QM method & Solvent model & $E_{\text {acet }}-E_{\text {water }}(\mathrm{eV})$ \\
\hline B3LYP & PCM & 0.00 \\
B3LYP & ASEC & $-0.04(-0.01)$ \\
B3LYP & Explicit $+(\text { p.c. })^{\mathrm{a}}$ & $-0.02(0.00)$ \\
PBE0 & ASEC & $-0.03(-0.01)$ \\
BHandHLYP & ASEC & $-0.01(0.02)$ \\
O3LYP & ASEC & $-0.05(-0.03)$ \\
CIS & ASEC & $0.00(0.03)$ \\
CIS(D) & ASEC & $0.04(0.10)$ \\
EOM-CCSD & ASEC & $0.04(0.08)$ \\
INDO/CIS & Explicit & 0.19 \\
Exp. [3] & & 0.04 \\
\hline
\end{tabular}

Values in parenthesis mean that the solute was polarized using an iterative procedure

a Statistical error in this case is $0.01 \mathrm{eV}$

better results $[44,45]$. Also, the present procedure considers only the polarization of the solute due to the solvent, assuming that the reversal is small. In the same vein, the geometry relaxation of the solute is assumed to lead to a negligible effect on the spectral transitions.

We now consider, in some more detail, the position of the unobserved $n-\pi^{*}$ transition in water and in acetonitrile. Theoretical considerations [7] along with consequences of the photophysical properties [9] indicate that the $\pi-\pi^{*}$ and $n-\pi^{*}$ transitions are reversed in water compared to the isolated condition. This is simple to understand on the basis of the redshift of the $\pi-\pi^{*}$ and blueshift of the $n-\pi^{*}$ transitions. Most theoretical models (Table 3) agree that in water the intense $\pi-\pi^{*}$ excited state of 5FU is lower than the dark $n-\pi^{*}$ state. The situation is less clear in acetonitrile. Experiments indicate that the fluorescence spectrum of 5FU in acetonitrile is much broader than in water [46] and the decay in acetonitrile is thus much faster. Experimental and theoretical works by Improta and coworkers [9] have shown that a decay channel is available for $5 \mathrm{FU}$ involving the dark $n-\pi^{*}$ state. One outcome of these investigations is that the $\pi-\pi^{*}$ and $n-\pi^{*}$ excited states are very close in energy in the FranckCondon region and then they cross in the path for the minimum of the $\pi-\pi^{*}$ state. The present theoretical results reflect this aspect. Table 4 shows that some theoretical methods still obtain the $n-\pi^{*}$ located lower but close to the $\pi-\pi^{*}$ state in the Franck-Condon region of the ground state. This is the case for the CIS(D) and EOM-CCSD. The PBE0/ASEC gives the same result, and the BHandHLYP reverses, giving the $\pi-\pi^{*}$ state lower. The INDO/CIS even including 63 explicit acetonitrile solvent molecules also gives the $n-\pi^{*}$ state lower. Consideration of the results obtained with B3LYP with and without explicit solvent molecules indicates that the delocalization of the wave function over the solvent region is more important for the $\pi-\pi^{*}$ state than for the $n-\pi^{*}$. Table 4 indicates, by comparing the results obtained with the B3LYP/ASEC and the B3LYP/ $5 \mathrm{FU}+8 \mathrm{CH}_{3} \mathrm{CN}+246 \mathrm{CH}_{3} \mathrm{CN}(\mathrm{pc})$, that this delocalization decreases the excitation energy of the $\pi-\pi^{*}$ state by $\sim 0.1 \mathrm{eV}$, but is immaterial for the $n-\pi^{*}$ state. The nonelectrostatic interactions thus play an important role in $\pi-\pi^{*}$ transition. Hence, we also calculated the transition energies of $5 \mathrm{FU}$ in acetonitrile using $\mathrm{CIS}(\mathrm{D}) / 6-311++\mathrm{G}(\mathrm{d}, \mathrm{p})$ and gradually increasing the number of explicit solvent molecules (Table 6). For this calculation we used only one representative configuration, since the CIS(D) method requires a very high computational demand. The results in Table 6 show that for the energy of the $n-\pi *$ transition the electrostatic interactions are dominant. In contrast, the $\pi-\pi^{*}$ transition decreases in energy by about $0.11 \mathrm{eV}$, emphasizing the importance of considering the non-electrostatic interactions. 
Table 6 Dependence of $n-\pi^{*}$ and $\pi-\pi^{*}$ transition energies $(\mathrm{eV})$ with non-electrostatic interactions using CIS(D)/6-311++G(d,p)

\begin{tabular}{lll}
\hline Solvent model & $n-\pi^{*}$ & $\pi-\pi^{*}$ \\
\hline $5 \mathrm{FU}+254 \mathrm{CH}_{3} \mathrm{CN}$ (p.c.) & 5.10 & 5.22 \\
$5 \mathrm{FU}+01 \mathrm{CH}_{3} \mathrm{CN}+253 \mathrm{CH}_{3} \mathrm{CN}$ (p.c.) & 5.08 & 5.23 \\
$5 \mathrm{FU}+02 \mathrm{CH}_{3} \mathrm{CN}+252 \mathrm{CH}_{3} \mathrm{CN}$ (p.c.) & 5.10 & 5.17 \\
$5 \mathrm{FU}+03 \mathrm{CH}_{3} \mathrm{CN}+251 \mathrm{CH}_{3} \mathrm{CN}$ (p.c.) & 5.12 & 5.14 \\
$5 \mathrm{FU}+04 \mathrm{CH}_{3} \mathrm{CN}+250 \mathrm{CH}_{3} \mathrm{CN}$ (p.c.) & 5.13 & 5.11 \\
$5 \mathrm{FU}+05 \mathrm{CH}_{3} \mathrm{CN}+249 \mathrm{CH}_{3} \mathrm{CN}$ (p.c.) & 5.11 & 5.13 \\
$5 \mathrm{FU}+06 \mathrm{CH}_{3} \mathrm{CN}+248 \mathrm{CH}_{3} \mathrm{CN}$ (p.c.) & 5.12 & 5.11 \\
\hline
\end{tabular}

Because of the very high computational demand, only one randomly chosen configuration was used

In summary, in solvent, the $n-\pi^{*}$ transition of $5 \mathrm{FU}$ molecule is displaced to the blue, while the $\pi-\pi^{*}$ transition undergoes a redshift. This shift is large enough to reverse the position of the transitions in water, but in acetonitrile it places them very close in energy, corroborating the discussion previously presented.

\section{Conclusions}

This work presents a theoretical study of the absorption spectra of the molecule 5-fluorouracil (5FU) in water and acetonitrile, using a sequential-quantum mechanics/ molecular mechanics model that combines the Monte Carlo method and subsequent quantum mechanical calculations.

Both solvents are treated using more than one approach: continuous, discrete and explicit. The polarization was accounted by two procedures: using PCM and an iterative method. The quantum mechanical calculations were made with different methods: TD-DFT, CI, EOM and INDO.

Using TD-DFT, specifically the B3LYP functional, the value of the lowest $\pi-\pi^{*}$ transition obtained was very close to the experimental value, a difference of only $0.1 \mathrm{eV}$. However, the method fails calculating the transition in water as more energetic than in acetonitrile, when the opposite is experimentally measured. This occurs in all solvent approaches and persists even changing the functional or changing the polarization method.

The ab initio CIS(D) and EOM-CCSD methods slightly overestimate the transition energy, but present a very good description of the spectral shifts and the relative locations of the bright and dark states in the two solvents.

The semiempirical method INDO/CIS shows the correct trend, but too large values for the separation of the same $\pi-\pi^{*}$ state in the two solvents.

The CIS(D) gives equivalent results compared to EOMCCSD, which gives the lowest $\pi-\pi^{*}$ and $n-\pi^{*}$ transitions very close in energy in the Franck-Condon region of the ground state, in agreement with the previous predictions.
The non-electrostatic solute-solvent interactions are found to be not relevant to the $n-\pi^{*}$ state, but play an important role in the positioning of the $\pi-\pi^{*}$ transition, thus being of crucial importance for the relative location of these two levels and, hence, for the photophysical processes.

DFT is able to reproduce the position of the transitions in reasonable agreement with the experimental values. However, for describing the transition energy shifts, we find the CIS(D) and EOM-CCSD to perform better. With the exception of the INDO/CIS, all methods agree that there is a reversal of the 5FU lowest transitions in aqueous solution, if compared with gas phase, while in acetonitrile, they become very close in energy.

The sequential-QM/MM methodology within the PCM polarization combined with the CIS(D) approach is seen to provide a good description of the solvation effects in the low-lying excited states of 5-fluorouracil with the best ratio between performance and computational cost.

Acknowledgments This work has been partially supported by FAPESP, CNPq and CAPES (Brazil). C. Bistafa thanks FAPESP for a graduate fellowship and A. Bistafa for technical support. We thank Dr. K. Coutinho for discussions.

\section{References}

1. GLOBOCAN project. http://globocan.iarc.fr/. Accessed 03 June 2012

2. Longley DB, Harkin DP, Johnston PG (2003) Nat Rev Cancer 3:330

3. Gustavsson T, Sarkar N, Lazzarotto E, Markovitsi D, Barone V, Improta RJ (2006) Phys Chem B 110:12843

4. Bednarek E, Dobrowolski JC, Dobrosz-Teperek K, Kozerski L, Lewandowski W, Mazurek AP (2000) J Mol Struct 554:233

5. Akalin E, Akyuz S, Akyuz T (2007) J Mol Struct 834-836: 477-481

6. Yamazaki S, Taketsugu T (2012) J Phys Chem A 116:491

7. Santoro F, Barone V, Gustavsson T, Improta R (2006) J Am Chem Soc 128:16312

8. Tomasi J (2004) Theor Chem Acc 112:184

9. Gustavsson T, Sarkar N, Bányász Á, Markovitsi D, Improta R (2007) Photochem Photobiol 83:595

10. Lim EC (1986) J Phys Chem 90:6770

11. Gustavsson T, Sarkar N, Lazzarotto E, Markovitsi D, Improta R (2006) Chem Phys Lett 429:551

12. Gustavsson T, Lazzarotto E, Markovitsi D, Scalmani G, Frisch MJ, Barone V, Improta R (2006) J Am Chem Soc 128:607

13. Sobolewski AL, Domcke W (2010) Phys Chem Chem Phys $12: 4897$

14. Canuto S (ed) (2008) Solvation effects on molecules and biomolecules: computational methods and applications. Springer, Berlin

15. Manzoni V, Lyra ML, Gester RM, Coutinho K, Canuto S (2010) Phys Chem Chem Phys 12:14023

16. Becke AD (1993) J Chem Phys 98:1372

17. Hoe W-M, Cohen AJ, Handy NC (2001) Chem Phys Lett 341:319

18. Adamo C, Barone V (1999) J Chem Phys 110:6158

19. Head-Gordon M, Rico RJ, Oumi M, Lee TJ (1994) Chem Phys Lett 219:21 
20. Barreto RC, Coutinho K, Georg HC, Canuto S (2009) Phys Chem Chem Phys 11:1388

21. Stanton JF, Bartlett RJ (1993) J Chem Phys 98:7029

22. Frisch MJ, Trucks GW, Schlegel HB, Scuseria GE, Robb MA, Cheeseman JR, Montgomery JA Jr, Vreven T, Kudin KN, Burant JC, Millam JM, Iyengar SS, Tomasi J, Barone V, Mennucci B, Cossi M, Scalmani G, Rega N, Petersson GA, Nakatsuji H, Hada M, Ehara M, Toyota K, Fukuda R, Hasegawa J, Ishida M, Nakajima T, Honda Y, Kitao O, Nakai H, Klene M, Li X, Knox JE, Hratchian HP, Cross JB, Bakken V, Adamo C, Jaramillo J, Gomperts R, Stratmann RE, Yazyev O, Austin AJ, Cammi R, Pomelli C, Ochterski JW, Ayala PY, Morokuma K, Voth GA, Salvador P, Dannenberg JJ, Zakrzewski VG, Dapprich S, Daniels AD, Strain MC, Farkas O, Malick DK, Rabuck AD, Raghavachari K, Foresman JB, Ortiz JV, Cui Q, Baboul AG, Clifford S, Cioslowski J, Stefanov BB, Liu G, Liashenko A, Piskorz P, Komaromi I, Martin RL, Fox DJ, Keith T, Al-Laham MA, Peng CY, Nanayakkara A, Challacombe M, Gill PMW, Johnson B, Chen W, Wong MW, Gonzalez C, Pople JA (2004) Gaussian 03, Revision D01. Gaussian Inc, Wallingford, CT

23. Coutinho K, Canuto S (2010) DICE: a Monte Carlo program for molecular liquid simulation, version 29. University of Sao Paulo, São Paulo

24. Pranata J, Wierschke SG, Jorgensen WL (1991) J Am Chem Soc $113: 2810$

25. Breneman CM, Wiberg KB (1990) J Comput Chem 11:361

26. Berendsen HJC, Postma JPM, van Gunsteren WF, Hermans J (1981) In: Pullman B (ed) Intermolecular forces. Reidel, Dordrecht, p 331

27. Böhm HJ, McDonald IR (1983) Mol Phys 49:347

28. Coutinho K, Canuto S (2000) J Chem Phys 113:9132

29. Canuto S, Coutinho K (2000) Int J Quantum Chem 77:192

30. Canuto S, Coutinho K, Trzesniak D (2002) Adv Quantum Chem $41: 161$

31. Coutinho K, Cabral BJC, Canuto S (2004) Chem Phys Lett 399:534

32. Georg HC, Coutinho K, Canuto S (2006) Chem Phys Lett 429:119
33. Coutinho K, Georg HC, Fonseca TL, Ludwig V, Canuto S (2007) Chem Phys Lett 437:148

34. Frisch MJ, Trucks GW, Schlegel HB, Scuseria GE, Robb MA, Cheeseman JR, Scalmani G, Barone V, Mennucci B, Petersson GA, Nakatsuji H, Caricato M, Li X, Hratchian HP, Izmaylov AF, Bloino J, Zheng G, Sonnenberg JL, Hada M, Ehara M, Toyota K, Fukuda R, Hasegawa J, Ishida M, Nakajima T, Honda Y, Kitao O, Nakai H, Vreven T, Montgomery JA Jr, Peralta JE, Ogliaro F, Bearpark M, Heyd JJ, Brothers E, Kudin KN, Staroverov VN, Kobayashi R, Normand J, Raghavachari K, Rendell A, Burant JC, Iyengar SS, Tomasi J, Cossi M, Rega N, Millam JM, Klene M, Knox JE, Cross JB, Bakken V, Adamo C, Jaramillo J, Gomperts R, Stratmann RE, Yazyev O, Austin AJ, Cammi R, Pomelli C, Ochterski JW, Martin RL, Morokuma K, Zakrzewski VG, Voth GA, Salvador P, Dannenberg JJ, Dapprich S, Daniels AD, Farkas O, Foresman JB, Ortiz JV, Cioslowski J, Fox DJ (2009) Gaussian 09, Revision A02. Gaussian Inc, Wallingford, CT

35. Ridley JE, Zerner MC (1973) Theor Chim Acta 32:111

36. Zerner MC (2000) ZINDO: a semi-empirical program package. University of Florida, Gainesville, FL

37. Markova N, Enchev V, Timtcheva I (2005) J Phys Chem A 109:1981

38. Blicharska B, Kupka T (2002) J Mol Struct 613:153

39. Brown RD, Godfrey PD, McNaughton D, Pierlot AP (1988) J Am Chem Soc 110:2329

40. Almeida TS, Coutinho K, Cabral BJC, Canuto S (2008) J Chem Phys 128:014506

41. Jaramillo P, Coutinho K, Cabral BJC, Canuto S (2011) Chem Phys Lett 516:250

42. Georg HC, Coutinho K, Canuto S (2007) J Chem Phys 126:034507

43. Ludwig V, Coutinho K, Canuto S (2007) Phys Chem Chem Phys 9:4907

44. Martín ME, Aguilar MA, Chalmet S, Ruiz-López MF (2002) Chem Phys 284:607

45. Chalmet S, Ruiz-López MF (2000) Chem Phys Lett 329:154

46. Gustavsson T, Sarkar N, Lazzarotto E, Markovitsi D, Barone V, Improta R (2006) J Phys Chem B 110:12843 


\title{
Solvent Effect on the Stokes Shift and on the Nonfluorescent Decay of the Daidzein Molecular System
}

\author{
Yoelvis Orozco-Gonzalez, Carlos Bistafa, and Sylvio Canuto* \\ Instituto de Física, Universidade de São Paulo, CP 66318, 05314-970 São Paulo, SP, Brazil
}

Supporting Information

ABSTRACT: The flavonoids have been the target of several experimental works due to its influence in the human health as antioxidant elements. The fluorescence properties of these compounds have been widely studied due to the large Stokes shifts experimentally observed and the variety of processes that lead to the fluorescence. In the present work the role of the solvent in the large Stokes shift experimentally observed in the daidzein molecular system in water is theoretically studied. Also studied is the nonfluorescent decay mechanism in a polar aprotic solvent like acetonitrile. The solvent effect in the ground and in the low-lying excited electronic states is taken into account by using the sequential-QM/MM methodology. Excited state properties like equilibrium geometries and transition energies were studied by using multiconfigurational calculations, CASSCF and CASPT2. The excited electronic state responsible for the fluorescence spectrum in water was identified, and the large Stokes shift seems to be the result of the large interaction of the system in this electronic state with the solvent. On the other hand, spin-orbit coupling calculations, between the singlet and triplet electronic states, indicate favorable conditions for intersystem crossing, in agreement with the experimental result of nonfluorescence observation.

\section{INTRODUCTION}

The flavonoids are members of a family of polyphenolic compounds with antioxidant properties directly linked to health benefits ${ }^{1-4}$ including a possible explanation for the French paradox. ${ }^{5,6}$ Many studies ${ }^{7-11}$ have suggested that the regular consumption of red wine could be the answer to the paradox, because the flavonoids are abundant in the seeds and skin of the grape and hence in the red wine.

For these and other reasons the flavonoids have been much studied. In particular, the fluorescence properties of these compounds have been the subject of several experimental works, ${ }^{12-25}$ increasing the interest of theoretical studies of the excited states. ${ }^{26-28}$ There is a wide variety of fluorescence characteristics of the flavonoids. Large Stokes shifts in solution have been observed in the 3-hydroxyflavones molecular systems (flavonols). The fluorescence, observed at about $500 \mathrm{~nm}$, originates in an excited electronic state that is characterized by an intramolecular proton transfer from the 3-hydroxy group to the 4-carbonyl group. ${ }^{12,16,18}$ Other systems characterized by the intramolecular excited-state proton transfer are the 5hydroxyflavones, in which two emission bands were experimentally observed. ${ }^{23}$ On the other hand, in the 7hydroxyflavones, a large Stokes shift is also observed in alcohol and water, but this is not attributed to the intramolecular excited-state proton transfer. In these systems, two emission bands are normally observed in solution with $\mathrm{pH}$ higher than 2 . The more intense is associated with the emission from the anionic form, and the weaker band is related to the keto tautomer. In solutions with $\mathrm{pH}$ less than 2 , the fluorescence is associated to the zwitterionic form of the enol tautomer. ${ }^{15,24,25}$

The isoflavones are a subset of flavonoids, shown in Figure 1, that have deserved some experimental and theoretical attention.<smiles>O=c1c(-c2ccc(Br)cc2)coc2cc(Br)ccc12</smiles>

Figure 1. Representation of the isoflavones subset. For daidzein, the radicals are $\mathrm{R}=\mathrm{R}^{\prime}=\mathrm{OH}$.

In a variety of these compounds, large Stokes shifts, on the order of $1.4 \mathrm{eV},{ }^{13,14,21,28}$ have been observed in the solvent environment. The fluorescence of these molecular systems have been observed in both basic and neutral conditions, ${ }^{13,21,22}$ and no $\mathrm{pH}$ dependence has been obtained in some of them. ${ }^{21}$ The experimental evidence concerning these compounds (see discussion in ref 28) indicate that the fluorescence can be assigned to the neutral forms.

In the present work we are particularly interested in the daidzein molecular system as a model compound. This is an isoflavone, as indicated in Figure 1, with $\mathrm{R}=\mathrm{OH}$ and $\mathrm{R}^{\prime}=\mathrm{OH}$.

Received: March 3, 2013

Revised: $\quad$ May 3, 2013

Published: May 6, 2013 
Our interest in studying this molecular system arises from the necessity of a better understanding of the large Stokes shift values observed experimentally in the isoflavones subset.

The daidzein molecular system exhibits large Stokes shifts in polar protic solvents like water and methanol. ${ }^{2,28}$ However, only a weak or nonfluorescence spectrum is detected when the daidzein is in a polar aprotic solvent like acetonitrile. ${ }^{21,22}$ Hence, the aim of the present work is to theoretically elucidate the causes of the large Stokes shifts in polar protic solvents, such as water, and in addition to understand the nonfluorescent deactivation mechanism in acetonitrile. There is a recent and interesting theoretical work ${ }^{28}$ that attempts to explain the role of the solvent in the photochemistry of isoflavones. There, analysis of the anomalous behavior is made using a simplified microsolvation model. In the present study we will consider a more realistic model for the solvent interaction with daidzein. Thus, Monte Carlo simulations of the liquid in the proper thermodynamic conditions are combined with quantum mechanics calculations to study the photophysics of this molecular system.

\section{COMPUTATIONAL DETAILS}

The energies of the low-lying excited electronic states of the daidzein were calculated using the multiconfigurational secondorder perturbation theory (CASPT2), ${ }^{29}$ based on the CASSCF reference wave function. In the CASSCF calculations, 12 electrons were correlated in 12 orbitals. The active orbitals are the five $\pi$ and six $\pi^{*}$ that better describe the three lowest $\pi \pi^{*}$ excited states and it was added the oxygen lone-pair orbital to describe the lowest $\mathrm{n} \pi^{*}$ excited state. These active orbitals were selected by analyzing the contribution to the low-lying excited states in a previous multiconfigurational calculation that involved a higher active space, but only considering the single, double, triple, and quadruple excitations. It was used the ANO$\mathrm{L}$ type basis set (atomic natural orbitals with Large primitive set), where the contraction scheme C, O (14s9p4d)/[4s3p1d], and $\mathrm{H}(8 \mathrm{~s} 4 \mathrm{p}) /[2 \mathrm{~s} 1 \mathrm{p}]^{30,31}$ has been used. This basis set yields converged results for the electronic transition energies, as verified in the early work of Roos and Fülscher. ${ }^{32}$ The 1 s core electrons of the oxygen and carbon atoms were kept frozen in the second-order perturbation step. In the CASSCF calculations, it was used the state average procedure, in which one single set of molecular orbitals is used to compute the five lowest roots.

The absorption transitions were studied using the ground electronic state equilibrium geometry optimized in the gas phase. This geometry was obtained at the MP2 level with the 6$31+\mathrm{G}(\mathrm{d})$ basis set. The optimization was carried out with the Gaussian 03 program package. ${ }^{33}$ The influence of the solvent in the ground state geometry was checked, using the polarizable continuum model (PCM) ${ }^{34}$ model. In the case of both solvents considered, water and acetonitrile, the geometries are similar and do not differ much from that obtained in the gas phase. The major difference has been the change in the $\left(2-3-1^{\prime}-2^{\prime}\right)$ dihedral angle from $49^{\circ}$ in the gas phase to $57^{\circ}$ and $56^{\circ}$, in acetonitrile and water, respectively. It is expected that the PCM could be a better approximation for the case of acetonitrile (nonprotic) than for water (protic solvent). To consider the protic aspect of water, we have also optimized the complex daidzein-water with one molecule of water attached to the oxygen atom of the $\mathrm{C}=\mathrm{O}$ bond. As expected, in this case we find a stretch of the $\mathrm{C}=\mathrm{O}$ bond length of $0.006 \AA$ with the $(2-$ $\left.3-1^{\prime}-2^{\prime}\right)$ dihedral of $50^{\circ}$, very close to that of the gas phase.
The $\mathrm{C}=\mathrm{O}$ stretch in the liquid should be smaller than this obtained in the minimum energy configuration. As expected, ${ }^{35}$ this $\mathrm{C}=\mathrm{O}$ bond stretch slightly decreases the ${ }^{1}\left(\mathrm{n} \pi^{*}\right)$ transition energy in water but these little modifications in the daidzein structure are not expected to change the qualitative conclusions regarding the radiative and nonradiative decays, so we only used the structure obtained in gas phase.

The study of the fluorescence spectrum was directed to identify the electronic state most populated in the absorption transitions and follow its behavior in solvent environment. The geometry optimizations of the excited electronic states were performed at the CASSCF level, considering the same active space and basis set discussed above. All multiconfiguration calculations were performed in the MOLCAS 7.4 program package. $^{36}$ The geometry optimizations of the excited states were performed for the isolated molecule.

Water and acetonitrile were the solvents considered in the present work, as used also in the experimental works. The solvent effect is taken into account using the sequential-QM/ MM methodology. ${ }^{37}$ Monte Carlo (MC) simulations were performed to generate solute-solvent configurations in the proper thermodynamic condition. These are then used in the quantum mechanical (QM) calculations of the electronic transitions. The MC simulations have been used as in previous applications in the ground electronic state ${ }^{38,39}$ and also in the excited states. ${ }^{40}$ We used the Metropolis sampling technique ${ }^{41}$ in the NPT ensemble implemented in the DICE program. ${ }^{42}$ In the simulations, one molecule of daidzein and 700 molecules of solvent were used in a cubic box with periodic boundary conditions and the image method, ${ }^{41}$ at room conditions $(T=$ $25^{\circ} \mathrm{C}$ and $\left.P=1 \mathrm{~atm}\right)$. The molecular interaction was described by the usual Lennard-Jones plus Coulomb potentials, with tree parameters for each atom $i\left(\varepsilon_{i}, \sigma_{i}\right.$, and $\left.q_{i}\right)$. The Lennard-Jones parameters are combined to generate the pair-potential parameters by $\varepsilon_{i j}=\left(\varepsilon_{i} \varepsilon_{j}\right)^{1 / 2}$ and $\sigma_{i j}=\left(\sigma_{i} \sigma_{j}\right)^{1 / 2}$. For daidzein in the ground and excited states, these parameters were obtained from Jorgensen's OPLS-AA force field. ${ }^{43}$ For the water molecules the TIP3P model ${ }^{44}$ was used and for acetonitrile the model proposed by Böhm and McDonald. ${ }^{45}$ The atomic charges $q_{i}$ for daidzein in the ground and the excited electronic states have been obtained by taking into account the electronic polarization of each electronic state caused by the solvent.

The electronic polarization was considered by performing the iterative and sequential-QM/MM procedure previously described, ${ }^{38,46,47}$ which brings the daidzein in the respective electronic state into electrostatic equilibrium with the solvent. Initially, the $q_{i}$ charges, obtained from the gas phase, were used in the MC simulation and the statistically uncorrelated configurations ${ }^{48}$ of the liquid were selected to recalculate the new atomic charges and the solute dipole moment in the presence of the solvent. These QM calculations were performed with the daidzein embedded in the electrostatic field of the solvent using the average solvent electrostatic configuration (ASEC) ${ }^{49}$ model. In the iteration, the calculated atomic charges of the solute are then updated in the Coulomb part of the potential for another MC simulation. This process is repeated until the convergence in the calculated dipole moment is obtained. The QM calculations of the solute dipole moments and charges were performed by using the electrostatic potential fitted (ESPF) method ${ }^{50}$ implemented in MOLCAS 7.4. ${ }^{36}$

The total number of configurations generated in each $\mathrm{MC}$ simulation was $3.0 \times 10^{5}$, after $2.1 \times 10^{8} \mathrm{MC}$ steps. After the 
convergence in the dipole moment, 100 statistically uncorrelated configurations were selected with less than $12 \%$ of statistical correlation for the QM calculation of the electronic transitions. In the absorption and emission energy calculation, the solvent was included by using the ASEC model. ${ }^{49}$ ASEC accounts for all the solute-solvent electrostatic interactions, and a single QM calculation gives the same value as the average obtained with the entire ensemble. ${ }^{49}$ In this model, after the MC simulation, statistically uncorrelated configurations are selected and used to construct an average configuration of the solvent, described as point charges. Explicit use of solvent molecules is not considered because of the very high computational effort involved.

To explain the inexistence of daidzein fluorescence in acetonitrile, the intersystem crossing transition was studied. In that sense, the spin-orbit coupling (SOC) elements between singlet and triplet electronic states were calculated by using the approximate one electron effective Hamiltonian ${ }^{51}$ for the spin-orbit interaction. These calculations were performed using the RASSI (restricted active space state interaction) program $^{52}$ also implemented in MOLCAS 7.4. ${ }^{36}$ The spin-orbit eigenstates are calculated in a variational way in the space spanned by the spin-free CASSCF wave functions, considering the spin-orbit interaction in the Hamiltonian. The dynamic correlation effects are included shifting the diagonal elements to the energies obtained in the CASPT 2 calculations. The SOC strength between the involved electronic states $(\mathrm{l}, \mathrm{k})$ was evaluated as in ref 53:

$$
\operatorname{SOC}_{\mathrm{lk}}=\sqrt{\sum_{u}\left|\left\langle T_{\mathrm{l}, u}\left|\hat{H}_{\mathrm{SO}}\right| S_{\mathrm{k}}\right\rangle\right|^{2}}
$$

where $u$ represents each spin component of the triplet state $(u$ $=x, y, z)$.

\section{RESULTS AND DISCUSSION}

A. Absorption Spectrum. The absorption spectra of daidzein molecular system in water and in acetonitrile were determined by using the ground electronic state optimized geometry, shown in Figure 2a. The dihedral angle between the

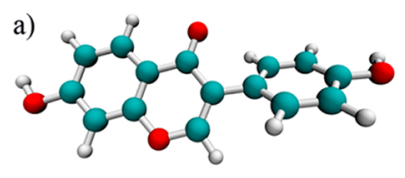

$\mathrm{S}_{0}$

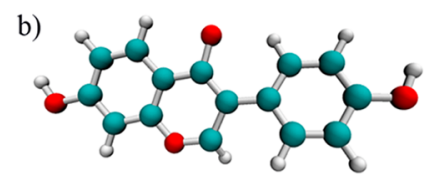

${ }^{1}\left(\pi \pi^{*} L_{b}\right)$

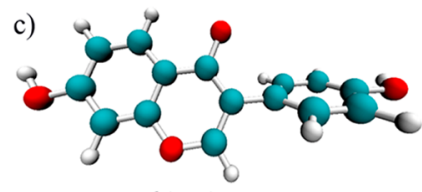

${ }^{1}\left(n \pi^{*}\right)$

Figure 2. Optimized geometries of the corresponding electronic states.

chromone and the phenyl ring obtained in our optimization calculation is $49^{\circ}$, which is in reasonable agreement with the result of Beyhan et al. ${ }^{28}$ of $39.9^{\circ}$, calculated at the CC2/aug-ccpVDZ level of theory. The full information of the geometry can be found in the Supporting Information.

To take into account the solvent effect in the absorption spectrum, the iterative procedure discussed in the previous section was performed to reach the solute-solvent electrostatic equilibrium of the daidzein in the ground electronic state. Parts $\mathrm{a}$ and $\mathrm{b}$ of Figure 3 show the convergence of the dipole moment in the iterative procedure for water and acetonitrile respectively, where the dipole moment of the ground state $S_{0}$ increases from $2.5 \mathrm{D}$ in the gas phase to $10.0 \mathrm{D}$ in water solution and to $3.8 \mathrm{D}$ in acetonitrile.

In Table 1 are shown the four lowest excited electronic states calculated in solvent at CASPT2/ANO-L level. To distinguish the low-lying $\pi \pi^{*}$ electronic states, the Platt nomenclature was adopted, ${ }^{54}$ where the ${ }^{1}\left(\pi \pi^{*} \mathrm{~L}_{\mathrm{a}}\right)$ state is mainly described by the $\operatorname{HOMO}(\mathrm{H}) \rightarrow$ LUMO $(\mathrm{L})$ transition and ${ }^{1}\left(\pi \pi^{*} \mathrm{~L}_{\mathrm{b}}\right)$ by $\mathrm{H}-1$ $\rightarrow$ L. The ${ }^{1}\left(\pi \pi^{*}\right)$ electronic state is characterized by the HOMO-2 to LUMO transition, whereas the ${ }^{1}\left(n \pi^{*}\right)$ is characterized by the transition from the oxygen lone-pair orbital to the LUMO. The molecular orbitals characterizing these electronic states are shown in Figure 4.

In the following, the results of the absorption transitions in water are discussed and subsequently those in acetonitrile. According to the results shown in Table 1, the calculated absorption spectrum in water shows two intense transitions, one due to the ${ }^{1}\left(\pi \pi^{*} \mathrm{~L}_{\mathrm{b}}\right)$ electronic state and the other to the ${ }^{1}\left(\pi \pi^{*} \mathrm{~L}_{\mathrm{a}}\right)$, with energies of $4.16 \mathrm{eV}(298 \mathrm{~nm})$ and $4.70 \mathrm{eV}(264$ $\mathrm{nm})$, respectively. The first of these transitions is in excellent agreement with the experimental band observed with a maximum at $4.09 \mathrm{eV}(303 \mathrm{~nm})$ and used in the fluorescence excitation. ${ }^{28}$ The second transition $(4.70 \mathrm{eV})$ is in very good agreement with the experimental band witha maximum at about $5.00 \mathrm{eV}(248 \mathrm{~nm}){ }^{28}$ On the other hand, the fourth electronic transition shown, with an energy of $5.44 \mathrm{eV}(228 \mathrm{~nm})$, agrees with the experimental band that appears at the edge of the spectrum at about $5.85 \mathrm{eV}(211 \mathrm{~nm})$. Finally, the transition to the ${ }^{1}\left(\mathrm{n} \pi^{*}\right)$ electronic state, with an energy of $4.14 \mathrm{eV}(300 \mathrm{~nm})$ is not observed experimentally because it is weak and beneath an intense band.

The results obtained for the absorption in acetonitrile are also shown in Table 1. As can be seen, only one intense transition appears, given by the transition to the ${ }^{1}\left(\pi \pi^{*} \mathrm{~L}_{\mathrm{b}}\right)$ electronic state with an energy of $5.09 \mathrm{eV}(244 \mathrm{~nm})$. This transition is very close to the main band, experimentally observed with a maximum at $4.77 \mathrm{eV}(260 \mathrm{~nm})$. Another transition, to the ${ }^{1}\left(\pi \pi^{*} \mathrm{~L}_{\mathrm{a}}\right)$ electronic state, is obtained with lower intensity and energy of $4.37 \mathrm{eV}(284 \mathrm{~nm})$. This transition is close to a weak experimental band observed as a shoulder at $4.09 \mathrm{eV}(303 \mathrm{~nm}) .{ }^{28}$ It can be noted that these two electronic transitions are simultaneously displaced to the higher energetic region by about $0.3 \mathrm{eV}$ (or $15 \mathrm{~nm}$ ) in relation to the maxima of the experimental bands. This behavior may be due to the ASEC model used in the QM calculations, wherein only the electrostatic interaction with the solvent is considered and, perhaps, the exchange and van der Waals energies might be important for describing the interaction with the acetonitrile. The transition calculated at $5.76 \mathrm{eV}(215 \mathrm{~nm})$ corresponding to the ${ }^{1}\left(\pi \pi^{*}\right)$ electronic state is in good agreement with the band observed at the edge of the spectrum at $5.85 \mathrm{eV}(212 \mathrm{~nm})$. Moreover, the ${ }^{1}\left(\mathrm{n} \pi^{*}\right)$ electronic state appears to be a dark state, indicated by the null oscillator strength.

B. Fluorescence Spectrum in Water. Based on the absorption spectrum of the daidzein, the emission spectrum description was oriented to the study of the ${ }^{1}\left(\pi \pi^{*} \mathrm{~L}_{\mathrm{b}}\right)$ excited state, because this state is most populated in the absorption transitions (Table 1) and reproduces very well the fluorescence excitation energy. In that way, the ${ }^{1}\left(\pi \pi^{*} \mathrm{~L}_{\mathrm{b}}\right)$ excited electronic 

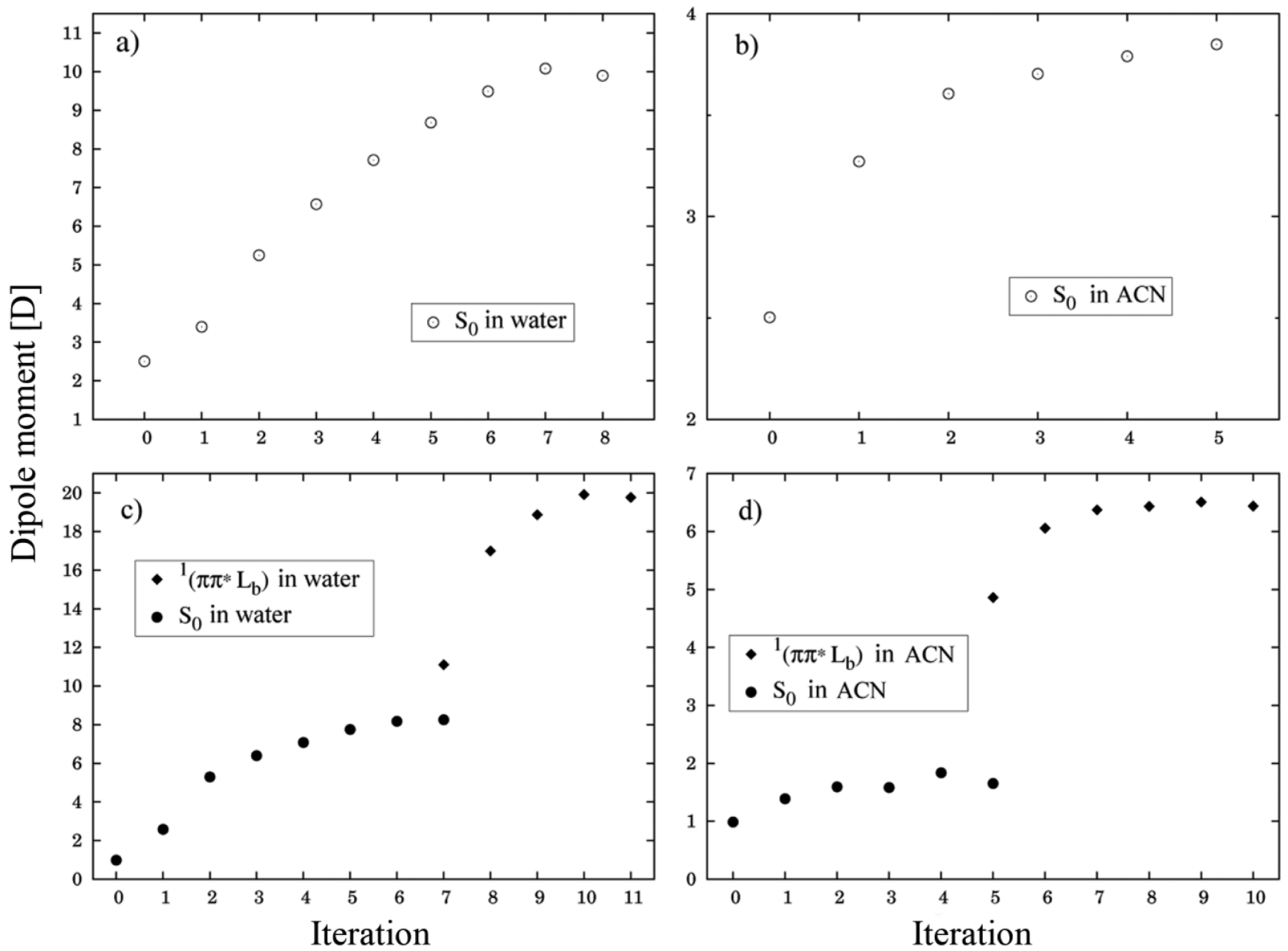

Figure 3. Changes of the dipole moment values of the corresponding electronic states in solvent, with respect to the number of iterations in the sequential-QM/MM procedure of solute electronic polarization. ACN means acetonitrile.

Table 1. Absorption Energies to the Four Lowest Excited Electronic States in Water and in Acetonitrile and Emission Energy in Water $^{a}$

\begin{tabular}{|c|c|c|c|c|c|c|c|}
\hline \multicolumn{8}{|c|}{ Absorption } \\
\hline \multicolumn{4}{|c|}{ water } & \multicolumn{4}{|c|}{ acetonitrile } \\
\hline state & $E_{\text {abs }}$ & $\bar{f}$ & $E_{\mathrm{abs}}^{b} \exp ^{28}$ & state & $E_{\text {abs }}$ & $\bar{f}$ & $E_{\text {abs }}^{b} \exp ^{28}$ \\
\hline${ }^{1}\left(n \pi^{*}\right)$ & 4.14 & 0.070 & & ${ }^{1}\left(n \pi^{*}\right)$ & 3.72 & 0.000 & \\
\hline${ }^{1}\left(\pi \pi^{*} \mathrm{~L}_{\mathrm{b}}\right)$ & 4.16 & 0.196 & 4.09 & ${ }^{1}\left(\pi \pi^{*} \mathrm{~L}_{\mathrm{a}}\right)$ & 4.37 & 0.077 & 4.09 \\
\hline${ }^{1}\left(\pi \pi^{*} \mathrm{~L}_{\mathrm{a}}\right)$ & 4.70 & 0.165 & 5.00 & ${ }^{1}\left(\pi \pi^{*} \mathrm{~L}_{\mathrm{b}}\right)$ & 5.09 & 0.305 & 4.77 \\
\hline${ }^{1}\left(\pi \pi^{*}\right)$ & 5.44 & 0.057 & 5.85 & ${ }^{1}\left(\pi \pi^{*}\right)$ & 5.76 & 0.027 & 5.85 \\
\hline \multicolumn{8}{|c|}{ Emission in Water } \\
\hline fluorescent state & & $E_{\mathrm{emi}}^{c}$ & \multicolumn{2}{|c|}{ Stokes shift ${ }^{d}$} & $E_{\mathrm{emi}}{ }^{b} \exp ^{28}$ & \multicolumn{2}{|c|}{ Stokes shift $\exp ^{28}$} \\
\hline${ }^{1}\left(\pi \pi^{*} \mathrm{~L}_{\mathrm{b}}\right)$ & & $2.85 / 3.24$ & \multicolumn{2}{|c|}{$1.31 / 0.92$} & 2.70 & \multicolumn{2}{|c|}{1.40} \\
\hline
\end{tabular}

${ }^{a}$ The energetic values are indicated in eV. $f$ is the oscillator strength. ${ }^{b}$ Energetic values corresponding to the experimental bands maxima. ${ }^{c}$ Emission energy calculated in electrostatic equilibrium/nonequilibrium with the solvent. ${ }^{d}$ Stokes shift calculated by using the absorption energy of the ${ }^{1}\left(\pi \pi^{*}\right.$ $\mathrm{L}_{\mathrm{b}}$ ) electronic state, which is the experimental fluorescence excitation, and the fluorescence energy obtained in electrostatic equilibrium/ nonequilibrium with the solvent.

state was optimized at the CASSCF/ANO-L level. In this optimized geometry, shown in Figure $2 \mathrm{~b}$, the chromone and the phenyl ring approximate to a planar configuration $\left(\sim 14^{\circ}\right.$, details can be found in the Supporting Information).

The solvation of the ${ }^{1}\left(\pi \pi^{*} \mathrm{~L}_{\mathrm{b}}\right)$ electronic state in water was studied in two stages. First, the lifetime of this electronic state is considered to be short and the solute-solvent electrostatic equilibrium is not reached. In that case, using the equilibrium geometry of the ${ }^{1}\left(\pi \pi^{*} \mathrm{~L}_{\mathrm{b}}\right)$ electronic state, solute-solvent configurations were obtained with the solvent in electrostatic equilibrium with the ground electronic state. That procedure is shown in Figure $3 \mathrm{c}$ by the circular points. The convergence of these points indicates the electrostatic equilibrium with the ground electronic state. Subsequently, an excited state lifetime large enough to reach the solute-solvent electrostatic equilibrium with the solvent is considered. That procedure is also shown in Figure $3 c$ by the convergence of the diamond points. Splitting the iterative procedure in these two stages, it is possible to explicitly observe the electronic polarization corresponding to the excited electronic state once it is 


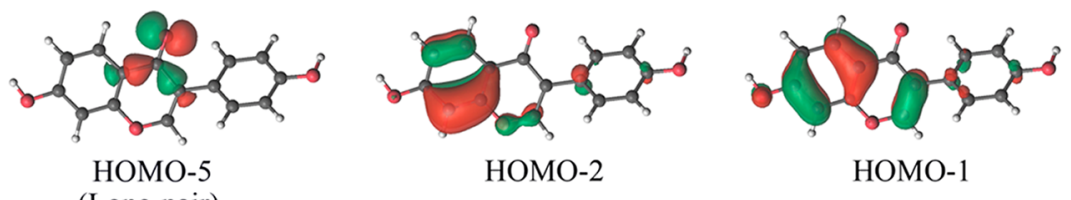

(Lone-pair)

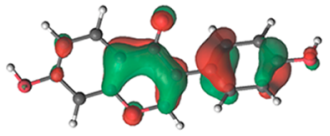

HOMO

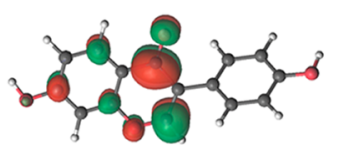

LUMO

Figure 4. Representation of the molecular orbitals involved in the studied electronic transitions.

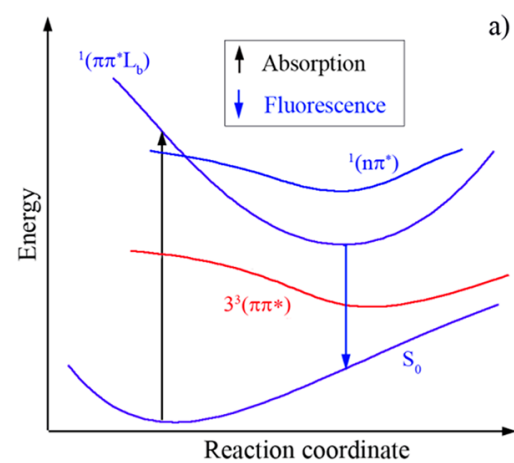

a)

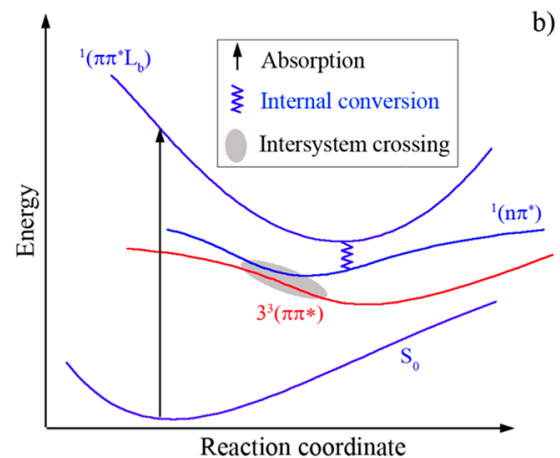

b)

Figure 5. Schematic energetic profiles of the electronic states and deactivation mechanisms of the daidzein in water (a) and in acetonitrile (b).

populated. From Figure 3c, it can be seen that the electronic polarization of the ${ }^{1}\left(\pi \pi^{*} \mathrm{~L}_{\mathrm{b}}\right)$ excited electronic state, caused by the interaction with the solvent, increases the dipole moment from 11.1 to $19.8 \mathrm{D}$.

Both in the equilibrium condition and in the nonequilibrium, the ${ }^{1}\left(\pi \pi^{*} \mathrm{~L}_{\mathrm{b}}\right)$ electronic state is the lowest excited state, as shown schematically in Figure 5a. This electronic state stabilizes considerably due to the interaction with the water, whereas the ${ }^{1}\left(\mathrm{n} \pi^{*}\right)$ electronic state, which in the gas phase appears as the lowest one, is shifted to the blue.

The emission energies in water, calculated at the CASPT2/ ANO-L level, are shown in Table 1 . In the solute-solvent electrostatic nonequilibrium condition, the emission energy corresponding to the ${ }^{1}\left(\pi \pi^{*} \mathrm{~L}_{\mathrm{b}}\right)$ electronic state is $3.24 \mathrm{eV}(383$ $\mathrm{nm})$. This leads to a Stokes shift value in water of $0.92 \mathrm{eV}(85$ $\mathrm{nm}$ ) when compared with the absorption energy. Considering, as previously commented, that the ${ }^{1}\left(\pi \pi^{*} \mathrm{~L}_{\mathrm{b}}\right)$ excited-state lifetime is large enough to reach the solute-solvent electrostatic equilibrium, the calculated emission energy in water is $2.85 \mathrm{eV}(435 \mathrm{~nm})$. This result is in very good agreement with the experimental result of Beyhan et al., ${ }^{28}$ wherein the emission band is observed with a maximum at $2.67 \mathrm{eV}(464 \mathrm{~nm})$. In comparison with the absorption energy, a Stokes shift in water of $1.31 \mathrm{eV}(137 \mathrm{~nm})$ is obtained. That large Stokes shift value is in very good agreement with the experimental result of 1.40 $\mathrm{eV}^{28}$

According to these results, the interaction with the solvent has great influence on the Stokes shift of the daidzein molecular system. We considered that the large electronic polarization of the ${ }^{1}\left(\pi \pi^{*} L_{b}\right)$ excited electronic state, shown in Figure $3 c$, is the main cause of the large Stokes shift value experimentally observed, because it leads to a considerable energy stabilization of this electronic state. The deactivation mechanism of the daidzein in water, after the absorption transitions, is summarized in Figure 5a. It is interesting to mention that an electron density transfer can be seen resulting from the interaction of the system with the solvent. The electronic polarization caused by the solvent modifies the molecular orbitals (Figure 6), delocalizing the electronic density from the phenyl ring to the chromone.

C. Suppression of the Fluorescence in Acetonitrile. The fluorescence of the daidzein in polar aprotic solvent like acetonitrile is not observed experimentally. In this section we analyze this nonfluorescent decay and attempt a possible explanation.

According to the results shown in Table 1 , the ${ }^{1}\left(\pi \pi^{*} \mathrm{~L}_{\mathrm{b}}\right)$ electronic state is the most populated in the absorption transitions. Hence, using the equilibrium geometry of this excited electronic state, the influence of the acetonitrile, as solvent, was considered in the low-lying excited states. As previously, the solvation of this electronic state was also studied in two stages. The electronic polarization of the ${ }^{1}\left(\pi \pi^{*} \mathrm{~L}_{\mathrm{b}}\right)$ electronic state, due to the interaction with acetonitrile, is weak, causing a small dipole moment change from 4.9 to $6.4 \mathrm{D}$. Because of this, the ${ }^{1}\left(\pi \pi^{*} \mathrm{~L}_{\mathrm{b}}\right)$ electronic state does not stabilize enough, being less stable than the ${ }^{1}\left(\mathrm{n} \pi^{*}\right)$ state, as shown schematically in Figure 5b.

In these conditions, according to the Kasha rule, ${ }^{55}$ the system will decay by internal conversion from the ${ }^{1}\left(\pi \pi^{*} \mathrm{~L}_{\mathrm{b}}\right)$ electronic state to the ${ }^{1}\left(\mathrm{n} \pi^{*}\right)$. Therefore, to clarify the mechanism of the nonfluorescent decay of the daidzein, we studied the intersystem crossing between the ${ }^{1}\left(\mathrm{n} \pi^{*}\right)$ electronic state and the triplet states. The equilibrium geometry of the ${ }^{1}\left(\mathrm{n} \pi^{*}\right)$ electronic state was optimized at the CASSCF/ANO-L level, obtaining the geometry shown in Figure $2 c$, wherein the chromone and the phenyl ring form an angle of about $59^{\circ}$. In that geometry, the spin-orbit couplings between this electronic state and the closest triplet states were calculated. The results are shown in Table 2. The largest SOC value, equal to 42.5 $\mathrm{cm}^{-1}$, is observed with the third triplet electronic state, $3^{3}\left(\pi \pi^{*}\right)$. 
Before the electronic polarization

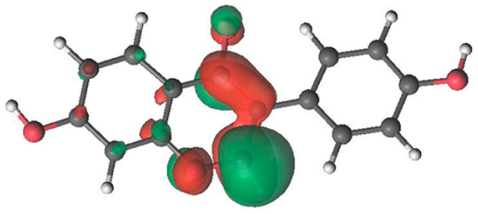

LUMO

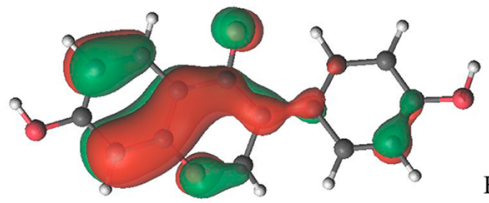

HOMO
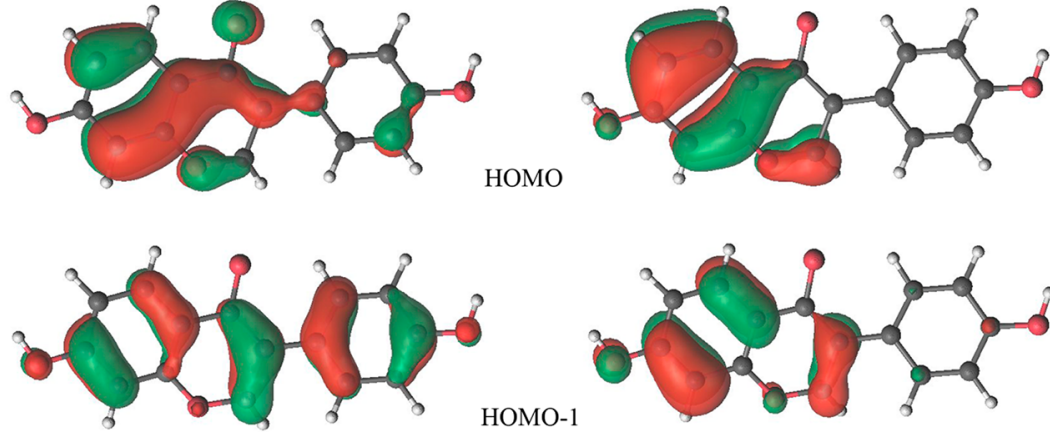

HOMO-1
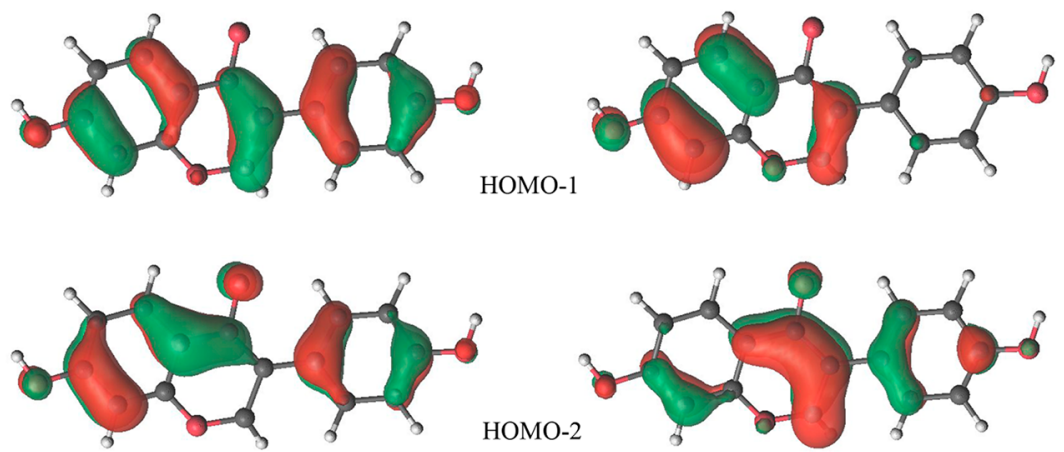

HOMO-2
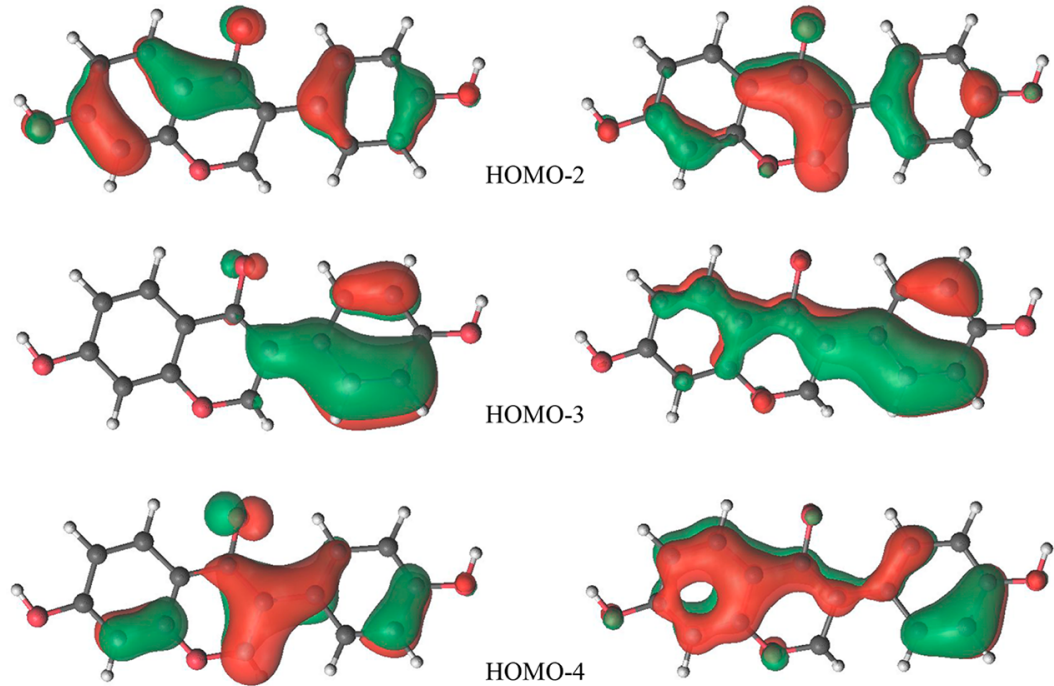

HOMO-4

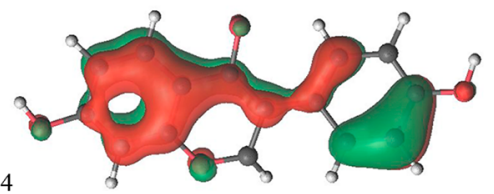

Figure 6. Changes in the molecular orbitals of the daidzein in the ${ }^{1}\left(\pi \pi^{*} L_{b}\right)$ excited electronic state due to the electronic polarization caused by the water solvent.

Table 2. Spin-Orbit Coupling Calculated Values and Energetic Gaps between the Considered Electronic States for Isolated Daidzein

\begin{tabular}{|c|c|c|c|}
\hline \multicolumn{2}{|c|}{ state } & $\operatorname{SOC}\left(\mathrm{cm}^{-1}\right)$ & $\Delta E^{a}(\mathrm{eV})$ \\
\hline${ }^{1}\left(\mathrm{n} \pi^{*}\right)$ & $1^{3}\left(\pi \pi^{*}\right)$ & 31.4 & -3.64 \\
\hline & $2^{3}\left(n \pi^{*}\right)$ & & -0.29 \\
\hline & $3^{3}\left(\pi \pi^{*}\right)$ & 42.5 & 0.20 \\
\hline
\end{tabular}

${ }^{a}$ Energies compared to the ${ }^{1}\left(\mathrm{n} \pi^{*}\right)$ electronic state.

Although the energy of this electronic state appears $0.2 \mathrm{eV}$ above the ${ }^{1}\left(\mathrm{n} \pi^{*}\right)$ state, this profile may be inverted in acetonitrile. We believe that, due to the weak interaction of the system with the acetonitrile, the ${ }^{1}\left(\mathrm{n} \pi^{*}\right)$ electronic state will be mildly shifted to the blue region whereas the $3^{3}\left(\pi \pi^{*}\right)$ state is shifted to the red, the triplet state remaining a little more stable than the singlet. The results shown in Table 2 are in excellent agreement with the El-Sayed rule, ${ }^{56}$ which indicates that the intersystem crossing is allowed when the involved electronic states are of different spatial symmetries, like the ${ }^{1}\left(\mathrm{n} \pi^{*}\right)$ singlet state with the triplets $1^{3}\left(\pi \pi^{*}\right)$ and $3^{3}\left(\pi \pi^{*}\right)$. The SOC with the $2^{3}\left(\mathrm{n} \pi^{*}\right)$ triplet state is negligible.

The intersystem crossing (ISC) rate is inversely proportional to the energy gap $(\Delta E)$ between the electronic states and proportional to the SOC magnitude. The ISC rate is proportional to the following interaction factor: ${ }^{57}$

$$
f_{\text {SO }}=\frac{\mathrm{SOC}^{2}}{\Delta E^{2}}
$$

Therefore, the large SOC value between the ${ }^{1}\left(\mathrm{n} \pi^{*}\right)$ and $3^{3}\left(\pi \pi^{*}\right)$ electronic states and the small energy gap between them can lead to an efficient intersystem crossing, preventing the fluorescent decay. This proposed deactivation mechanism of the daidzein in acetonitrile is summarized in the schematic representation shown in Figure 5b.

It is interesting to observe that different deactivation mechanisms depending on the solvent type were also experimentally observed in the 5-fluorouracil molecular system. In that system, it is experimentally observed that the fluorescent rate is much lower in acetonitrile than in water. The theoretical 
results of Improta et al. ${ }^{58,59}$ indicate, in general, that in acetonitrile the $\mathrm{n} \pi^{*}$ (dark) and $\pi \pi^{*}$ (bright) electronic states are very close energetically. Therefore, besides the fluorescence of the $\pi \pi^{*}$ electronic state, another deactivation mechanism appears through a conical intersection between these electronic states. This behavior is not observed in water because the $n \pi^{*}$ state is less stable than the $\pi \pi^{*}$.

\section{CONCLUSIONS}

The photophysics of the daidzein molecular system was theoretically studied in water and in acetonitrile. The absorption spectra were properly characterized in both solvents, but the electronic deactivation is different depending on the solvent type, as indicated in the experimental works. The obtained results are summarized in the schematic energetic profiles shown in Figure 5. The fluorescence mechanism of the daidzein in water, after the absorption transition, is shown in Figure 5a. The ${ }^{1}\left(\mathrm{n} \pi^{*}\right)$ state, that in the gas phase and in acetonitrile is the lowest excited electronic state, is shifted to the blue region due to the interaction with water, whereas the ${ }^{1}\left(\pi \pi^{*} \mathrm{~L}_{\mathrm{b}}\right)$ electronic state is energetically stabilized. The emission energy corresponding to this electronic state is in excellent agreement with the experimental results, as well as the calculated Stokes shift value.

In acetonitrile the picture is different, as indicated in Figure $5 b$. The ${ }^{1}\left(\pi \pi^{*} \mathrm{~L}_{\mathrm{b}}\right)$ electronic state is the most populated in the absorption transitions. This electronic state in the equilibrium geometry is weakly solvated by the acetonitrile and does not stabilize enough. In the same way, the ${ }^{1}\left(\mathrm{n} \pi^{*}\right)$ electronic state is mildly shifted to the blue and remains more stable energetically than the ${ }^{1}\left(\pi \pi^{*} \mathrm{~L}_{\mathrm{b}}\right)$ state. The ${ }^{1}\left(\mathrm{n} \pi^{*}\right)$ electronic state, which is populated by internal conversion according to the Kasha rule, shows very favorable conditions for an intersystem crossing with the $3^{3}\left(\pi \pi^{*}\right)$ electronic states. It can be concluded that the deactivation mechanism proposed in Figure $5 b$ explains the nonfluorescent decay experimentally observed for the daidzein in acetonitrile. The deactivation mechanism of the triplet electronic states is still open for future investigation.

\section{ASSOCIATED CONTENT}

\section{S Supporting Information}

Optimized equilibrium geometries of the ground $\left(\mathrm{S}_{0}\right)$ and excited electronic states $\left({ }^{1} \pi \pi^{*} \mathrm{~L}_{\mathrm{b}}\right.$ and $\left.{ }^{1} \mathrm{n} \pi^{*}\right)$. This material is available free of charge via the Internet at http://pubs.acs.org/.

\section{AUTHOR INFORMATION}

\section{Corresponding Author}

*E-mail: canuto@if.usp.br.

\section{Notes}

The authors declare no competing financial interest.

\section{ACKNOWLEDGMENTS}

This work has been partially supported by INCT-FCx, nBioNet, CNPq, CAPES and FAPESP (Brazil).

\section{REFERENCES}

(1) Shimoi, K.; Masuda, S.; Shen, B.; Furugori, M.; Kinae, N. Radioprotective Effects of Antioxidative Plant Flavonoids in Mice. Mutat. Res., Fundam. Mol. Mech. Mutagen.. 1996, 350, 153-161.

(2) Knekt, P.; Jarvinen, R.; Seppanen, R.; Heliovaara, M.; Teppo, L.; Pukkala, E.; Aromaa, A. Dietary Flavonoids and the Risk of Lung Cancer and Other Malignant Neoplasms. Am. J. Epidemiol. 1997, 146, 223-230.
(3) Monasterio, A.; Urdaci, M. C.; Pinchuk, I. V.; Lopez-Moratalla, N.; Martinez-Irujo, J. J. Flavonoids Induce Apoptosis in Human Leukemia U937 Cells through Caspase- and Caspase-CalpainDependent Pathways. Nutr. Cancer 2004, 50, 90-100.

(4) Terao, J.; Kawai, Y.; Murcita, K. Vegetable Flavonoids and Cardiovascular Disease. Asia Pac. J. Clin. Nutr. 2008, 17, 291-293.

(5) Renaud, S.; Delorgeril, M. Wine, Alcohol, Platelets, and the French Paradox for Coronary Heart-Disease. Lancet 1992, 339, 15231526.

(6) Tunstall-Pedoe, H.; Kuulasmaa, K.; Mahonen, M.; Tolonen, H.; Ruokokoski, E.; Amouyel, P.; Project, W. M. Contribution of Trends in Survival and Coronary-Event Rates to Changes in Coronary Heart Disease Mortality: 10-Year Results from 37 WHO MONICA Project Populations. Lancet 1999, 353, 1547-1557.

(7) Rosenkranz, S.; Knirel, D.; Dietrich, H.; Flesch, M.; Erdmann, E.; Böhm, M. Inhibition of the PDGF Receptor by Red Wine Flavonoids Provides a Molecular Explanation for the "French Paradox". FASEB J. 2002, 16, 1958-1960.

(8) Criqui, M. H.; Ringel, B. L. Does Diet or Alcohol Explain the French Paradox. Lancet 1994, 344, 1719-1723.

(9) Gronbaek, M.; Deis, A.; Sorensen, T. I. A.; Becker, U.; Schnohr, P.; Jensen, G. Mortality Associated with Moderate Intakes of Wine, Beer, or Spirits. Br. Med. J. 1995, 310, 1165-1169.

(10) Klatsky, A. L.; Armstrong, M. A.; Friedman, G. D. Red Wine, White Wine, Liquor, Beer, and Risk for Coronary Artery Disease Hospitalization. Am. J. Cardiol. 1997, 80, 416-420.

(11) Gronbaek, M.; Becker, U.; Johansen, D.; Gottschau, A.; Schnohr, P.; Hein, H. O.; Jensen, G.; Sorensen, T. I. A. Type of Alcohol Consumed and Mortality from All Causes, Coronary Heart Disease, and Cancer. Ann. Intern. Med. 2000, 133, 411-419.

(12) Sengupta, P. K.; Kasha, M. Excited-State Proton-Transfer Spectroscopy of 3-Hydroxyflavone and Quercetin. Chem. Phys. Lett. $1979,68,382-385$.

(13) Wolfbeis, O. S.; Schipfer, R. Acidity Dependence of the Absorption and Fluorescence-Spectra of Isoflavone and 7-Hydroxyisoflavone. Photochem. Photobiol. 1981, 34, 567-571.

(14) Wolfbeis, O. S.; Furlinger, E.; Jha, H. C.; Zilliken, F. Absorption and Fluorescence of Isoflavones and the Effect of Shift Reagents. $Z$. Naturforsch. 1984, 39b, 238-243.

(15) Itoh, M.; Hasegawa, K.; Fujiwara, Y. 2-Step Laser Excitation Fluorescence Study of the Ground-State and Excited-State ProtonTransfer in Alcohol-Solutions of 7-Hydroxyisoflavone. J. Am. Chem. Soc. 1986, 108, 5853-5857.

(16) Mcmorrow, D.; Kasha, M. Intramolecular Excited-State ProtonTransfer in 3-Hydroxyflavone - Hydrogen-Bonding Solvent Perturbations. J. Phys. Chem. 1984, 88, 2235-2243.

(17) Sarkar, M.; Guha Ray, J.; Sengupta, P. K. Luminescence Behaviour of 7-Hydroxyflavone in Aerosol OT Reverse Micelles: Excited-State Proton Transfer and Red-Edge Excitation Effects. J. Photochem. Photobiol. A. 1996, 95, 157-160.

(18) Schwartz, B. J.; Peteanu, L. A.; Harris, C. B. Direct Observation of Fast Proton-Transfer - Femtosecond Photophysics of 3-Hydroxyflavone. J. Phys. Chem. 1992, 96, 3591-3598.

(19) Ameer-Beg, S.; Ormson, S. M.; Brown, R. G.; Matousek, P.; Towrie, M.; Nibbering, E. T. J.; Foggi, P.; Neuwahl, F. V. R. Ultrafast Measurements of Excited State Intramolecular Proton Transfer (Esipt) in Room Temperature Solutions of 3-Hydroxyflavone and Derivatives. J. Phys. Chem. A 2001, 105, 3709-3718.

(20) Bader, A. N.; Ariese, F.; Gooijer, C. Proton Transfer in 3Hydroxyflavone Studied by High-Resolution $10 \mathrm{~K}$ Laser-Excited Shpol'skii Spectroscopy. J. Phys. Chem. A 2002, 106, 2844-2849.

(21) de Rijke, E.; Joshi, H. C.; Sanderse, H. R.; Ariese, F.; Brinkman, U. A. T.; Gooijer, C. Natively Fluorescent Isoflavones Exhibiting Anomalous Stokes' Shifts. Anal. Chim. Acta 2002, 468, 3-11.

(22) Dunford, C. L.; Smith, G. J.; Swinny, E. E.; Markham, K. R. The Fluorescence and Photostabilities of Naturally Occurring Isoflavones. Photochem. Photobiol. Sci. 2003, 2, 611-615. 
(23) Chou, P. T.; Chen, Y. C.; Yu, W. S.; Cheng, Y. M. Spectroscopy and Dynamics of Excited-State Intramolecular Proton-Transfer Reaction in 5-Hydroxyflavone. Chem. Phys. Lett. 2001, 340, 89-97.

(24) Sarkar, M.; Sengupta, P. K. Luminescence Behaviour of 7 Hydroxyflavone: Temperature-Dependent Effects. J. Photochem. Photobiol. A 1989, 48, 175-183.

(25) Schipfer, R.; Wolfbeis, O. S.; Knierzinger, A. Ph-Dependent Fluorescence Spectroscopy 0.12. Flavone, 7-Hydroxyflavone, and 7Methoxyflavone. J. Chem. Soc., Perkin Trans. 2. 1981, 1443-1448.

(26) Prasad, De, S.; Ash, S.; Bar, H.; Kumar Bhui, D.; Dalai, S.; Misra, A. Excited State Intramolecular Proton Transfer in 5-Hydroxy Flavone: A DFT Study. J. Mol. Struct.: THEOCHEM. 2007, 824, 8-14.

(27) Marian, C. M. Spin-Forbidden Transitions in Flavone. Spectrochim. Acta Part A. 2009, 73, 1-5.

(28) Beyhan, S. M.; Gotz, A. W.; Ariese, F.; Visscher, L.; Gooijer, C. Computational Study on the Anomalous Fluorescence Behavior of Isoflavones. J. Phys. Chem. A 2011, 115, 1493-1499.

(29) Andersson, K.; Malmqvist, P. A.; Roos, B. O. 2nd-Order Perturbation-Theory with a Complete Active Space Self-Consistent Field Reference Function. J. Chem. Phys. 1992, 96, 1218-1226.

(30) Widmark, P. O.; Malmqvist, P. A.; Roos, B. O. Density-Matrix Averaged Atomic Natural Orbital (Ano) Basis-Sets for Correlated Molecular Wave-Functions 0.1. 1st Row Atoms. Theor. Chim. Acta 1990, 77, 291-306.

(31) Widmark, P. O.; Joakim, B.; Persson; Roos, B. O. DensityMatrix Averaged Atomic Natural Orbital (Ano) Basis-Sets for Correlated Molecular Wave-Functions 0.2. 2nd Row Atoms. Theor. Chim. Acta 1991, 79, 419-432.

(32) Fulscher, M. P.; Roos, B. O. The Excited-States of Pyrazine - a Basis-Set Study. Theor. Chim. Acta 1994, 87, 403-413.

(33) Frisch, M. J.; Trucks, G. W.; Schlegel, H. B.; Scuseria, G. E.; Robb, M. A.; Cheeseman, J. R.; Montgomery, J. A., Jr.; Vreven, T.; Kudin, K. N.; Burant, J. C.; et al. Gaussian 03, Revision D.01; Gaussian Inc.: Wallingford, CT, 2004.

(34) Tomasi, J. Thirty Years of Continuum Solvation Chemistry: A Review, and Prospects for the near Future. Theor. Chem. Acc. 2004, 112, 184-203.

(35) Coutinho, K.; Saavedra, N.; Canuto, S. Theoretical Analysis of the Hydrogen Bond Interaction between Acetone and Water. J. Mol. Struct.: THEOCHEM. 1999, 466, 69-75.

(36) Karlström, G.; Lindh, R.; Malmqvist, P.-Å.; Roos, B. O.; Ryde, U.; Veryazov, V.; Widmark, P. O.; Cossi, M.; Schimmelpfennig, B.; Neogrady, P.; et al. Molcas: A Program Package for Computational Chemistry; Lund University: Lund, Sweden, 2003.

(37) Canuto, S. Solvation Effects on Molecules and Biomolecules: Computational Methods and Applications; Springer: London, 2008.

(38) Georg, H. C.; Coutinho, K.; Canuto, S. Converged Electronic Polarization of Acetone in Liquid Water and the Role in the $\mathrm{n}-\pi^{*}$ Transition. Chem. Phys. Lett. 2006, 429, 119-123.

(39) Fonseca, T. L.; Georg, H. C.; Coutinho, K.; Canuto, S. Polarization and Spectral Shift of Benzophenone in Supercritical Water. J. Phys. Chem. A 2009, 113, 5112-5118.

(40) Orozco-Gonzalez, Y.; Coutinho, K.; Peon, J.; Canuto, S. Theoretical Study of the Absorption and Nonradiative Deactivation of 1-Nitronaphthalene in the Low-Lying Singlet and Triplet Excited States Including Methanol and Ethanol Solvent Effects. J. Chem. Phys. 2012, 137, 054307-8.

(41) Allen, M. P.; Tildesley, D. J. Computer Simulation of Liquids; Clarendon Press: Oxford, U.K., 1987.

(42) Coutinho, K.; Canuto, S. Dice: A Monte Carlo Program for Molecular Liquid Simulations; University of São Paulo: São Paulo, 2009.

(43) Jorgensen, W. L.; Maxwell, D. S.; Tirado-Rives, J. Development and Testing of the OPLS All-Atom Force Field on Conformational Energetics and Properties of Organic Liquids. J. Am. Chem. Soc. 1996, $118,11225-11236$

(44) Jorgensen, W. L.; Chandrasekhar, J.; Madura, J. D.; Impey, R. W.; Klein, M. L. Comparison of Simple Potential Functions for Simulating Liquid Water. J. Chem. Phys. 1983, 79, 926-935.
(45) Bohm, H. J.; McDonald, I. R.; Madden, P. A. An Effective Pair Potential for Liquid Acetonitrile. Mol. Phys. 1983, 49, 347-360.

(46) Kongsted, J.; Osted, A.; Mikkelsen, K. V.; Christiansen, O. The QM/MM Approach for Wavefunctions, Energies and Response Functions within Self-Consistent Field and Coupled Cluster Theories. Mol. Phys. 2002, 100, 1813-1828.

(47) Martin, M. E.; Sanchez, M. L.; del Valle, F. J. O.; Aguilar, M. A. A Multiconfiguration Self-Consistent Field/Molecular Dynamics Study of the $\left(\mathrm{n}-\pi^{*}\right)^{1}$ Transition of Carbonyl Compounds in Liquid Water. J. Chem. Phys. 2000, 113, 6308-6315.

(48) Coutinho, K.; Canuto, S.; Zerner, M. C. A Monte CarloQuantum Mechanics Study of the Solvatochromic Shifts of the Lowest Transition of Benzene. J. Chem. Phys. 2000, 112, 9874-9880.

(49) Coutinho, K.; Georg, H. C.; Fonseca, T. L.; Ludwig, V.; Canuto, S. An Efficient Statistically Converged Average Configuration for Solvent Effects. Chem. Phys. Lett. 2007, 437, 148-152.

(50) Ferré, N.; Ángyán, J. G. Approximate Electrostatic Interaction Operator for QM/MM Calculations. Chem. Phys. Lett. 2002, 356, 331-339.

(51) Hess, B. A.; Marian, C. M.; Wahlgren, U.; Gropen, O. A MeanField Spin-Orbit Method Applicable to Correlated Wavefunctions. Chem. Phys. Lett. 1996, 251, 365-371.

(52) Malmqvist, P. A.; Roos, B. O. The CASSCF State Interaction Method. Chem. Phys. Lett. 1989, 155, 189-194.

(53) Merchan, M.; Serrano-Andres, L.; Robb, M. A.; Blancafort, L. Triplet-State Formation Along the Ultrafast Decay of Excited Singlet Cytosine. J. Am. Chem. Soc. 2005, 127, 1820-1825.

(54) Platt, J. R. Classification of Spectra of Cata-Condensed Hydrocarbons. J. Chem. Phys. 1949, 17, 484-495.

(55) Kasha, M. Characterization of Electronic Transitions in Complex Molecules. Discuss. Faraday Soc. 1950, 14-19.

(56) El-Sayed, M. A. Spin-Orbit Coupling and the Radiationless Processes in Nitrogen Heterocyclics. J. Chem. Phys. 1963, 38, 28342838.

(57) Turro, N. J. Modern Molecular Photochemistry; University Science Books: Sausalito, CA, 1991.

(58) Gustavsson, T.; Sarkar, N.; Lazzarotto, E.; Markovitsi, D.; Barone, V.; Improta, R. Solvent Effect on the Singlet Excited-State Dynamics of 5-Fluorouracil in Acetonitrile as Compared with Water. J. Phys. Chem. B 2006, 110, 12843-12847.

(59) Santoro, F.; Barone, V.; Gustavsson, T.; Improta, R. Solvent Effect on the Singlet Excited-State Lifetimes of Nucleic Acid Bases: A Computational Study of 5-Fluorouracil and Uracil in Acetonitrile and Water. J. Am. Chem. Soc. 2006, 128, 16312-16322. 


\title{
Combining ab initio multiconfigurational and Free Energy Gradient methods to study the $\pi-\pi^{*}$ excited state structure and properties of uracil in water
}

\author{
Carlos Bistafa ${ }^{a}$, Herbert C. Georg ${ }^{b}$, Sylvio Canuto ${ }^{\mathrm{a}, *}$ \\ a Instituto de Física, Universidade de São Paulo, CP 66318, 05314-970 São Paulo, SP, Brazil \\ ${ }^{\mathrm{b}}$ Instituto de Física, Universidade Federal de Goiás, CP 131, 74001-970 Goiânia, GO, Brazil
}

\section{A R T I C L E I N F O}

\section{Article history:}

Received 3 February 2014

Received in revised form 22 April 2014

Accepted 23 April 2014

Available online 5 May 2014

\section{Keywords:}

Solvent effects

Uracil in water

Free Energy Gradient

Absorption and emission spectra

Stokes shift

\begin{abstract}
A B S T R A C T
The Free Energy Gradient method is used to obtain the $\pi-\pi^{*}$ excited state structure of uracil in aqueous environment. The geometry calculations are made at the CASSCF level. The CASPT2 method is employed to calculate absorption and emission energies of uracil in gas and in aqueous solution. An average discrete electrostatic model is used to include the solvent effect. The results for the calculated absorption and emission transitions are found in good agreement with experiment both in gas phase and in water The solvent effect on the Stokes shift is also calculated in good agreement with experiment. These agreements lend additional credence to the structures obtained for the lowest $\pi-\pi^{*}$ excited state.
\end{abstract}

(c) 2014 Elsevier B.V. All rights reserved.

\section{Introduction}

There has been an increasing interest in the understanding of the properties and dynamics of molecular excited states. As both the absorption and emission of the electromagnetic radiation are sensitive to the environment, this justifies the increasing interest on the role of solvent effects. Important applications with biological interest are provided by fluorescent probes, such as Laurdan and Prodan, that show great sensitivity to the solvent environment [1]. In biological processes, the DNA and RNA nucleobases, as thymine [2], adenine [3,4] and uracil [5-9] have dominated recent theoretical studies, because of the low quantum yield of emission associated to an intense absorption. This implies the existence of possible non-radiative decays and has stimulated the development of methodologies to study the structure and dynamics of excited states [10]. Such studies have shown some recent and interesting developments to include the effects of the solvent environment. In this work we address to the solvent effects on the excited $\pi-\pi^{*}$ state of uracil.

Among the nucleobases, uracil (Fig. 1) has been the subject of some previous studies, since the absorption and emission spectra have been observed in several solvents [2,11,12]. Previous

\footnotetext{
* Corresponding author.

E-mail address: canuto@if.usp.br (S. Canuto).
}

theoretical studies focused in describing the absorption spectrum $[6,13,14]$ agreeing that the dominant, most intense, transition has a $\pi-\pi^{*}$ character, with a close and weak $n-\pi^{*}$ transition. The order of these transitions depends on the environment, but in gas phase the $n-\pi^{*}$ is located lowest $[8,14,15]$. As in solvent $n-\pi^{*}$ transitions are expected to blue shift whereas $\pi-\pi^{*}$ are expected to red shift there is the possibility of reversal and indeed this seems to be the case in aqueous environment, but not in acetonitrile [16]. This possible reversal raises some interesting photophysical properties that have been addressed before [6]. Upon excitation to the bright $\pi-\pi^{*}$ excited state uracil undergoes important photophysical dynamics responsible for its known photostability. The clarification of the precise mechanisms and the dynamics of the low-lying excited states have been the subject of some important theoretical investigations $[6-9,16]$. In these, one important aspect is the role of the solvent in the deactivation mechanism and in the structure and position of the vertical and relaxed $\pi-\pi^{*}$ excited state. Although several studies have been performed before, they were mostly done for isolated uracil. In this work we are devoted to study the structure of the $\pi-\pi^{*}$ excited state in gas and in aqueous environment and on the nature of the emission transition.

Regarding the structural aspects Serrano-Andrés and coworkers [7] have used the complete active space self-consistent field (CASSCF) method [17] and the second-order corrected (CASPT2) [18], with an active space including all $\pi$ orbitals and found the excited $\pi-\pi^{*}$ state to have a planar structure after full geometry relaxation. 


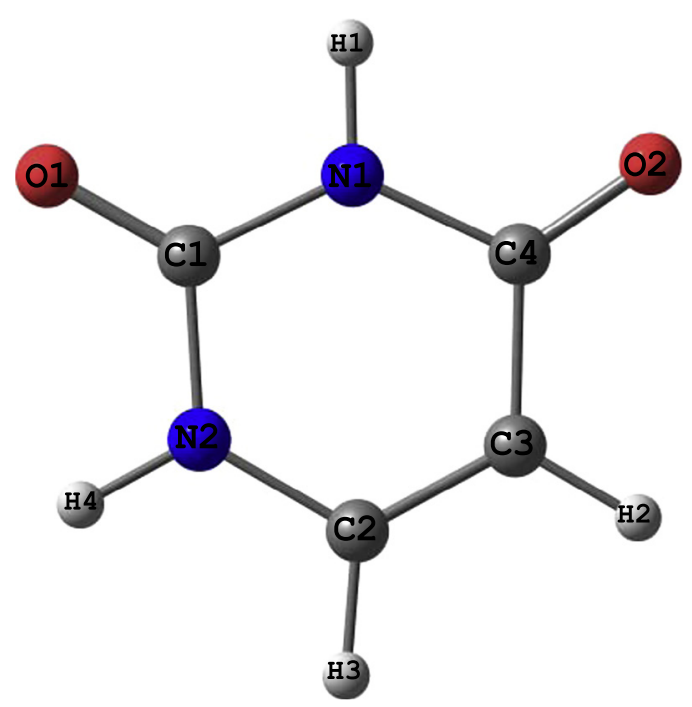

Fig. 1. The uracil molecule. Atomic labels are used in the text, Table 1 and Figs. 6 and 7 .

Next, Lischka and coworkers [8] have used the CASSCF method with a similar active space and also found a planar structure, but with one of the hydrogen atoms ( $\mathrm{H} 3$ in Fig. 1) lying out of the plane. This corroborated the result obtained by performing multi-reference configuration interaction (MR-CISD) calculations [8]. Recently, Yamazaki and Taketsugu [9] have used the CASSCF and CASPT2 methods (as implemented in Molpro package) with the full- $\pi$ active space. With the CASSCF method, they found a similar structure as obtained by Lischka and coworkers [8], but with the CASPT2 calculation they obtained instead a non-planar boatlike geometry. In a previous work Barone and coworkers [16] have used density-functional theory (DFT) combined with the polarizable continuum method (PCM) and microsolvation to study the excited state of uracil in solvent and they found a boat-like structure [16], whereas a planar structure was obtained in gas phase [14]. Despite the similarity in the shape, the geometries obtained in [16] using DFT and that obtained by Yamazaki and Taketsugu [9] with CASPT2 are not the same, because in these two cases the atoms in the ring are dislocated to opposite sides.

These theoretical disagreements recommend additional studies that will be important for the understanding of the emission properties of uracil in water. This is an interesting opportunity to apply the promising Free Energy Gradient (FEG) method developed by Nagaoka and co-workers $[19,20]$. In this present study we then focus in implementing the FEG method for excited state and thus in obtaining the structure of the excited state of uracil and its corresponding emission properties. Having obtained the absorption and the emission properties we naturally analyze the associated Stokes shift that is one of the characteristic aspects of the solvent effects in the photophysics of uracil in water. We will use the FEG procedure in a sequential QM/MM method [21] combined with the CASSCF method to obtain the geometry of the $\pi-\pi^{*}$ excited state of uracil in water environment. Solvent effects are included by using Monte Carlo simulations to generate an average solvent electrostatic configuration (ASEC) [22]. Thus to obtain the excited state geometry of uracil in water we use a scheme based on the FEG method [19,20], similar to that also used by Aguilar and coworkers to study reactions in solution [23]. We also obtain the ground state geometry and therefore calculate both the absorption and emission transition energies. These transition energies are obtained with the CASPT2 method and are used to analyze the solvent effects on the absorption, the emission and in the corresponding Stokes shift.

\section{Computational details}

The ground state geometry of uracil in gas phase was obtained at the MP2/aug-cc-pVDZ level using the Gaussian 03 package [24]. For the calculation of the geometry of the $\pi-\pi^{*}$ excited state it was used the state-average CASSCF with the atomic natural orbital basis, usually termed as SA-CASSCF/ANO-L-VDZP $[17,25]$. We consider the full- $\pi$ as active space ( 5 occupied and 3 virtual orbitals, Fig. 2), denoted as $\operatorname{CASSCF}(10,8)$, where 5 roots were included (the ground state and four excited states). This excited state is dominated by the HOMO $\rightarrow$ LUMO transition and is the most populated in the electronic excitation $[2,6-8,26]$. As noted before $[8,27]$, some earlier works reported that the unrestricted optimization of this state starting from the Frank-Condon region can lead directly to the conical intersection. We avoided this by performing a first optimization using the minimal ANO basis set (ANO-S-MB) and taking the converged result as new starting point for the definitive optimization. Just the diketo form of uracil was considered, because it is well established that this is the most stable form [28].

All transition energies (absorption and emission) were calculated by using the Multi State CASPT2 (MS-CASPT2) method [29], which is an extension of the CASPT2 for the case where SA-CASSCF reference functions are used. In this calculation, we used the full- $\pi$ active space, plus the lone-pair of the $\mathrm{O} 2$ atom (see Fig. 1) to describe the $n-\pi^{*}$ transition. Yamazaki and Taketsugu [9] observed that the lone-pair related to the $\mathrm{O} 1$ atom gives origin to transitions whose energies are beyond the range considered in our study, so it was not included in the active space. The 3 lowest roots were calculated corresponding to the ground, the excited $n-\pi^{*}$ and the $\pi-\pi^{*}$ states. The basis set adopted was the ANO-L, with the contraction scheme $\mathrm{C}, \mathrm{O}, \mathrm{N}\{14 \mathrm{~s} 9 \mathrm{p} 4 \mathrm{~d}\} /\{4 \mathrm{~s} 3 \mathrm{p} 1 \mathrm{~d}\}, \mathrm{H}\{8 \mathrm{~s} 4 \mathrm{p}\} /\{2 \mathrm{~s} 1 \mathrm{p}\}$. The selection of these bases sets was made because generally lead to converged results for the low-lying electronic transition energies of organic molecules [30]. These calculations are denoted as CASPT2 $(12,9)$. Finally, all calculations of the excited state structures and electronic transition energies were performed with the Molcas 7.6 Program Package [31].

As mentioned before the inclusion of solvent effects use the S-QM/MM methodology [21] with classical Monte Carlo (MC) simulations. These MC simulations were performed first to generate statistically uncorrelated configurations, which are used to construct the average solvent electrostatic configuration (ASEC) [22], where the water molecules are represented only by point charges (Fig. 3) in the atomic sites. Thus, although ASEC accounts only for the electrostatic effects it contains the variety of the possible liquid configurations including the solvent molecules involved in hydrogen bonds. This can be seen in the representation of the ASEC shown in Fig. 3, with the non-uniform distribution of the solvent molecules around the solute.

The MC simulations were performed using the DICE program [32]. The simulations were carried out in the NPT ensemble, in the normal thermodynamic conditions $\left(T=20^{\circ} \mathrm{C}\right.$ and $\left.P=1 \mathrm{~atm}\right)$ also used in the experiments [2]. After the thermalization has been assured, $3 \times 10^{5} \mathrm{MC}$ steps per molecule were performed. The simulation box was composed of 1 uracil molecule and 500 water molecules. Boundary conditions and image method were employed [33]. The molecules were taken as rigid and the molecular interaction was described by the Lennard-Jones (LJ) plus Coulomb potential. For uracil, the all-atom optimized potentials for liquid simulations (OPLS-AA) [34] were used for the Lennard-Jones parameters both in the ground and the excited states. However, to account for the electronic polarization, the atomic charges of uracil were obtained by using the ElectroStatic Potential Fitted (ESPF) method [35] at the SA-CASSCF(10,8)/ANO-L-VDZP level (see details below). For the water molecules, the simple point charge (SPC) model [36] was adopted. 

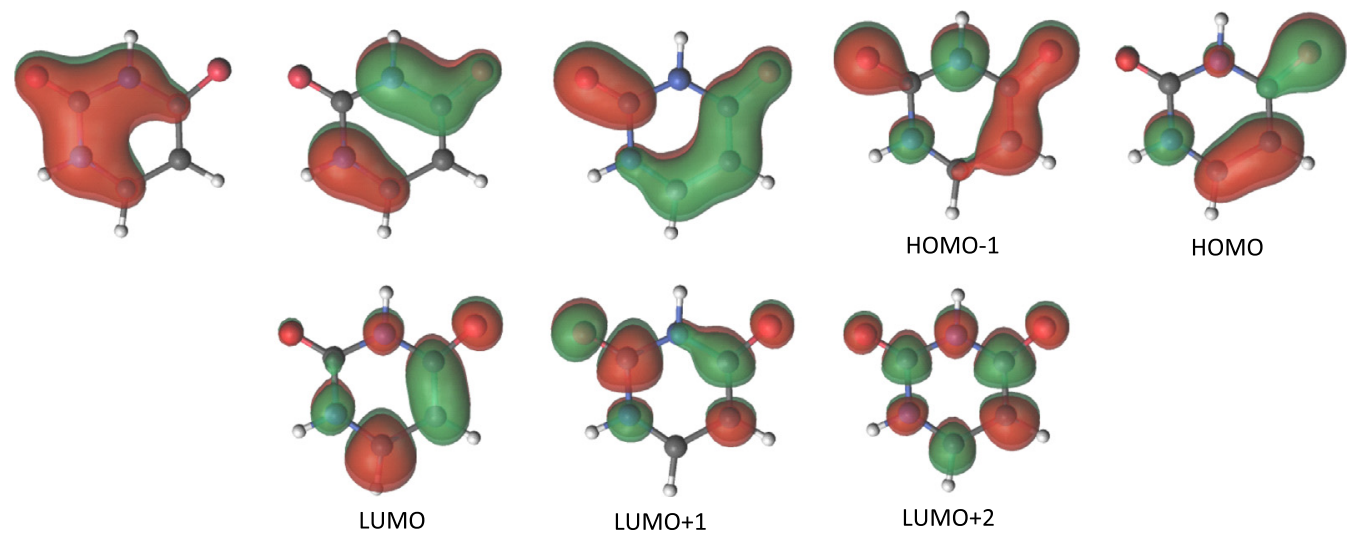

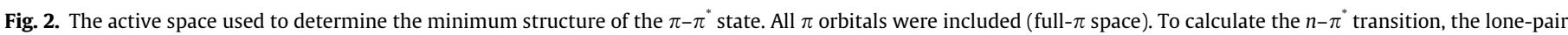
of the $\mathrm{O} 2$ atom was also included.

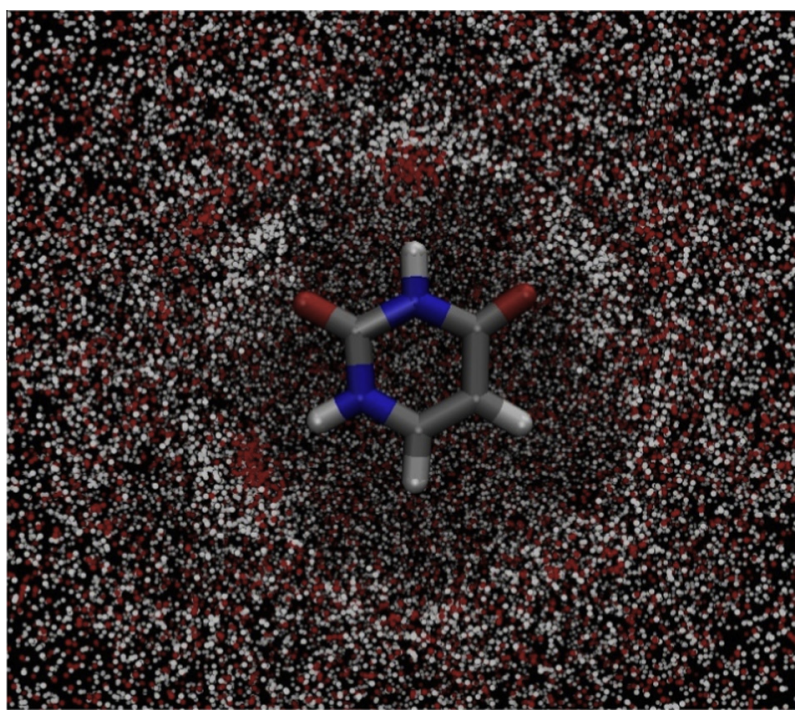

Fig. 3. Schematic representation of the ASEC, the solvent model used. Note the nonhomogenous distribution, corresponding to the solute-solvent hydrogen bonds.

The classical and quantum mechanical calculations are made sequentially, so appropriate care is necessary to include the electronic polarization of the solute due the presence of the solvent. Here, we used an iterative procedure [37] that has been successfully used in many applications [38-40], including excited states $[41,42]$. In this procedure, a simulation is performed using some initial solute charges, for instance those obtained for the isolated molecule. After a first simulation, the ASEC is generated and used to represent the solvent in a new calculation to fit the solute atomic charges, which are used in a second simulation and so on. The cycle is repeated until the convergence of the atomic charges. This convergence is monitored by looking at the corresponding calculated dipole moment. Here we consider convergence when the change in the calculated dipole moment is less than $0.1 \mathrm{D}$ $(\Delta \mu \leqslant 0.1 D)$.

For the excited state case, we extend the FEG methodology previously developed to obtain the ground state geometry of solute molecules in solution [43]. This is essentially based on the previous scheme used by Aguilar and co-workers to study reactions in solution [23], combining the FEG method [19,20] and the iterative polarization scheme aforementioned. It was used here just to obtain the excited $\pi-\pi^{*}$ state geometry of uracil in aqueous solution. In this case, the electrostatic field provided by ASEC is used to represent the solvent and the forces in the solute atoms are calculated. The atoms are displaced in the direction of the force and the new charges are fitted. Thus, in each step of the iterative procedure, charges and geometry are updated and the cycle is performed until the calculated dipole moment and the changes in the geometry achieve the pre-established threshold. This calculation was carried out in the Diceplayer Program [44], which is an interface between the DICE program and the Molcas Quantum Chemistry package. For the optimization in solvation, two different starting geometries were considered: the planar structure of the Franck-Condon region and the boat-like structure obtained by Gustavsson et al. using TD-DFT and microsolvation [16].

\section{Results}

\subsection{Geometries and electronic spectra in gas phase}

Table 1 shows the bond distances and bond angles calculated for the structures of the ground and the lowest $\pi-\pi^{*}$ states of isolated uracil. Also shown are the average experimental values for the ground state, compiled by Epifanovsky et al. [15]. Our calculated results give that both the ground and the $\pi-\pi^{*}$ excited states are planar. To facilitate the direct comparison we overlap the two calculated structures in Fig. 4. The changes are found to be small, but perceptible. The structure which we obtain for the $\pi-\pi^{*}$ excited state is in agreement with that obtained by Serrano-Andrés and coworkers, (for additional details see the supplementary material of Ref. [7]).

As discussed in the introduction, different results were obtained for the excited $\pi-\pi^{*}$ structure using different methods. In the gas phase the planar structures obtained in this present work was also obtained by Serrano-Andrés and coworkers [7], using the CASSCF method and the full- $\pi$ space. It has also been obtained by Improta and Barone [14] using time-dependent DFT with the PBEO functional. But it differs slightly from the nearly planar structures (only the $\mathrm{H} 3$ atom outside the plane) obtained by Nachtigallová et al. [8], using both CASSCF and MRCI-SD methods. This, however, is of the same type as obtained by Yamazaki and Taketsugu [9], using CASSCF.

In the absence of direct experimental information for the structure of the $\pi-\pi^{*}$ excited state we resort to the corresponding results for the spectral results. The consistency of the results obtained for the absorption, emission and in special the Stokes shift will lend credence to the structures we have obtained. Thus, we performed CASPT2 $(12,9)$ calculations to obtain the electronic transitions (absorption and emission). For the gas phase, experimental result is available for the absorption spectrum [26], while for the emission spectrum, the experimental data available was 
Table 1

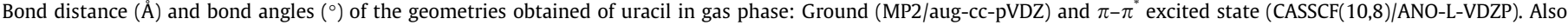

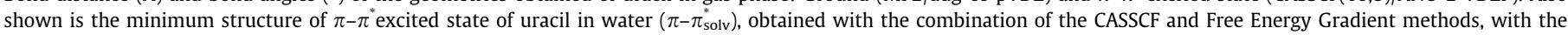
starting geometry in the Franck-Condon region. The atomic labels refer to Fig. 1 . The experimental values for the ground state are also shown for comparison. ${ }^{2}$

\begin{tabular}{|c|c|c|c|c|c|c|c|c|c|}
\hline Distance & $\operatorname{Exp}^{a}$ & Ground & $\pi-\pi^{*}$ & $\pi-\pi_{\text {solv }}^{*}$ & Angle & $\operatorname{Exp}^{\mathrm{a}}$ & Ground & $\pi-\pi^{*}$ & $\pi-\pi_{\text {solv }}^{*}$ \\
\hline $\mathrm{N} 2-\mathrm{C} 1$ & 1.379 & 1.394 & 1.373 & 1.340 & $\mathrm{C} 2-\mathrm{N} 2-\mathrm{C} 1$ & 121.3 & 123.7 & 127.3 & 120.0 \\
\hline C1-N1 & 1.373 & 1.389 & 1.377 & 1.342 & N2-C1-N1 & 114.8 & 113.0 & 113.3 & 123.0 \\
\hline $\mathrm{N} 1-\mathrm{C} 4$ & 1.383 & 1.412 & 1.374 & 1.432 & C1-N1-C4 & 127.0 & 128.4 & 124.7 & 122.4 \\
\hline C4-C3 & 1.440 & 1.463 & 1.351 & 1.401 & $\mathrm{~N} 1-\mathrm{C} 4-\mathrm{C} 3$ & 114.7 & 113.6 & 121.6 & 114.3 \\
\hline $\mathrm{C} 3-\mathrm{C} 2$ & 1.338 & 1.364 & 1.494 & 1.431 & $\mathrm{C} 4-\mathrm{C} 3-\mathrm{C} 2$ & 119.2 & 119.6 & 116.8 & 123.0 \\
\hline $\mathrm{C} 2-\mathrm{N} 2$ & 1.380 & 1.381 & 1.360 & 1.401 & $\mathrm{C} 3-\mathrm{C} 2-\mathrm{N} 2$ & 122.8 & 121.8 & 116.3 & 117.4 \\
\hline $\mathrm{C} 1-\mathrm{O} 1$ & 1.218 & 1.228 & 1.203 & 1.267 & O1-C1-N1 & 122.0 & 124.1 & 123.7 & 119.2 \\
\hline $\mathrm{C} 4-\mathrm{O} 2$ & 1.227 & 1.232 & 1.335 & 1.310 & $\mathrm{O} 2-\mathrm{C} 4-\mathrm{C} 3$ & 125.4 & 126.1 & 128.5 & 127.9 \\
\hline N1-H1 & - & 1.014 & 1.003 & 1.023 & $\mathrm{H} 4-\mathrm{N} 2-\mathrm{C} 1$ & - & 115.1 & 113.3 & 117.6 \\
\hline $\mathrm{C} 3-\mathrm{H} 2$ & - & 1.089 & 1.074 & 1.079 & H1-N1-C4 & - & 116.2 & 117.6 & 121.0 \\
\hline $\mathrm{C} 2-\mathrm{H} 3$ & - & 1.092 & 1.072 & 1.073 & $\mathrm{H} 2-\mathrm{C} 3-\mathrm{C} 2$ & - & 121.5 & 121.4 & 118.3 \\
\hline $\mathrm{N} 2-\mathrm{H} 4$ & - & 1.018 & 1.004 & 1.030 & $\mathrm{H} 3-\mathrm{C} 2-\mathrm{N} 2$ & - & 115.6 & 117.8 & 117.4 \\
\hline
\end{tabular}

a Values from average of X-ray measurements in crystalline structures (see Ref. [15]).

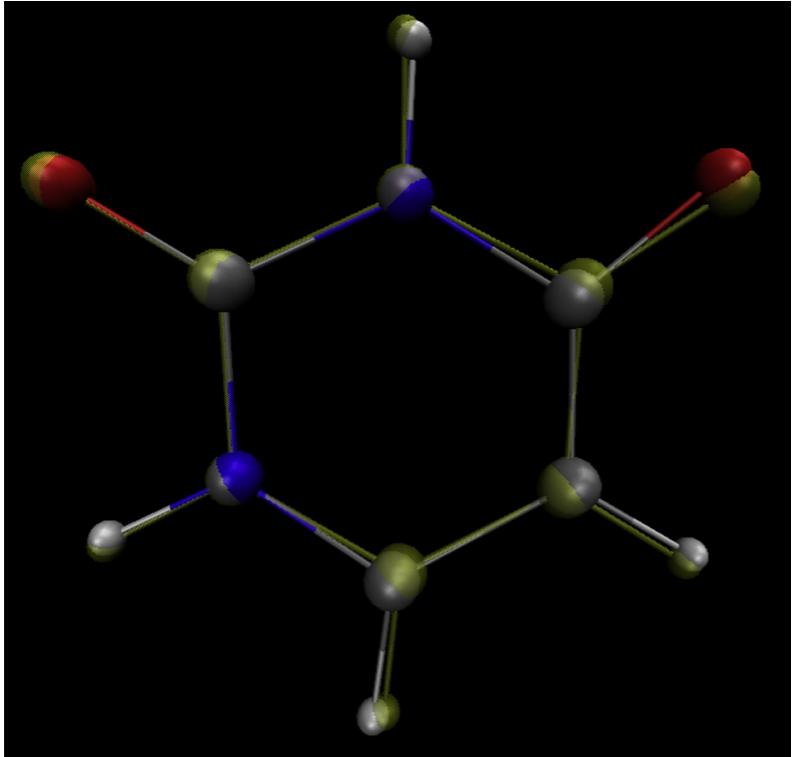

Fig. 4. Superposition of the equilibrium geometries of the ground (MP2/aug-ccpVDZ, yellow) and the $\pi-\pi^{*}$ excited state CASSCF(10,8)/ANO-L-VDZP of uracil in gas phase. (For interpretation of the references to colour in this figure legend, the reader is referred to the web version of this article.)

Table 2

Absorption and emission transition energies of uracil in gas phase (top) and in water solution (bottom), obtained using the CASPT2(12,9)/ANO-L-C,O,N $\{4 \mathrm{~s} 3 \mathrm{p} 1 \mathrm{~d}\} / \mathrm{H}\{2 \mathrm{~s} 1 \mathrm{p}\}$ level. Values in $\mathrm{eV}$.

\begin{tabular}{|c|c|c|c|c|c|}
\hline & & \multicolumn{2}{|c|}{ Absorption } & \multirow{2}{*}{$\begin{array}{l}\text { Emission } \\
\pi-\pi^{*}\end{array}$} & \multirow[t]{2}{*}{ Stokes shift } \\
\hline & & $n-\pi^{*}$ & $\pi-\pi^{*}$ & & \\
\hline Gas & & 4.91 & 5.18 & 4.29 & 0.89 \\
\hline Exp. & & - & $5.08^{\mathrm{a}}$ & $4.37^{\mathrm{b}}$ & 0.71 \\
\hline \multirow[t]{2}{*}{ Polarization } & Solvent & \multicolumn{2}{|c|}{ Absorption } & Emission & Stokes shift \\
\hline & Model & $n-\pi^{*}$ & $\pi-\pi^{*}$ & $\pi-\pi^{*}$ & \\
\hline Iterative & ASEC & 5.70 & 4.99 & $4.28 / 3.95^{c}$ & $0.71 / 1.04^{c}$ \\
\hline Iterative + FEG & ASEC & & & 3.68 & 1.31 \\
\hline Exp. & & $5.17^{d}$ & $4.79^{\mathrm{e}}$ & $3.88^{\mathrm{e}}$ & 0.91 \\
\hline
\end{tabular}

a Ref. [26].

b Value obtained in a supersonic jet experiment, Ref. [45] (see text).

c Results obtained considering the solvent in electrostatic non-equilibrium/ equilibrium with the excited state (see text).

${ }^{d}$ Non-conclusive evidence obtained in ECD spectrum, Ref. [51].

e Ref. [2]. obtained by using supersonic jet technique [45]. These experimental values are presented together with our CASPT2(12,9) results in Table 2.

For the absorption, we obtained for the vertical transition the value of $5.18 \mathrm{eV}$, in good agreement with the experimental band maximum value of $5.08 \mathrm{eV}$ [26]. This value compares very favorably also with some previous theoretical results. Climent et al. [7] also obtained the value of $5.18 \mathrm{eV}$. Ludwig et al. [46] using the time-dependent B3PW91/6-31G $(2 \mathrm{~d}, 2 \mathrm{p})$ also obtained the value of $5.18 \mathrm{eV}$ and a slightly lower value of $5.14 \mathrm{eV}$ in B3PW91/6$31+G(d, p)$. Gustavsson et al. [16] report the theoretical value of $\sim 5 \mathrm{eV}$. More recently, Yamazaki and Taketsugu [9] obtained the value of $4.92 \mathrm{eV}$, also in good agreement with experiment.

For the emission, our calculated value is $4.29 \mathrm{eV}$, in even better agreement with the experimental value reported at $4.37 \mathrm{eV}$ [45]. This emission has, in fact, been previously suggested to be the $n-\pi^{*}$ transition. For this reason we have also looked at the weak $n-\pi^{*}$ emission and have calculated it to be located at the lower value of $3.37 \mathrm{eV}$, just $0.45 \mathrm{eV}$ away from another transition measured in the same experiment at $3.83 \mathrm{eV}$ and suggested to be the $n-\pi^{*}$ transition of (possibly) a dienol tautomer of uracil. Thus we attribute the observed emission at $4.37 \mathrm{eV}$ to be due to the $\pi-\pi^{*}$ state that we calculate at $4.29 \mathrm{eV}$. This interpretation is within the expected accuracy of CASPT2 [47] contrasting with the location of the $n-\pi^{*}$ emission [45]. We should note that the experimental work was performed before the theoretical work of Roos and co-workers [13] has clarified the assignment of the low-lying excited states. Some works have shown that the $n-\pi^{*}$ excited state of uracil, which should lie below the $\pi-\pi^{*}$ state in the gas phase, can be populated through conical intersection and also the $n-\pi^{*}$ can couple with the ground state through another conical intersection. This mechanism, together with a direct channel coupling the ground and the $\pi-\pi^{*}$ states, are the standard mechanisms to explain the low quantum yields of uracil $[8,9,48]$.

Using the values we calculated for the absorption and emission transition energies, we obtain a Stokes Shift of $0.89 \mathrm{eV}$ in good agreement with the experimental value of $0.71 \mathrm{eV}$ that can be derived from the two experiments $[26,45]$. The agreement is significantly better than the one obtained in Ref. [9] for instance, in which the emission is calculated as $4.53 \mathrm{eV}$ and the Stokes shift is calculated as $0.39 \mathrm{eV}$.

Some previous studies raise doubts about the stability of this $\pi-\pi^{*}$ excited state in gas phase [5], even suggesting that the planar minimum obtained in CASSCF is lost when more correlation is included in the calculation [27]. The results obtained in the present work, may be taken as an indication that the minimum of the $\pi-\pi^{*}$ excited state energy surface is very shallow, being sensitive to the electron correlation effects. Moreover, a shallow minimum, a short 
lifetime and an almost barrierless way to the conical intersection is a consistent picture with the absence of direct experimental results of the emission of uracil in gas, with the supersonic jet experiment presenting the only available result. In the next session we will show that while the structure of the $\pi-\pi^{*}$ excited state of uracil can be considered an open question, the same is not true for the system in aqueous solution.

\subsection{Geometries and spectra in solution}

Now we analyze the emission spectra and the Stokes shift in solution. First, we will consider the geometrical structures obtained in gas phase and include the solvent effects without consideration of the solvent influence in the relaxation of the geometries. Next we will consider how the solvent affects, in special, the structure of the excited state.

To include the uracil electronic polarization due to the interaction with the aqueous environment, the iterative procedure previously mentioned was used. The change in the dipole moment of the ground and excited state is shown in Fig. 5a and b, respectively. The ground state dipole moment increases from 4.48 to $7.5 \mathrm{D}$, in agreement with previous result obtained with MP2/aug-cc-pVDZ [46].

Now to include the solute polarization in the excited state we consider its lifetime. Experimentally, the lifetime of the $\pi-\pi^{*}$ excited state has been measured as $0.1 \mathrm{ps}$ [16]. As it is noted in Fig. 4, the differences in geometry between the ground and excited state are mild. Hence this lifetime should be long enough to allow for the intermolecular changes in the excited state but it remains unclear whether the solvent polarization accompanies this change or remains in the electrostatic equilibrium with the ground state electronic structure. Hence with the purpose of studying the emission in electrostatic equilibrium/non-equilibrium with the solvent [42] the polarization is divided in two parts. First, we suppose that the lifetime of the excited state is short so, using the excited state geometry, the charges are obtained for the solvent in electrostatic equilibrium still with the ground state geometry of uracil (empty circles, Fig. 5b). In the second stage, we assume the solvent to be in electrostatic equilibrium with the relaxed geometry of the excited state (diamonds, Fig. 5b). In the second case the dipole moment of the $\pi-\pi^{*}$ has a converged value of $13.6 \mathrm{D}$. It should be noted the very large electronic polarization of uracil in the excited state. At the end of each stage, a CASPT2 $(12,9)$ calculation is performed to obtain the electronic transition energies in nonequilibrium (using the polarization obtained at the last point of the empty circle) and in equilibrium (last diamond point) with the solvent. These results are also presented in Table 2.

The $\pi-\pi^{*}$ absorption transition is calculated as $4.99 \mathrm{eV}$, in good agreement with the experimental value of $4.79 \mathrm{eV}$ [2]. For the emission, we obtain a value of $4.28 \mathrm{eV}$ when the solvent is in non-equilibrium with the solute, whereas the experimental value is $3.88 \mathrm{eV}$ [2]. In the other situation where there is electrostatic equilibrium, the emission is calculated as $3.95 \mathrm{eV}$, in much better agreement with the experiment. This result suggests that the lifetime of the excited state (experimentally measured as $0.1 \mathrm{ps}$ [16]) is long enough to allow the solute and the solvent to reach the electrostatic equilibrium. We may note that in water, the solvatochromic effect inverts the position of the $n-\pi^{*}$ state and $\pi-\pi^{*}$ states, as seen in Table 2 and in agreement with previous works $[16,46]$.

Using the values calculated for the absorption and emission transitions, we obtain a Stokes shift of $0.71 \mathrm{eV}$, in the non-equilibrium situation and $1.04 \mathrm{eV}$, in the equilibrium case, compared to the experimental value of $0.91 \mathrm{eV}$ [2]. Although both calculated values may be considered in fair agreement with the experimental
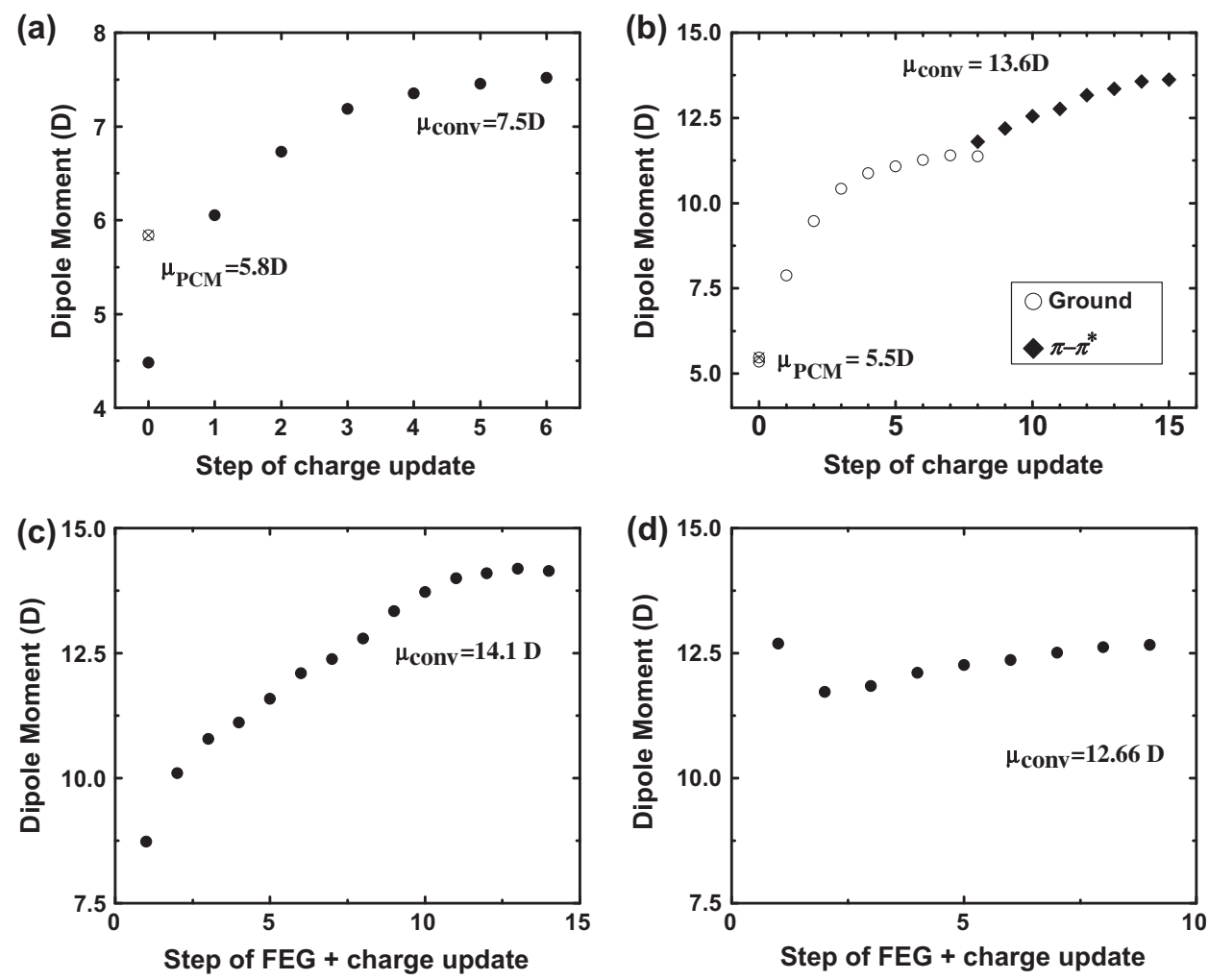

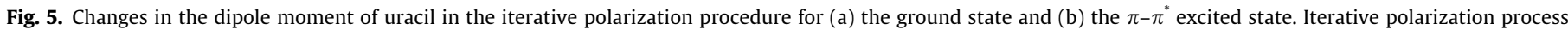

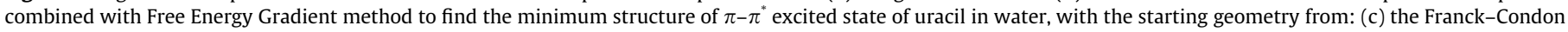
region and (d) Ref. [16]. The value obtained with PCM $(\otimes)$ is show for comparison. The converged dipole moment value $\left(\mu_{\text {conv }}\right)$ is the value of the last point. 
one, the value in the equilibrium condition shows a more satisfactory result, with the non-equilibrium case giving an incorrect trend, with the same value that is obtained in the gas phase.

Now we consider the solvent effects on the fully relaxed geometry of the excited state. First, we note that in an interesting and previous work [16] the solvent effect in the $\pi-\pi^{*}$ excited state structure of uracil was studied by using TD-DFT combined with continuum solvation and microsolvation approaches. Using the TD-PBE0/6-31G(d) level, a boat-like structure was found to be more stable considering uracil in acetonitrile (described by PCM) and in water (with addition of four explicit water molecules in the PCM calculation). At the same level of calculation the structure of the gas phase was obtained as planar [14].

For obtaining the geometry of the $\pi-\pi^{*}$ excited state of uracil, we implemented the iterative polarization method combined with the FEG method $[19,20]$, which was successfully used to describe the ground state of water in the liquid phase at normal condition [43]. So the atomic forces in uracil in the presence of the solvent water (represented by the ASEC) were determined at the SA-CASS$\mathrm{CF}(10,8) / A N O-L-V D Z P$ level and the atoms displaced in the direction of the forces. Thus, geometry and charges are updated in each step. From the results obtained before we assume that the emission occurs in electrostatic equilibrium, so only one iterative procedure was used, the one that considers electrostatic equilibrium (Fig. $5 \mathrm{c}$ ). In this case, the dipole moment of the excited state increases to $14.1 D$, a value that is close to the previous converged value of $13.6 D$, because the geometry relaxation is small. The convergence in the dipole moment shows only the electronic polarization effect. Fig. 6 then shows the variation of bond distance and bond angles due to the solvent. It is clear that after 10 steps, no significant variations occur and the convergence is attained within the expected accuracy [49] (in this case, $0.005 \AA$ in distances and $0.3^{\circ}$ in bond angles). The atomic forces in the last step are also shown. Note that they are larger than in gas phase optimization, but their effect is lower than typical thermodynamics effects [49]. The average and the maximum atomic forces converge to a constant value, with the RMS close to zero.

After convergence, the structure is in electrostatic and geometrical equilibrium with the solvent and again, we obtain a planar structure. Using this structure and representing the solvent by the ASEC, we performed a CASPT2 $(12,9)$ calculation to determine the electronic transition energies (Table 2). The value obtained for the emission is $3.68 \mathrm{eV}$, underestimating the experimental value by $0.2 \mathrm{eV}$, in contrast with the previous result that overestimates the experimental value by only $0.1 \mathrm{eV}$, both within the accuracy expected for the CASPT2 method. Considering the Stokes shift and the solvent effect on this shift the results are more in favor of the emission calculated at $3.95 \mathrm{eV}$. This contrast may be indicative that the lifetime of the excited state allows an electrostatic equilibrium between the solute and solvent, but that the emission occurs before the complete equilibration of the $\pi-\pi^{*}$ state in aqueous environment. Note that after step 10 (Fig. 6), the changes are very
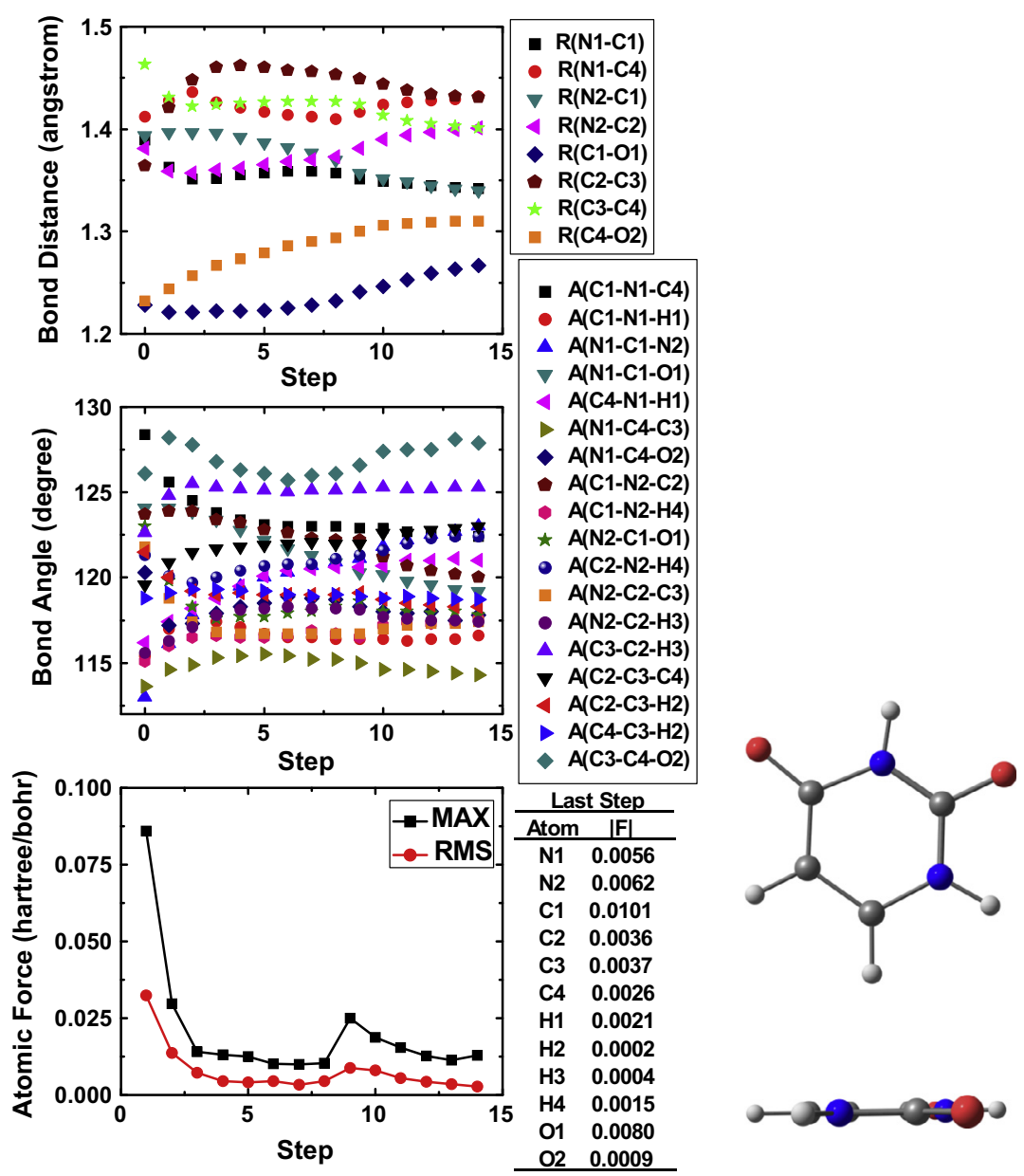

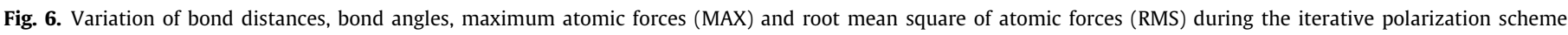

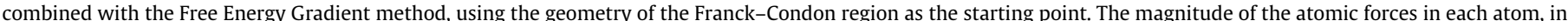

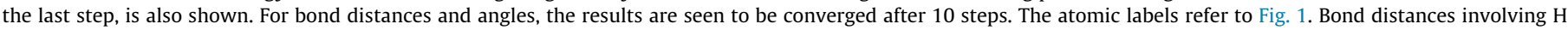
atoms are not shown because the changes are very small. The converged geometry of the molecule is also shown. 
small, so the geometry of the solute is almost converged. However the dipole moment still increases, from $13.7 \mathrm{D}$ in the step 10 (practically the converged value obtained in the previous calculation where just the charges were updated), up to the converged value 14.1 D. This increase can possibly be related to a final accommodation of the solvent due to the changes in the solute structure and, for this part, it seems there is no time. Indeed, performing a CASPT2 $(12,9)$ in the step 10 gives a emission value of $3.82 \mathrm{eV}$, in a better agreement with the experimental value than the value obtained in the convergence.

Regarding the solvent effect on the Stokes shift in water the experimental result of 0.91 can be compared with the result of gas phase of $0.71 \mathrm{eV}$ to give a solvent change in the Stokes shift of $0.20 \mathrm{eV}$. The present theoretical results indicate a solvent effect in the Stokes shift of $0.15 \mathrm{eV}$, in very good agreement with the experimental value. This effect is a consequence that the solvatochromic shift is more pronounced in the emission than in the absorption.

Finally, we consider some possible dependence of the calculated excited state geometry with the starting solute structure [19]. Thus, we performed the same procedure, but starting with the boat-like optimized geometry obtained before using microsolvation and TD-PBE0 [16]. In this case, because the starting point is already close to an optimized structure, the changes are only small (Fig. 7). The dipole moment originally decreases but during the iterative procedure, it increases again to the same value obtained in the first point (Fig. 5d). In the last point, a CASPT2 $(10,8)$
Table 3

Total energy (hartree) of the $\pi-\pi^{*}$ excited state of uracil using ASEC, after optimization performed with the FEG method. The total energy was obtained by using multiconfigurational methods, with the full- $\pi$ space and ANO-L-VDZP basis set. Bottom: the difference of energy between the two models, in hartree and $\mathrm{kcal} / \mathrm{mol}$. Estimated accuracy of the CASPT2 calculation is $0.1-0.2 \mathrm{eV}$ (see Ref. [47]).

\begin{tabular}{llll}
\hline Starting geometry & SA-CASSCF & SS-CASPT2 & MS-CASPT2 \\
\hline Ref. [16] & -412.58560 & -413.74232 & -413.74322 \\
Franck-Condon & -412.61969 & -413.76565 & -413.76733 \\
\hline$\Delta \mathrm{E}(\mathrm{hartree})$ & -0.03409 & -0.02333 & -0.024111 \\
$\Delta \mathrm{E}(\mathrm{kcal} / \mathrm{mol})$ & -21.38 & -14.63 & -15.12 \\
\hline
\end{tabular}

calculation was performed, giving a value for the emission transition that is $3.0 \mathrm{eV}$, or nearly $0.9 \mathrm{eV}$ far from the experimental value. We did not use the CASPT2 $(12,9)$ calculation in this case, because it shows an orbital rotation in the active space, such that the lone-pair becomes an inactive orbital.

We also compare the total energy of the system to find which of these two is the most stable structure. Table 3 shows the values of the total energy of the system (solute + ASEC), in the SA-CASSCF, SS-CASPT2 and MS-CASPT2 levels, with ANO-L-VDZP basis set and using the full- $\pi$ space. In all cases, the planar structure is the most stable by at least $14 \mathrm{kcal} / \mathrm{mol}$, concluding for a planar $\pi-\pi^{*}$ excited state in solution.

Summarizing, the present theoretical studies indicate that the geometry of the $\pi-\pi^{*}$ excited state of uracil in water is planar. This
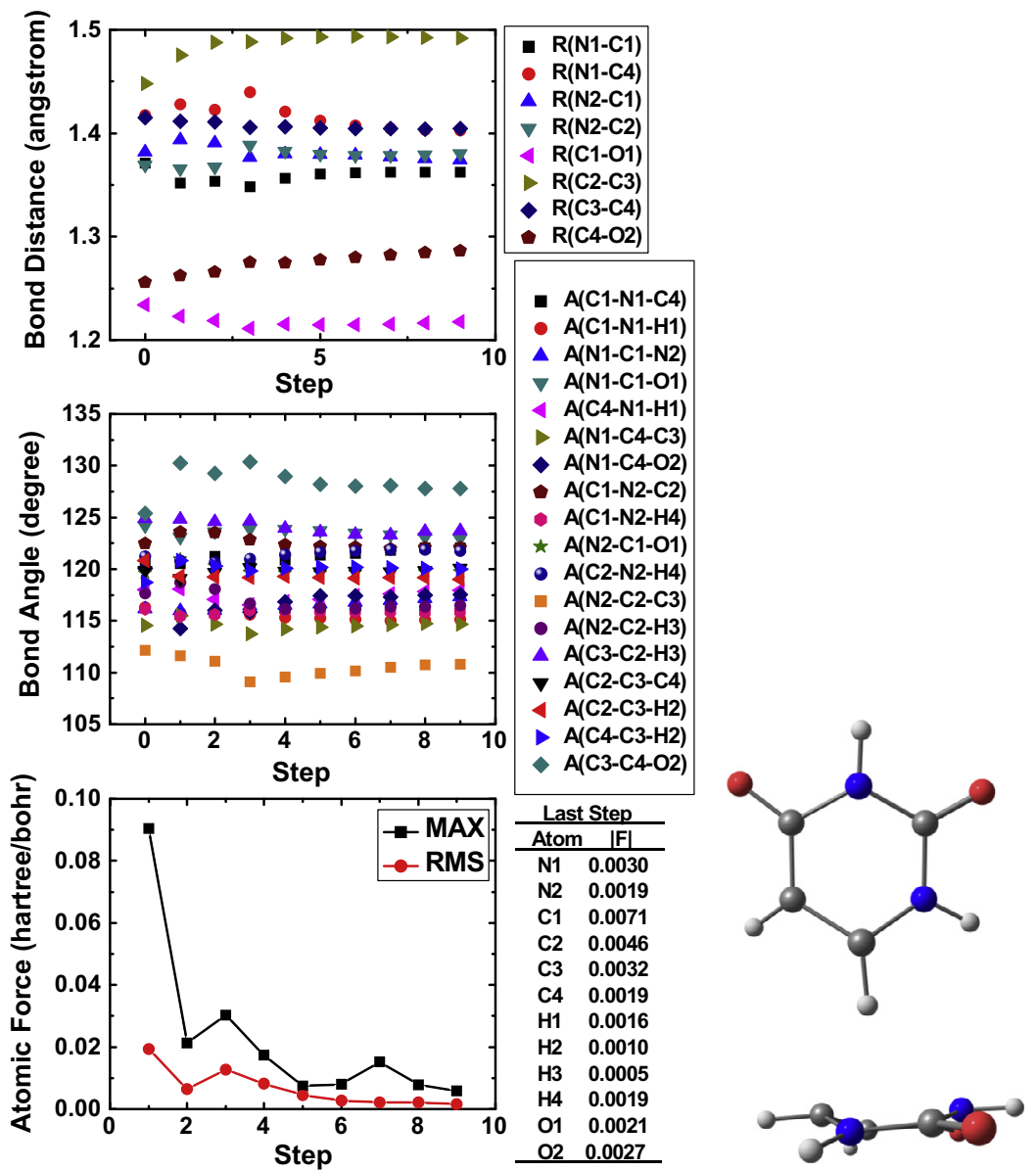

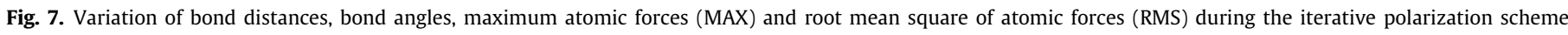

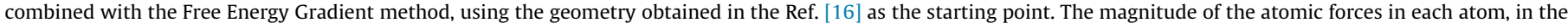

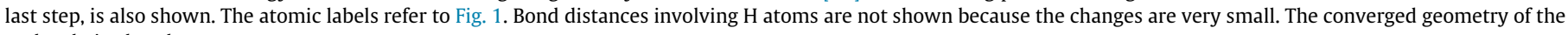
molecule is also shown. 
is used in the calculations of the emission transition and good results compared to experiments are found in both the gas phase and in solution. The results also indicate that the lifetime of the excited state should be large enough to allow for the solute-solvent electrostatic equilibrium, but the emission possibly occurs before a complete structural equilibration of the entire system.

\section{Conclusions}

In this work, we have studied the solvent influence in the structure of the $\pi-\pi^{*}$ excited state of uracil, and its consequence in the absorption and emission spectra. The solvent effect was accounted for by using the S-QM/MM method. Classical simulations were used to generate an average electrostatic configuration to represent the solvent. Special consideration was made for including the electronic polarization of uracil due to the aqueous environment.

Using the SA-CASSCF method to obtain the excited state structure and the MS-CASPT2 method to calculate the electronic transitions, with ANO-large basis set, we obtained the gas phase emission at $4.29 \mathrm{eV}$ in good agreement with the experimental value of $4.37 \mathrm{eV}$ obtained in supersonic jet experiment. In aqueous environment the emission is found at $3.95 \mathrm{eV}$ also in good agreement with experiment $(3.88 \mathrm{eV})$. The solvent effect in the Stokes shift is calculated as $0.15 \mathrm{eV}$, compared to the experimental value of $0.20 \mathrm{eV}$, leading additional credence to the structure of the excited state.

Combining the iterative polarization with the Free Energy Gradient method in CASSCF/ANO-L-VDZP calculations, with the full- $\pi$ space a planar structure was obtained for the fully relaxed $\pi-\pi^{*}$ excited state of uracil both in gas and in aqueous environment. In gas this minimum is probably too shallow to be observed and in water it is calculated to be more stable than the boat-like structure.

The consistence of the results motivates the forthcoming study of non-radiative decays in solution, along the lines previously adopted [50].

\section{Acknowledgments}

This work has been partially supported by FAPESP, CAPES, CNPq, INCT-FCX and nBioNet. CB thanks FAPESP for a PhD scholarship.

\section{References}

[1] J.R. Lakowicz, Principles of Fluorescence Spectroscopy, second ed., Springer, 2004

[2] T. Gustavsson, N. Sarkar, Á. Bányász, D. Markovitsi, R. Improta, Solvent effects on the steady-state absorption and fluorescence spectra of uracil thymina and 5-fluorouracil, Photochem. Photobiol. 83 (2007) 595-599.

[3] A. Broo, A theoretical investigation of the physical reason for the very different luminescence properties of the two isomers adenine and 2-aminopurine, J. Phys. Chem. A 102 (1998) 526-531.

[4] V. Ludwig, Z.M. da Costa, M.S. do Amaral, A.C. Borin, S. Canuto, L. SerranoAndrés, Photophysics and photostability of adenine in aqueous solution: theoretical study, Chem. Phys. Lett. 492 (2010) 164-169.

[5] S. Matsika, Radiationless decay of excited states of uracil through conical intersections, J. Phys. Chem. A 108 (2004) 7584-7590.

[6] F. Santoro, V. Barone, T. Gustavsson, R. Improta, Solvent effect on the singlet excited-state lifetimes of nucleic acid bases: a computational study of 5 fluorouracil and uracil in acetonitrile and water, J. Am. Chem. Soc. 128 (2006 $16312-16322$.

[7] T. Climent, R. González-Luque, M. Merchán, L. Serrano-Andrés, On the intrinsic population of the lowest triplet state of uracil, Chem. Phys. Lett. 441 (2007) 327-331.

[8] D. Nachtigallová, A.J.A. Aquino, J.J. Szymczak, M. Barbatti, P. Hobza, H. Lischka, Nonadiabatic dynamics of uracil: population split among different decay mechanisms, J. Phys. Chem. A 115 (2011) 5247-5255.

[9] S. Yamazaki, T. Taketsugu, Nonradiative deactivation mechanisms of uracil, thymine, and 5-fluorouracil: a comparative ab initio study, J. Phys. Chem. A 116 (2012) 491-503.
[10] K. Kleinermanns, D. Nachtigallová, M.S. de Vries, Excited state dynamics of DNA bases, Int. Rev. Phys. Chem. 32 (2013) 308-342.

[11] T. Gustavsson, N. Sarkar, E. Lazzarotto, D. Markovitsi, R. Improta, Singlet excited state dynamics of uracil and thymine derivatives: a femtosecond fluorescence upconversion study in acetonitrile, Chem. Phys. Lett. 429 (2006) $551-557$.

[12] T. Gustavsson, Á. Bányász, N. Sarkar, D. Markovitsi, R. Improta, Assessing solvent effects on the singlet excited state lifetime of uracil derivatives: a femtosecond fluorescence upconversion study in alcohols and D2O, Chem. Phys. 350 (2008) 186-192.

[13] J. Lorentzon, M.P. Fülscher, B.O. Roos, Theoretical study of the electronic spectra of uracil and thymine, J. Am. Chem. Soc. 117 (1995) 9265-9273.

[14] R. Improta, V. Barone, Absorption and fluorescence spectra of uracil in the gas phase and in aqueous solution: a TD-DFT quantum mechanical study, J. Am. Chem. Soc. 126 (2004) 14320-14321.

[15] E. Epifanovsky, K. Kowalski, P.-D. Fan, M. Valiev, S. Matsika, A.I. Krylov, On the electronically excited states of uracil, J. Phys. Chem. A 112 (2008) 99839992.

[16] T. Gustavsson, Á. Bányász, E. Lazzarotto, D. Markovitsi, G. Scalmani, M.J. Frisch, et al., Singlet excited-state behavior of uracil and thymine in aqueous solution: a combined experimental and computational study of 11 uracil derivatives, J. Am. Chem. Soc. 128 (2006) 607-619.

[17] B.O. Roos, The complete active space self-consistent field method and its applications in electronic structure calculations, in: K.P. Lawley (Ed.), Advances in Chemical Physics: Ab Initio Methods in Quantum Chemistry Part 2, vol. 69, John Wiley \& Sons, Inc., Hoboken, NJ, USA, 1987, pp. 399-445.

[18] K. Andersson, P.-Å. Malmqvist, B.O. Roos, Second-order perturbation theory with a complete active space self-consistent field reference function, J. Chem. Phys. 96 (1992) 1218-1226.

[19] N. Okuyama-Yoshida, M. Nagaoka, T. Yamabe, Transition-state optimization on free energy surface. Toward solution chemical reaction ergodography, Int. J. Quantum Chem. 70 (1998) 95-103.

[20] M. Nagaoka, Structure optimization of solute molecules via Free Energy Gradient method, Bull. Korean Chem. Soc. 24 (2003) 805-808.

[21] K. Coutinho, R. Rivelino, H.C. Georg, S. Canuto, The sequential QM/MM method and its applications to solvent effects in electronic and structural properties of solutes, in: S. Canuto (Ed.). Solvation Effects on Molecules and Biomolecules Computational Methods and Applications, Springer, 2008, pp. 159-189.

[22] K. Coutinho, H.C. Georg, T.L. Fonseca, V. Ludwig, S. Canuto, An efficient statistically converged average configuration for solvent effects, Chem. Phys. Lett. 437 (2007) 148-152.

[23] I.F. Galván, M.E. Martín, M.A. Aguilar, A new method to locate saddle points for reactions in solution by using the free-energy gradient method and the mean field approximation, J. Comput. Chem. 25 (2004) 1227-1233.

[24] M.J. Frisch, G.W. Trucks, H.B. Schlegel, G.E. Scuseria, M.A. Robb, J.R. Cheeseman, et al., Gaussian 03 (2004).

[25] P.-O. Widmark, P.-Å. Malmqvist, B.O. Roos, Density matrix averaged atomic natural orbital (ANO) basis sets for correlated molecular wave functions, Theor. Chim. Acta. 77 (1990) 291-306.

[26] L.B. Clark, G.G. Peschel, I. Tinoco Jr., Vapor spectra and heats of vaporization of some purine and pyrimidine bases, J. Phys. Chem. 69 (1965) 3615-3618.

[27] Z. Lan, E. Fabiano, W. Thiel, Photoinduced nonadiabatic dynamics of pyrimidine nucleobases: on-the-fly surface-hopping study with semiempirical methods, J. Phys. Chem. B 113 (2009) 3548-3555.

[28] C.M. Marian, F. Schneider, M. Kleinschmidt, J. Tatchen, Electronic excitation and singlet-triplet coupling in uracil tautomers and uracil-water complexes, Eur. Phys. J. D. 20 (2002) 357-367.

[29] J. Finley, P.-Å. Malmqvist, B.O. Roos, L. Serrano-Andrés, The multi-state CASPT2 method, Chem. Phys. Lett. 288 (1998) 299-306.

[30] M.P. Fülscher, B.O. Roos, The excited states of pyrazine: a basis set study, Theor. Chim. Acta. 87 (1994) 403-413.

[31] G. Karlström, R. Lindh, P.-Å. Malmqvist, B.O. Roos, U. Ryde, V. Veryazov, et al., MOLCAS: a program package for computational chemistry, Comput. Mater. Sci. 28 (2003) 222-239.

[32] K. Coutinho, S. Canuto, DICE, A Monte Carlo program for molecular liquid simulation (2010).

[33] M.P. Allen, D.J. Tildesley, Computer Simulation of Liquids, Oxford University Press, 1987.

[34] J. Pranata, S.G. Wierschke, W.L. Jorgensen, OPLS potential functions for nucleotide bases. relative association constants of hydrogen-bonded base pairs in chloroform, J. Am. Chem. Soc. 113 (1991) 2810-2819.

[35] N. Ferré, J.G. Ángyán, Approximate electrostatic interaction operator for QM/ MM calculations, Chem. Phys. Lett. 356 (2002) 331-339.

[36] H.J.C. Berendsen, J.P.M. Postma, W.F. van Gunsteren, J. Hermans, Interaction models for water in relation to protein hydration, in: B. Pullman (Ed.), Intermol, D. Reidel Publishing Company, Forces, 1981, pp. 331-338.

[37] H.C. Georg, K. Coutinho, S. Canuto, Converged electronic polarization of acetone in liquid water and the role in the $n-\pi^{*}$ transition, Chem. Phys. Lett. 429 (2006) 119-123.

[38] C. Bistafa, S. Canuto, Solvent effects on the two lowest-lying singlet excited states of 5-fluorouracil, Theor. Chem. Acc. 132 (2013) 1299.

[39] R.M. Gester, H.C. Georg, S. Canuto, M.C. Caputo, P.F. Provasi, NMR chemical shielding and spin-spin coupling constants of liquid $\mathrm{NH}_{3}$. A systematic investigation using the sequential QM/MM method, J. Phys. Chem. A 113 (2009) 14936-14942. 
[40] T.S. Almeida, K. Coutinho, B.J.C. Cabral, S. Canuto, Electronic properties of liquid ammonia: a sequential molecular dynamics/quantum mechanics approach, J. Chem. Phys. 128 (2008) 014506.

[41] Y. Orozco-González, K. Coutinho, S. Canuto, Excited state electronic polarization and reappraisal of the $\mathrm{n} \leftarrow \pi^{*}$ emission of acetone in water, Chem. Phys. Lett. 499 (2010) 108-112.

[42] Y. Orozco-Gonzalez, C. Bistafa, S. Canuto, Solvent effect on the Stokes shift and on the nonfluorescent decay of the daidzein molecular system, J. Phys. Chem. A 117 (2013) 4404-4411.

[43] H.C. Georg, S. Canuto, Electronic properties of water in liquid environment. A sequential QM/MM study using the Free Energy Gradient method, J. Phys. Chem. B 116 (2012) 11247-11254.

[44] H.C. Georg, S. Canuto, Diceplayer (2013).

[45] M. Fujii, T. Tamura, N. Mikami, M. Ito, Electronic spectra of uracil in a supersonic jet, Chem. Phys. Lett. 126 (1986) 583-587.
46] V. Ludwig, K. Coutinho, S. Canuto, A Monte Carlo-quantum mechanics study of the lowest $n-\pi^{*}$ and $\pi-\pi^{*}$ states of uracil in water, Phys. Chem. Chem. Phys. 9 (2007) 4907-4912.

[47] M. Merchán, L. Serrano-Andrés, Ab initio methods for excited states, in: M. Olivucci (Ed.) Computational Photochemistry, Elsevier B.V., 2005, pp, 35-91.

[48] A. Yoshikawa, S. Matsika, Excited electronic states and photophysics of uracilwater complexes, Chem. Phys. 347 (2008) 393-404.

[49] N. Okuyama-Yoshida, K. Kataoka, M. Nagaoka, T. Yamabe, Structure optimization via Free Energy Gradient method: application to glycine zwitterion in aqueous solution, J. Chem. Phys. 113 (2000) 3519.

[50] A. Muñoz-Losa, M.E. Martín, I.F. Galván, M.L. Sánchez, M.A. Aguilar, Solvent effects on the radiative and nonradiative decay of a model of the rhodopsin chromophore, J. Chem. Theory Comput. 7 (2011) 4050-4059.

[51] C.A. Sprecher, W.C. Johnson, Circular dichroism of the nucleic acid monomers, Biopolymers 16 (1977) 2243-2264. 


\section{Paranitrophenol and paranitrophenalate solvatochromic shift. A study combining ab initio multiconfigurational calculations and the Free Energy Gradient method}

Carlos Bistafa $^{1,2}$, Yukichi Kitamura ${ }^{2}$, Masataka Nagaoka² \& Sylvio Canuto ${ }^{1}$

${ }^{1}$ Institute of Physics, University of São Paulo, CP 66318, 05914-370 São Paulo, SP, Brazil

2 Graduate School of Information Science, Nagoya University, Furo-cho, Chikusaku, Nagoya, Aichi 464-8601, Japan

\section{ABSTRACT:}

A theoretical study about the paranitrophenol and paranitrophenalate solvatochromic shift is presented. The determination of the solute geometry in solution was carefully considered, by using continuum and QM/MM approaches. Molecular Dynamics simulations were used to sampling the liquid configurations and CASPT2 calculations were used to calculate the electronic transitions. Our results show that the solvatocromic shift of paranitrophenol can be explained by geometrical changes in the nitro group when interacting with water molecules, whereas this is not true for the paranitrophenalate.

[ARTIGO EM PREPARAÇÃO] 


\section{ANEXO B:}

Outras publicações do autor durante o Doutorado:

$>$ Theoretically describing the ${ }^{17} \mathrm{O}$ magnetic shielding constant of biomolecular systems: uracil and 5-fluorouracil in water environment

Rodrigo M. Gester, Carlos Bistafa, Herbert C. Georg, Kaline Coutinho \& Sylvio Canuto Theoretical Chemistry Accounts 133, 1424 (2014)

$>$ Including Thermal Disorder of Hydrogen Bonding to Describe the Vibrational Circular Dichroism Spectrum of Zwitterionic L-Alanine in Water

Ednilsom Orestes, Carlos Bistafa, Roberto Rivelino \& Sylvio Canuto, The Journal of Physical Chemistry A 119, 5099 (2015)

$>$ A systematic study of the lowest $n-\pi^{*}$ and $\pi-\pi^{*}$ electronic transitions of acrolein in solvent

Carlos Bistafa, Lucas Modesto-Costa \& Sylvio Canuto (em preparação) 



\title{
Theoretically describing the ${ }^{17} \mathrm{O}$ magnetic shielding constant of biomolecular systems: uracil and 5-fluorouracil in water environment
}

\author{
Rodrigo M. Gester - Carlos Bistafa • \\ Herbert C. Georg $\cdot$ Kaline Coutinho • \\ Sylvio Canuto
}

Received: 12 August 2013/ Accepted: 12 November 2013

(c) Springer-Verlag Berlin Heidelberg 2013

\begin{abstract}
The nuclear magnetic resonance chemical shielding of ${ }^{17} \mathrm{O}$ is of great importance for biomolecular characterization in water environment. In these systems, oxygen atoms occupy important positions and are involved in hydrogen bonds with the water environment. In this work, different solvation models are used for the theoretical determination of the ${ }^{17} \mathrm{O}$ chemical shielding of the nucleobase uracil and the substituted 5-fluorouracil in aqueous environment. Continuum, discrete and explicit solvent models are used, and an analysis is made of the role played by the solute polarization due the solvent. The best results are obtained using the sequential quantum mechanics/molecular mechanics methodology using an iterative procedure for the solute polarization, but a good compromise is obtained by using the electronic polarization provided by the polarizable continuum model. Quantum mechanical calculations of the chemical shieldings are made using density-functional theory in two different exchange-correlation approximations. Using an iterative procedure for the solute polarization and the mPW1PW91/ aug-pcS-2 model in the electrostatic approximation, we obtained magnetic shielding constants for the two $\mathrm{O}$ atoms of uracil within $2 \mathrm{ppm}$ of the experimental results. For
\end{abstract}

R. M. Gester - C. Bistafa - K. Coutinho - S. Canuto $(\bowtie)$ Instituto de Física, Universidade de São Paulo, CP 66318, São Paulo, SP 05315-970, Brazil

e-mail: canuto@if.usp.br

R. M. Gester

Faculdade de Física, Universidade Federal do Pará, Marabá, PA 68505-080, Brazil

H. C. Georg

Instituto de Física, Universidade Federal de Goiás, CP 131, Goiânia, GO 74001-970, Brazil 5-fluorouracil, the theoretical results, with the same model, are again in good agreement with the experimental values. An analysis of the influence of the solute-solvent hydrogen bonds in the chemical shielding of uracil case is also made, and it is concluded that the most important contribution to the calculated shielding derives from the electrostatic contribution to the solute-solvent interaction.

Keywords Magnetic shielding $\cdot$ QM/MM methods . Solvent effects · Hydrogen bonds · DFT method

\section{Introduction}

Nuclear magnetic resonance (NMR) is one of the most important spectroscopic techniques in molecular characterization [1]. In recent years, it has been widely and successfully used to characterize biomolecular systems. In this vein, oxygen is one of the most important atoms in both, chemistry and biology. Oxygen is essential in most biomolecules occupying important positions and often involved in relevant intra- and intermolecular hydrogenbonded interactions. These features make the oxygen spectrum of great importance in NMR experiments $[2,3]$. The ${ }^{17} \mathrm{O}$ is the only naturally occurring oxygen isotope with nonzero nuclear spin. Its low natural abundance $(0.04 \%)$ is reported as the most experimental difficulty and justifies the restricted attention dedicated to this isotope. In fact, there are only few experimental NMR works dealing with ${ }^{17} \mathrm{O}$ magnetic constants [2-5]. There is then a clear importance in better understanding the magnetic properties of oxygen atoms in biomolecular systems. Although ${ }^{17} \mathrm{O}$ is found on several biomolecules, there are only a limited number of experimental works that use ${ }^{17} \mathrm{O}$ NMR to investigate biomolecular systems such as the nucleobases 
$[4,5]$. This is the major interest of this present theoretical study where the NMR properties of ${ }^{17} \mathrm{O}$ in uracil and 5-fluorouracil are analyzed. We focus in the magnetic shielding of ${ }^{17} \mathrm{O}$ in both uracil and 5-fluorouracil, but have in mind also larger biological systems. Hence, the use of simplified models is analyzed in comparison with more elaborated procedures. As we will demonstrate for these two systems, the inclusion of the electrostatic interaction between the solute and the solvent is the major effect dominating the oxygen magnetic shielding, and in fact, very good results are obtained at this level.

The uracil molecule (Fig. 1) is a nucleobase naturally found in RNA making base pair with adenine. A simple change in uracil generates the 5-fluorouracil molecule (also shown in Fig. 1) that is used as an anticancer drug by blocking the RNA replication of disease cells [6]. For proper biological considerations, the interest is to study not the isolated biomolecule, but to consider the water environment. There is an early experimental work on the ${ }^{17} \mathrm{O}$ magnetic constants in uracil, and its derivatives performed by Chandrasekaran et al. [7]. A theoretical and experimental work [8] has clarified some aspects, using a microsolvation approach. In this present work, we consider in detail the role of the solute-solvent interaction and the water solvent environment using a combined and sequential classical simulation and quantum mechanics calculations, termed as sequential quantum mechanics/molecular mechanics methodology (S-QM/MM) [9-11].

Solvation effects [9-11] are one of the primary focuses of developments in present computational quantum chemistry. Therefore, we have seen several theoretical works dedicated to NMR constants and its applications [12-26]. There are essentially two major possibilities for theoretical calculations of solvent effects. The first is the use of a continuum model such as the polarizable continuum model (PCM) [27, 28] that still dominates the theoretical applications. The second is the use of explicit solvent molecules with consideration of the thermodynamic condition. Both are used here. In the second, liquid configurations are generated by Monte Carlo (MC) simulation and used in subsequent calculations of the NMR properties. As the quantum mechanical (QM) calculations are made after the classical MC simulation, this uncoupling imposes the need for a proper consideration of the electronic polarization of the solute by the solvent. The solute polarization is a response of the electrostatic moments of the reference solute molecule due to its interaction with the solvent. This solute polarization has proven to be important in several previous studies [15, 29-31]. There are different possibilities available [29-35] for dealing with this. We have successfully used an iterative procedure [34, 35] bringing the solute into electrostatic equilibrium with the solvent. This is rather feasible for relatively small molecules such as uracil and 5-fluorouracil. Thus, it will also be used here. However, for larger solute molecules of biological interest, this procedure may become computationally inconvenient. Hence, in previous works [12, 13], we have also used a combination of PCM and $\mathrm{S}-\mathrm{QM} / \mathrm{MM}$. In this, the atomic charges of the solute are obtained in the solvent environment using PCM. These charges are then used in the force field of the classical simulation. This is also used here. These iterative and PCM-QM/MM schemes have been successfully applied in the study of several molecular properties in solution [15], including magnetic constants [12-16].

In this work, we focus on the biologically important ${ }^{17} \mathrm{O}$ and therefore present an investigation of the oxygen nuclear magnetic chemical shielding of uracil and 5-fluorouracil in explicit aqueous environment with consideration of the solute polarization and analyzing different solvent models. The influence of the hydrogen bonds formed between the solute and the water solvent is also discussed.
Fig. 1 Structures of a uracil and b 5-fluorouracil. The labels are used in the text and tables
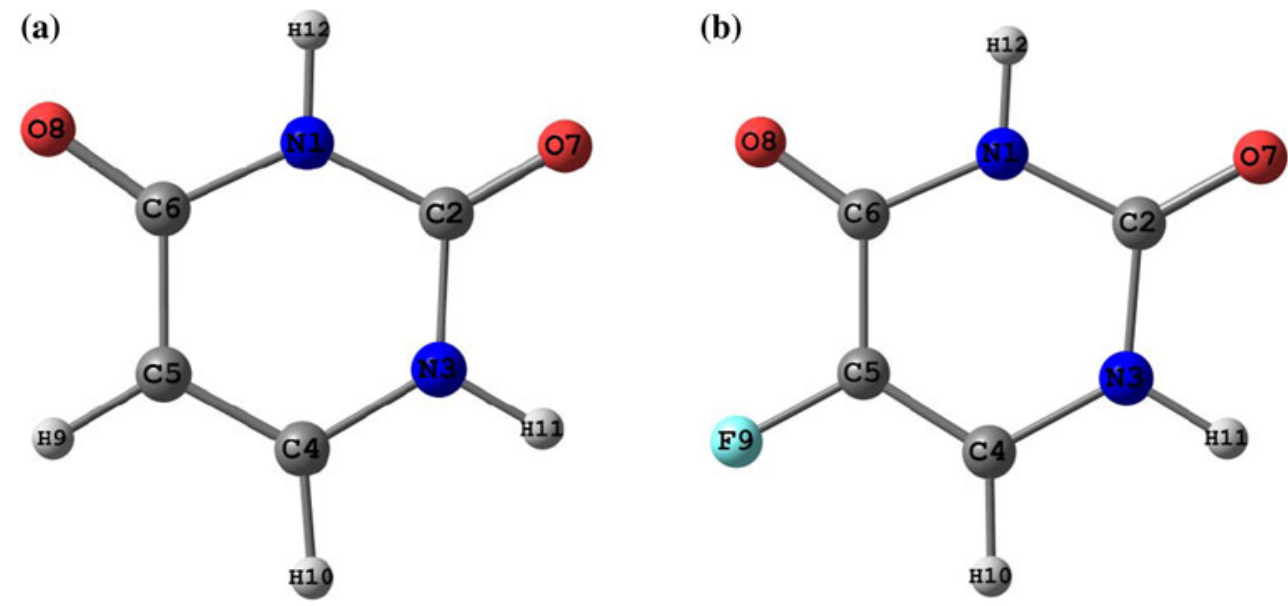


\section{Methods}

We use a sequential QM/MM methodology where the liquid configurations are generated and structures are sampled for subsequent QM calculations. The liquid structure was then obtained using the Metropolis MC simulation in the NPT ensemble, where one solute molecule was solvated by 700 water molecules. The uracil and 5-fluorouracil geometries used were first obtained by optimizing the geometry at the MP2/aug-ccpVTZ level.

The systems were treated at $95{ }^{\circ} \mathrm{C}$ and 1 atm corresponding to the experimental condition [7]. The intermolecular interactions were mediated by the standard Lennard-Jones (LJ) plus Coulomb potential. The LJ parameters of the solute correspond to the OPLS force field [36]. The water model used was the TIP3P [37]. The atomic charges for the solute Coulomb potential were obtained including the solute polarization by the solvent. Solute polarization is the change in the electrostatic moments due to its interaction with the solvent molecules. This is first included by using a simple PCM calculation and obtaining the solute atomic charges in the solvent environment. Another possibility used is an iterative procedure that brings the solute and the solvent into electrostatic equilibrium and has been described before [34]. The solute atomic charges are fitted with the CHELPG scheme [38] in MP2/aug-cc-pVTZ calculations and iterated until the dipole moment of the solute converges within $0.01 \mathrm{D}$. The MP2/aug-cc-pVTZ level of calculation has been found to give good results for the dipole moment and atomic charges and has then been employed here [39]. The MC simulations were performed using the DICE program [40]. After equilibration, the liquid structures were generated using $3.51 \times 10^{8} \mathrm{MC}$ steps. After concluding the MC simulation, configurations composed by the solute and the solvent are sampled for the QM calculations. Of course, it is not realistic the use of all structures generated by the MC simulation, and in fact, it is not necessary. The sampling can be optimized by using the autocorrelation function of the energy to systematically use statistically uncorrelated configurations [41]. A total of 100 configurations were then selected, with a correlation that is less than $13 \%$. These are the structures used in the quantum mechanics (QM) calculations, and the final result is taken as statistically converged averages. Part of the system is treated as explicit molecules, with a wave function that is antisymmetric and the remainder that are treated as point charges, only. The selection of the solvent molecules to be used in the QM part is based on the analysis of the solvation shells. In particular, we will pay special attention to the solvent molecules that are hydrogen bonded to the solute. In this case, both the solute and the HB solvent molecules are treated quantum mechanically. If all solvent molecules are treated as point charges, only the electrostatic solute-solvent interaction is included. In this specific case, it is possible to obtain the same statistically converged average value with only one QM calculation performed using an average configuration. This has been termed before as the average solvent electrostatic configuration (ASEC) [42]. The ASEC is a configuration counterpart of the average potential used by Aguilar and co-workers and termed ASEP [43]. Including the HB solvent molecules requires a proper identification of the hydrogen bonds. We use both geometrical and energetic criteria $[44,45]$ to select the water molecules making hydrogen bond (HB) with the solute, as successfully used before [46]. The geometrical criterion is obtained from the radial distribution function and the energetic one from the pairwise energy interaction [46]. Hence, we use here $r\left(O_{\text {solute }}-O_{\mathrm{w}}\right)<4.0 \AA, E<-4.0$ $\mathrm{kcal} / \mathrm{mol}$ and $\theta_{\mathrm{O}-(\mathrm{OH}) \mathrm{w}}<40.0^{\circ}$. The calculations that use only the solute and the HB solvent molecules are termed as HB model. In addition to this, we have considered the bulk effect and used the remaining solvent molecules as an electrostatic embedding thus using 350 nearest water molecules treated as point charges. This model is then called $\mathrm{HB}+\mathrm{PC}$ with the solvent and hydrogen-bonded water molecules treated quantum mechanically and the entire system embedded in the electrostatic field of the remaining water molecules.

For the calculation of the magnetic shielding constants, we have used density-functional theory (DFT). Based in successful previous results for shielding constants [13, 4749] and indirect spin-spin coupling [14, 50], all NMR parameters were calculated using B3LYP [51, 52] and mPW1PW91 [53, 54] functionals with the appropriate augpcS-n [55] basis set, specially designed for chemical shielding calculations. For the gas-phase calculations and both the PCM and ASEC solvation models, the aug-pcS-2 basis set was used. In the case of $\mathrm{HB}$ and $\mathrm{HB}+\mathrm{PC}$ models, this is computationally more involved and we compromised still using the aug-pcS-2 basis set on the oxygen atom but the pcS-2 on the other atoms. To avoid the gauge problem, we have used the gauge-included atomic orbital method (GIAO) [56-61]. Finally, for better comparison, the chemical shift $(\delta)$ was converted to the theoretical magnetic shielding $(\sigma)$ by using the absolute shielding scale of Wasylishen and Bryce [62] for oxygen:

$\sigma_{\text {liquid }}=287.5 \pm 0.6 \mathrm{ppm}-\delta_{\text {liquid }}$

All quantum mechanics calculations were carried out in the Gaussian 03 program [63]. 
Table 1 The electronic charges $(e)$ of oxygen obtained with the CHELPG scheme and the calculated dipole moments $\mu(\mathrm{D})$ of uracil (5fluorouracil) in gas phase and in aqueous environment

\begin{tabular}{llccc}
\hline Atom & Gas & PCM $^{\mathrm{a}}$ & PCM/PCM & Iterative \\
\hline $\mathrm{O}_{7}$ & $-0.575(-0.567)$ & $-0.685(-0.674)$ & $-0.698(-0.689)$ & $-0.743(-0.726)$ \\
$\mathrm{O}_{8}$ & $-0.566(0.176)$ & $-0.687(0.214)$ & $-0.702(0.215)$ & $-0.747(0.195)$ \\
$\mu$ & $4.34(3.93)$ & $6.03(5.60)$ & $6.36(5.91)$ & $6.45(5.92)$ \\
\hline
\end{tabular}

Results obtained at the MP2/aug-cc-pVTZ level

${ }^{\text {a }}$ For this calculation, we used $\varepsilon=55.6$, which is the dielectric constant of water at $100{ }^{\circ} \mathrm{C}$

b PCM/PCM means that the geometry was optimized considering the solute involved by PCM, and subsequently, it was used to fit the charges, again considering the molecule involved by PCM

\section{Results and discussion}

\subsection{Solute polarization}

First, we discuss the electronic polarization of the solute due to the solvent. Table 1 shows the calculated charges on the oxygen atoms and the dipole moments of uracil and 5 -fluorouracil. For the isolated uracil, the dipole moment computed here is $4.34 \mathrm{D}$. This value agrees with the previous result of $4.39 \mathrm{D}$, which was calculated at the MP2/ aug-cc-pVDZ level [64]. These results are in good agreement with the results of $4.51,4.29$ and $4.33 \mathrm{D}$ [65], respectively, obtained using DFT/PBE1PBE, MP2 and $\operatorname{CCSD}(\mathrm{T})$ calculations with the Dunning aug-cc-pVDZ basis functions. An early experimental result indicates a value of $3.87 \mathrm{D}$ for uracil in gas phase [66], a value that seems too low considering the theoretical calculations, as noted before [64]. We obtained a dipole moment of isolated 5-fluorouracil as $3.93 \mathrm{D}$ (Table 1), but apparently there are no experimental results for comparison.

For hydrated uracil, the iterative procedure yields a dipole moment of $6.45 \mathrm{D}$. This value is in fair agreement with the result obtained by describing the solvent using PCM (6.03 D). In water solution, the iterative method and PCM predict that polarization effects increase the dipole moment by about 50 and $40 \%$ from its value in theoretical gas phase (Fig. 2). A recent work [64] also used the S-QM/ MM method to calculate the dipole moment and found a value of $7.01 \mathrm{D}$ for uracil in water at the different thermodynamic condition of $25{ }^{\circ} \mathrm{C}$ and $1 \mathrm{~atm}$.

Similarly, in the case of 5-fluorouracil, we obtained a dipole moment of 5.60 D using PCM and 5.92 D using the iterative procedure corresponding to about 43 and $51 \%$ larger than the gas-phase value, respectively.

To consider how the geometry change induced by the solvent affects the charges, the geometry of both uracil and 5-fluorouracil was re-optimized including solvent effects using PCM (named as PCM/PCM, Table 1). In this case, the calculated dipole moments were $6.36 \mathrm{D}$ for uracil and $5.91 \mathrm{D}$ for 5-fluorouracil, very close to the values obtained
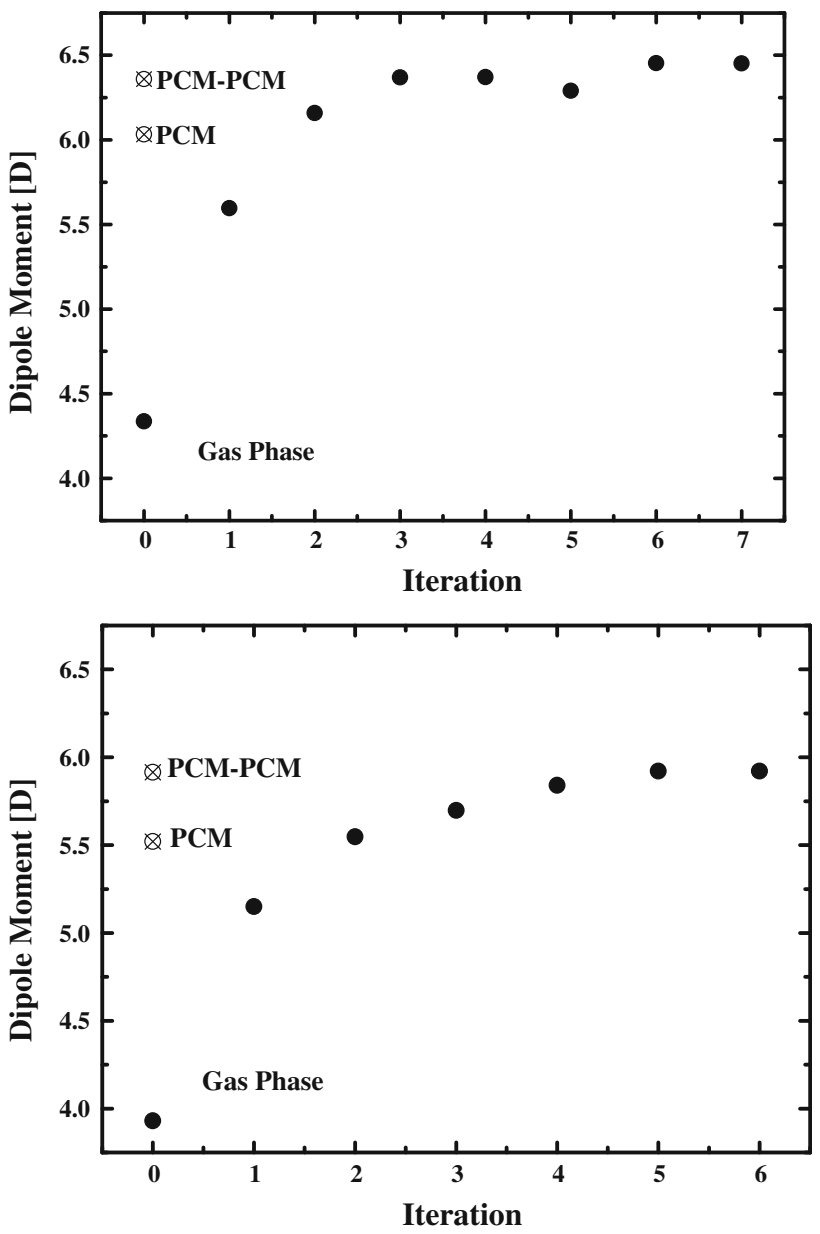

Fig. 2 The dipole moment for hydrated uracil (top) and 5-fluorouracil (bottom) versus the number of iterations. PCM means the value was obtained in the optimized gas-phase geometry and the solvent represented by the PCM model. PCM-PCM means the geometry and charges were obtained considering the solute in the solvent environment described by the PCM model

using the gas-phase geometry (Table 1). Thus, the contribution of the geometry relaxation to the electronic polarization of the solute is only $0.3 \mathrm{D}$ for both uracil and 5-fluorouracil. 


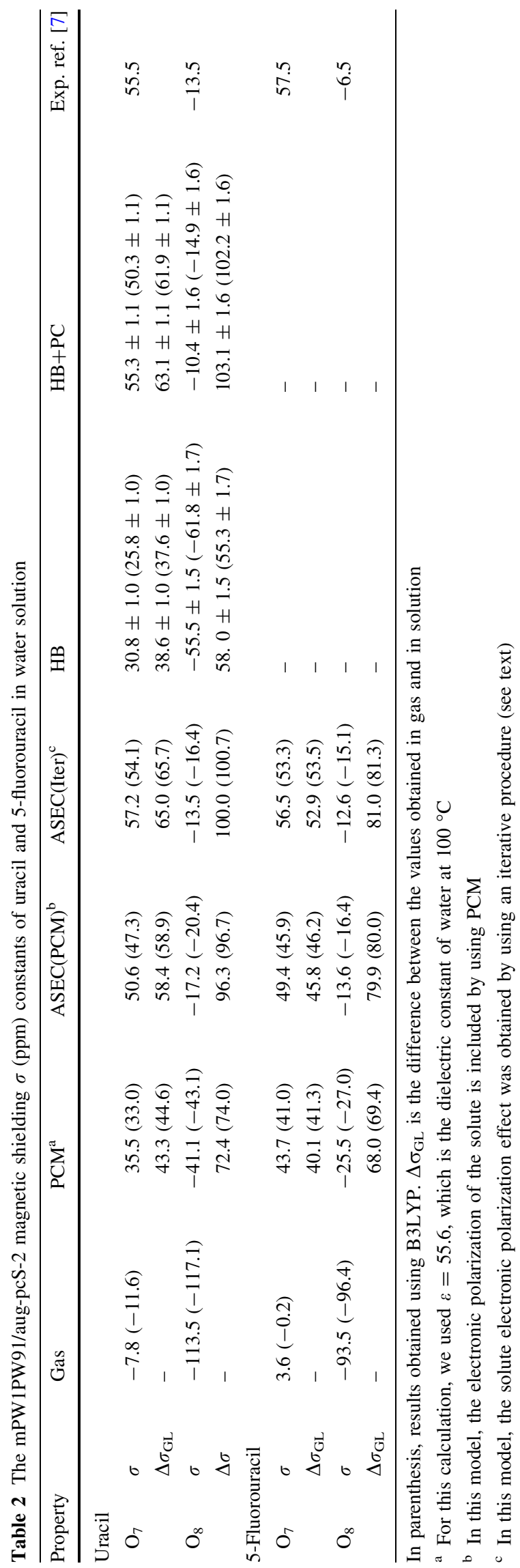

$3.2{ }^{17} \mathrm{O}$ magnetic shielding constants in uracil

Now we will discuss the ${ }^{17} \mathrm{O}$ shielding constants in uracil. Table 2 contains our theoretical results, as well as the experimental results available. Uracil and 5-fluorouracil have two non-symmetric oxygen atoms, which experience different environmental effects (see Fig. 1). This feature originates two different peaks in the ${ }^{17} \mathrm{O}$ NMR spectrum. Experimental measurements for the chemical shielding on $\mathrm{O}_{7}$ and $\mathrm{O}_{8}$ in water at $95{ }^{\circ} \mathrm{C}$ [7] show, respectively, resonances at 55.5 and $-13.5 \mathrm{ppm}$. We investigated these magnetic shielding using different solvent models.

Combining the PCM representation for the solvent and mPW1PW91/aug-pcS-2, we calculated the shielding constants of 35.5 and $-41.1 \mathrm{ppm}$ on $\mathrm{O}_{7}$ and $\mathrm{O}_{8}$. These PCM values differ from the experiment by $\sim 20 \mathrm{ppm}$ in the case of $\mathrm{O}_{7}$ and $\sim 30 \mathrm{ppm}$ in the case of $\mathrm{O}_{8}$ (Table 1).

Considerable improvement is obtained including electronic polarization of the solute and describing the solvent by the ASEC model. Using the iterative polarization, we obtained a result of $57.2 \mathrm{ppm}$ for $\mathrm{O}_{7}$ (ASEC(Iter), Table 2), in very good agreement with experiment, differing by less than $2 \mathrm{ppm}$. The same level of calculation yields a shielding constant of $-13.5 \mathrm{ppm}$ for $\mathrm{O}_{8}$, again in very good agreement with the experimental result. To verify the dependence of the results with the functional, B3LYP was also used and found again to be in good agreement with experiment differing by only 2-3 ppm from those obtained with mPW1PW91. These results show that the electrostatic interaction between the solute and the solvent water molecules is dominant and good agreement with experimental values for the ${ }^{17} \mathrm{O}$ chemical shift is obtained using the ASEC model and treating accurately the solute polarization.

Figure 3 shows the $\sigma\left({ }^{17} \mathrm{O}_{7}\right)$ as a function of the iterative step. It is clear that the solute electronic polarization is very important and increases the shielding constant from gas to liquid leading to a value in very good agreement with experiment. The polarization increases the net charge on the oxygen site. Witanowski et al. [67] discussed a possible relation between the magnetic shielding and the charge on atomic sites. It is naturally expected that the increase in the electronic charge on a given atom increases its magnetic shielding, as discussed by Pople and Karplus [68] for the ${ }^{13} \mathrm{C}$ case. The Fig. 4 then shows the shielding constant and the corresponding electronic charges calculated on $\mathrm{O}_{7}$ in each iterative step and confirms this expectation.

The iterative method used to obtain the electronic polarization demands several classical simulations and quantum mechanical calculations. Thus, it is worth analyzing a simpler method previously described $[12,15,35]$. We consider now a simplified approach where the solute 


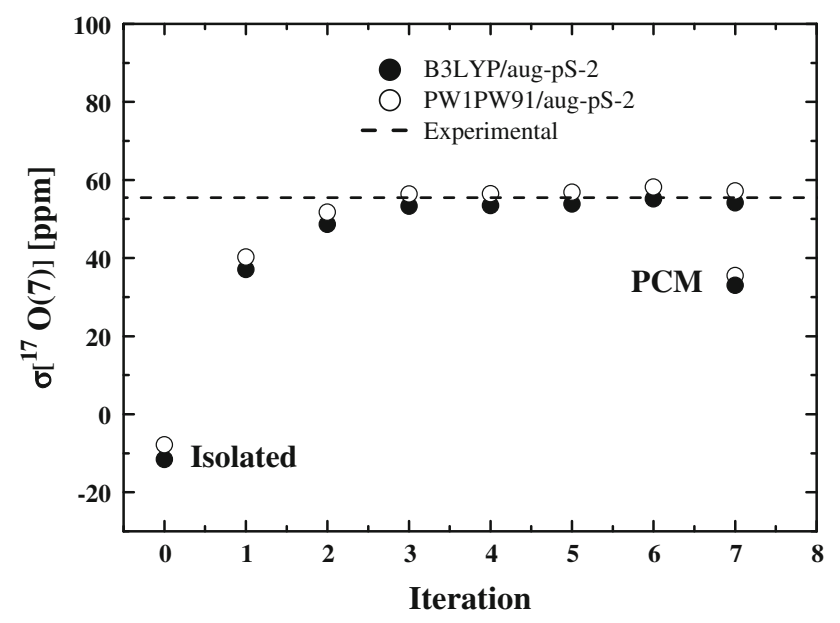

Fig. 3 The isotropic magnetic chemical shielding for ${ }^{17} \mathrm{O}_{7}$. The bold and blank circles correspond, respectively, to B3LYP and mPW1PW91 data for an iterative procedure. The dotted line corresponds to the experimental value (see text)

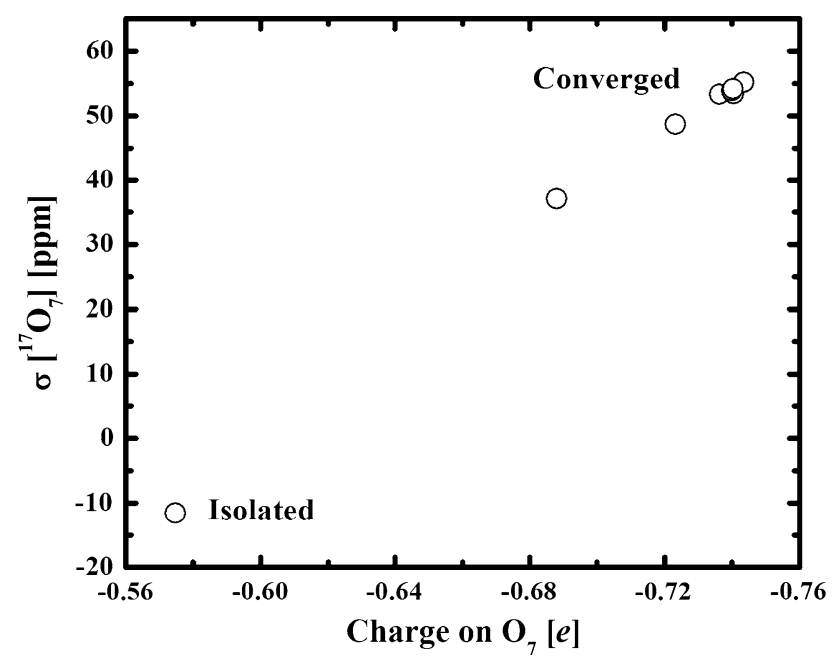

Fig. 4 The nuclear magnetic shielding on $\mathrm{O}_{7}$ as function of the electron density on the atom. The magnetic shielding and atomic charges are simultaneously computed at each iteration step

geometry and, subsequently, the charges are obtained using the PCM approach. Next, we use these parameters in a single simulation generating the ASEC to be used in the calculations of the NMR constants. These results are also shown in the Table 2 and termed as ASEC(PCM). One can see that in general the results represent a good compromise differing by less than $7 \mathrm{ppm}$ from the fully iterated result. Table 1 and Fig. 2 show that the solute polarization obtained by this procedure is close to that obtained by the iterative procedure. This confirms that this discrete polarized model is an interesting alternative for large biomolecular systems, corroborating our previous results $[15,35]$.

Next, we consider the effect of explicitly including some solvent water molecules in the calculation. We focus now in the solute-solvent hydrogen-bonded (HB) water molecules. We first identify the water molecules that are hydrogen bonded to the solute. This is made using the geometrical and energetic criteria, described before [15]. These criteria are $r\left(O_{\text {solute }}-O_{\text {water }}\right)<4.0 \AA, \theta_{\mathrm{O}-(\mathrm{OH}) \mathrm{w}}<40.0^{\circ}$ and $E<-4.0$ $\mathrm{kcal} / \mathrm{mol}$ and are obtained from the distribution functions and the pairwise energy interaction. For instance, the radial distribution function between oxygen of uracil and oxygen of water completes the hydrogen bond shell at $4.0 \AA$. Using these criteria, an average of 1.44 and 1.73 hydrogen bonds are formed on $\mathrm{O}_{7}$ and $\mathrm{O}_{8}$, respectively. This is in line with early works $[69,70]$ that pointed two water molecules hydrogen bonded with the $\mathrm{O}_{8}$ atom. Table 2 shows in addition, the NMR results after including explicitly the water molecules involved in the hydrogen-bonding (HB) uracil-water on $\mathrm{O}_{7}$ and $\mathrm{O}_{8}$. The results obtained with the mPW1PW91 functional are a magnetic shielding of $30.8 \pm 1.0 \mathrm{ppm}$ on $\mathrm{O}_{7}$ and a shielding of $-55.5 \pm 1.7 \mathrm{ppm}$ on $\mathrm{O}_{8}$. This indicates clearly that the sole inclusion of the hydrogen-bonded water is not sufficient to describe the magnetic shielding. The reason is that the electrostatic interaction with the bulk water molecules is very important as seen above. The results improve considerably after including the electrostatic embedding $(\mathrm{HB}+\mathrm{PC})$ of 350 waters molecules treated as simple point charges. This corresponds to including all solvent water molecules up to 13.5 $\AA$ from the center-of-mass of the solute. Explicitly considering the hydrogen-bonded water molecules precludes the use of the average configuration (ASEC), and thus, $100 \mathrm{QM}$ calculations are needed to obtain statistically converged results. This increases considerably the computational effort, thus we compromised by still using the augpcS-2 basis set on oxygen but the pcS-2 on the other atoms. The explicit use of the HB molecules surrounded by the electrostatic embedding for uracil gives results of $55.3 \pm 1.1$ and $-10.4 \pm 1.6 \mathrm{ppm}$ on $\mathrm{O}_{7}$ and $\mathrm{O}_{8}$, respectively. These results are also in very good agreement with experiment.

Finally, for obtaining the solvent effect on the magnetic shielding, we consider gas-phase results. Apparently, experimental values are not available. For uracil $\mathrm{O}_{7}$, we obtain a gas-phase shielding constants of $-7.8 \mathrm{ppm}$ with mPW1PW91/aug-pcS-2 model. Considering our best results, ASEC(Iter), these calculations predict a gas-liquid shift of $\Delta \sigma_{\mathrm{GL}} \sim 60.0 \mathrm{ppm}$ on $\mathrm{O}_{7}$. In the case of $\mathrm{O}_{8}$, the solvent effect of $100.0 \mathrm{ppm}$ shows a larger contribution of the aqueous environment.

\section{$3.3{ }^{17} \mathrm{O}$ magnetic shielding constants in 5-fluorouracil}

Now we will briefly discuss the 5-fluorouracil results. Table 2 shows the main theoretical and experimental reports. The experiment reports chemical shielding 
constants of 57.5 and $-6.5 \mathrm{ppm}$ on $\mathrm{O}_{7}$ and $\mathrm{O}_{8}$, respectively. The HB and HB + PC solvent models are not used here, and only the PCM and ASEC models with the mPW1PW91 and B3LYP functionals are considered. The PCM results of 43.7 and $-25.5 \mathrm{ppm}$ for $\mathrm{O}_{7}$ and $\mathrm{O}_{8}$, respectively, differ appreciably from experiment, being $\sim 20 \mathrm{ppm}$ apart from the experimental values. The ASEC(PCM) presents results in better agreement with the experiments. Shielding constants of 49.4 and $-13.6 \mathrm{ppm}$ were calculated on $\mathrm{O}_{7}$ and $\mathrm{O}_{8}$. The best results are again obtained using the ASEC(Iter) method that gives shielding constants of 56.5 and $-12.6 \mathrm{ppm}$ on $\mathrm{O}_{7}$ and $\mathrm{O}_{8}$, respectively. Again the solvent effect is very strong with a gasliquid shift $\left(\Delta \sigma_{\mathrm{GL}}\right)$ of $52.9 \mathrm{ppm}$ on $\mathrm{O}_{7}$. The $\mathrm{O}_{8}$ chemical shielding is more sensitive to solvent effects giving $81.0 \mathrm{ppm}$ for the gas-liquid shift.

\section{Conclusions}

Theoretical studies of the chemical shielding of the oxygen atom are very important because of its great biological interest and can complement the interpretation of experiments. In this study, we have performed a systematic investigation of the magnetic shielding constants $\sigma\left({ }^{17} \mathrm{O}\right)$ of uracil and 5-fluorouracil in water. Because of the solutesolvent interaction, the electrostatic moments of the reference solute molecule changes. Thus, we have first paid attention to this electronic polarization effect. This is large and changes the dipole moment of uracil from a gas-phase value of $4.34 \mathrm{D}$ into an in-water value of $6.45 \mathrm{D}$. For 5-fluorouracil, similar sizable effect is observed and changes the dipole moment from 3.94 into the in-water value of 5.92. These polarizations are incorporated in the force field for the Monte Carlo simulation that generated the liquid configurations. Chemical shielding calculations were made using these configurations generated by the MC simulation. Continuum, discrete and explicit solvent models were applied in combination with two DFT models to estimate the ${ }^{17} \mathrm{O}$ shielding constants of uracil and 5-fluorouracil under the influence of a liquid water environment. Our best results were obtained using the mPW1PW91 density functional using the aug-pcS-2 basis set. Using the iterative polarization in the pure electrostatic model, we obtained magnetic shielding constants of 57.2 and $-13.5 \mathrm{ppm}$ for uracil in very good agreement with the experimental results of 55.5 and $-13.5 \mathrm{ppm}$, respectively. For 5-fluorouracil, the theoretical results with the same model are 56.5 and $-12.6 \mathrm{ppm}$, again in good agreement with the experimental values of 57.5 and $-6.5 \mathrm{ppm}$. A combined use of PCM and QM/MM was also considered with good results. This combination where PCM is used for the electronic polarization of the solute and incorporated into the $\mathrm{QM} / \mathrm{MM}$ calculations is very promising for treating larger solute molecules, as also noted before $[12,15$, 35]. Using PCM to introduce the polarization effects and then using the ASEC model to represent the solvent in the magnetic shielding calculations leads to a good computational performance with a minor compromising in the accuracy of the results. Thus, it becomes an interesting alternative also for the study of ${ }^{17} \mathrm{O}$ shielding constants on larger biological systems.

Acknowledgments This work has been partially supported by FAPESP, CAPES, CNPq, INCT-FCx and N-BioNet.

\section{References}

1. Macomber RS (1997) A complete introduction to modern NMR spectroscopy. Wiley, New Jersey

2. Gerothanassis IP (2010) Prog Nucl Magn Reson Spectrosc 56:95

3. Gerothanassis IP (2010) Prog Nucl Magn Reson Spectrosc 57:1

4. Klemperer WG (1978) Angew Chem Int Ed Engl 17:246

5. Wu G, Dong S, Ida R, Reen N (2002) J Am Chem Soc 124:1768

6. Longley DB, Harkin DP, Jonhston PG (2003) Nat Rev Cancer 3:330

7. Chandrasekaran S, Wilson WD, Boykin DW (1985) J Org Chem 50:829

8. Bednarek E, Dobrowolski JCz, Dobrosz-Teperek K, Kozerski L, Lewandowski W, Mazurek AP (2000) J Mol Struct 554:233

9. Coutinho K, Canuto S, Zerner MC (2000) J Chem Phys 112:9874

10. Rivelino R, Cabral BJC, Coutinho K, Canuto S (2005) Chem Phys Lett 407:13

11. Coutinho K, Rivelino R, Georg HC, Canuto S (2008) In: Canuto $\mathrm{S}$ (ed) Solvation effects on molecules and biomolecules. Computational methods and applications. Springer, New York

12. Manzoni V, Lyra ML, Gester RM, Coutinho K, Canuto S (2010) Phys Chem Chem Phys 12:14023

13. Gester RM, Georg HC, Fonseca TL, Provasi PF, Canuto S (2012) Theory Chem Acc 131:1220

14. Gester RM, Georg HC, Canuto S, Caputo MC, Provasi PF (2009) J Phys Chem A 113:14936

15. Manzoni V, Lyra ML, Coutinho K, Canuto S (2011) J Chem Phys 135:144103

16. Fonseca TL, Coutinho K, Canuto S (2008) J Chem Phys 129:34502

17. Kongsted J, Mennucci B (2007) J Phys Chem A 111:9890

18. Mennucci B, Martinez JM (2005) J Phys Chem B 109:9830

19. Fileti EE, Georg HC, Coutinho K, Canuto S (2007) J Braz Chem Soc 18:74

20. Esrafili MD, Alizadeh V (2011) Struct Chem 22:1195

21. Karami L, Behzadi H, Hadipour NL, Mousavi-Khoshdel M (2011) Comput Theor Chem 965:137

22. Esrafili MD, Alizadeh V (2011) Comput Theor Chem 974:66

23. Claramunt RM, Pérez-Torralba M, Santa María D, Sanz D, Elena B, Alkorta I, Elguero J (2010) J Magn Reson 206:274

24. Amini SK, Shaghaghi H, Bain AD, Chabok A, Tafazzoli M (2010) Solid State Nucl Magn Reson 37:13

25. Alkorta I, Blanco F, Elguero J (2009) Magn Reson Chem 47:249

26. Del Bene JE, Bartlett RJ (2000) J Am Chem Soc 122:10480

27. Miertuš S, Scrocco E, Tomasi J (1981) Chem Phys 55:117

28. Mennucci B, Cammi R (eds) Continuum solvation models In: Chemical physics (2007) John Wiley, New Jersey

29. Marenich AV, Olson RM, Chamberlin AC, Cramer CJ, Truhlar DG (2007) J Chem Theory Comput 3:2055 
30. Kongsted J, Osted A, Mikkelsen KV, Christiansen O (2002) Mol Phys 100:1813

31. McDonald NA, Carlson HA, Jorgensen WL (1997) J Phys Org Chem 10:563

32. Xie W, Gao J (2007) J Chem Theory Comput 3:1890

33. Öhrn A, Karlström G (2007) J Chem Theory Comput 3:1993

34. Georg HC, Coutinho K, Canuto S (2006) Chem Phys Lett 429:119

35. Bistafa C, Canuto S (2013) Theor Chem Acc 132:1299

36. Pranata TJ, Wierchke SG, Jorgensen WL (1991) J Am Chem Soc 113:2810

37. Jorgensen WL, Chandrasekhar J, Madura JD, Impey RW, Klein ML (1983) J Chem Phys 79:926

38. Breneman CM, Wiberg KB (1990) J Comput Chem 11:361

39. Coutinho K, Guedes RC, Cabral BJC, Canuto S (2003) Chem Phys Lett 369:345

40. Coutinho K, Canuto S (2010) DICE (version 2.9): a Monte Carlo program for molecular liquid simulation, version 2.9. University of São Paulo, São Paulo

41. Allen MP, Tildesley DJ (1987) Computer simulation of liquids. Oxford University Press, Oxford

42. Coutinho K, Georg HC, Fonseca TL, Ludwig V, Canuto S (2007) Chem Phys Lett 437:148

43. Galván IF, Sánchez ML, Martín ME, del Valle FJO, Aguilar MA (2003) Comput Phys Commun 155:244

44. Stillinger FH, Rahman A (1972) J Chem Phys 57:1281

45. Mezei M, Beveridge DL (1981) J Chem Phys 74:622

46. Coutinho K, Canuto S (2000) Int J Quantum Chem 77:192

47. Helgaker T, Jaszunski M, Ruud K (1999) Chem Rev 99:293

48. Auer AA (2009) Chem Phys Lett 467:230

49. Ozimiski WP, Garnuszek P, Bednarek E, Dobrowolski JCz (2007) Inorg Chim Acta 360:1902

50. Keal TW, Helgaker T, Salek P, Tozer DJ (2006) Chem Phys Lett 425:163

51. Becke AD (1993) J Chem Phys 98:5648

52. Lee C, Yang W, Parr RG (1988) Phys Rev B 37:785

53. Adamo C, Barone V (1998) J Chem Phys 108:664

54. Burke K, Perdew JP, Wang Y (1998) In: Dobson JF, Vignale G, Das MP (eds) Electronic density functional theory: recent progress and new directions. Plenum, Berlin
55. Jensen F (2008) J Chem Theory Comput 4:719

56. London F (1937) J Phys Radium 8:397

57. McWeeny R (1962) Phys Rev 126:1028

58. Ditchfield R (1974) Mol Phys 27:789

59. Wolinski K, Hilton JF, Pulay P (1990) J Am Chem Soc 112:8251

60. Gauss J (1993) J Chem Phys 99:3629

61. Cheeseman JR, Trucks GW, Keith TA, Frisch MJ (1996) J Chem Phys 104:5497

62. Wasylishen RE, Bryce DL (2002) J Chem Phys 117:10061

63. Frisch MJ, Trucks GW, Schlegel HB, Scuseria GE, Robb MA, Cheeseman JR, Montgomery JA Jr, Vreven T, Kudin KN, Burant JC, Millam JM, Iyengar SS, Tomasi J, Barone V, Mennucci B, Cossi M, Scalmani G, Rega N, Petersson GA, Nakatsuji H, Hada M, Ehara M, Toyota K, Fukuda R, Hasegawa J, Ishida M, Nakajima T, Honda Y, Kitao O, Nakai H, Klene M, Li X, Knox JE, Hratchian HP, Cross JB, Bakken V, Adamo C, Jaramillo J, Gomperts R, Stratmann RE, Yazyev O, Austin AJ, Cammi R, Pomelli C, Ochterski JW, Ayala PY, Morokuma K, Voth GA, Salvador P, Dannenberg JJ, Zakrzewski VG, Dapprich S, Daniels AD, Strain MC, Farkas O, Malick DK, Rabuck AD, Raghavachari K, Foresman JB, Ortiz JV, Cui Q, Baboul AG, Clifford S, Cioslowski J, Stefanov BB, Liu G, Liashenko A, Piskorz P, Komaromi I, Martin RL, Fox DJ, Keith T, Al-Laham MA, Peng CY, Nanayakkara A, Challacombe M, Gill PMW, Johnson B, Chen W, Wong MW, Gonzalez C, Pople JA (2004) Gaussian 03, revision D01. Gaussian Inc, Wallingford

64. Ludwig V, Coutinho K, Canuto S (2007) Phys Chem Chem Phys 9:4907

65. Millefiori S, Alparone A (2004) Chem Phys 303:27

66. Brown RD, Godfrey PD, McNaughton D, Pierlot AP (1988) J Am Chem Soc 110:2329

67. Witanowski M, Biedrzycka Z, Sicinska W, Grabowski Z (2003) J Magn Reson 164:212

68. Karplus M, Pople JA (1963) J Chem Phys 38:2803

69. Del Bene JE (1981) J Comput Chem 2:188

70. Schwarz HM, MacCross M, Danyluk SS (1983) J Am Chem Soc 105:5901 


\title{
Including Thermal Disorder of Hydrogen Bonding to Describe the Vibrational Circular Dichroism Spectrum of Zwitterionic L-Alanine in Water
}

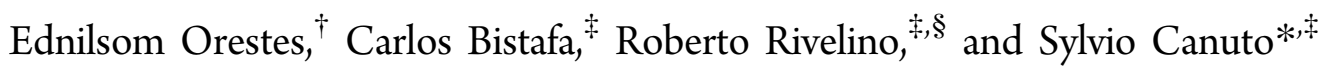 \\ ${ }^{\dagger}$ Instituto de Química, Universidade Federal Fluminense Campus do Valonguinho, CEP 24020-141, Niterói, RJ, Brazil \\ ${ }^{\ddagger}$ Instituto de Física, Universidade de São Paulo, CP 66318, 05914-370 São Paulo, SP, Brazil \\ ${ }^{\S}$ Instituto de Física, Universidade Federal da Bahia, 40210-340 Salvador, BA, Brazil
}

ABSTRACT: The vibrational circular dichroism (VCD) spectrum of $\mathrm{L}_{\text {- }}$ alanine amino acid in aqueous solution in ambient conditions has been studied. The emphasis has been placed on the inclusion of the thermal disorder of the solute-solvent hydrogen bonds that characterize the aqueous solution condition. A combined and sequential use of molecular mechanics and quantum mechanics was adopted. To calculate the average VCD spectrum, the DFT B3LYP/6-311++G(d,p) level of calculation was employed, over one-hundred configurations composed of the solute plus all water molecules making hydrogen bonds with the solute. Simplified considerations including only four explicit solvent molecules and the polarizable continuum model were also made for comparison. Considering the large number of vibration frequencies with only limited

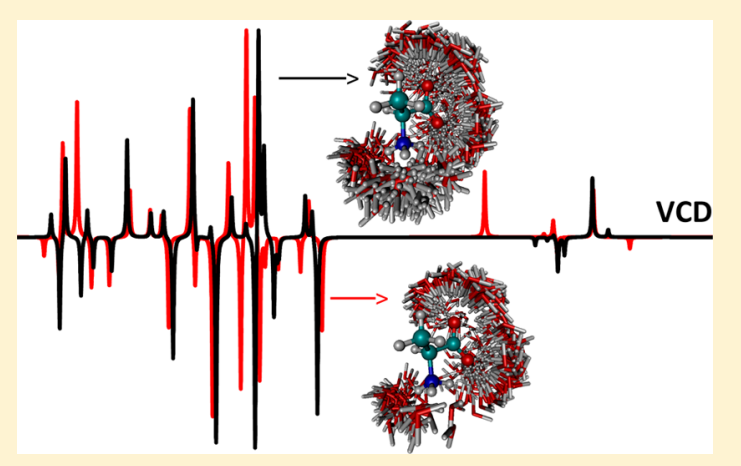
experimental results a direct comparison is presented, when possible, and in addition a statistical analysis of the calculated values was performed. The results are found to be in line with the experiment, leading to the conclusion that including thermal disorder may improve the agreement of the vibrational frequencies with experimental results, but the thermal effects may be of greater value in the calculations of the rotational strengths.

\section{INTRODUCTION}

The vibrational circular dichroism (VCD) spectroscopy ${ }^{1,2}$ has long been recognized as an efficient technique to determine the structure and conformations of chiral molecules of biological interest. Defined as the differential absorption between left and right circularly polarized infrared light by chiral molecules, 3,4 VCD combines the versatility of the vibrational spectroscopy with the stereochemical sensitivity of the optical activity. ${ }^{5}$ Among the molecules of interest for calculations of VCD, amino acids have attracted great attention because of their important role in building peptides and proteins, as well as their relatively small size in comparison to the sizes of common biomolecules. Except glycine, all other amino acids are chiral. For this reason, theoretical advances on VCD spectra have been performed by studying the conformations of several chiral molecules. ${ }^{6-13}$ However, in such studies the role played by the environment may be crucial to understand the biochemical behavior of these chiral organic compounds. Indeed, to take into account the effects of a biological medium most of the theoretical investigations have to consider a representation of the aqueous environment around the system of interest. Theoretically, this issue has been a great challenge because VCD requires electronic structure calculations and determination of the force field and atomic axial and polar tensors of the molecule in a solvent environment.
Theoretical VCD studies of amino acids have appeared soon after the development of the VCD technique, ${ }^{14}$ but neglecting the environmental effects, which can cause large discrepancies between experimental and theoretical results, mainly for biologically relevant polar molecules. ${ }^{15}$ For example, the medium influence has been more evident when specific solvent-solute interactions are present, such as hydrogen bonding $(\mathrm{HB})$ formation that is responsible for the internal proton transfer in some amino acids, resulting in a zwitterionic specie. ${ }^{16-18}$ Even in the absence of $\mathrm{HB}$, the inclusion of interactions between the solute and the entire first solvation shell, as well as the bulk solvent molecules, may be necessary in some cases. ${ }^{19}$ Including the solvent effects along with VCD calculations, however, requires not only a treatment of a significant number of amino acid conformations, which are separated by low energy barriers, but also a significant number of solvent molecules necessary to effectively model the solvent effect. $^{16}$ Therefore, despite their relatively small size, solvated amino acids still constitute a challenging problem for theoretical studies aiming at including solvent effects in the VCD spectra. ${ }^{6}$

Special Issue: Jacopo Tomasi Festschrift

Received: August 13, 2014

Revised: November 25, 2014

Published: November 26, 2014 
Generally, the method of choice to include the solvent effects around a single molecule is the polarizable continuum model (PCM) ${ }^{20-22}$ which is computationally inexpensive and largely adopted currently. However, though implicit solvation, such as PCM and other related models, ${ }^{23}$ can be adequate to obtain different properties, ${ }^{24}$ explicit solvation is required when the property of interest is directly related with the specific solutesolvent interactions, responsible for important structural changes. ${ }^{16}$ This affects the VCD spectra of amino acids, as well as other chiral molecules, in aqueous solution. In this direction, the standard approach to include solvent effects in the VCD spectrum is the microsolvation model. ${ }^{8,12,16,17,25-28}$ In this case, few solvent molecules are included in the calculation, near the sites that are amenable to the formation of HB. Constrained optimization of clusters have been also suggested. ${ }^{29}$ Additionally, a dielectric continuum model may be employed to describe the medium bulk effects. Thus, the optimized geometries of small clusters are commonly utilized to determine vibrational frequencies and rotational strengths of the system. This has largely been employed to access the VCD spectra of solvated chiral molecules. ${ }^{8,12,16,17,25-28}$ A justification of the use of microsolvation in VCD studies is that it is more sensitive to the local environment, with minor influence of the outer solvent molecules around the solute.

In turn, the microsolvation model may have some important limitations: (i) geometry optimizations lead to only one minimum energy structure corresponding to very small temperatures, neglecting the thermal fluctuations of the solvent and hiding the true nature of the liquid, which should be represented by several accessible configurations statistically determined by the thermodynamic conditions. (ii) The choice of the specific sites amenable to bind the solvent molecules and the number of $\mathrm{HB}$ are based on chemical intuition, which can influence the calculated properties. For instance, in the case of the calculated VCD spectra changes in the sign of the rotational strength can be obtained, depending on the water distribution around the chiral molecule. ${ }^{17}$ In this sense, some works have used $\mathrm{QM} / \mathrm{MM}$ methods to improve the results. ${ }^{30-33}$

In this work we are interested in analyzing the influence of the thermal disorder of the solute-solvent hydrogen bonds ${ }^{34,35}$ in the VCD spectra of amino acids (L-alanine) in water. Opposite to a fixed hydrogen-bond structure (in a minimumenergy condition, or not), in the aqueous environment one must consider the proper thermodynamic condition and therefore the natural disorder of the liquid. Therefore, the proton-acceptor site of a solute molecule in an aqueous environment experiences local thermal disorder that affects the vibrational motion. This disorder has been overlooked in previous theoretical studies of VCD spectra and it is one of our interests here to analyze it in some detail.

We employ the sequential quantum mechanics/molecular mechanics (S-QM/MM $)^{36}$ scheme to overcome these limitations and include the thermodynamics effects in the calculated VCD spectrum. The S-QM/MM has successfully been utilized in the calculations of UV-vis spectra, ${ }^{37-41}$ NMR constants, ${ }^{42,43}$ and excited states. ${ }^{44,45}$ In our S-QM/MM approach, the MM calculations are carried out via Monte Carlo (MC) simulations, ${ }^{46}$ which generate proper configurations of the solvated system for subsequent QM calculations. ${ }^{36}$ In the present purpose, our VCD calculations are performed within density functional theory (DFT). ${ }^{47}$

We compute the VCD spectrum of the zwitterionic L-alanine (zw-L-Ala) amino acid in an aqueous solution under ambient conditions. L-Alanine was selected because it is the smallest naturally occurring chiral amino acid, being present in the primary structure of several proteins. Furthermore, because its zwitterionic form is recognized to be more stable in aqueous solution, giving rise to only one conformer, ${ }^{16-18}$ it is a suitable solute for the present study. Our QM solvated amino acid model is, hence, the zw-L-Ala structure embedded in several statistically uncorrelated configurations of water molecules making $\mathrm{HB}$ with the solute. In this, we take into account the thermal fluctuations of the solvent around the amino acid. Consequently, these effects are present in the VCD calculations, from which we obtain the corresponding average spectrum of the solvated zw-L-Ala species. For comparison, we also consider calculations using the PCM solvation. Our results for the VCD spectrum are statistically analyzed and compared with available experimental data, as well as with other previous theoretical calculations ${ }^{17}$ based on successful microsolvation models.

\section{METHODS AND COMPUTATIONAL DETAILS}

In the aqueous solution, the zwitterionic form (illustrated in Figure 1) is the most stable structure of L-alanine. Contrary to

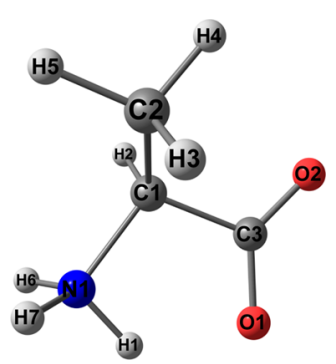

Figure 1. Illustration of the optimized zwitterionic L-alanine (zw-LAla) molecule, obtained using PCM at the B3LYP/6-311++G(d,p) level. The labels are used along the text and in other figures.

the neutral form of L-alanine, zW-L-Ala presents just one stable conformer. ${ }^{16-18}$ The zw-L-Ala geometry was optimized along with harmonic frequency calculations by employing density functional theory (DFT) ${ }^{47}$ methods. As is well-accepted for this system, ${ }^{16,17,25}$ we have employed the Becke three-parameter hybrid functional for exchange energy ${ }^{48}$ combined with the Lee-Yang-Parr functional for correlation ${ }^{49}$ (B3LYP) and calculations were carried out with the $6-311++G(d, p)$ basis set as implemented in the Gaussian 09 package. ${ }^{50}$ The geometry in the water environment was obtained using the $\mathrm{PCM}^{20-22}$ representation of the solvent. This optimized structure of the Zw-L-Ala was then used in the MM part of the sequential QM/ MM calculation. ${ }^{36}$ As extensively discussed elsewhere, ${ }^{36,51}$ this method is a variation of the traditional $\mathrm{QM} / \mathrm{MM},{ }^{52,53}$ where statistically uncorrelated configurations from the MM partitioning are selected and used in the QM calculations.

In the classical partitioning of S-QM/MM, a Monte Carlo Metropolis simulation (MC) was performed, at $25{ }^{\circ} \mathrm{C}$ and 1 atm, using the DICE code. ${ }^{54}$ The system, composed of one $\mathrm{zw}$ L-Ala species surrounded by 500 water molecules, was simulated in a cubic box with periodic boundary conditions. After thermalization, a simulation of $3.5 \times 10^{6}$ steps/molecule in the isothermal-isobaric (NPT) ensemble was performed. The intermolecular interaction was treated using Lennard-Jones (LJ) plus Coulomb potential. The water molecules were modeled by the TIP3P potential. ${ }^{55}$ For zw-L-Ala, we have 
adopted the optimized potentials for liquid simulation-all atoms (OPLS-AA) force field ${ }^{56}$ with atomic charges obtained by using the charges from electrostatic potentials using a grid based method (CHELPG), ${ }^{57}$ calculated with second order MøllerPlesset perturbation theory (MP2) with the aug-cc-pVDZ basis set, as implemented in the Gaussian 09 package. The present level of calculation provides a good compromise between performance and accuracy to describe charges and dipole moments. ${ }^{58}$ To include the electronic polarization effects, both geometry and charges were obtained considering the zw-L-Ala in aqueous environment, using the PCM representation of the solvent.

As in previous works, ${ }^{37-41}$ we used the autocorrelation function of the energy ${ }^{36,46}$ to select 100 uncorrelated solutesolvent configurations from the MC simulation, with less than $10 \%$ of statistical correlation. All of these solute-solvent configurations are employed in the quantum mechanical calculations at the DFT level. Before performing these DFT calculations, we have carefully identified the hydrogen bonds using the energetic and geometric criteria, ${ }^{35,59,60}$ and this will be detailed in the following section. During the DFT calculations, only the water molecules satisfying the $\mathrm{HB}$ criteria are included. For the calculation of the vibration frequencies and the VCD spectrum of zw-L-Ala without including the frequencies of the water molecules, only the geometry of the solute $\mathrm{zw}$-L-Ala was re-optimized in the presence of the $\mathrm{HB}$ water molecules that are kept fixed. This gives the separated spectrum of zw-L-Ala and preserves the thermal disorder associated with the thermodynamic distribution of the solvent molecules as obtained from the simulation. To determine the VCD intensities, atomic polar and axial tensors were calculated using analytical derivative methods. The electronic properties were obtained as simple averages over the calculations for each configuration.

\section{RESULTS AND DISCUSSION}

Statistical Analysis of the Solute-Solvent Hydrogen Bonds. Hydrogen bonds are normally characterized by the appropriate angular distribution and the pairwise radial distribution function. Although this gives the coordination of solvent molecules around a certain atom of the solute, it cannot be assured that all neighboring solvent molecules are indeed hydrogen bonded to the solute. In addition, to these geometric criteria it is important to add an energetic condition. ${ }^{35,59,60}$ Figure 2 shows the pairwise radial distribution functions, $G(r)$ needed for analyzing the solute-solvent hydrogen bonds. In Figure 2a we show, for instance the distribution between the two oxygen atoms of zw-L-Ala and the hydrogen atom of water. For the oxygen atom, termed as O1, Figure 1, we clearly note a first peak in the $G_{\mathrm{O} 1-\mathrm{Ow}}$ starting at $2.3 \AA$ and ending at $3.2 \AA$. These define the first hydration shell around O1. Integration of this peak gives, on average, 2.5 water molecules around the $\mathrm{O} 1$ atom. Similar results are also shown for the other oxygen atom as well as the nitrogen atom. For instance, the first peaks of $G_{\mathrm{O} 2-\mathrm{Ow}}$ and $G_{\mathrm{N} 1-\mathrm{Ow}}$ end in 3.2 and $3.5 \AA$, respectively. Analysis of these peaks gives, on average, 3.1 and 3.9 water molecules coordinating with $\mathrm{O} 2$ and $\mathrm{NH}_{x}(x=1,2,3)$, respectively, Figure 1. Hence, the geometric criteria adopted for a solutesolvent $\mathrm{HB}$ is $R_{\mathrm{O}-\mathrm{Ow}}$ or $R_{\mathrm{N}-\mathrm{Ow}}<3.5 \AA$ and the angle $\theta_{\mathrm{O}-(\mathrm{OH}) \mathrm{w}}$ $<40^{\circ}$ or $\theta_{\mathrm{NH}-\mathrm{Ow}}<40^{\circ}$.

The energetic criterion was established by analyzing the histogram of the pairwise interaction energy between zw-L-Ala and the water molecules, displayed in Figure 3. The first bump
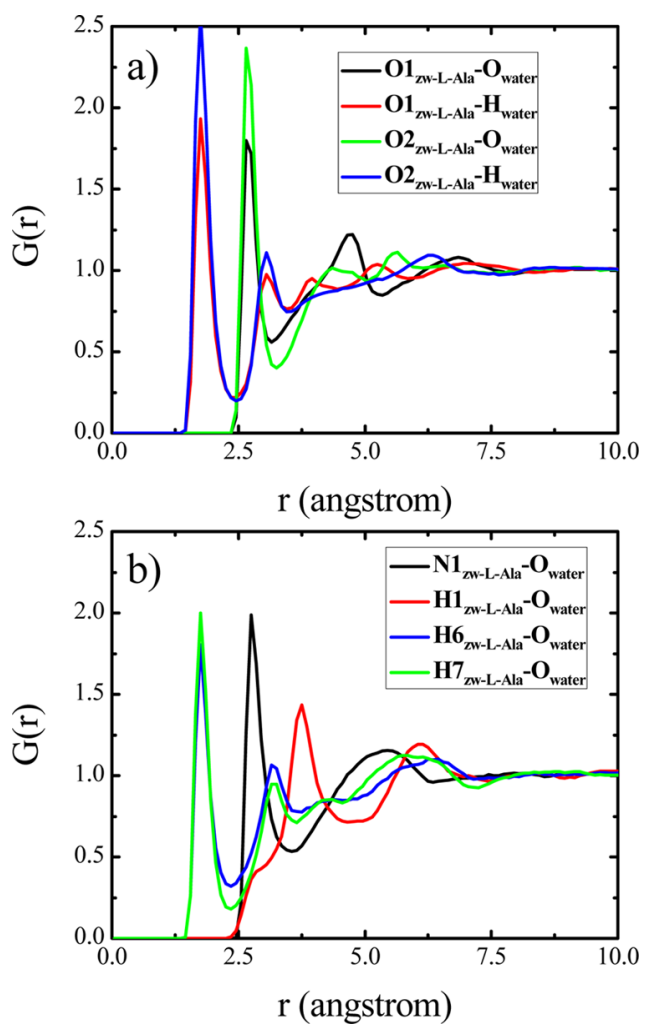

Figure 2. Calculated $G(r)$ : (a) between the zw-L-Ala oxygen atoms and water hydrogen atoms; (b) between the $\mathrm{zw}-\mathrm{L}-\mathrm{Ala} \mathrm{NH}_{3}{ }^{+}$group and water oxygen atoms. See atomic labels in Figure 1.

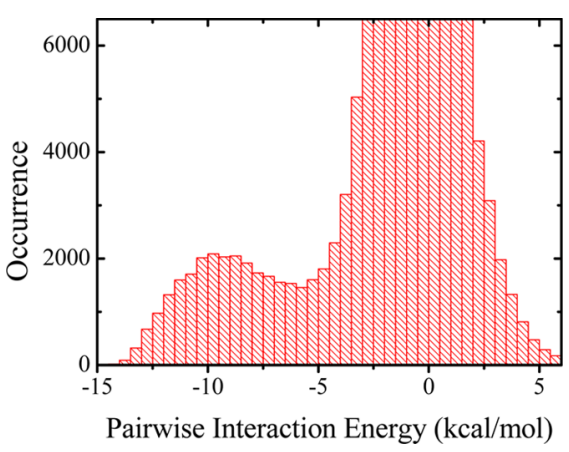

Figure 3. Distribution of pairwise interaction energy between zw-L-Ala and water.

corresponding to the HBs exhibits a minimum around -5.5 $\mathrm{kcal} / \mathrm{mol}$. The energetic condition is thus that the interaction energy between water $\mathrm{zw}-\mathrm{L}-\mathrm{Ala}$ is at least $-5.5 \mathrm{kcal} / \mathrm{mol}$.

Using both geometric and energetic criteria, we find the distribution of the numbers of hydrogen bonds ranging from a minimum of 5 water molecules and a maximum of 9 . Figure $4 \mathrm{a}$ illustrates the configuration space occupied by these hydrogen bonds by showing a superposition of all these configurations with water molecules hydrogen bonded to zw-L-Ala. On the average we obtain 7 water molecules that are hydrogen bonded to zw-L-Ala. There are $2.3 \mathrm{HB}$ in the O1, 2.6 in the $\mathrm{O} 2$, and 2.1 in the $\mathrm{NH}_{x}$ sites. These numbers are summarized in Table 1 . Using the angular distribution, it is possible to discern the three $\mathrm{NH}_{x}$ possibilities and in more detail: on average we find 0.13 $\mathrm{HBs}$ around $\mathrm{N} 1 \mathrm{H} 1,1.01$ around $\mathrm{N} 1 \mathrm{H} 6$, and 0.99 around $\mathrm{N} 1 \mathrm{H} 7$. The small number of hydrogen bonds in the $\mathrm{N} 1 \mathrm{H} 1$ site is an indication of some steric effect but more likely that $\mathrm{H} 1$ 


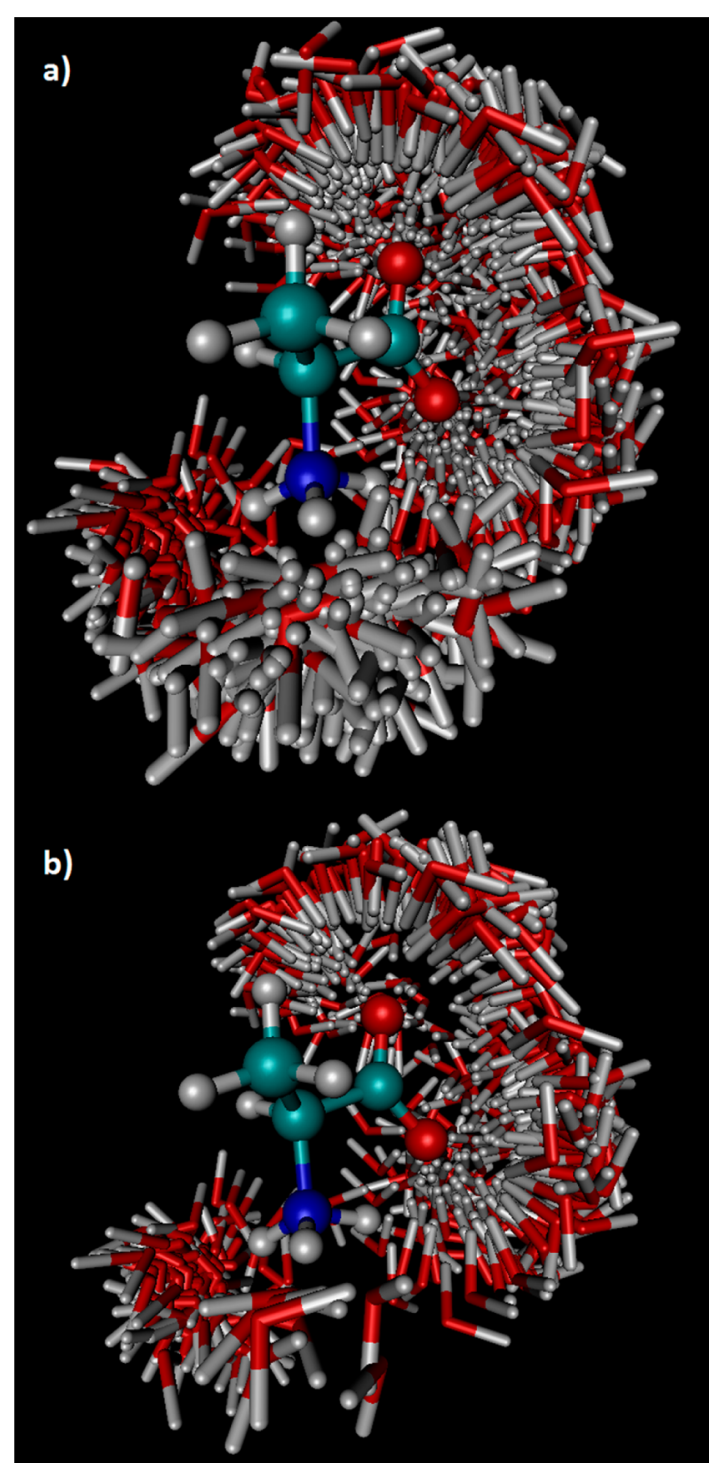

Figure 4. Illustration of the configuration space spanned by all the water molecules that are hydrogen bonded to $\mathrm{HB}$ zw-L-Ala as obtained from the MC simulation. In (b) only four water molecules are considered. This figure was constructed using the VMD program. ${ }^{61}$

Table 1. Distribution of Water Molecules around the Sites Amenable to Hydrogen Bonds

\begin{tabular}{|lllc|} 
& $\mathrm{O} 1$ & $\mathrm{O} 2$ & $\mathrm{NHx}$ \\
\hline coordination no. $^{a}$ & 2.5 & 3.1 & 3.9 \\
no. of hydrogen bonds $^{b}$ & 2.3 & 2.6 & 2.1 \\
\hline
\end{tabular}

${ }^{a}$ Integration of the first peak of the radial distribution function. ${ }^{b}$ Obtained using the geometric and energetic criterion (see text).

makes an intramolecular hydrogen bond with the $\mathrm{O} 1$ atom of zw-L-Ala. Indeed, this can be noted by the absence of an intermolecular hydrogen bond shell in the $\mathrm{G}_{\mathrm{H} 1-\mathrm{Ow}}$ (red curve in Figure 2b), distribution.

In microsolvation studies four water molecules are normally considered in optimized clusters of alanine. ${ }^{17,25}$ Thus, in addition, for comparison, we have also calculated the VCD spectrum using another set of calculations with only the 4 nearest water molecules forming HB. We constrain in this case, three water molecules around the $\mathrm{COO}^{-}$group and one around the $\mathrm{NH}_{3}^{+}$group. These configurations are illustrated in
Figure $4 \mathrm{~b}$. The first case is termed as " $\mathrm{zw}-\mathrm{L}-\mathrm{Ala}_{\text {re-opt }}+$ all $\mathrm{HB}_{\text {average" and the second as "zw-L-Ala }}$ re-opt $+4 \mathrm{HB}_{\text {average }}$ ". In the first, in each configuration the number of water molecules varies between five and nine. In the second the number of water molecules is fixed to four and are extracted from the simulation, thus also including thermal disorder.

To obtain the spectrum, the calculated vibrational rotational strengths are averaged over the 100 configurations. The subscript "re-opt" in zw-L-Ala means that the solute molecular structure was relaxed in the presence of the solvent and the subscript "average" denotes that the results are obtained as average of 100 configurations generated in the MC simulation.

Analysis of the Calculated VCD Spectrum. Now we discuss the results obtained with two statistically oriented models and compare with the simple PCM approach and the previous microsolvation study. Jalkanen et al. ${ }^{18}$ have compared microsolvation models (optimized clusters) of zw-L-Ala +9 $\mathrm{H}_{2} \mathrm{O}$ and $\mathrm{zW}$-L-Ala $+20 \mathrm{H}_{2} \mathrm{O}$ (corresponding to the entire first solvation shell) and found mild differences in the calculated VCD spectra. Indeed, the inclusion of additional water molecules beyond those forming $\mathrm{HB}$ produces no significant effects in the VCD spectrum of zw-L-Ala. For this reason, we have first computed the vibrational rotation strengths considering all statistically uncorrelated configurations containing the hydrated $\mathrm{zw}-\mathrm{L}-\mathrm{Ala}$ species satisfying the $\mathrm{HB}$ criteria, i.e., employing our "zw-L-Ala re-opt + all $\mathrm{HB}_{\text {average" model. The }}$ calculated frequencies and VCD intensities are reported in Table 2. Other works using the microsolvation model for $\mathrm{zw}-\mathrm{L}-$ Ala have adopted four water molecules to represent the possible HB with the solvent. ${ }^{17,25}$ Table 2 also shows our results obtained using the simpler PCM and the same B3LYP/6-311+ $+\mathrm{G}(\mathrm{d}, \mathrm{p})$ level. The experimental vibrational frequencies were determined in the work of Diem et al., ${ }^{62}$ and the microsolvation results were carried out by Frimand et al. ${ }^{17}$ that used an optimized cluster of zw-L-Ala $+9 \mathrm{H}_{2} \mathrm{O}$ combined with the reaction field of Onsager and the B3LYP/6-31G(d) level of theory. They have shown that nine hydrogen-bonded water molecules around zw-L-Ala, along with the Onsager model essentially gives the entire solvent effect in the VCD spectrum.

In the high-frequency side our theoretical results are overestimated compared to experimental results, as expected. For proper comparison we should mention that our results in Table 2 were not rescaled by convenient but arbitrary factors. ${ }^{63,64}$ In the intermediate and more interesting spectral region ranging from 1100 to $1460 \mathrm{~cm}^{-1}$ two experimental results are available for comparison. The lowest frequency observed at $1110-1117 \mathrm{~cm}^{-1}$, assigned to the $\nu^{\text {as }}(\mathrm{CCN})$ mode of the $\mathrm{CH}_{3}-\mathrm{C}-\mathrm{NH}_{3}{ }^{+}$group, is well described by all theoretical methods considered and it can be noted that the $\mathrm{zw}-\mathrm{L}-\mathrm{Ala}_{\text {re-opt }}+$ all $\mathrm{HB}_{\text {average }}$ is in agreement with experiment. Similarly for the highest frequency observed at $1459-1471 \mathrm{~cm}^{-1}$, assigned to the $\delta^{\text {as }}\left(-\mathrm{CH}_{3}\right)$ mode, the $\mathrm{zw}-\mathrm{L}-\mathrm{Ala}_{\text {re-opt }}+$ all $\mathrm{HB}_{\text {average }}$ result is $1478 \mathrm{~cm}^{-1}$. The analysis of the vibrational mode of a molecule in solution is not always simple because closely lying transitions may interchange position in different configurations. For example, in a selected configuration the frequency of the $\nu^{\mathrm{s}}\left(\mathrm{NH}_{3}^{+}\right)$symmetric stretch mode is only slightly larger than the asymmetric stretch $\nu^{\text {as }}\left(\mathrm{NH}_{3}{ }^{+}\right)$and may interchange in different configurations. Moreover, the sign of the VCD intensity can appear inverted for specific vibrational modes and strongly depends on the local environment. This inversion can also be obtained in different optimized clusters commonly used in microsolvation models. ${ }^{17}$ In a liquid situation, the 
Table 2. Calculated VCD Spectrum of zw-L-Ala in Water, Using B3LYP/6-311++G(d,p $)^{a}$

\begin{tabular}{|c|c|c|c|c|c|c|c|c|c|}
\hline \multicolumn{2}{|c|}{ Frimand et al. ${ }^{b}$} & \multicolumn{2}{|c|}{ zw-l-Ala + PCM } & \multicolumn{2}{|c|}{$\mathrm{zw}-\mathrm{L}-\mathrm{Ala}_{\text {re-opt }}+4 \mathrm{HB}_{\text {average }}$} & \multicolumn{2}{|c|}{$\mathrm{zw}-\mathrm{l}-\mathrm{Ala}_{\text {re-opt }}+$ all $\mathrm{HB}_{\text {average }}$} & \multicolumn{2}{|c|}{$\exp ^{c}$} \\
\hline freq & $\mathrm{RS}$ & freq & RS & freq & $\mathrm{RS}$ & freq & $\mathrm{RS}$ & freq & $A \varepsilon / \varepsilon^{d}$ \\
\hline 3161 & 3 & 3543 & -1 & 3525 & -6 & 3400 & 3 & 3080 & \\
\hline 3138 & -14 & 3482 & 13 & 3315 & 23 & 3310 & 20 & 3060 & \\
\hline 3103 & -8 & 3135 & 2 & 3137 & 0 & 3149 & -6 & 3020 & \\
\hline 3086 & -24 & 3113 & -27 & 3106 & -9 & 3111 & -12 & 3003 & \\
\hline 3066 & 17 & 3096 & 19 & 3084 & 8 & 3086 & 1 & 2993 & \\
\hline 3026 & 40 & 3037 & 1 & 3030 & 2 & 3050 & -1 & 2962 & \\
\hline 2990 & 17 & 3030 & -30 & 2690 & 31 & 2981 & -3 & 2949 & \\
\hline 1778 & 14 & 1665 & -19 & 1754 & -45 & 1728 & -61 & 1645 & \\
\hline 1766 & -17 & 1654 & -75 & 1678 & 18 & 1697 & 10 & 1625 & \\
\hline 1678 & -65 & 1632 & 19 & 1630 & -17 & 1657 & 14 & 1607 & \\
\hline 1653 & -26 & 1492 & -20 & 1502 & -16 & 1507 & -6 & 1498 & \\
\hline 1536 & 0 & 1489 & 5 & 1492 & 2 & 1497 & -6 & 1459 & \\
\hline 1529 & -14 & 1426 & -22 & 1427 & -13 & 1478 & -27 & $1459,1471^{d}$ & \\
\hline 1456 & 77 & 1404 & 38 & 1396 & -71 & 1420 & 30 & $1410,1418^{d}$ & 5.2 \\
\hline 1422 & 21 & 1374 & 74 & 1368 & 69 & 1389 & 75 & $1375,1381^{d}$ & \\
\hline 1394 & -171 & 1349 & -27 & 1319 & 100 & 1369 & -77 & $1351,1358^{d}$ & -27 \\
\hline 1351 & 99 & 1306 & -11 & 1287 & -75 & 1317 & 5 & $1301,1306^{d}$ & 16 \\
\hline 1274 & 14 & 1210 & 14 & 1216 & 36 & 1234 & 14 & $1220,1221^{d}$ & 5.3 \\
\hline 1207 & 4 & 1114 & -71 & 1124 & -86 & 1145 & -70 & $1145,1139^{d}$ & -4.2 \\
\hline 1143 & -10 & 1092 & 14 & 1089 & 1 & 1114 & 5 & $1110,1117^{d}$ & -4.7 \\
\hline 1057 & 12 & 996 & -43 & 1024 & -25 & 1033 & -6 & 1001 & \\
\hline 1030 & -7 & 990 & 67 & 994 & 62 & 1012 & 48 & 995 & \\
\hline 938 & -19 & 875 & -46 & 872 & -44 & 898 & -42 & 922 & \\
\hline 854 & 18 & 822 & 3 & 831 & 11 & 843 & 9 & 850 & \\
\hline 771 & -3 & 764 & 24 & 765 & 13 & 770 & 8 & 775 & \\
\hline 704 & 4 & 624 & 31 & 649 & 22 & 633 & 33 & 640 & \\
\hline 632 & 29 & 517 & -17 & 531 & -23 & 544 & -12 & 527 & \\
\hline 533 & 6 & 393 & 4 & 428 & -24 & 439 & -10 & 477 & \\
\hline 436 & -12 & 334 & 29 & 391 & 0 & 404 & 10 & 399 & \\
\hline 363 & -35 & 266 & 26 & 345 & 65 & 368 & -20 & 296 & \\
\hline 291 & 37 & 247 & -36 & 262 & 46 & 279 & 28 & 283 & \\
\hline 262 & -28 & 239 & -39 & 240 & -20 & 245 & -32 & 219 & \\
\hline 152 & -1 & 44 & -0.5 & 155 & -9 & 195 & 8 & 184 & \\
\hline
\end{tabular}

${ }^{a}$ Frequencies in $\mathrm{cm}^{-1}$ and rotational strength in $10^{-44} \mathrm{esu}^{2} \mathrm{~cm}^{2}$. Also presented are the experimental VCD intensities in terms of molar extinction coefficients $(\Delta \varepsilon / \varepsilon)$ in $\mathrm{L} /(\mathrm{mol} \mathrm{cm})$, related to the rotational strength through the integration of the peak. ${ }^{b w}$-L-Ala $+9 \mathrm{H}_{2} \mathrm{O}+\mathrm{Onsager}$, at the B3LYP/6-31G* level, calculated in ref $17 .{ }^{c}$ Reference $62 .{ }^{d}$ Reference 65.

experimental VCD spectra will not correspond to an optimized configuration, but to an average over several configurations, and it is important to be able to capture this thermal effect of the solvent.

To have a better overall comparison between the different theoretical methods, we show in Table 3 the corresponding statistical parameters for comparing the accuracy. We have considered the root-mean-square deviation (RMSD), the mean

Table 3. Root Mean Square Deviation (RMSD), Mean Accumulated Deviation (MAD), and Mean Absolute Percentage Error (MAPE)

\begin{tabular}{|c|c|c|c|}
\hline & RMSD & MAD & MAPE \\
\hline Frimand et al. ${ }^{a}$ & 70.3 & 61.0 & 5.92 \\
\hline zw-L-Ala + PCM & 120.9 & 63.0 & 14.08 \\
\hline zw-L-Ala ${ }_{\text {re-opt }}+4 \mathrm{HB}_{\text {average }}$ & 109.8 & 60.5 & 4.34 \\
\hline zw-L-Ala $a_{\text {re-opt }}+$ all $\mathrm{HB}_{\text {average }}$ & 84.9 & 49.5 & 3.48 \\
\hline
\end{tabular}

$a_{\text {ZW-L-Ala }}+9 \mathrm{H}_{2} \mathrm{O}+$ Onsager, at the B3LYP/6-31G* level, calculated in ref 17. accumulated deviation (MAD), and the mean absolute percentage error (MAPE), defined below

$$
\begin{aligned}
& \operatorname{RMSD}\left(f^{\text {calc }}, f^{\text {exp }}\right)=\sqrt{\frac{\sum_{i}\left(f_{i}^{\text {calc }}-f_{i}^{\text {exp }}\right)^{2}}{n_{\text {freq }}}} \\
& \operatorname{MAD}\left(f^{\text {calc }}, f^{\exp }\right)=\frac{\sum_{i} \mid f_{i}^{\text {calc }}-f_{i}^{\exp \mid}}{n_{\text {freq }}}
\end{aligned}
$$

$$
\operatorname{MAPE}\left(f^{\text {calc }}, f^{\exp }\right)=\frac{1}{n_{\text {freq }}} \sum_{i} \frac{\left|f_{i}^{\text {calc }}-f_{i}^{\exp }\right|}{f_{i}^{\text {calc }}}
$$

In all of the above equations, falc and $f^{\text {exp }}$ are, respectively, the calculated and experimental vibrational frequencies, and $n_{\text {freq }}$ is the total number of vibrational modes. From the analysis of RMSD, MAD, and MAP (Table 3) we can evaluate the performance of each method. The frequencies calculated using PCM are only in a reasonable agreement with the experimental values. The frequencies calculated by Frimand et al. ${ }^{17}$ using a microsolvation model represent an improvement in comparison with the PCM results by including structural effects of the 
solvent. We note a considerable reduction of the statistical errors, specially the mean average percentage error. Considering now the two models including the thermal disorder of the hydrogen-bonded water molecules, an even better agreement is achieved. We obtain, however, a larger RMSD value, as compared to the microsolvation model because, as discussed above, our calculated higher frequencies are overestimated compared to the experimental values. In the microsolvation model all molecules hydrogen-bonded to the solute are also optimized, but the thermal disorder is entirely neglected. The highest frequencies of the microsolvated system tend to be shifted to lower values.

Our results support the findings ${ }^{17,18}$ that the inclusion of the $\mathrm{HB}$ water molecules is enough to account for the solvent effects in the VCD frequencies of the zw-L-Ala in aqueous solution. In complement, our results also emphasize the importance of the inclusion of thermodynamic conditions in this study. For example, using our model containing only four $\mathrm{HB}$ with the solute (zw-L-Ala ${ }_{\text {re-opt }}+4 \mathrm{HB}_{\text {average }}$ ), we obtain a better agreement with experimental values than the previous work, which used nine $\mathrm{H}_{2} \mathrm{O}$ molecules around zw-L-Ala.

Figure 5 shows the calculated VCD spectrum obtained from a convolution using a Lorentzian function around the individual

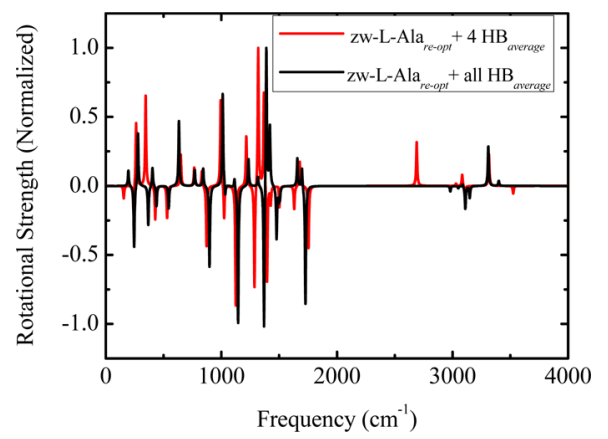

Figure 5. Convoluted average VCD spectra of zw-L-Ala in water using the average frequencies and intensities values. A Lorentzian function with a half-width of $5 \mathrm{~cm}^{-1}$ was used.

average frequencies and rotational strengths with an arbitrary half-width of $5 \mathrm{~cm}^{-1}$. This compares favorably with the experimental spectrum ${ }^{62,65}$ (see also ref 17 ).

We now discuss the rotational strength of some individual modes. For ZW-L-Ala, the VCD intensities of six modes are experimentally well-known. ${ }^{65}$ Their values, in terms of molar extinction coefficients $[\mathrm{L} /(\mathrm{mol} \mathrm{cm})]$, are also shown in Table 2. The comparison is not straightforward (the molar extinction coefficients are related to the rotational strength through the integration of a peak) but gives the correct idea of the intensities and their signs. Regarding the experimental mode at $1418 \mathrm{~cm}^{-1}$, with an intensity of $5.2 \mathrm{~L} /(\mathrm{mol} \mathrm{cm})$, the theoretical average rotational strength with the $\mathrm{zw}-\mathrm{L}-\mathrm{Ala}_{\text {re-opt }}+$ all $\mathrm{HB}_{\text {average }}$ model is $30 \times 10^{-44} \mathrm{esu}^{2} \mathrm{~cm}^{2}$, whereas the $\mathrm{zw}-\mathrm{L}-\mathrm{Ala}_{\text {re-opt }}+4$ $\mathrm{HB}_{\text {average }}$ model presents the rotational strength with opposite signal $\left(-71 \times 10^{-44} \mathrm{esu}^{2} \mathrm{~cm}^{2}\right)$. The same is observed for the modes at 1351-1358 and 1301-1306 cm $\mathrm{cm}^{-1}$, where the correct sign is obtained with the $\mathrm{zw}-\mathrm{L}-\mathrm{Ala}_{\text {re-opt }}+$ all $\mathrm{HB}_{\text {average }}$ model, but an opposite sign is obtained using $\mathrm{zW}-\mathrm{L}-\mathrm{Ala}_{\text {re-opt }}+4 \mathrm{HB}_{\text {average }}$. This gives evidence that using a limited number of water molecules can still present good values for the frequencies but may present limitations for the description of the rotational strengths. In particular, those two vibrational modes are mainly related to a bending of $\mathrm{H}$ bonded to the chiral $\mathrm{C}, \delta\left(\mathrm{C}^{*}-\mathrm{H}\right)$, and due to the limited number of water molecules included, the ordering of the modes may be reversed. Of the six rotational strength values known experimentally, the $\mathrm{zw}-\mathrm{L}-\mathrm{Ala}_{\text {re-opt }}+$ all $\mathrm{HB}_{\text {average }}$ model describe five correctly. It fails only in describing the sign of the rotational strength of the mode measured at $1110-1117 \mathrm{~cm}^{-1}$. For this, also the PCM and the zw-L-Ala $+4 \mathrm{HB}_{\text {average }}$ model fail, presenting a positive rotational strength, compared with the experimental small but negative value.

In general, the $\mathrm{zw}-\mathrm{L}-\mathrm{Ala}_{\text {re-opt }}+4 \mathrm{HB}_{\text {average }}$ does not work in the same fashion as the $\mathrm{zw}-\mathrm{L}-\mathrm{Ala}_{\text {re-opt }}+$ all $\mathrm{HB}_{\text {average }}$ model in describing the sign of the rotational strength. However, the results of Frimand et al. ${ }^{17}$ using nine water molecules with the microsolvation model have a performance that can be considered close to our best model, in describing the sign of the rotational strength. Note that Frimand et al. ${ }^{17}$ correctly describe the rotational strength of the vibrational mode at $1110-1117 \mathrm{~cm}^{-1}$ but fail in describing the mode measured at $1139 \mathrm{~cm}^{-1}$, whereas all other theoretical models describe it correctly. As has been recognized, improvements are still necessary to accurately describe the rotational strength by using DFT methods. ${ }^{10}$ As is known, the rotational strength in VCD is a local property so that the dominant solvent effect depends essentially on the molecules forming $\mathrm{HB}$ with the solute. $8,12,16,17,25-28$ This is reemphasized from the present results, considering explicit solvent molecules around the solute.

\section{CONCLUSIONS}

The importance of including the appropriate thermal disorder of $\mathrm{HB}$ molecules, associated with the thermodynamic conditions, to accurately describe the solvent effect in the VCD spectrum of solvated molecules has been analyzed. We have considered the theoretical VCD spectrum of the L-alanine in solution, at ambient condition, considering its zwitterionic form. Most studies considering explicit solvent molecules use microsolvation models that are known to eventually present their limitations for the VCD spectra of amino acids in aqueous solution. The emphasis of this study has been placed in including the thermal disorder of the hydrogen bonds and to analyze its effect on the VCD spectrum, including both the vibrational frequencies and the rotational strengths. Thus, we have considered a combined and sequential use of molecular mechanics and quantum mechanics. Monte Carlo simulations were performed to generate the structures composed of alanine and water in normal thermodynamic condition. To evaluate the VCD spectrum, we have employed the DFT B3LYP/6-311+ $+\mathrm{G}(\mathrm{d}, \mathrm{p})$ level of calculations for over 100 configurations composed of the solute plus all water molecules making hydrogen bonds with the solute. This relies on the general agreement that solvent water molecules forming hydrogen bonding with the solute dominate the influence of the aqueous medium on the VCD spectrum of the zwitterionic L-alanine.

We have also considered calculations using a smaller number of water molecules and the polarizable continuum model. Including all solvent molecules that make a hydrogen bond with the solute improves the results. Considering the large number of vibrations and the limited access to experimental values available, we present in addition to a direct comparison, when possible, also the statistical analysis of the calculated values. In general the results are found to be in good agreement with experiment with the conclusion that including thermal 
disorder leads to an overall better agreement with experiment. In general, the results indicate that the thermal effects may be of greater value in the calculations of the rotational strengths.

\section{AUTHOR INFORMATION}

\section{Notes}

The authors declare no competing financial interest.

\section{ACKNOWLEDGMENTS}

This work has been partially supported by FAPESP, CNPq, and CAPES (Brazil).

\section{REFERENCES}

(1) Holzwarth, G.; Hsu, E. C.; Mosher, H. S.; Faulkner, T. R.; Moscowitz, A. Infrared Circular Dichroism of Carbon-Hydrogen and Carbon-Deuterium Stretching Modes. Observations. J. Am. Chem. Soc. 1974, 96, 251-252.

(2) Nafie, L. A.; Keiderling, T. A.; Stephens, P. J. Vibrational Circular Dichroism. J. Am. Chem. Soc. 1976, 98, 2715-2723.

(3) Nordén, B.; Rodger, A.; Dafforn, T. Linear Dichroism and Circular Dichroism: A Textbook on Polarized-Light Spectroscopy; RSC Publishing: London, 2010; p 304.

(4) Ruud, K. Ab Initio Methods for Vibrational Circular Dichroism and Raman Optical Activity. In Comprehensive Chiroptical Spectroscopy Vol. 1; Berova, N., Polavarapu, P. L., Nakanishi, K., Woody, R. W., Eds.; Wiley: Hoboken, NJ, USA, 2012; pp 699-728.

(5) Eliel, E. L.; Wilen, S. H.; Doyle, M. P. Basic Organic Stereochemistry; John Wiley \& Sons, Inc.: Hoboken, NJ, USA, 2001; p 704.

(6) Freedman, T. B.; Cao, X.; Oliveira, R. V.; Cass, Q. B.; Nafie, L. A. Determination of the Absolute Configuration and Solution Conformation of Gossypol by Vibrational Circuldar Dichroism. Chirality 2003, 15, 196-200.

(7) Sadlej, J.; Dobrowolski, J. C.; Rode, J. E.; Jamróz, M. H. DFT Study of Vibrational Circular Dichroism Spectra of D-Lactic AcidWater Complexes. Phys. Chem. Chem. Phys. 2006, 8, 101-113.

(8) Sadlej, J.; Dobrowolski, J. C.; Rode, J. E.; Jamróz, M. H. Density Functional Theory Study on Vibrational Circular Dichroism as a Tool for Analysis of Intermolecular Systems: (1:1) Cysteine-Water Complex Conformations. J. Phys. Chem. A 2007, 111, 10703-10711.

(9) Mcconnell, O.; He, Y.; Nogle, L.; Sarkahian, A. N. I. Application of Chiral Technology in a Pharmaceutical Company. Enantiomeric Separation and Spectroscopic Studies of Key Asymmetric Intermediates Using a Combination of Techniques. Phenylglycidols. Chirality 2007, 19, 716-730.

(10) Sadlej, J.; Dobrowolski, J. C.; Rode, J. E. VCD Spectroscopy as a Novel Probe for Chirality Transfer in Molecular Interactions. Chem. Soc. Rev. 2010, 39, 1478-1488.

(11) Barone, V.; Baiardi, A.; Biczysko, M.; Bloino, J.; Cappelli, C.; Lipparini, F. Implementation and Validation of a Multi-Purpose Virtual Spectrometer for Large Systems in Complex Environments. Phys. Chem. Chem. Phys. 2012, 14, 12404.

(12) Rode, J. E.; Dobrowolski, J. C.; Sadlej, J. Prediction of (L)Methionine VCD Spectra in the Gas Phase and Water Solution. J. Phys. Chem. B 2013, 117, 14202-14214.

(13) Ganesan, A.; Brunger, M. J.; Wang, F. A Study of Aliphatic Amino Acids Using Simulated Vibrational Circular Dichroism and Raman Optical Activity Spectra. Eur. Phys. J. D 2013, 67, 229.

(14) Barron, L. D. Theoretical Rayleigh Optical Activity of Hexahelicene. J. Am. Chem. Soc. 1974, 96, 6761-6762.

(15) Compagnon, I.; Oomens, J.; Meijer, G.; von Helden, G. MidInfrared Spectroscopy of Protected Peptides in the Gas Phase: A Probe of the Backbone Conformation. J. Am. Chem. Soc. 2006, 128, 3592-3597.

(16) Jalkanen, K. J.; Degtyarenko, I. M.; Nieminen, R. M.; Cao, X.; Nafie, L. A.; Zhu, F.; Barron, L. D. Role of Hydration in Determining the Structure and Vibrational Spectra of L-Alanine and N-Acetyl L-
Alanine $\mathrm{N}^{\prime}$-Methylamide in Aqueous Solution: A Combined Theoretical and Experimental Approach. Theor. Chem. Acc. 2008, $119,191-210$.

(17) Frimand, K.; Bohr, H.; Jalkanen, K. J.; Suhai, S. Structures, Vibrational Absorption and Vibrational Circular Dichroism Spectra of L-Alanine in Aqueous Solution: A Density Functional Theory and RHF Study. Chem. Phys. 2000, 255, 165-194.

(18) Jalkanen, K. J.; Suhai, S.; Bohr, H. G. Quantum Molecular Biological Methods Using Density Functional Theory. In Handbook of Molecular Biophysics. Methods and Applications; Bohr, H. G., Ed.; Wiley-VCH: Weinheim, 2009; pp 7-66.

(19) Müller, T.; Wiberg, K. B.; Vaccaro, P. H. Cavity Ring-Down Polarimetry (CRDP): A New Scheme for Probing Circular Birefringence and Circular Dichroism in the Gas Phase. J. Phys. Chem. A 2000, 104, 5959-5968.

(20) Tomasi, J.; Persico, M. Molecular Interactions in Solution: An Overview of Methods Based on Continuous Distributions of the Solvent. Chem. Rev. 1994, 1994, 2027-2094.

(21) Tomasi, J. Thirty Years of Continuum Solvation Chemistry: A Review, and Prospects for the near Future. Theor. Chem. Acc. 2004, 112, 184-203.

(22) Tomasi, J.; Mennucci, B.; Cammi, R. Quantum Mechanical Continuum Solvation Models. Chem. Rev. 2005, 105, 2999-3093.

(23) Klamt, A.; Schüürmann, G. COSMO: A New Approach to Dielectric Screening in Solvents with Explicit Expressions for the Screening Energy and Its Gradient. J. Chem. Soc., Perkin Trans. 1993, 2, 799-805.

(24) Barone, V.; Cossi, M. Quantum Calculation of Molecular Energies and Energy Gradients in Solution by a Conductor Solvent Model. J. Phys. Chem. A 1998, 102, 1995-2001.

(25) Tajkhorshid, E.; Jalkanen, K. J.; Suhai, S. Structure and Vibrational Spectra of the Zwitterion L-Alanine in the Presence of Explicit Water Molecules: A Density Functional Analysis. J. Phys. Chem. B 1998, 102, 5899-5913.

(26) Abdali, S.; Jalkanen, K. J.; Bohr, H.; Suhai, S.; Nieminen, R. M. The VA and VCD Spectra of Various Isotopomers of L -Alanine in Aqueous Solution. Chem. Phys. 2002, 282, 219-235.

(27) Debie, E.; Bultinck, P.; Herrebout, W.; van der Veken, B. Solvent Effects on IR and VCD Spectra of Natural Products: An Experimental and Theoretical VCD Study of Pulegone. Phys. Chem. Chem. Phys. 2008, 10, 3498-3508.

(28) Zhang, R. bo; Eriksson, L. A. Theoretical Study on Conformational Preferences of Ribose in 2-Thiouridine-the Role of the 2'OH Group. Phys. Chem. Chem. Phys. 2010, 12, 3690-3697.

(29) Hudecová, J.; Hopmann, K. H.; Bouř, P. Correction of Vibrational Broadening in Molecular Dynamics Clusters with the Normal Mode Optimization Method. J. Phys. Chem. B 2012, 116, 336-342.

(30) Poopari, M. R.; Dezhahang, Z.; Xu, Y. A Comparative VCD Study of Methyl Mandelate in Methanol, Dimethyl Sulfoxide, and Chloroform: Explicit and Implicit Solvation Models. Phys. Chem. Chem. Phys. 2013, 15, 1655-1665.

(31) Mukhopadhyay, P.; Zuber, G.; Wipf, P.; Beratan, D. N. Contribution of a Solute's Chiral Solvent Imprint to Optical Rotation. Angew. Chem. Int. Ed. 2007, 46, 6450-6452.

(32) Kundrat, M. D.; Autschbach, J. Ab Initio and Density Functional Theory Modeling of the Chiroptical Response of Glycine and Alanine in Solution Using Explicit Solvation and Molecular Dynamics. J. Chem. Theory Comput. 2008, 4, 1902-1914.

(33) Kundrat, M. D.; Autschbach, J. Modeling of the Chiroptical Response of Chiral Amino Acids in Solution Using Explicit Solvation and Molecular Dynamics. J. Chem. Theory Comput. 2009, 5, 10511060.

(34) Malaspina, T.; Coutinho, K.; Canuto, S. Ab Initio Calculation of Hydrogen Bonds in Liquids: A Sequential Monte Carlo Quantum Mechanics Study of Pyridine in Water. J. Chem. Phys. 2002, 117, $1692-1699$ 
(35) Fileti, E. E.; Coutinho, K.; Malaspina, T.; Canuto, S. Electronic Changes due to Thermal Disorder of Hydrogen Bonds in Liquids: Pyridine in an Aqueous Environment. Phys. Rev. E 2003, 67, 061504.

(36) Coutinho, K.; Rivelino, R.; Georg, H. C.; Canuto, S. The Sequential QM/MM Method and Its Applications to Solvent Effects in Electronic and Structural Properties of Solutes. In Solvation Effects on Molecules and Biomolecules. Computational Methods and Applications; Canuto, S., Ed.; Springer: Berlin, 2008; pp 159-189.

(37) Ludwig, V.; Coutinho, K.; Canuto, S. Sequential ClassicalQuantum Description of the Absorption Spectrum of the Hydrated Electron. Phys. Rev. B 2004, 70, 214110.

(38) Ludwig, V.; Coutinho, K.; Canuto, S. A Monte Carlo-Quantum Mechanics Study of the Lowest $\mathrm{N}-\pi^{*}$ and $\Pi-\pi^{*}$ States of Uracil in Water. Phys. Chem. Chem. Phys. 2007, 9, 4907-4912.

(39) Malaspina, T.; Coutinho, K.; Canuto, S. Analyzing the N-ח* Eletronic Transition of Formaldehyde in Water. A Sequential Monte Carlo/Time-Dependent Density Functional Theory. J. Brazilian Chem. Soc. 2008, 19, 305-311.

(40) Jaramillo, P.; Coutinho, K.; Cabral, B. J. C.; Canuto, S. Explicit Solvent Effects on the Visible Absorption Spectrum of a Photosynthetic Pigment: Chlorophyll-c2 in Methanol. Chem. Phys. Lett. 2011, 516, 250-253.

(41) Bistafa, C.; Canuto, S. Solvent Effects on the Two Lowest-Lying Singlet Excited States of 5-Fluorouracil. Theor. Chem. Acc. 2013, 132, 1299.

(42) Manzoni, V.; Lyra, M. L.; Gester, R. M.; Coutinho, K.; Canuto, S. Study of the Optical and Magnetic Properties of Pyrimidine in Water Combining PCM and QM/MM Methodologies. Phys. Chem. Chem. Phys. 2010, 12, 14023-14033.

(43) Gester, R. M.; Bistafa, C.; Georg, H. C.; Coutinho, K.; Canuto, S. Theoretically Describing the $17 \mathrm{O}$ Magnetic Shielding Constant of Biomolecular Systems: Uracil and 5-Fluorouracil in Water Environment. Theor. Chem. Acc. 2014, 133, 1424.

(44) Orozco-González, Y.; Coutinho, K.; Canuto, S. Excited State Electronic Polarization and Reappraisal of the $\mathrm{N} \leftarrow \pi^{*}$ Emission of Acetone in Water. Chem. Phys. Lett. 2010, 499, 108-112.

(45) Orozco-Gonzalez, Y.; Bistafa, C.; Canuto, S. Solvent Effect on the Stokes Shift and on the Nonfluorescent Decay of the Daidzein Molecular System. J. Phys. Chem. A 2013, 117, 4404-4411.

(46) Allen, M. P.; Tildesley, D. J. Computer Simulation of Liquids; Oxford University Press: Oxford, U.K., 1987; p 385.

(47) Parr, R. G.; Yang, W. Density-Functional Theory of Atoms and Molecules; Oxford Science Publications: New York, 1989.

(48) Becke, A. D. A New Mixing of Hartree-Fock and Local Density-Functional Theories. J. Chem. Phys. 1993, 98, 1372-1377.

(49) Lee, C.; Yang, W.; Parr, R. G. Development of the Colle-Salvetti Correlation-Energy Formula into a Functional of the Electron Density. Phys. Rev. B 1988, 37, 785-789.

(50) Frisch, M. J.; Trucks, G. W.; Schlegel, H. B.; Scuseria, G. E.; Robb, M. A.; Cheeseman, J. R.; Scalmani, G.; Barone, V.; Mennucci, B.; Petersson, G. A.; et al. Gaussian 09; Gaussian Inc.: Wallingford, CT, 2009.

(51) Coutinho, K.; Canuto, S. Solvent Effects in Emission Spectroscopy: A Monte Carlo Quantum Mechanics Study of the N$\Pi^{*}$ Shift of Formaldehyde in Water. J. Chem. Phys. 2000, 113, 91329139.

(52) Warshel, A.; Levitt, M. Theoretical Studies of Enzymic Reactions: Dielectric, Electrostatic and Steric Stabilization of the Carbonium Ion in the Reaction of Lysozyme. J. Mol. Biol. 1976, 103, 227-249.

(53) Field, M. J.; Bash, P. A.; Karplus, M. A Combined Quantum Mechanical and Molecular Mechanical Potential for Molecular Dynamics Simulations. J. Comput. Chem. 1990, 11, 700-733.

(54) Coutinho, K.; Canuto, S. DICE, A Monte Carlo Program for Molecular Liquid Simulation, Universidade de São Paulo, 2010.

(55) Jorgensen, W. L.; Chandrasekhar, J.; Madura, J. D.; Impey, R. W.; Klein, M. L. Comparison of Simple Potential Functions for Simulating Liquid Water. J. Chem. Phys. 1983, 79, 926-935.
(56) Jorgensen, W. L.; Maxwell, D. S.; Tirado-Rives, J. Development and Testing of the OPLS All-Atom Force Field on Conformational Energetics and Properties of Organic Liquids. J. Am. Chem. Soc. 1996, $118,11225-11236$

(57) Breneman, C. M.; Wiberg, K. B. Determining Atom-Centered Monopoles from Molecular Electrostatic Potentials. The Need for High Sampling Density in Formamide Conformational Analysis. J. Comput. Chem. 1990, 11, 361-373.

(58) Coutinho, K.; Guedes, R. C.; Cabral, B. J. C.; Canuto, S. Electronic Polarization of Liquid Water: Converged Monte CarloQuantum Mechanics Results for the Multipole Moments. Chem. Phys. Lett. 2003, 369, 345-353.

(59) Stillinger, F. H.; Rahman, A. Molecular Dynamics Study of Temperature Effects on Water Structure and Kinetics. J. Chem. Phys. 1972, 57, 1281-1292.

(60) Mezei, M.; Beveridge, D. L. Theoretical Studies of Hydrogen Bonding in Liquid Water and Dilute Aqueous Solutions. J. Chem. Phys. 1981, 74, 622-632.

(61) Humphrey, W.; Dalke, A.; Schulten, K. VMD: Visual Molecular Dynamics. J. Mol. Graph. 1996, 14, 33-38.

(62) Diem, M.; Photos, E.; Khouri, H.; Nafie, L. A. Vibrational Circular Dichroism in Amino Acids and Peptides. 3. Solution- and Solid-Phase Spectra of Alanine and Serine. J. Am. Chem. Soc. 1979, 101, 6829-6837.

(63) Pople, J. A.; Scott, A. P.; Wong, M. W.; Radom, L. Scaling Factors for Obtaining Fundamental Vibrational Frequencies and ZeroPoint Energies from HF/6-31G* and MP2/6-31G* Harmonic Frequencies. Isr. J. Chem. 1993, 33, 345-350.

(64) Wong, M. W. Vibrational Frequency Prediction Using Density Functional Theory. Chem. Phys. Lett. 1996, 256, 391-399.

(65) Diem, M. Infrared Vibrational Circular Dichroism of Alanine in the Midinfrared Region: Isotopic Effects. J. Am. Chem. Soc. 1988, 110, $6967-6970$ 


\title{
A systematic study of the lowest $n-\pi^{*}$ and $\pi-\pi^{*}$ electronic transitions of acrolein in solvent
}

\author{
Carlos Bistafa, Lucas Modesto-Costa, Sylvio Canuto \\ Instituto de Física, Universidade de São Paulo, Brasil
}

\begin{abstract}
We study the solvatochromic shift of the first $n-\pi^{*}$ and $\pi-\pi^{*}$ transitions of s-trans acrolein molecule, in gas phase and in water environment. We analyzed the effect of basis set size and inclusion of solvent explicit molecules in the two transitions. Using the S-QM/MM methodology, we performed Monte Carlo simulations to generate snapshots that are used in $\mathrm{CIS}(\mathrm{D}) /$ aug-cc-pVXZ $(X=2,3,4,5,6)$ calculations. We also analyze the convergence of the results with the number of explicit solvent molecules included. Our results to the solvatochromic shift show that to the $n-\pi^{*}$ transition a good description can be achieved by using an electrostatic model, while for the $\pi-\pi^{*}$ transition, specific interaction plays a major role, being the converged result obtained just when all the first solvation shell is included.
\end{abstract}

[ARTIGO EM PREPARAÇÃO] 